\title{
DEVELOPMENT OF FLUORESCENT SENSORS
}

FOR THE DETECTION OF HYDROPHOBIC AMINES AND GLYCOLIPIDS

\begin{tabular}{c} 
A Dissertation \\
Presented to \\
the Faculty of the Graduate School \\
at the University of Missouri-Columbia \\
\hline
\end{tabular}

In Partial Fulfillment

of the Requirements for the Degree

Doctor of Philosophy

By

CHARLES W. LITTLEFIELD JR.

Dr. Timothy E. Glass, Dissertation Supervisor

December 2017 
The undersigned, appointed by the dean of the Graduate School, have examined the dissertation entitled

\section{DEVELOPMENT OF FLUORESCENT SENSORS}

\section{FOR THE DETECTION OF AMINES AND GLYCOLIPIDS}

presented by Charles W. Littlefield Jr., a candidate for the degree of Doctor of Philosophy, and hereby certify that, in their opinion, it is worthy of acceptance

Professor Timothy E. Glass, Dissertation Supervisor

Professor Kent Gates, Committee Member

Professor Renee JiJi, Committee Member

Professor Charles Brown, Committee Member 


\section{Dedication}

This dissertation is dedicated to my mother Debbie Littlefield, who passed away shortly after my comprehensive exam. My mother always supported me through school in every way possible, ensuring that she could do anything to help me succeed. I would also like to thank my other family members who have supported me throughout the years of my graduate education. It is also dedicated to Andrea Overman, my fiancé, thank you for always being there for me. 


\section{Acknowledgements}

I would like to thank my advisor Dr. Timothy Glass, for his encouragement, patience, and advice throughout my graduate education. Without his help and expertise I would not have been able to do it. I would also like to thank my committee members, Dr. Kent Gates, Dr. Charles Brown, and Dr. Renee JiJi for their time and attention. I would like to thank former group members Dr. Jessica Klockow, Dr. Kenneth Hettie, Dr. Chad Cooley and Dr. Chun Ren for mentoring me as a new graduate student in the lab. I am also thankful for the help provided to me by former and current group members: Le Zhang, Nick Cooley, Dr. Tam Tran, Ming Xu, and Dr. Patrick Cavins. 


\section{Table of Contents}

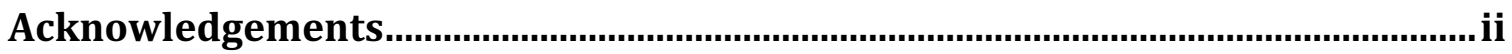

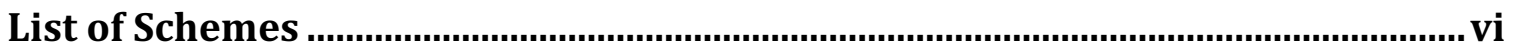

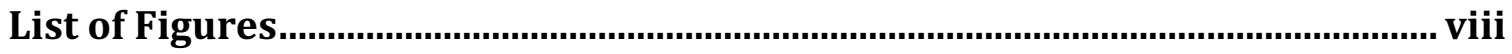

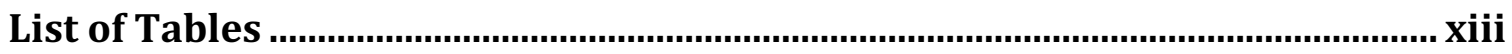

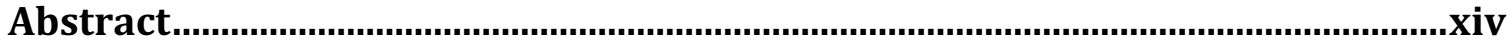

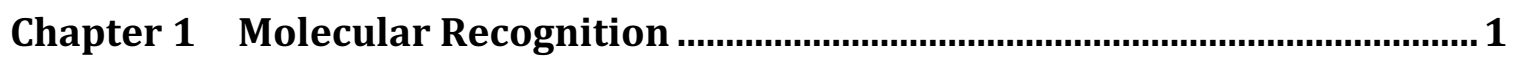

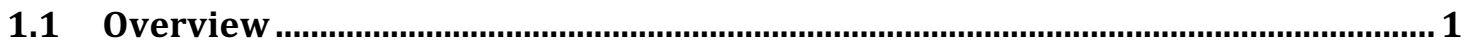

1.2 Hydrogen Bonding Interactions........................................................................

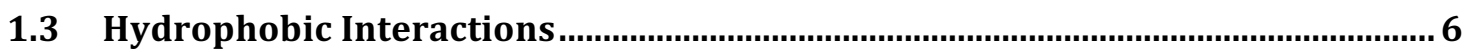

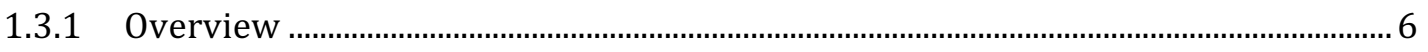

1.3.2 Calixarenes and Cucubiturils..........................................................................................

$1.4 \quad$ Reversible Covalent Binding ............................................................................12

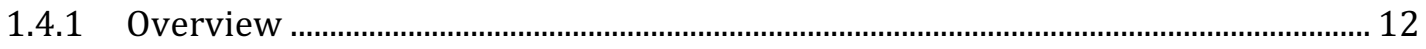

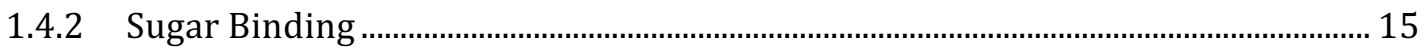

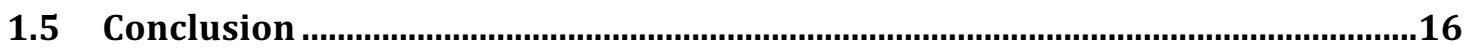

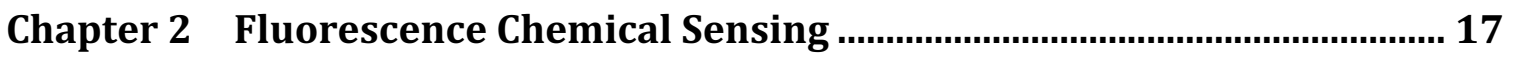

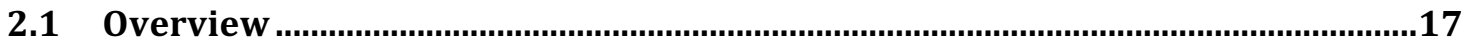

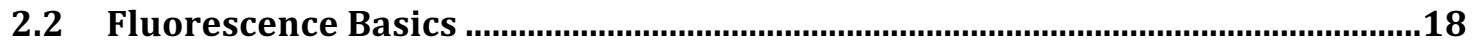

2.3 Overview of Fluorescent Sensing .........................................................................21

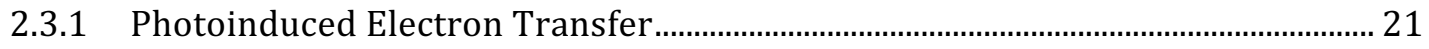

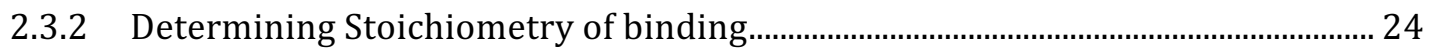

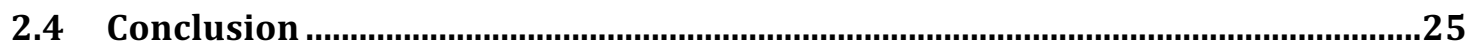




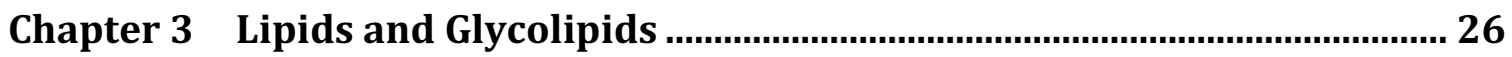

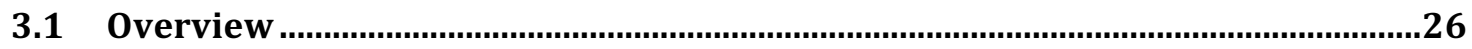

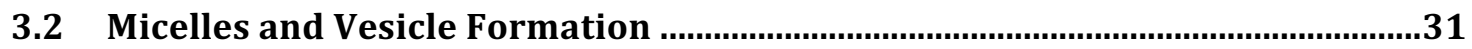

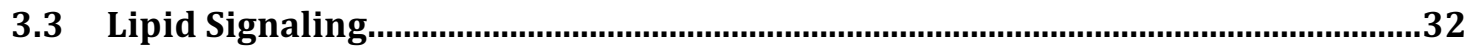

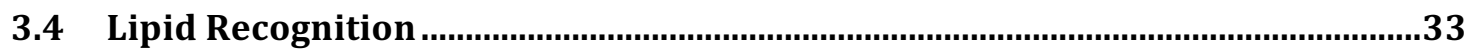

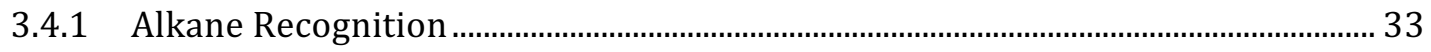

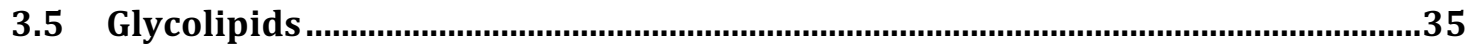

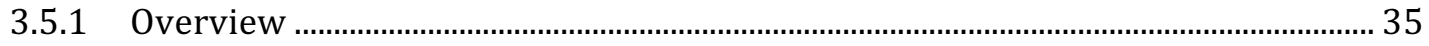

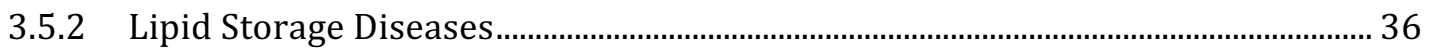

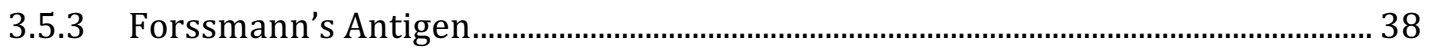

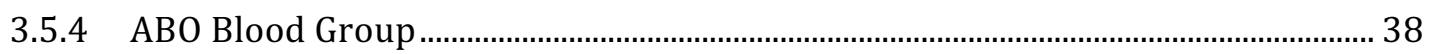

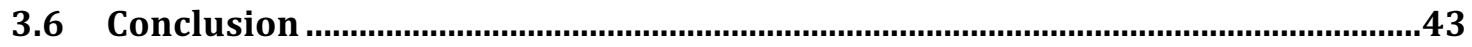

Chapter 4 Molecular Tubes for the Detection and Extraction of Hydrophobic

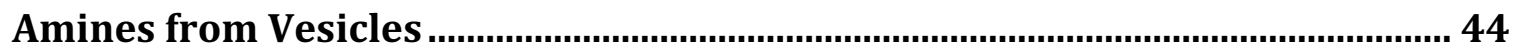

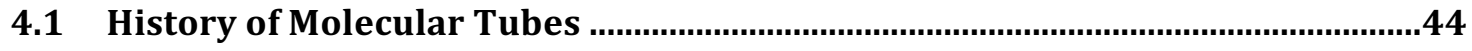

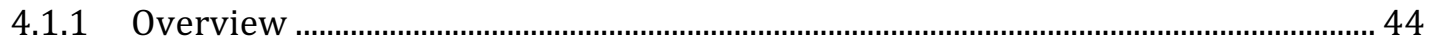

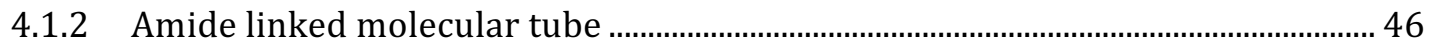

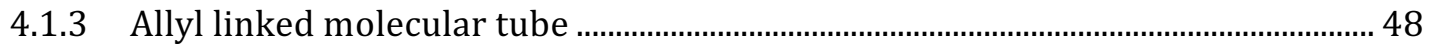

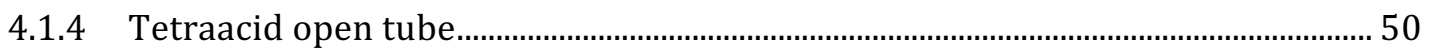

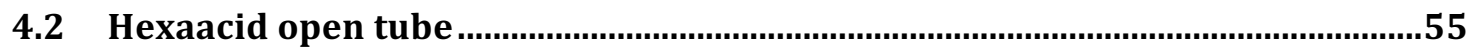

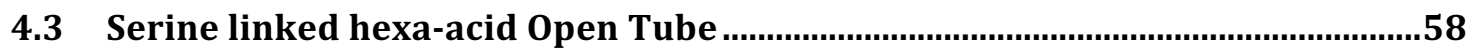

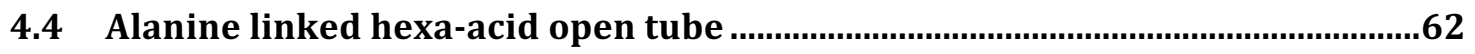

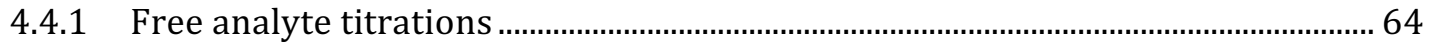

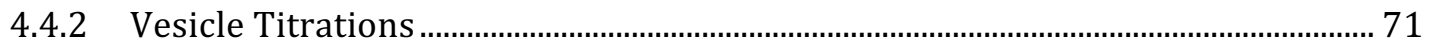

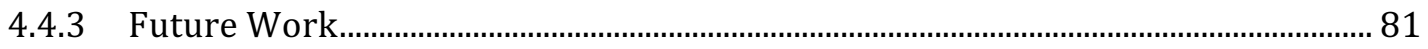




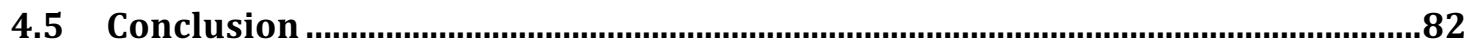

Chapter 5 Molecular Tubes for the Detection of Glycolipids............................ 83

5.1 Molecular Tubes for the Sensing of Glycolipids................................................83

5.2 Future Work

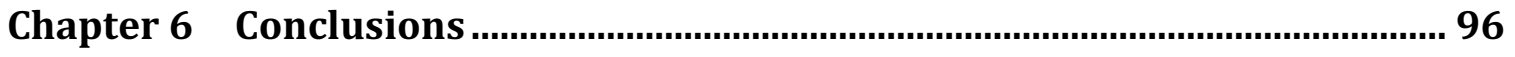

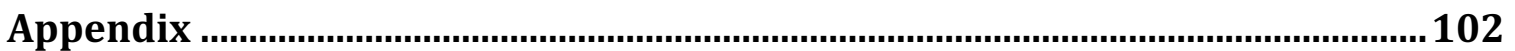

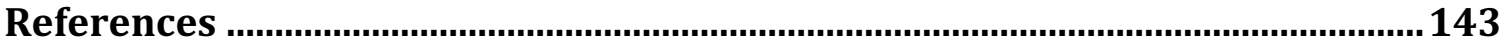

Vita........................................................................................................................................ 154 


\section{List of Schemes}

Scheme 1.1: Hydrophobic effect of hexane (or other oils) in water.................................. 6

Scheme 1.2: Encapsulation of cholesterol by ß-cyclodextrin ........................................... 8

Scheme 1.3: Synthesis of cucubiturils........................................................................... 11

Scheme 1.4: Phenylboronic acid binding with diol.......................................................... 13

Scheme 1.5: Coumarin aldehyde binding an amine ${ }^{32}$...................................................... 13

Scheme 1.6: Phenylboronic acid binding to catechol....................................................... 13

Scheme 1.7: Shinkai Sensor for D-glucose …………………………………………...... 16

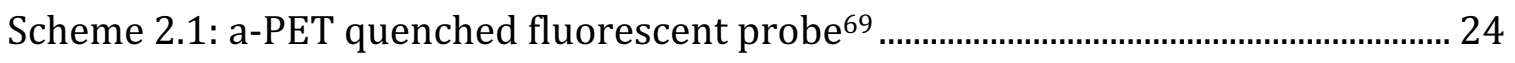

Scheme 4.1: Condensation of 2,7-dihydroxynaphthalene ............................................... 44

Scheme 4.2: Synthesis of hydrophobic amine tube …………………………………..... 53

Scheme 4.3: Hexyl bromoacetate synthesis ..................................................................... 55

Scheme 4.4: Synthesis of hexyl dimer............................................................................. 56

Scheme 4.5: Synthesis of hexyl/ethyl ester Carbazole ...................................................... 56

Scheme 4.6: Synthesis of hexyl/ethyl ester open tube...................................................... 57

Scheme 4.7: Saponification of hexyl/ethyl ester tube ..................................................... 57

Scheme 4.8: Synthesis of TMSE pinacol boronic acid ...................................................... 59

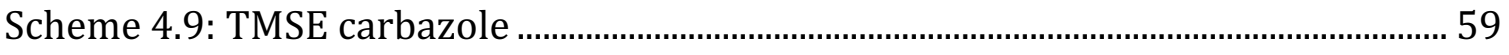

Scheme 4.10: TMSE Tube synthesis ……………………................................................ 59

Scheme 4.11: TMSE cleavage, amide bond formation, and saponification.................... 61

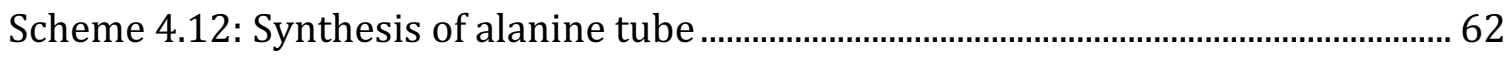

Scheme 5.1: Open aldehyde tube intramolecular reaction................................................ 84

Scheme 5.2: Ethyl carbazole aldehyde Fmoc reactivity ..................................................... 85 
Scheme 5.3: Hexyl carbazole aldehyde Fmoc reactivity ………………………………..... 85

Scheme 5.4: Aldehyde tube reaction with Fmoc ............................................................... 86

Scheme 5.5: Carbazole reductive amination with amino phenylboronic acid............. 87

Scheme 5.6: Aminoboronic acid amide bond formaiton .................................................... 88

Scheme 5.7: Fluoroaminoboronic acid amide bond formation ....................................... 89

Scheme 5.8: fluoroaminoboronic acid amide bond formation with new reagent...... 90

Scheme 5.9: pinacol boronic acid amide bond formation ................................................. 92

Scheme 5.10: Miyaura borylation approach for carbazole acid ........................................ 94

Scheme 5.11: Miyaura borylation approach for tube diacid.............................................. 94

Scheme 5.12: Pinacol boronic acid tube saponification...................................................... 95 


\section{List of Figures}

Figure 1.1: Reversible host-guest interaction .................................................................... 3

Figure 1.2: (a) hydrogen bonding between two water molecules (b) hydrogen

bonding network

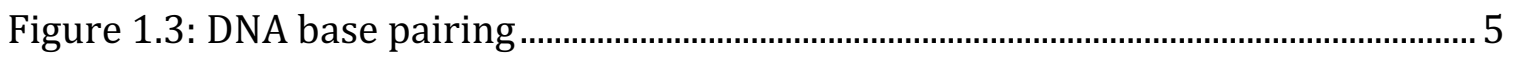

Figure 1.4: (a) $\gamma$-cyclodextrin (b) $\gamma$-cyclodextrin toroid structural arrangement......... 7

Figure 1.5: Select drugs that use CD's for delivery and their delivery process ${ }^{20} \ldots \ldots \ldots . . .9$

Figure 1.6: (a) Calix[4]arene structure (b) Calix[4]arene molecular model from

Spartan

Figure 1.7: 3-D representation of some common cucubituril derivatives..................... 11

Figure 2.1: A few common fluorophores ........................................................................ 17

Figure 2.2: A Turn on fluorescent sensor schematic representation.............................. 18

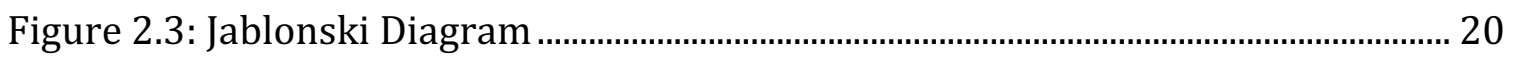

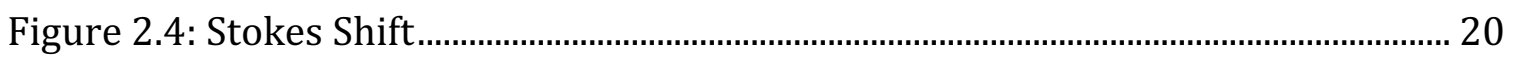

Figure 2.5: a-PET frontier molecular orbital quenching mechanism.............................. 22

Figure 2.6: non quenchend a-PET system......................................................................... 22

Figure 2.7: d-PET Frontier molecular orbital quenching mechanism ............................. 23

Figure 2.8: d-PET non-quenched system .......................................................................... 23

Figure 2.9: Job Plot showing 1:1 binding........................................................................ 25

Figure 3.1: A few common fatty acids............................................................................... 26

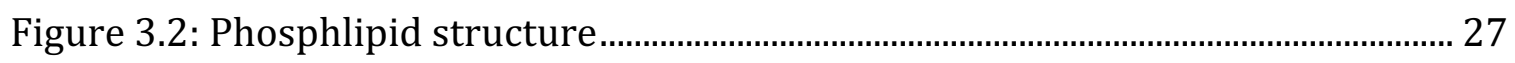

Figure 3.3: Various headgroups of phospholipids (where R is the phospholipid) .... 28

Figure 3.4: Sphingolipid examples ………………………........................................... 29 
Figure 3.5: Steroid ring system and examples .................................................................. 30

Figure 3.6: Example of a triglyceride ………………………………………………... 31

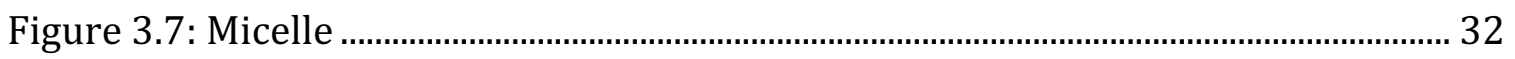

Figure 3.8: Anandamide and oleoylethanolamide.............................................................. 33

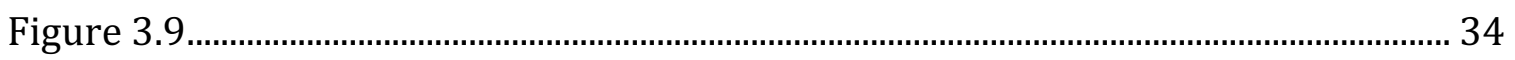

Figure 3.10: A simple glycolipid ............................................................................................ 36

Figure 3.11: Glucocerebroside - a simple glycolipid............................................................ 36

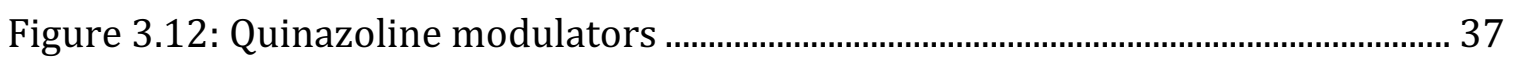

Figure 3.13: Structure of Forssman's antigen ..................................................................... 38

Figure 3.14: Blood Group Antigens ............................................................................................. 39

Figure 3.15: Various saccharide chain types to which A antigens are present on erythrocytes and other cell types ............................................................................ 42

Figure 3.16: Site of cleavage of A or B antigens with GH98 EABase of type 2 chains 43

Figure 4.1: Geometries of naphthalene dimer ................................................................... 45

Figure 4.2: Thioether Model ............................................................................................................. 46

Figure 4.3 First hydrophobic amine sensor by our group ................................................. 52

Figure 4.4 Binding constants for some hydrophobic amines with previous sensor. 53

Figure 4.5: Hydrophobic/Hydrophilic portions of amine sensor …………………….... 54

Figure 4.6: Initially designed sensor for lipid extraction ................................................. 55

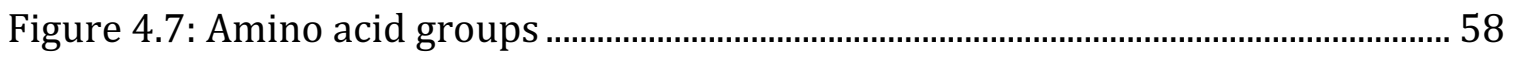

Figure 4.8: Newly designed hydrophobic amine sensor .................................................. 60

Figure 4.9: Absorbance and fluorescence spectrum of serine amino acid sensor in buffer (25 mM HEPES, 120 mM NaCl; pH = 7.4), [58] = 10-5 M ............................. 61 
Figure 4.10: Absorbance and fluorescence of sensor 60, $10 \mu \mathrm{M}$ sensor in buffer (25 mM HEPES, $120 \mathrm{mM} \mathrm{NaCl} ; \mathrm{pH}=7.4),[60]=10^{-5} \mathrm{M}$

Figure 4.11: Sensor 60 stability scan, excitation $315 \mathrm{~nm}, 10 \mu \mathrm{M}$ sensor in buffer (25 mM HEPES, $120 \mathrm{mM} \mathrm{NaCl} ; \mathrm{pH}=7.4),[60]=10^{-5} \mathrm{M}$ 63

Figure 4.12: UV titration of 60 in buffer ( $25 \mathrm{mM}$ HEPES, $120 \mathrm{mM} \mathrm{NaCl}$; $\mathrm{pH}=7.4)$; [60] $=2 \mu \mathrm{M}$ 64

Figure 4.12: Structures of the alkyl amines tested in binding studies 65

Figure 4.13: Fluorescence Titration of sensor 60 with 1,10-diaminodecane in buffer (25 mM HEPES, $120 \mathrm{mM} \mathrm{NaCl} ; \mathrm{pH}=7.4$ ); [60] = $2 \mu \mathrm{M}, \lambda_{\mathrm{ex}}=315 \mathrm{~nm}$. 66

Figure 4.14: Stuctures of additional analytes tested 67

Figure 4.15: Fluorescence Titration of sensor 60 with octyltrimethylammonium bromide in buffer (25 mM HEPES, $120 \mathrm{mM} \mathrm{NaCl}$; $\mathrm{pH}=7.4$ ); [60] $=2 \mu \mathrm{M}, \lambda_{\mathrm{ex}}=$ $315 \mathrm{~nm}$; 68

Figure 4.16: Fluorescence titration of sensor 60 with 5-nonylamine in buffer ( $25 \mathrm{mM}$ HEPES, $120 \mathrm{mM} \mathrm{NaCl} ; \mathrm{pH}=7.4) ;[60]=2 \mu \mathrm{M}, \lambda_{\mathrm{ex}}=315 \mathrm{~nm}$; 68

Figure 4.17: Structures of $2^{\circ}$ amines tested 69

Figure 4.18: Fluorescence titration of sensor 60 with dihexylamine in buffer $(25 \mathrm{mM}$ HEPES, $120 \mathrm{mM} \mathrm{NaCl} ; \mathrm{pH}=7.4$ ); [60] = $2 \mu \mathrm{M}, \lambda_{\mathrm{ex}}=315 \mathrm{~nm}$ 69

Figure 4.19: Structure of benzyl viologen dibromide 70

Figure 4.20: Fluorescence titration of sensor 60 with benzyl viologen in buffer (25 mM HEPES, $120 \mathrm{mM} \mathrm{NaCl} ; \mathrm{pH}=7.4$ ); [60] = $2 \mu \mathrm{M}, \lambda_{\mathrm{ex}}=315 \mathrm{~nm}$;. 71

Figure 4.22: Fluorescence titration of sensor 60 with DMPC in buffer (25 mM HEPES, $120 \mathrm{mM} \mathrm{NaCl} ; \mathrm{pH}=7.4$ ); [60] $=2 \mu \mathrm{M}, \lambda_{\mathrm{ex}}=315 \mathrm{~nm}$ 72 
(Figure 4.22: Fluorescence titration of sensor 60 with DMPS in buffer $(25 \mathrm{mM}$ HEPES, $120 \mathrm{mM} \mathrm{NaCl} ; \mathrm{pH}=7.4$ ); [60] $=2 \mu \mathrm{M}, \lambda_{\mathrm{ex}}=315 \mathrm{~nm}$. 73

Figure 4.23: Fluorescence titration of sensor 60 with DMPC/DMPS (80:20) in buffer (25 mM HEPES, $120 \mathrm{mM} \mathrm{NaCl} ; \mathrm{pH}=7.4$ ); [60] = $\left.2 \mu \mathrm{M}, \lambda_{\mathrm{ex}}=315 \mathrm{~nm} ; \mathrm{a}\right)$ fluorescence emission spectra as a function of added DMPC/DMPS $(80: 20) \ldots 73$ Figure 4.24: Fluorescence titration of sensor 60 with DMPC vesicles with 10 mol\% cholesterol in buffer (25 mM HEPES, $120 \mathrm{mM} \mathrm{NaCl}$; $\mathrm{pH}=7.4$ ); [60] $=2 \mu \mathrm{M}, \lambda_{\mathrm{ex}}=$ $315 \mathrm{~nm}$

Figure 4.25: Fluorescence titration of sensor 60 with DMPC vesicles with 5 mol\% 1,10-diaminodecane in buffer (25 mM HEPES, $120 \mathrm{mM} \mathrm{NaCl}$; $\mathrm{pH}=7.4$ ); [60] = 2 $\mu \mathrm{M}, \lambda_{\mathrm{ex}}=315 \mathrm{~nm}$ 75

Figure 4.26: Fluorescence titration of sensor 60 with DMPC/DMPS (80:20) vesicles with 5 mol\% 1,10-diaminodecane in buffer (25 mM HEPES, $120 \mathrm{mM} \mathrm{NaCl}$; $\mathrm{pH}=$ 7.4); $[60]=2 \mu \mathrm{M}, \lambda_{\mathrm{ex}}=315 \mathrm{~nm}$ 76

Figure 4.27: Fluorescence titration of sensor 60 with DMPC/DMPS (80:20) vesicles containing 10 mol\% cholesterol and 5 mol\% 1,10-diaminodecane in buffer (25 mM HEPES, $120 \mathrm{mM} \mathrm{NaCl} ; \mathrm{pH}=7.4) ;[60]=2 \mu \mathrm{M}, \lambda_{\mathrm{ex}}=315 \mathrm{~nm}$ 77

Figure 4.28: Fluorescence titration of alanine hexaacid with DMPC vesicles with 5 mol\% benzyl viologen in buffer (25 mM HEPES, $120 \mathrm{mM} \mathrm{NaCl}$; $\mathrm{pH}$ = 7.4); [60] = $2 \mu \mathrm{M}, \lambda_{\mathrm{ex}}=315 \mathrm{~nm}$ 78

Figure 4.29: Fluorescence titration of sensor 60 with DMPC vesicles with 5 mol\% octylamine in buffer (25 mM HEPES, $120 \mathrm{mM} \mathrm{NaCl} ; \mathrm{pH}=7.4$ ). 79 
Figure 4.30: Fluorescence titration of sensor 62 with DMPC vesicles with 5 mol\% dodecyltrimethylammonium bromide in buffer $(25 \mathrm{mM}$ HEPES, $120 \mathrm{mM} \mathrm{NaCl}$;

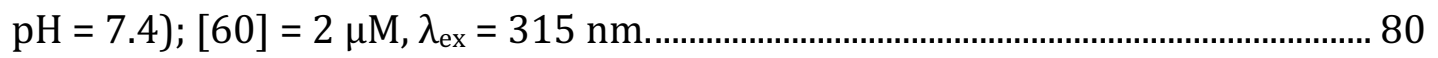

Figure 4.31: Fluorescent lipids .......................................................................................... 81

Figure 5.1: Originally Designed glycolipid sensor ................................................................. 83

Figure 5.2: Side product obtained from amide bond formation reactions with

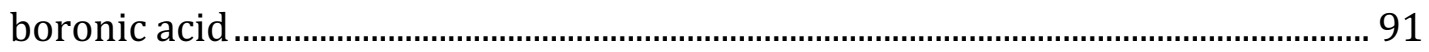

Figure 5.3: Formation of pinacol tetraester tube............................................................... 93

Figure 5.4: Glycolipids to be tested .................................................................................... 95 


\section{List of Tables}

Table 1.1: Binding Constants of L-amino acids with meso calix[4]arene-bis- $\alpha$ -

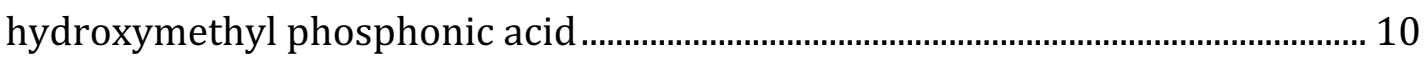

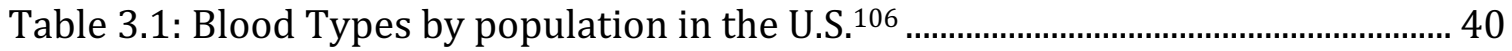

Table 4.1: Association constants for amide linked tube .................................................. 48

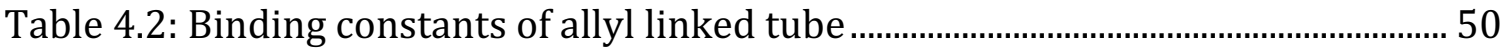

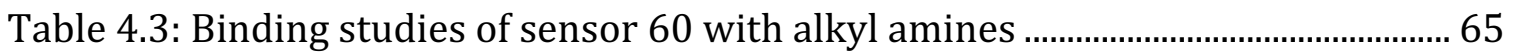

Table 5.1: Ethyl carbazole aldehyde Fmoc reaction conditions ....................................... 85

Table 5.2: Hexyl carbazole aldehyde Fmoc reaction conditions ..................................... 86

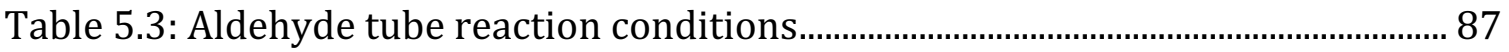

Table 5.4: amino phenylboronic acid reductive amination reaction conditions ........ 88

Table 5.5: Aminoboronic acid amide bond reaction conditions and results ................ 89

Table 5.6: Fluoroaminoboronic acid amide bond reaction conditions and results ... 89

Table 5.7: Fluoroaminoboronic acid reaction conditions and results............................ 90

Table 5.8: Pinacol boronic acid amide bond reaction conditions and results.............. 92 


\begin{abstract}
A novel fluorescent sensor was designed and synthesized to detect hydrophobic amines and was used to extract them from synthetically prepared vesicles. This sensor had a higher affinity for diamines than primary amines, providing a fluorescence decrease upon binding both analytes. This sensor bound longer chain amines such as decylamine and 1,10-diaminodecane, better than shorter chain amines such as octylamine. This binding is influenced by both hydrophobic effects and electrostatic interactions between the sensor and analyte, driven by the hydrophobic cavity on the sensor. The sensor also unexpectedly binds to spermine and spermidine, however, with an increase in fluorescence. The mechanism for this phenomenon is not yet understood. The sensor showed it is possible to remove hydrophobic amines from synthetic veiscles, which can be applied to biological systems. A fluorescent sensor for glycolipids was also attempted to be synthesized by several different methods, incurring a new synthesis through redesigning the synthesis. Each method provided undesired products, decomposition, or no reactivity. Initial redesigns were due to complications in solubility of the carbazole aldehyde. Elongating the ester chain enhanced the solubility, but it remained unreactive towards any of the attempted reactions. This redesigned the sensor with a protected acid group that has been tested towards amide bond formation reactions to install the boronic acid or a haloarene, which will then undergo a Miyaura Borylation to install the boronic acid. If this does not prove successful, it will require alternative synthetic methods to install the boronic acid.
\end{abstract}




\section{Chapter 1 Molecular Recognition}

\subsection{Overview}

Research in molecular recognition originated in 1967 when Charles J. Pedersen discovered crown ethers. ${ }^{1}$ This accidentally synthesized dibenzo[18]crown-6 1, was found to have remarkable solubility properties. Specifically, it was only slightly soluble in methanol, while being more so when alkali metal salts were added. This led Pedersen to synthesize many similar compounds, such as $\mathbf{2}$ which shows strong binding affinity for $\mathrm{K}^{+}$and $\mathbf{3}$ for $\mathrm{Na}^{+}{ }^{2}$ The oxygen atoms are directed to the interior of the ring leaving the hydrophobic ethylene units exposed to the organic solvent. This placement permits crown ethers to solubilize otherwise insoluble ions in organic media.

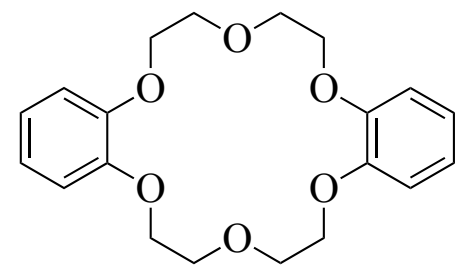

1

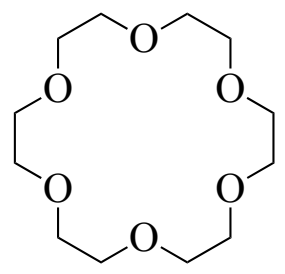

2

[18]crown-6

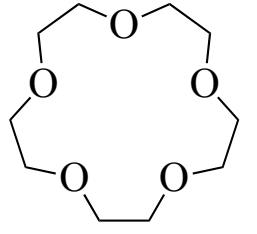

3

[15]crown-5

The Nobel Prize in Chemistry was awarded in 1987 to Donald J. Cram, Jean-Marie Lehn and Charles J. Pedersen for their "development and use of molecules with structurespecific interactions in high selectivity", which included Pedersen's work with crown ethers. A large number of crown ether derivatives have subsequently been prepared substituting the oxygen in the ring with a nitrogen $\mathbf{4}$ or sulfur $\mathbf{5}$. These new crown ethers 
have achieved selective recognition of alkaline earth metals, mercury, lead, and various transition metals.

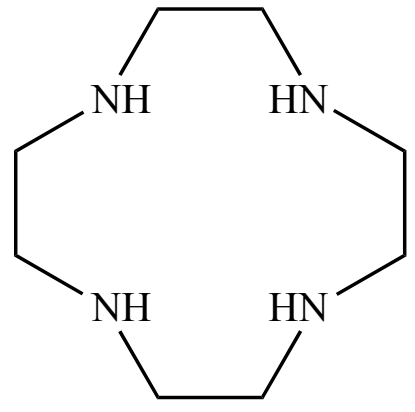

4

cyclen

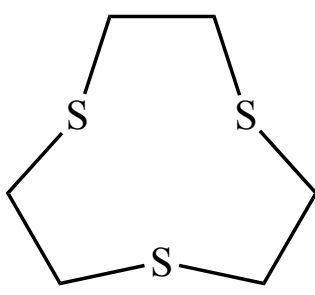

5

1,4,7-trithiacylcononane

Work since the 1960's has gradually established molecular recognition as a new field of supramolecular chemistry. This work has progressed from the recognition of simple ions, including metal cations and halide anions to much more complex guests. Some examples include drugs ${ }^{3-4}$, hydrogen peroxide ${ }^{5}$, chemical warfare agents ${ }^{6-9}$, $\operatorname{sugars}^{10}$, carboxylate $^{11}$, phosphate $^{12}$, and adenosine triphosphate (ATP) $)^{13}$, thus creating a vast array of new and diverse receptors.

Molecular recognition involves the selective binding of a host complex to a guest through reversible non-covalent electronic and structural bonding interactions. ${ }^{2}$ A host complex is comparable to an enzyme where its guest would be a substrate. Similarly, a synthetically made host molecule is designed to bind an intended guest. These binding interactions include cation- $\pi$ interactions $\left(5-80 \mathrm{~kJ} \mathrm{~mol}^{-1}\right)$, dipole-dipole interactions (5-50 $\mathrm{kJ} \mathrm{mol}^{-1}$ ), hydrogen bonding (4-120 $\left.\mathrm{kJ} \mathrm{mol}^{-1}\right)$, hydrophobic forces, ion-dipole interactions $\left(50-200 \mathrm{~kJ} \mathrm{~mol}^{-1}\right)$, ion-ion interactions $\left(100-350 \mathrm{~kJ} \mathrm{~mol}^{-1}\right), \pi-\pi$ stacking interactions $(0-50$ $\left.\mathrm{kJ} \mathrm{mol}^{-1}\right)$, as well as van-der Waals forces $\left(<5 \mathrm{~kJ} \mathrm{~mol}^{-1}\right.$; variable $){ }^{2}$ Each of these 
interactions are weak, ranging $0-350 \mathrm{~kJ} / \mathrm{mol}$, in comparison to covalent bonding interactions, $180-854 \mathrm{~kJ} / \mathrm{mol} .{ }^{14} \mathrm{~A}$ common problem in developing these host complexes is the design, making the host selective for one or a very limited number of chemical species.

Self-formation of micelles in water, DNA base pairing, protein folding, and enzymes binding to substrates are all examples of molecular recognition processes. While these processes are predominantly non-covalent bonding (and therefore reversible) interactions (Figure 1.1), more emphasis has been placed on processes that form reversible covalent bonds, such as boronic acids to form boronate esters when binding to saccharides or catechols.

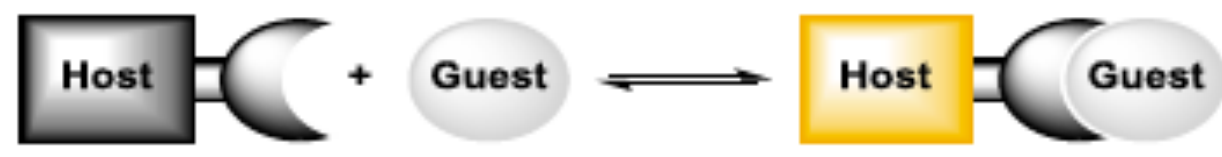

Figure 1.1: Reversible host-guest interaction

While it is a novel feat to selectively recognize a chemical species via a synthetically created scaffold, it is also essential to provide a signal or measurable change to inform us that this specific chemical bonding event has occurred. When Pedersen placed $\mathrm{KMnO}_{4}$ into benzene containing the dibenzo[18]crown-6 1 the solution changed from colorless to a purple color ${ }^{1}$. Unfortunately, a change in color is not an inherent quality of host/guest interactions, indicating the importance of developing chemical sensing probes, which will be discussed in the following chapter. 


\subsection{Hydrogen Bonding Interactions}

A hydrogen bond is a bond between a donor group possessing an acidic hydrogen and an acceptor with a lone pair (often a nitrogen, oxygen, or fluorine). ${ }^{14}$ For example, two water molecules can interact together to form a hydrogen bond between the hydrogen of one molecule to the oxygen of another, denoted by a dotted/dashed line, as seen in Figure 1.2a. One water molecule can be involved in hydrogen bonding with four other water molecules, two as a donor and two as an acceptor (Figure 1.2b).

(a) $\mathrm{H}$

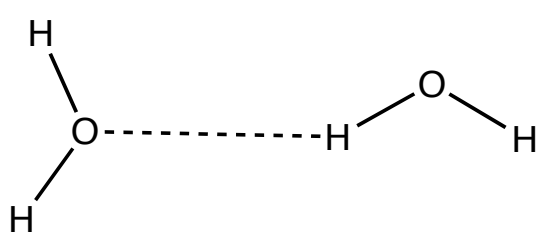

(b)

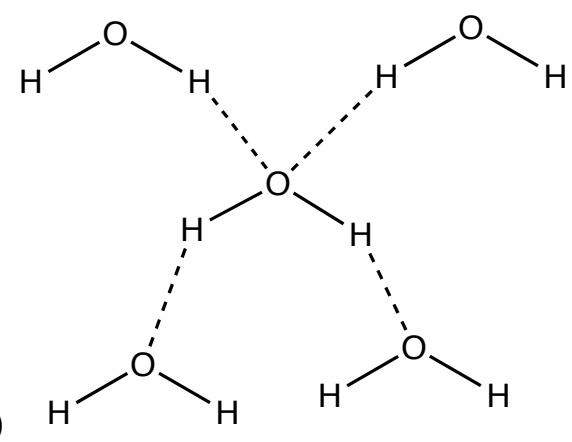

Figure 1.2: (a) hydrogen bonding between two water molecules (b) hydrogen bonding network

An example of the importance bonding in biological systems is seen in DNA base pairing (Figure 1.3). Here we see the pairing of thymine with adenine forming two intermolecular hydrogen bonds and guanine with cytosine forming three intermolecular hydrogen bonds. 

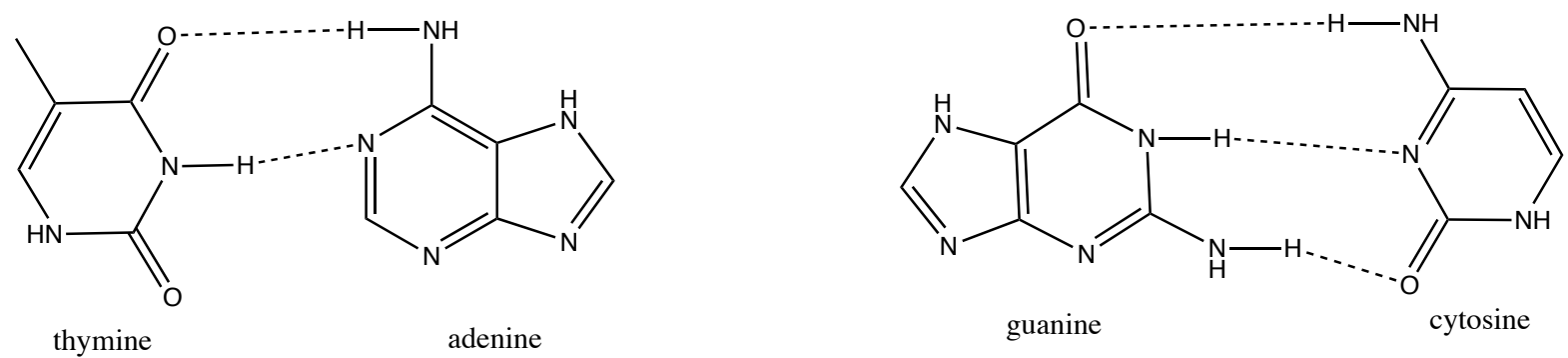

Figure 1.3: DNA base pairing

Hydrogen bonding receptors work best in organic mediums, where the polar host and guest would favorably interact with each other instead of the non-polar solvent. In polar solvents such as water, the host and guest are well solvated requiring the displacement of enthalpically favorable solvent shells for the host and guest to bind, significantly shifting the equilibrium away from the host-guest complex.

Hydrogen bonding has been applied in many sensors or receptors including 6 which shows a binding affinity towards glutaric acid, $\mathrm{K}_{\mathrm{a}}=(1.0 \pm .2) \times 10^{4} \mathrm{M}^{-1}{ }^{15}$ Furthermore, it was reported that 7 had a significantly higher binding affinity to glutaric acid, but was beyond the range to be determined via ${ }^{1} \mathrm{H}$ NMR by Hamilton with $\mathrm{K}_{\mathrm{a}}>5 \mathrm{x}$ $10^{4} \mathrm{M}^{-1}$. The titrations were performed in DMSO, thus the analytes are not able to have many hydrogen bonding interactions with the solvent and therefore interact with each other. However, the authors found upon addition of $12 \% \mathrm{D}_{2} \mathrm{O}$ the $\mathrm{K}_{\mathrm{a}}=(8.5 \pm 1.5) \times 10^{3}$ $\mathrm{M}^{-1}$ and $25 \% \mathrm{D}_{2} \mathrm{O} \mathrm{K} \mathrm{a}_{\mathrm{a}}=(4.8 \pm 2.5) \times 10^{2} \mathrm{M}^{-1}$, demonstrating that synthetic hydrogen bonding receptors typically only operating in nonpolar solvents can still bind strongly in competitive solvents. 


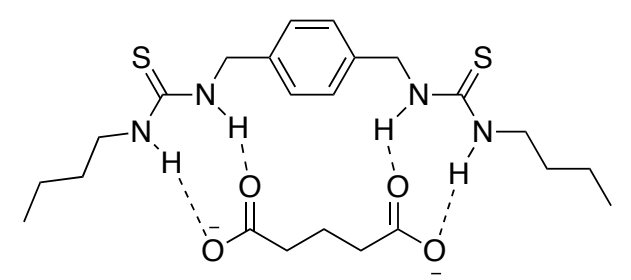

6

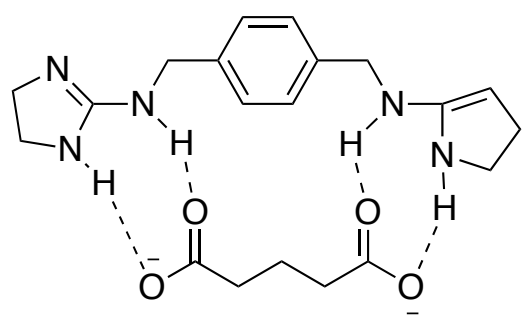

7

\subsection{Hydrophobic Interactions}

\subsubsection{Overview}

Hydrophobic interactions can be described by the immiscibility of hexane (or oil) in water. Water posses a large hydrogen bonding framework that must be disrupted for the addition of any solutes to create a solution. This disruption is energetically unfavorable in comparison to other aprotic solvent systems. When adding hexane to water, hexane disrupts the strong hydrogen bonding framework in water replacing them with weaker dipole-dipole and van der Waals interactions. To minimize this energetic loss, the hexane molecules associate together decreasing the water-solute interactions and therefore increasing the water-water hydrogen bonding interactions (Scheme 1.1). This type of interaction is the process of how micelles form when lipids are added to water.
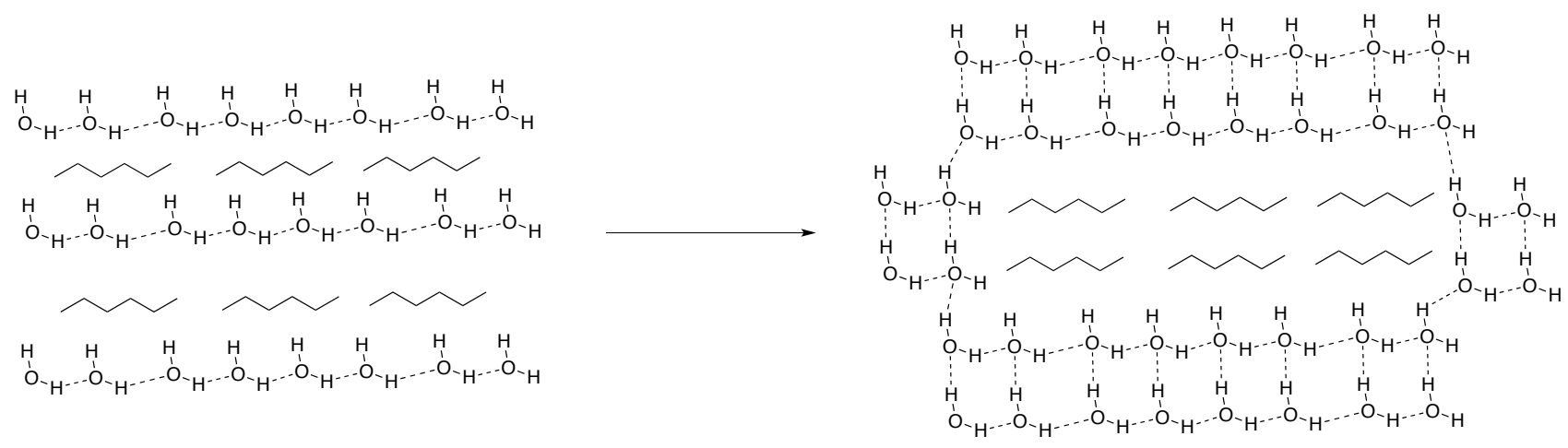

Scheme 1.1: Hydrophobic effect of hexane (or other oils) in water. 
Molecular recognition has taken advantage of hydrophobic interactions by creating hydrophobic cavities to encapsulate hydrophobic guests and as delivery units for therapeutic drugs. One of the first examples published in this area was the use of cyclodextrin (CD), a cyclic cup-shaped oligosaccharide consisting of 6-8 repeat glucose units, to create inclusion compounds. ${ }^{16}$

(a)

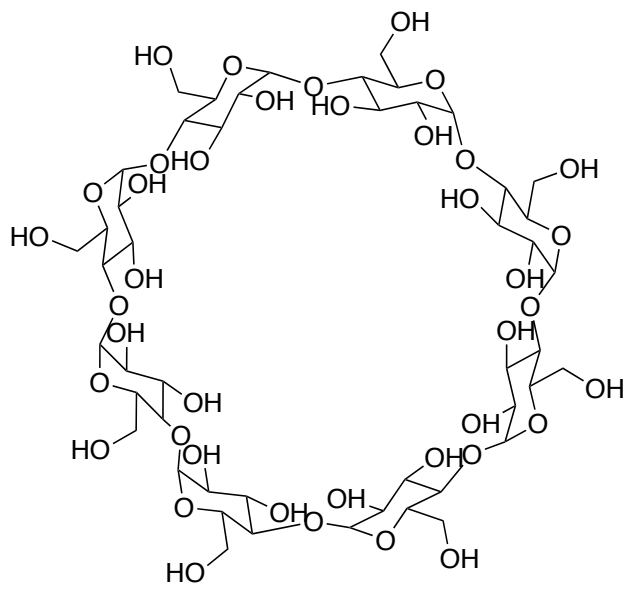

(b)

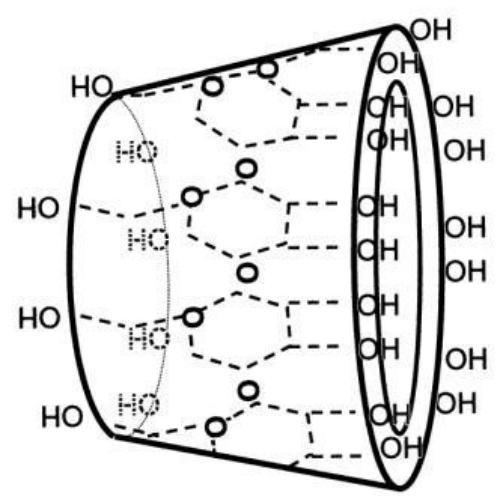

Figure 1.4: (a) $\gamma$-cyclodextrin (b) $\gamma$-cyclodextrin toroid structural arrangement

The structure of cyclodextrin (Figure 1.4a) is influenced by the network of intramolecular hydrogen bonds present on the top and bottom surfaces of the cup. As these hydroxyl groups are involved in hydrogen bonding this makes the interior cavity less polar creating a hydrophobic environment promoting the encapsulation or inclusion of hydrophobic guests.

Many derivatives of cyclodextrin are available each differing in ring size $(\alpha=6, \beta=$ 7 , or $\gamma=8$ glucose units), providing the ability to select among them based on guest size and fit within the cavity. The $\alpha-C D$ has an interior cavity size of $5.7 \AA, \beta-C D$ is $7.8 \AA$ and $\gamma$-CD is $9.5 \AA .{ }^{17} \mathrm{CD}$ 's have proven to be a valuable tool in chemical sensing and drug 
delivery for a wide range of guests. For example, research has shown that hydroxypropylB-cyclodextrin has remarkable properties facilitating the removal of cholesterol from tissue culture cells (Scheme 1.2). ${ }^{18-19}$
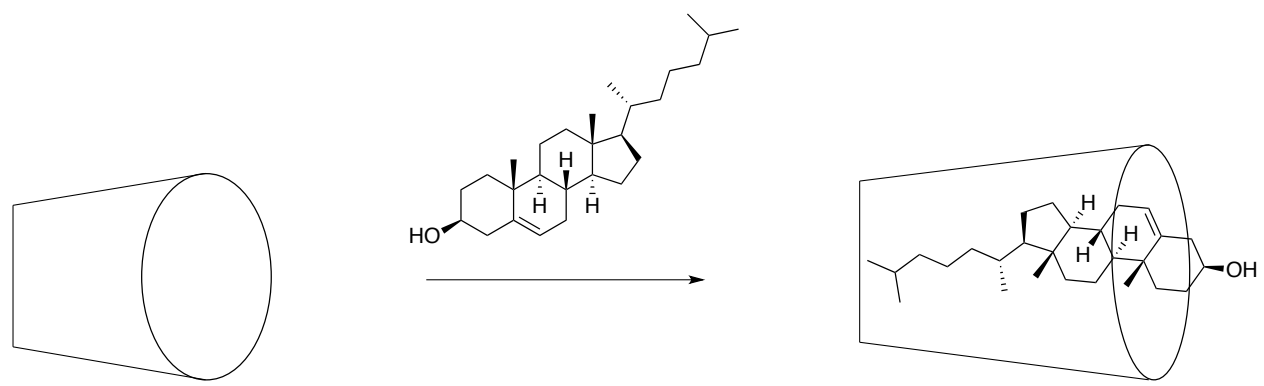

Scheme 1.2: Encapsulation of cholesterol by ß-cyclodextrin

ß-cyclodextrin is also widely used in the application of drug delivery. As many drugs are minimally water soluble, $\beta-\mathrm{CD}$ is used to solubilize the drug for oral and ocular delivery $^{20}$. Examples include Dexamethasone, Diclofenac, Pilocarpine, Digoxin, and Danazole shown in Figure 1.4. The binding constants for the drug/CD complexes range from 100 to $20,000 \mathrm{M}^{-1}$. When the drug is administered either by injection or orally, the drug/CD complex becomes very dilute, releasing the free drug to permeate through biological membranes. Evidence has shown that a 1:100 dilution of the drug/CD complexes reduces the complexed drug from $100 \%$ to $30 \%{ }^{20}$. 

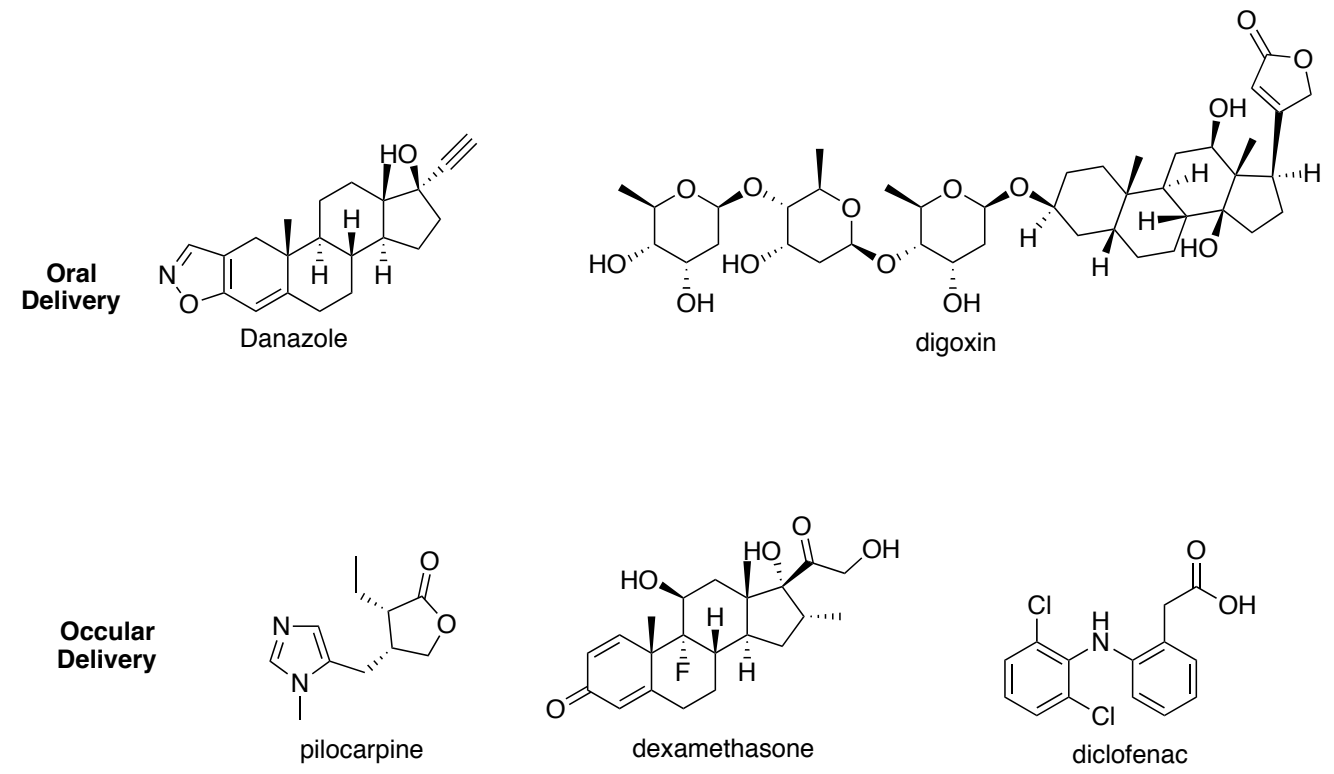

Figure 1.5: Select drugs that use CD's for delivery and their delivery process ${ }^{20}$

This creation of a hydrophobic toroidal cavity to encapsulate guests has lead to the discovery of more hosts possessing notable host-guest properties, such as calixarenes and cucubiturils.

\subsubsection{Calixarenes and Cucubiturils}

The structure of calix[4]arene (Figure 1.6) was established in 1970 by Gutsche $e^{21-22}$ and colleagues. It is synthesized via the reaction of para substituted phenols with formaldehyde and can vary in size by the number of phenol units. The substituents can vary as well. As shown in Figure 1.6b, calix[4]arene forms a cavity much like CD's and has been used to detect a wide array of species including anions ${ }^{23}$, cations ${ }^{24-26}$, and other small organic guests. 
(a)

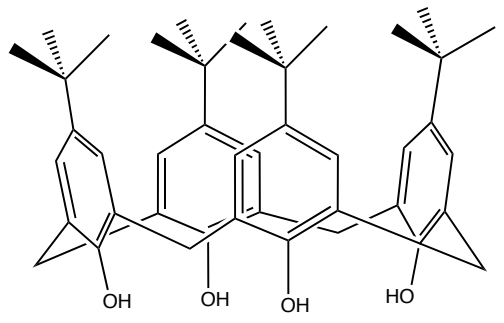

(b)

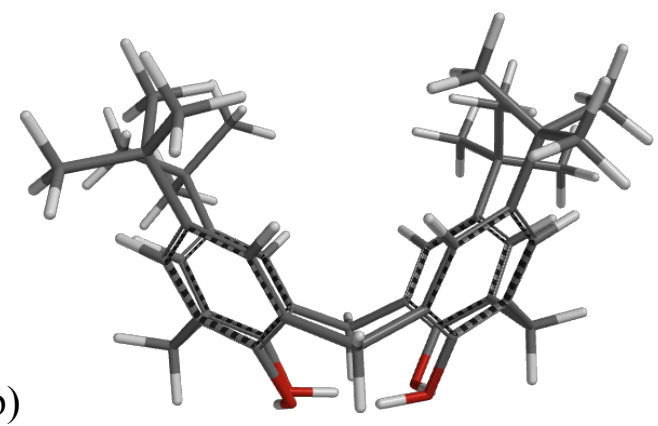

Figure 1.6: (a) Calix[4]arene structure (b) Calix[4]arene molecular model from Spartan

Recent research on binding of L-amino acids with calix[4]arenehydroxymethylphosphonic acids have shown binding constants that vary between $20,000 \mathrm{M}^{-1}$ and $50,000 \mathrm{M}^{-1}$, as indicated in Table 1.1. ${ }^{27}$

Table 1.1: Binding constants of L-amino acids with meso calix[4]arene-bis- $\alpha$ hydroxymethyl phosphonic acid

\begin{tabular}{|l|l|}
\hline L-amino & $\mathrm{K}_{\mathrm{a}}, \mathrm{M}^{-1}$ \\
\hline Gly & 31,234 \\
\hline Ala & 47,299 \\
\hline Pro & 40,082 \\
\hline His & 48,189 \\
\hline Lys & 42,572 \\
\hline Asp & 29,947 \\
\hline Arg & 35,992 \\
\hline Phe & 30,185 \\
\hline Trp & 27,490 \\
\hline Tyr & 20,983 \\
\hline
\end{tabular}


Cucubiturils are synthesized by the reaction of glycouril with formaldehyde (Scheme 1.3). This macrocycle was first synthesized in 1905 by Behrend et $\mathrm{al}^{28}$; however, the structure wasn't confirmed until 1981 by Freeman et. $\mathrm{al}^{29}$. These structures form a hydrophobic cavity, with the inner cavity size increasing by the number of repeat units. Figure 1.7 shows a 3-D representation of some of the cucubituril derivatives, thus demonstrating how the size of the cavity increases as the number of repeat glycouril units increases.
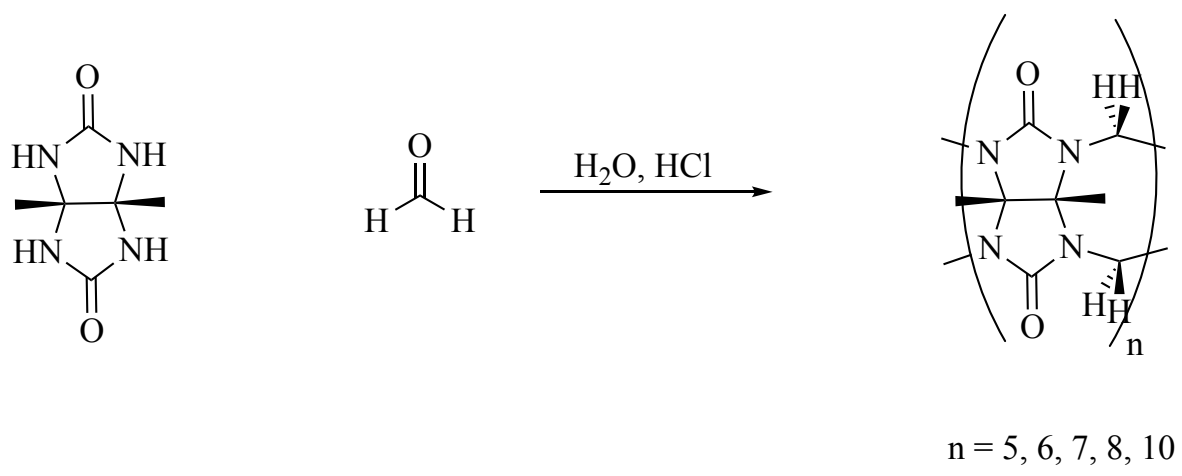

Scheme 1.3: Synthesis of cucubiturils
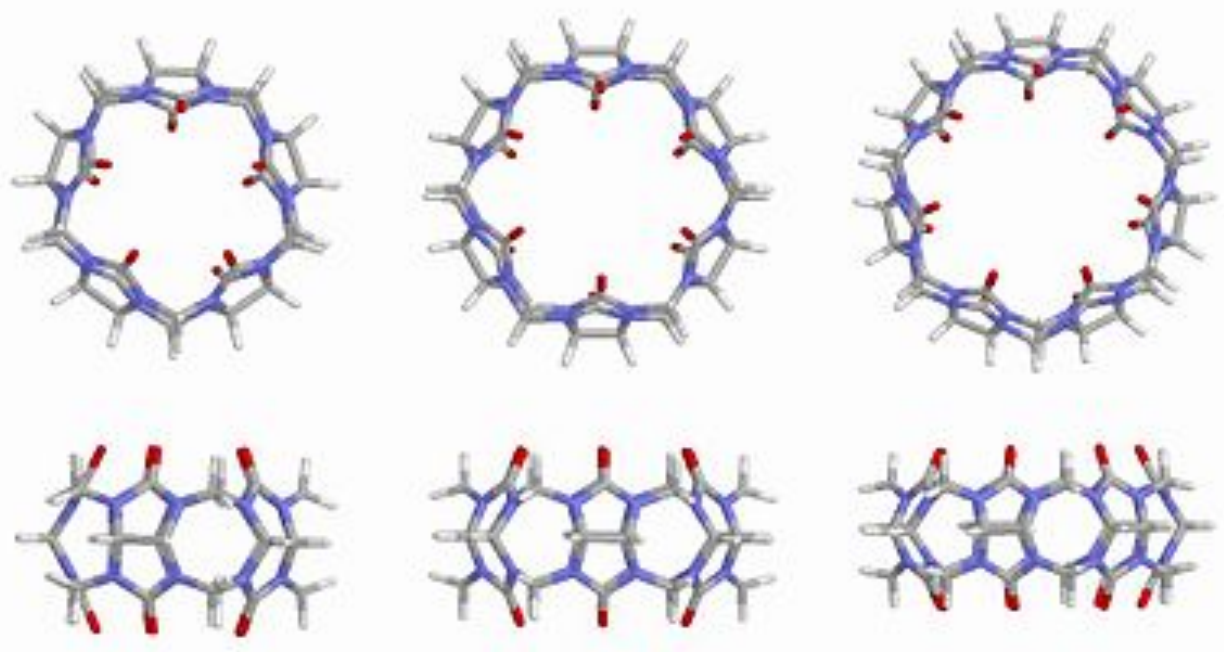

cucurbit[5]uril cucurbit[6]uril cucurbit[7]uril

Figure 1.7: 3-D representation of some common cucubituril derivatives 
In a recent publication ${ }^{30}$ Isaacs et. al. has shown cucubit[7]uril (CB[7]) to possess remarkable binding properties. Specifically, he has demonstrated that it possesses a binding constant of $7.2 \times 10^{17} \mathrm{M}^{-1}$ with the diamantane diammonium guest $\mathbf{8}$, an attomolar binding constant. This is one of the tightest binding monovalent non-covalent complexes in pure water $\left(\mathrm{D}_{2} \mathrm{O}\right)$ ever reported. In $\mathrm{D}_{2} \mathrm{O}$ buffered with $50 \mathrm{mM} \mathrm{NaO} \mathrm{CCD}_{3}$ the binding constant was slightly less but still very tight, $1.9 \times 10^{15} \mathrm{M}^{-1}$.

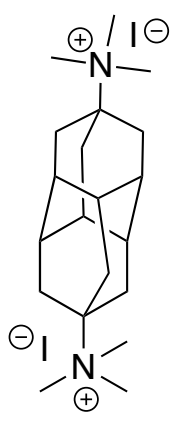

8

Their findings supplemented the known ions that CB's can bind, further illustrating that binding of hydrophobic trimethylammonium compounds, iron sandwich complexes, multiple adamantane type guests, and acridine-3,6-diamine can be accomplished with binding constants varying between $2.5 \times 10^{4}-3 \times 10^{13} \mathrm{M}^{-1}$.

\subsection{Reversible Covalent Binding}

\subsubsection{Overview}

As mentioned above, molecular recognition involves non-covalent bonding interactions. However, interactions that are covalent in nature but exist in equilibrium can also achieve a similar purpose. Examples of reversible covalent bonding interactions include those of phenylboronic acids with diols (Scheme 1.4) and electron deficient carbonyls with amines (Scheme 1.5). Boronic acids are widely used for their interactions 
with sugars, catechols, and other diols. This is a potentially valuable property in the medical field as a potential diagnostic tool for the monitoring of blood glucose levels of patients diagnosed with diabetes ${ }^{31}$.<smiles>OB(O)c1ccccc1</smiles>

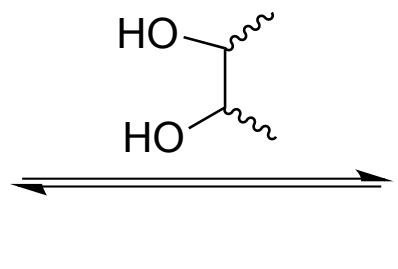<smiles>CC1OB(c2ccccc2)OC1C</smiles>

Scheme 1.4: Phenylboronic acid binding with diol<smiles>CCN(CC)c1ccc2c(Br)c(C=O)c(=O)oc2c1</smiles><smiles>[R]C(N)C(=O)O[C@@H](C)CCC</smiles><smiles>CCN(CC)c1ccc2c(Br)c(/C=N/CC(=O)[O-])c(=O)oc2c1</smiles>

Scheme 1.5: Coumarin aldehyde binding an amine ${ }^{32}$

Phenylboronic acid binding has been widely studied since the discovery of boronic acids solubilizing saccharides and polyols by Kuivila et al. ${ }^{33}$ Since then numerous publications have demonstrated sensors targeting saccharides ${ }^{34-41}$, nucleotides and carbohydrate transporters $^{42-49}$, and as affinity ligands for the separation of carbohydrates and glycoproteins ${ }^{50-55}$.<smiles>OB(O)c1ccccc1</smiles><smiles>Oc1ccccc1O</smiles>

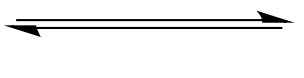<smiles>c1ccc(B2Oc3ccccc3O2)cc1</smiles>

Scheme 1.6: Phenylboronic acid binding to catechol 
Springsteen and Wang demonstrated that phenylboronic acid can bind to catechol with an equilibrium constant of $800 \mathrm{M}^{-1} .{ }^{56-57}$ This discovery inspired the development of fluorescent sensors for dopamine and norepinephrine $9^{58}$, and glucosamine $\mathbf{1 0}^{59}$ from the Glass group. Sensor 9 was selective for the binding of dopamine and norepinephrine, but did not bind glucosamine very well due to the large size of the binding cavity. This lead to the development of sensor 10, which showed highly selective binding for glucosamine $\mathrm{K}_{\mathrm{a}}=4,100 \mathrm{M}^{-1}$ over other catechols such as norepinephrine $\left(\mathrm{K}_{\mathrm{a}}=25 \mathrm{M}^{-1}\right)^{59}$.

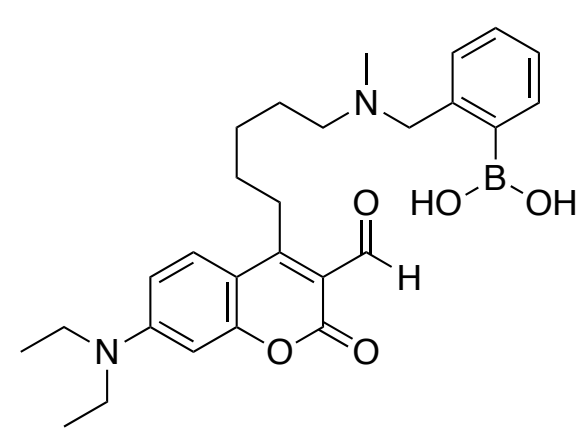

9

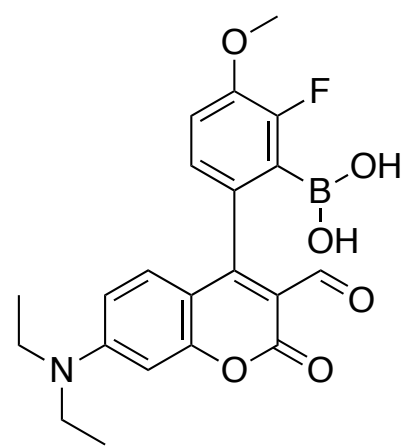

10

Wang also performed additional research into the relationship between $\mathrm{pK}_{\mathrm{a}}, \mathrm{pH}$, and binding constants between the interactions of phenylboronic acids and diols. It was found that (1) a Hammet plot can describe the relationship between $\mathrm{pK}_{\mathrm{a}}$ of monosubstituted phenylboronic acids and its substituents, (2) the optimal binding $\mathrm{pH}$ is not always above the $\mathrm{pK}_{\mathrm{a}}$ of the boronic acid, and is affected by the $\mathrm{pK}_{\mathrm{a}}$ values of the boronic acid and the diol, and (3) boronic acids with lower $\mathrm{pK}_{\mathrm{a}}$ values do not always have greater binding affinities. ${ }^{60}$ 


\subsubsection{Sugar Binding}

Sugars such as glucose 11 and fructose 12 have multiple diol groups that allow them to successfully bind to phenyl boronic acids. The first fluorescent sensor for carbohydrates was presented by Yoon and Czarnik in $1992^{61}$. Since then a wide array of boronic acid sensors have been made, many purposed for incorporation into blood sugar monitors for diabetic patients ${ }^{10,62-63}$. Interestingly, the desire for blood sugar monitoring has been advanced to commercial production of contact lenses that change the color of the lens to alert the wearer of a drop in circulating glucose levels ${ }^{64}$. Furthermore, peptide boronic acids have demonstrated the capability of binding to the tertiary structure of HIV-1 RRE IIB in the low micromolar region ${ }^{65-66}$.

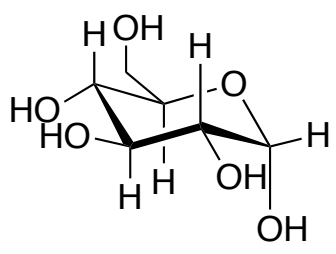

11

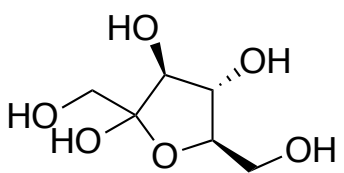

12

Shinkai developed one of the first phenyl boronic acid sensors selective for glucose over other monosaccharide sugars as evidenced by circular dichromism. ${ }^{67}$ Specifically, the diboronic acid shown in Scheme 1.7 bound glucose 190 times more favorably than the next strongest binding analyte, maltose. Since then it has been established that the relative affinity of boronates for diols in most carbohydrates is of the order cis-1,2-diol $>-1,3-$ diol $>>$ trans-1,2-diol $^{68}$. This feature explains why some sugars intrinsically bind better than others. 

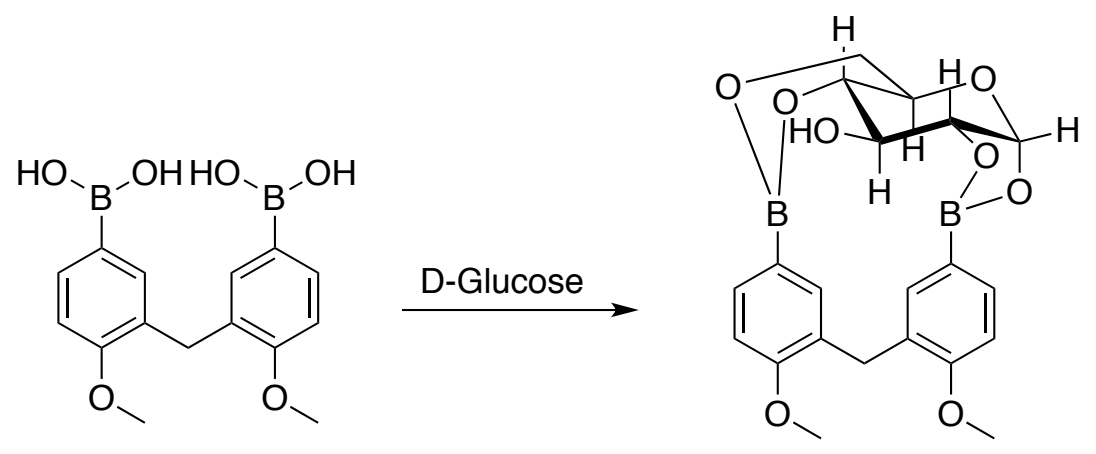

Scheme 1.7: Shinkai Sensor for D-glucose

\subsection{Conclusion}

Molecular recognition has come a long way in the past 50 years. It has grown in popularity for not only it's ability to recognize molecules, but to also help us understand many biological processes. Molecular recognition is most known for using non-covalent interactions, however a growing use of reversible covalent interactions is being explored. These interactions between the host and guest depend on the shape, size and charge between the host and guest. This specificity allows for selective interaction between targeted guests and have promoted a growing number of medicinal applications. The novelty, complexity, and possible medicinal applications of these applications has created groundbreaking new fields in chemistry, with one of the most notable being fluorescent chemical sensing. 


\section{Chapter 2 Fluorescence Chemical Sensing}

\subsection{Overview}

A chemical sensor transforms chemical information (presence, concentration, activity) into an analytical signal that can be quantified. Fluorogenic probes are a unique class of chemical sensing probes, an area that was pioneered by Gregorio Weber. Weber is responsible for the development of probe chemistry, by being the first to demonstrate the use of dansyl chloride as a fluorophore ${ }^{69}$. Figure 2.1 illustrates a few examples of the many known fluorophores.<smiles>CN(C)c1cccc2c(S(=O)(=O)Cl)cccc12</smiles>

dansyl chloride<smiles>c1ccc2c(c1)Cc1ccccc1O2</smiles><smiles>c1ccc2ccccc2c1</smiles>

naphthalene<smiles>O=C(O)c1ccccc1-c1c2ccc(=O)cc-2oc2cc(O)ccc12</smiles>

fluorescein<smiles>CCN(CC)c1ccc2c(-c3ccccc3C(=O)O)c3ccc(=[N+](CC)CCl)cc-3oc2c1</smiles><smiles>c1ccc2nc3ccccc3cc2c1</smiles><smiles>c1ccc2c(c1)[nH]c1ccccc12</smiles>

carbazole<smiles>c1ccc2onnc2c1</smiles>

benzoxadiazole<smiles>CCN(CC)c1ccc2ccc(=O)oc2c1</smiles>

Figure 2.1: A few common fluorophores 
Fluorescent molecules are organic compounds containing conjugated $\pi$-systems. The fluorescence event occurs from the transition of an electron from the HOMO (highest occupied molecular orbital) to the LUMO (lowest unoccupied molecular orbital). The larger the conjugated $\pi$ system is, the smaller the HOMO-LUMO gap becomes, resulting in an emission at longer wavelengths.

Sensors are either weakly fluorescent or nonfluorescent until a bonding interaction occurs, indicating a chemical change. Fluorescent sensing, especially near-IR fluorescent probes, allows for the use of these probes for in vivo and in vitro imaging. A sensor possesses a recognition site intended to bind to a desired guest, which is tethered to the fluorophore by a spacer unit (Figure 2.2). To "turn-on", the fluorescent sensor binds to a guest causing an enhancement in fluorescence. Alternatively some sensors are "turn-off", being quenched by the guest and thus show a decrease in or loss of fluorescence signal. Measuring this increase or decrease in fluorescence due to the binding event allows us to determine a binding constant, $\mathrm{K}_{\mathrm{a}}$.

\section{Free receptor}

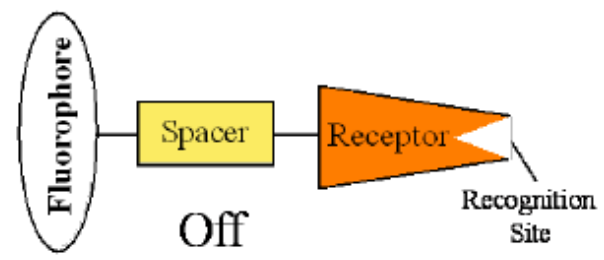

Bound receptor

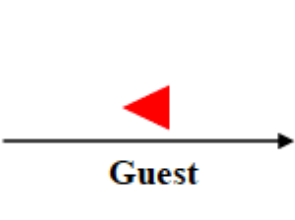

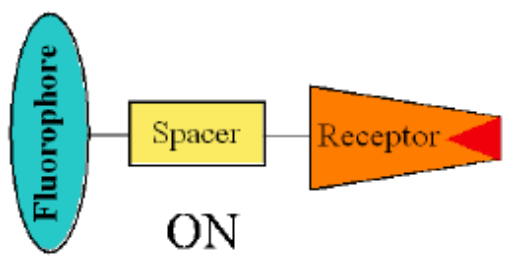

Figure 2.2: A Turn on fluorescent sensor schematic representation

\subsection{Fluorescence Basics}

Fluorescence is defined by IUPAC as a luminescence occurring when a substance is irradiated by (absorbs) electromagnetic irradiation. The scheme in Figure 2.3 shows the process of how fluorescence occurs. A molecule or fluorescent dye begins in its ground 
electronic state $\left(\mathrm{S}_{0}\right)$ and absorbs electromagnetic radiation, becoming excited to a higher singlet excited state $\left(\mathrm{S}_{1}\right.$ or $\left.\mathrm{S}_{2}\right)$, each composed of their own vibrational levels. Once excited, the molecule can undergo a non-radiative decay or internal conversion between the two states which have the same spin-multiplicity ${ }^{70}$. It is then followed by a vibrational relaxation to the lowest level of the $\mathrm{S}_{1}$ state. Once in the lowest $\mathrm{S}_{1}$ level, the molecule can return to its ground electronic state, through the emission of photons, which is fluorescence. The photons that are released are of lower energy than the absorbed photons, thus giving the fluorescence wavelength a longer wavelength than the absorption. This difference between the absorption maxima and the fluorescence wavelength maxima is known as a Stokes' shift (Figure 2.4). For example, excitation of coumarin 6 at $420 \mathrm{~nm}$ results in a fluorescence max at $500 \mathrm{~nm}$ providing a $80 \mathrm{~nm}$ Stokes' shift. These maximas are dependent on factors such as the structure of the fluorophore and the solvent. The timescale of this process is on the order of $10^{-8}$ to $10^{-11}$ seconds. $^{71}$ 


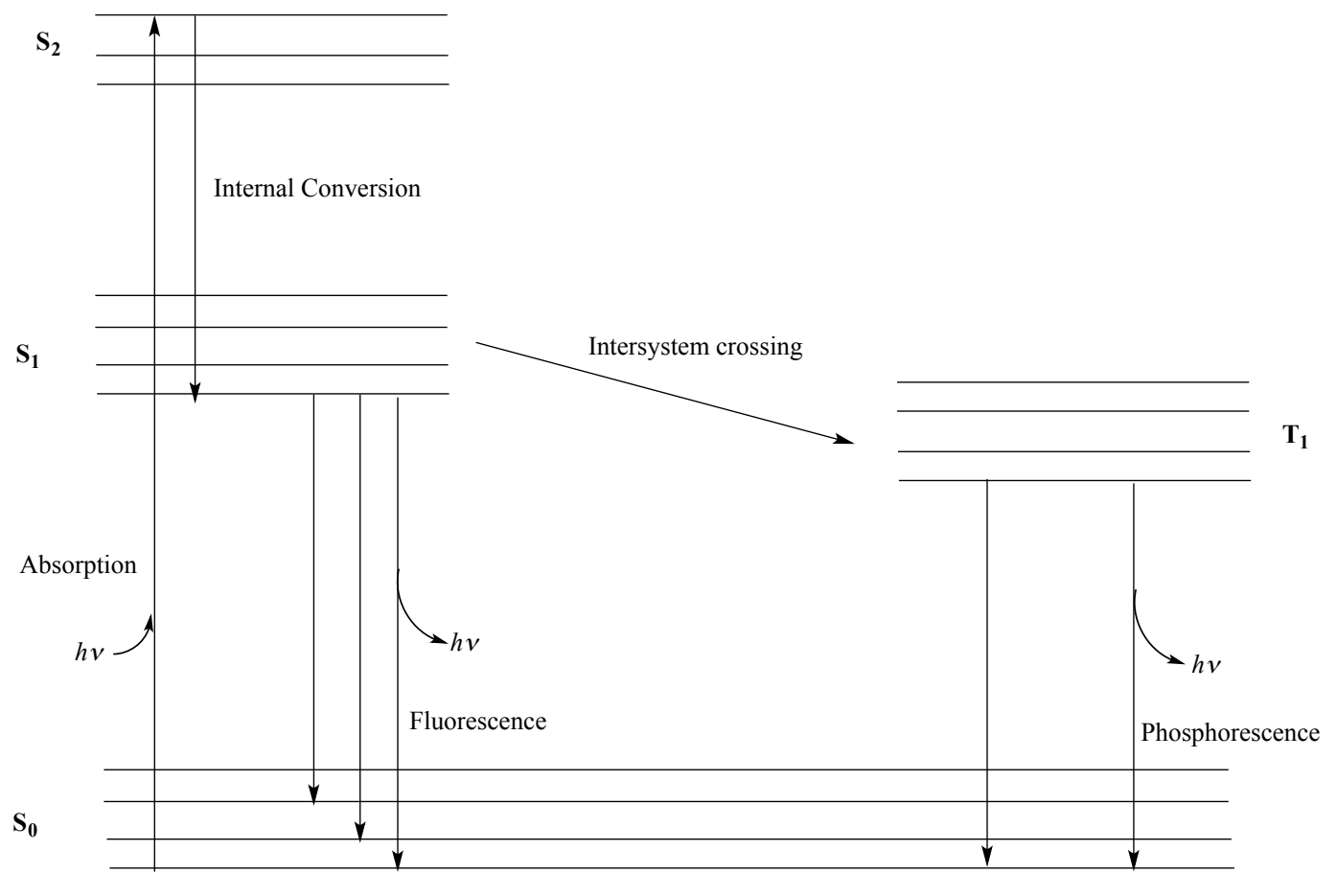

Figure 2.3: Jablonski Diagram

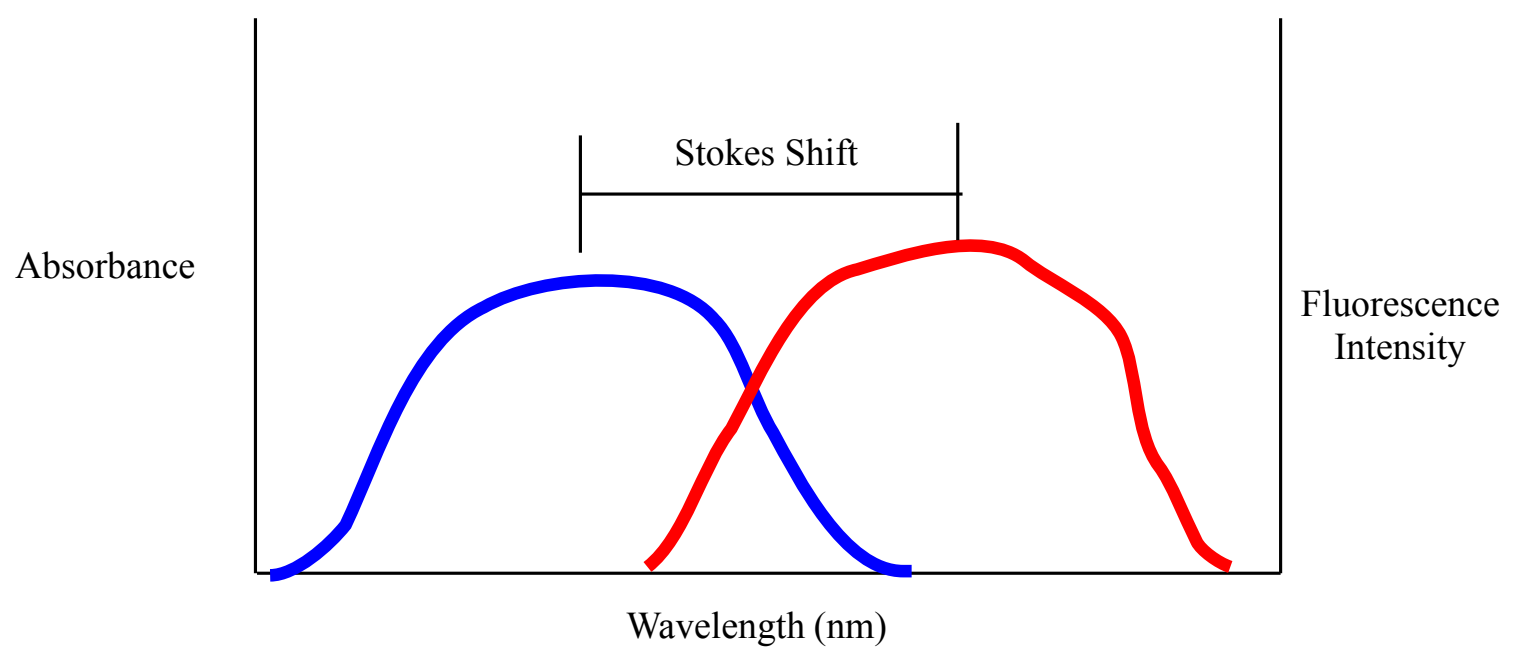

Figure 2.4: Stokes Shift

Absorption will not always lead to fluorescence. A separate process can occur upon excitation and relaxation to the lowest excited state $\mathrm{S}_{1}$. The molecule can undergo a non-radiative transition (intersystem crossing) to the triplet state $T_{1}$. This is the transition 
between isoenergetic vibrational levels belonging to electronic states of different multiplicities. ${ }^{70}$ Upon relaxation from the $\mathrm{T}_{1}$ state to the $\mathrm{S}_{0}$ state, the emission of photons is called phosphorescence. While it is commonly said that this transition from $T_{1}$ to $S_{0}$ is electronically forbidden, it can occur due to spin-orbital coupling, which occurs over a longer period of time on a scale of seconds to minutes. This is what gives stick on stars their ability to glow in the dark.

Quantum yield $(\Phi)$ indicates how efficiently a molecule will behave as a fluorophore. It is calculated by measuring the ratio of photons emitted to photons absorbed. A quantum yield of 1.0 would indicate that all of the photons absorbed are emitted. Energy transfer due to fluorescence quenching causes the quantum yield to decrease. The energy can then be transferred to the solvent, another chemical species in the solution, or another excited molecule.

\subsection{Overview of Fluorescent Sensing}

Fluorophores are designed such that their spectra change as a function of the concentration of added analyte, such as biological amines, $\mathrm{pH}$, anions, or cations. Fluorescent sensing can use a variety of quenching mechanisms including photoinduced electron transfer (PET), intramolecular charge transfer (ICT), or Förster Resonance Energy Transfer (FRET). These quenching mechanisms allow probes to selectively give a turn-on or turn-off response upon binding to their intended analyte.

\subsubsection{Photoinduced Electron Transfer}

Photoinduced electron transfer, PET, involves a light induced transfer of an electron resulting in a quenching effect. Upon excitation, a fluorophore has two half filled orbitals with a significant energy gap between them. If another molecule not conjugated 
to the fluorophore has a HOMO or LUMO within this HOMO/LUMO gap, a photoinduced electron transfer can happen by one of two methods, a-PET or d-PET.

When the HOMO of the tethered system falls within the energy gap of the fluorophore, this process is called acceptor PET, a-PET. The fluorophore has a half filled HOMO, allowing an electron from the HOMO of the other molecule to be transferred into the lower energy HOMO, quenching the fluorescence. In this case the fluorophore is acting as an electron accepter and this process is termed a-PET (Figure 2.5). An a-PET designed sensor can be designed to be quenched by this process until it binds to the analyte of interest, changing the HOMO/LUMO energy levels and giving rise to fluorescence as depicted in Figure 2.6.
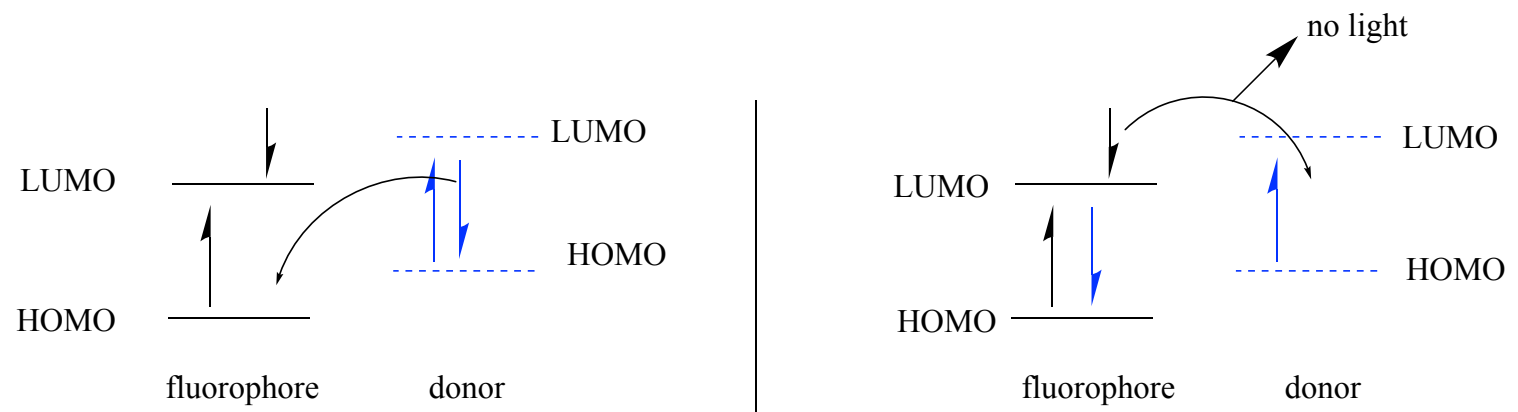

Figure 2.5: a-PET frontier molecular orbital quenching mechanism

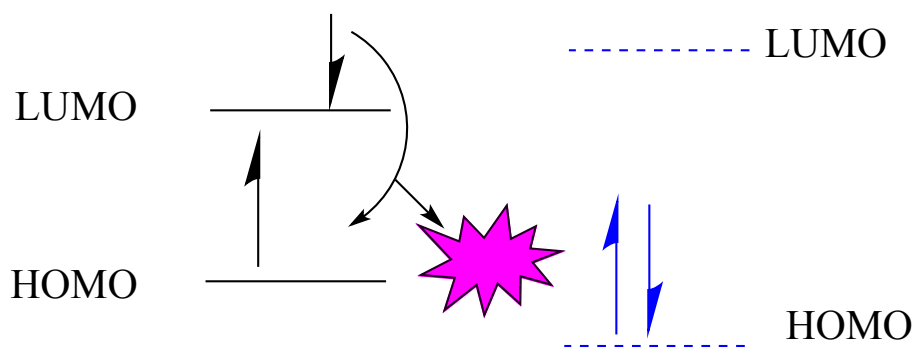

Figure 2.6: non quenched a-PET system

If instead the LUMO of the other molecule was in the energy gap, as demonstrated in Figure 2.7, the quenching process is d-PET (donor PET). The electron 
that was excited to the LUMO of the fluorophore is transferred into the lower energy LUMO of the acceptor molecule before it can fluoresce. However, upon binding the energy of the LUMO rises, giving rise to the fluorescence as seen in Figure 2.8.

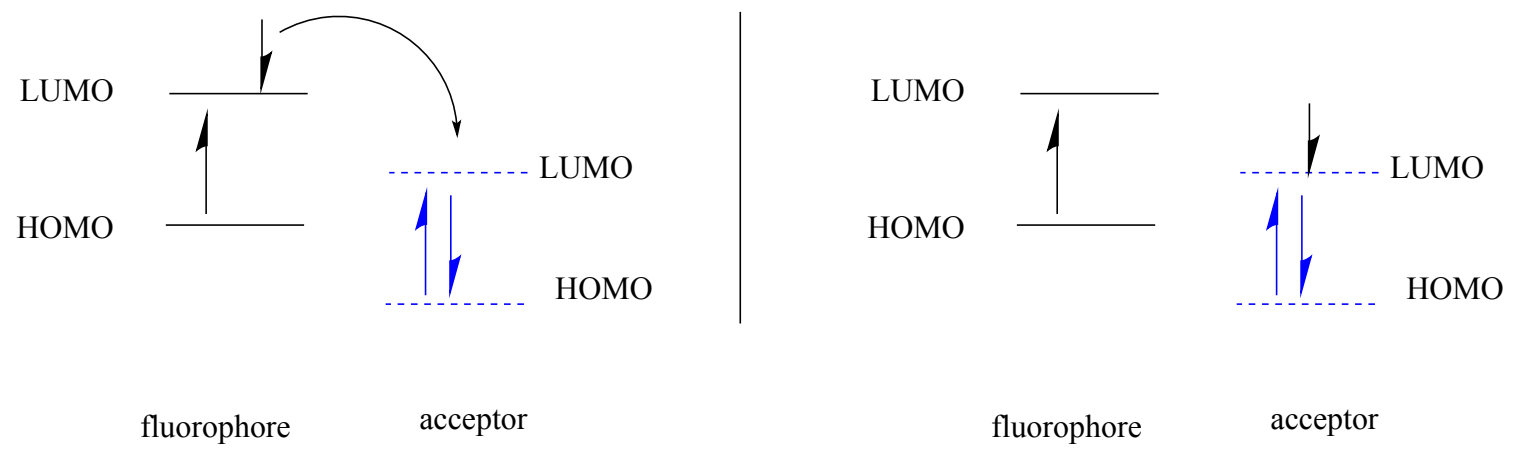

Figure 2.7: d-PET Frontier molecular orbital quenching mechanism

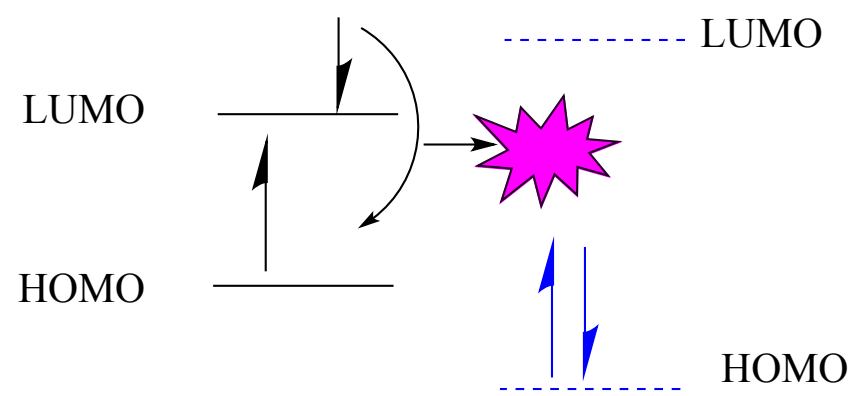

fluorophore acceptor

Figure 2.8: d-PET non-quenched system

The fluorophore system is quenched in Scheme 2.1 by an electron in lone pair of the nitrogen atom donating into the fluorophore system (a-PET). When the sensor binds with $\mathrm{HPO}_{4}{ }^{2-}$ the electrons in the lone pair become coordinated with the hydrogen atom giving rise to its fluorescence enhancement. ${ }^{69}$ 


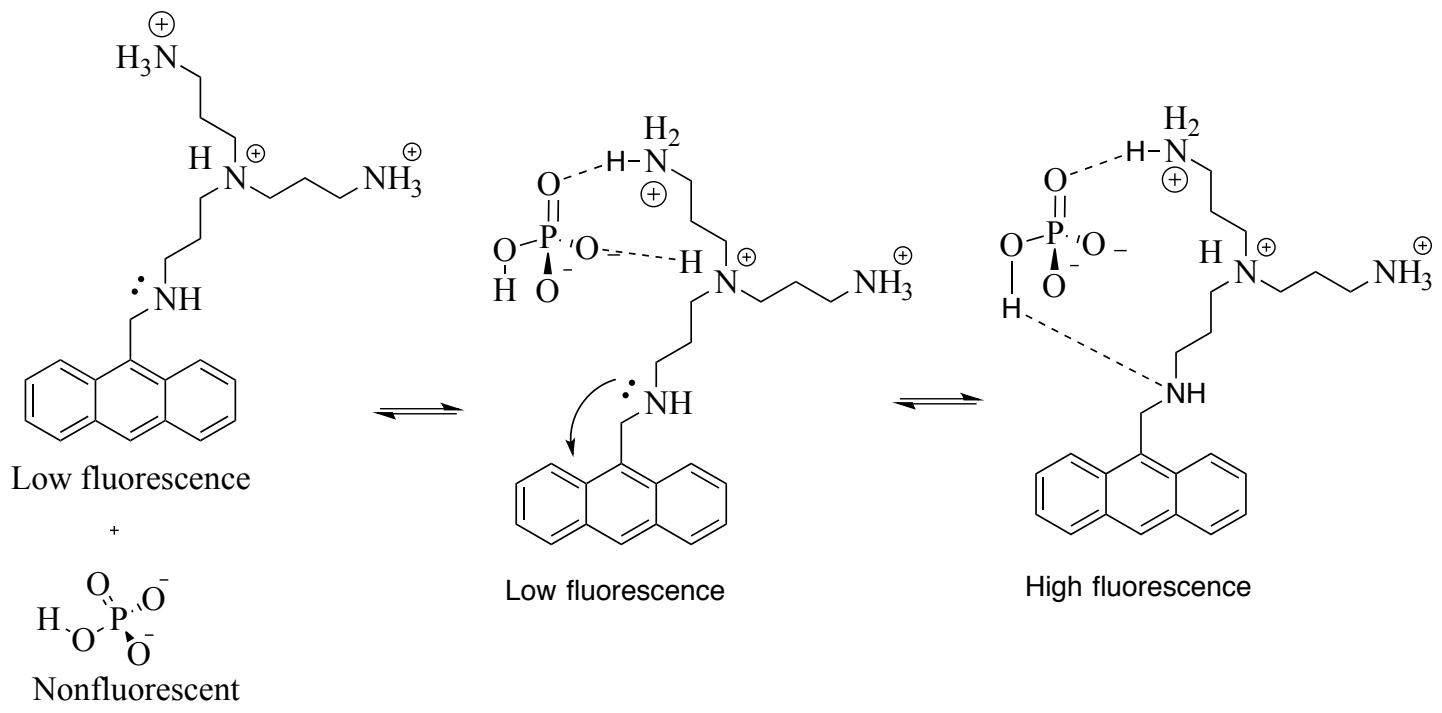

Scheme 2.1: a-PET quenched fluorescent probe ${ }^{69}$

\subsubsection{Determining Stoichiometry of binding}

When a titration reveals that binding could be occurring, a Job plot titration is performed to determine the stoichiometry of the binding between the host $(\mathrm{H})$ and guest (G): 1:1, 1:2, 2:1, etc. To perform this, the concentration of the host and guest remain constant while varying the mole fraction of the guest. They are then titrated and measured over UV or fluorescence intensity signals. A plot is then created using the mole fraction guest vs. UV signal, which provides a curve with a maxima corresponding to the stoichiometry of the complex formed when $\mathrm{H}$ and $\mathrm{G}$ bind. Figure 2.9 illustrates a plot with a 1:1 stoichiometry. 


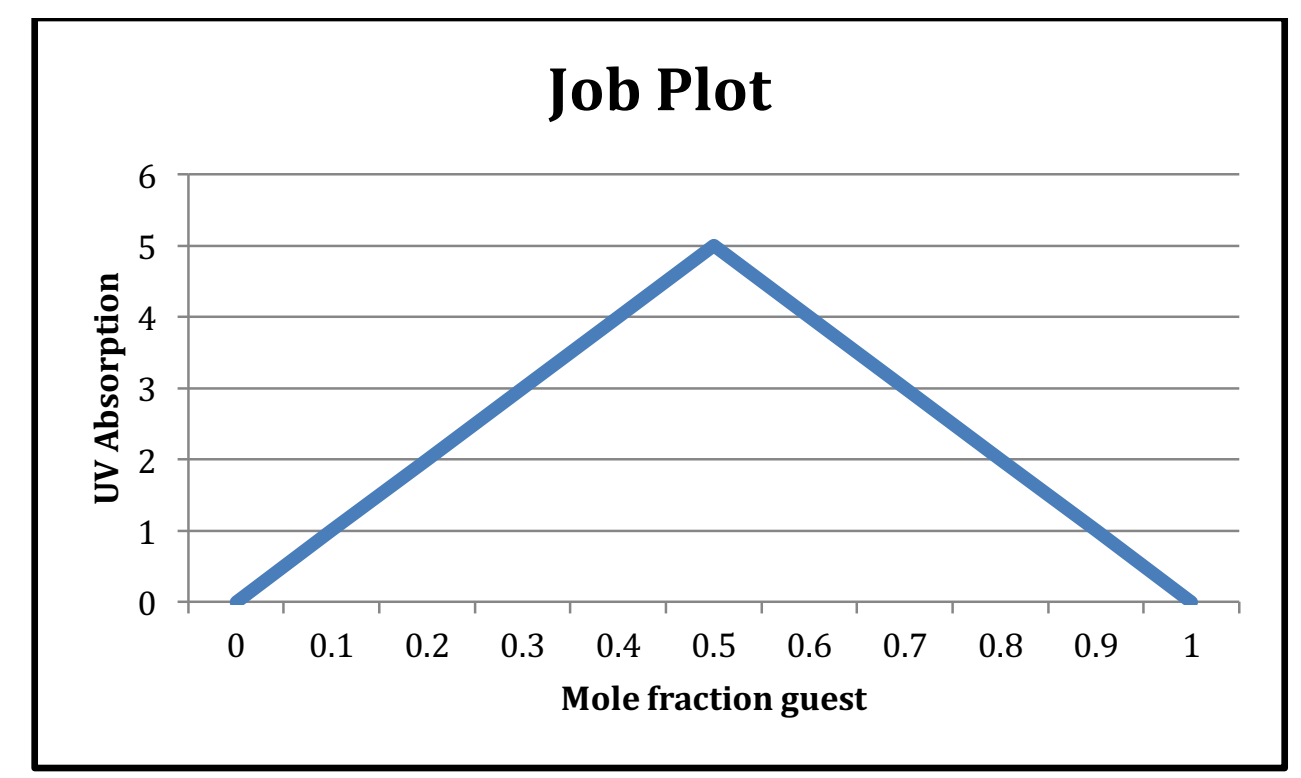

Figure 2.9: Job plot showing 1:1 binding

\subsection{Conclusion}

Fluorescent sensors provide a valuable method of detection of multiple analytes, which can be selective when a sensor is properly designed. Through many different quenching mechanisms such as PET, FRET, ICT, a sensor can be designed such that it gives a desired "turn-on" or "turn-off" response when the analyte is present. Fluorescent sensing also allows us to predict the ratio of binding between the host and guest when a Job plot is analyzed. 


\section{Chapter 3 Lipids and Glycolipids}

\subsection{Overview}

Lipids are biological molecules that are insoluble or weakly soluble in water, while being soluble in fat or organic solvents such as toluene, ether, and chloroform ${ }^{72}$. Lipids are the primary components of cellular membranes, protecting the cell and allow selective cellular processes in the body to be achieved. Lipids can contain long hydrocarbon chains such as in fatty acids and isoprenes, or multiple rings similar to those found in steroids. Their diverse structures present five main types of lipids: fatty acids, phospholipids, sphingolipids, steroid lipids, and triacylglycerol's.

Fatty acids, FA, are carboxylic acids with long chain hydrocarbons that can be saturated, unsaturated or polyunsaturated. Their aliphatic chains can range from 12-20 carbon atoms ${ }^{73}$, with the $\mathrm{C}_{16}$ and $\mathrm{C}_{18}$ species including oleic acid (shown in Figure 3.1), stearic acid, linoleic acid, and palmitic acid being among the most abundant found in plants and animals. Fatty acids are important as they represent a major component of the other lipid classes, as they contain one or more fatty acid esters in their structures. In mammals, fatty acids are found in adipose tissues which serves as energy storage ${ }^{74}$.
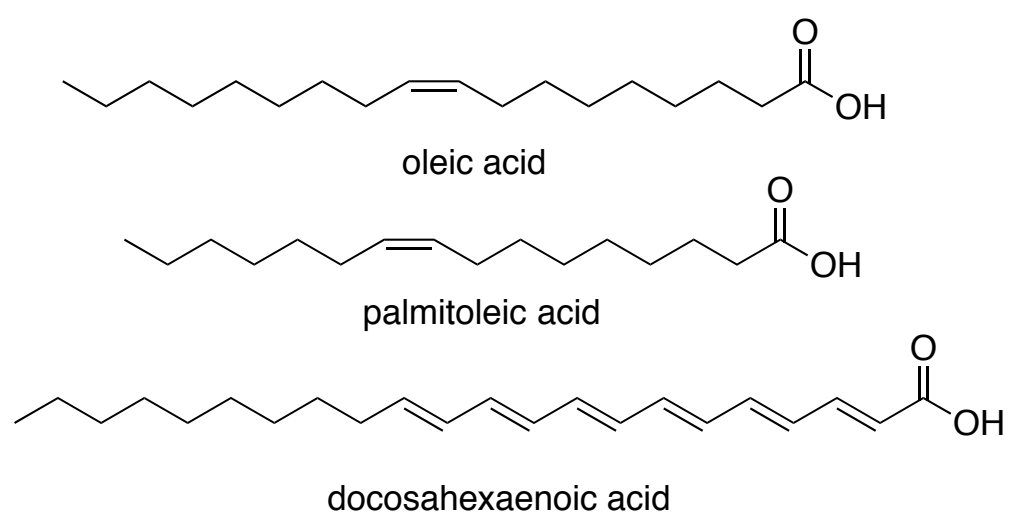

Figure 3.1: A few common fatty acids 
Phospholipids (Figure 3.2) are the major lipid component of cellular membranes and are responsible for some of the cell-to-cell signaling pathways in the body. They contain a glycerol unit with two hydrophobic fatty acid tails and a hydrophilic phosphate group. Additionally, the phosphate group can be attached to a hydrophilic compound (-R) such as choline, serving as a headgroup. As these lipids contain a hydrophilic head and hydrophobic tails, they are termed amphipathic or amphiphilic. Common headgroups include choline, serine, ethanolamine, glycerol, and inositol (Figure 3.3), with choline, ethanolamine, and serine, accounting for $35-45 \%, 22-29 \%$, and $12-19 \%$ of all phospholipids in cell membranes, respectively ${ }^{75}$. The fatty acid (hydrophobic tail) anchors the phospholipid into the membrane and the headgroup (hydrophilic headgroup) is on the exterior of the membrane exposed to the surrounding water environment.

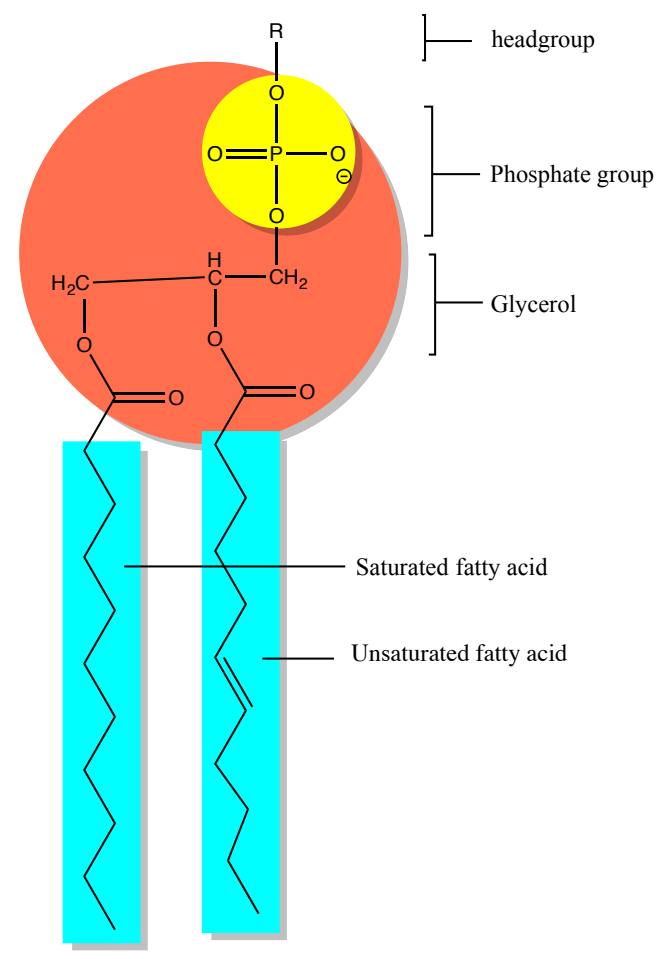

Figure 3.2: Phospholipid structure 
<smiles>[R]O[C@H]1[C@@H](O)[C@@H](O)[C@@H](O)[C@H](O)[C@H]1O</smiles>

Inositol<smiles>[NH3+]C(CO)C(=O)[O-]</smiles>

Serine<smiles>C[N+](C)(C)CCO</smiles>

Choline<smiles>[2H]OCC[Hg]</smiles>

Ethanolamine<smiles>OCC(O)CO</smiles>

Glycerol

Figure 3.3: Various headgroups of phospholipids (where $\mathrm{R}$ is the phospholipid)

Sphingolipids are also a major lipid component of cell membranes. While phospholipids contain two fatty acid chains, sphingolipids contain a sphingosine backbone with one fatty acid residue attached to the 2-amino position of the sphingosine. Substitution of the terminal hydroxy group on the sphingosine with a choline phosphate ester results in a sphingomyelin, or with a sugar acetal, yields a glycosphingolipid or cerebroside, shown in Figure 3.4. 

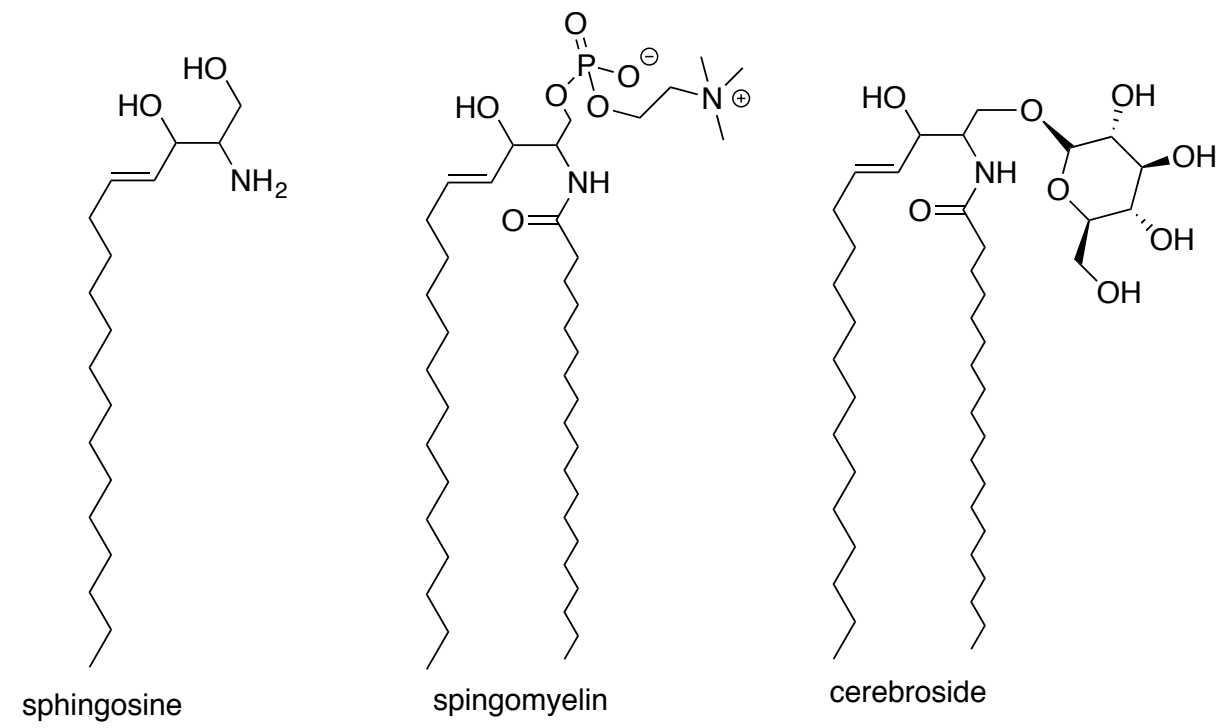

Figure 3.4: Sphingolipid examples

Steroids contain four fused rings as illustrated in Figure 3.5. Cholesterol is the most abundant steroid found in mammals and the major component in membranes. It's presence decreases membrane fluidity and inhibits fatty acids from crystallization by interaction between the fused ring system and the long tails of the fatty acids. Progesterone is an example of the progestogen steroid hormone found in humans that is responsible for the regulation of the female menstrual cycle, embryogenesis, and pregnancy. Dexamethasone, a synthetic corticosteroid drug, has been used in many medical treatments including treatment of inflammation, severe allergies, adrenal problems, arthritis, asthma, blood and bone marrow disease, kidney disease, skin conditions, and symptoms of multiple sclerosis ${ }^{76}$. 


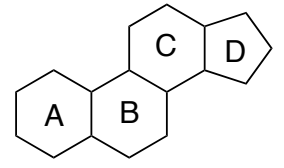

steroid ring system

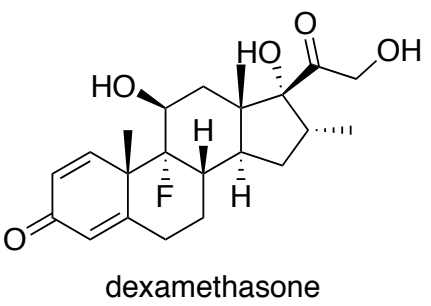

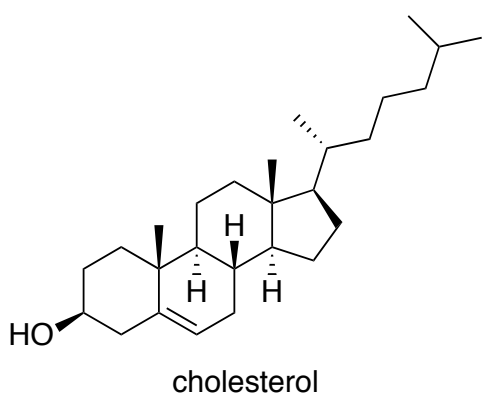

cholesterol
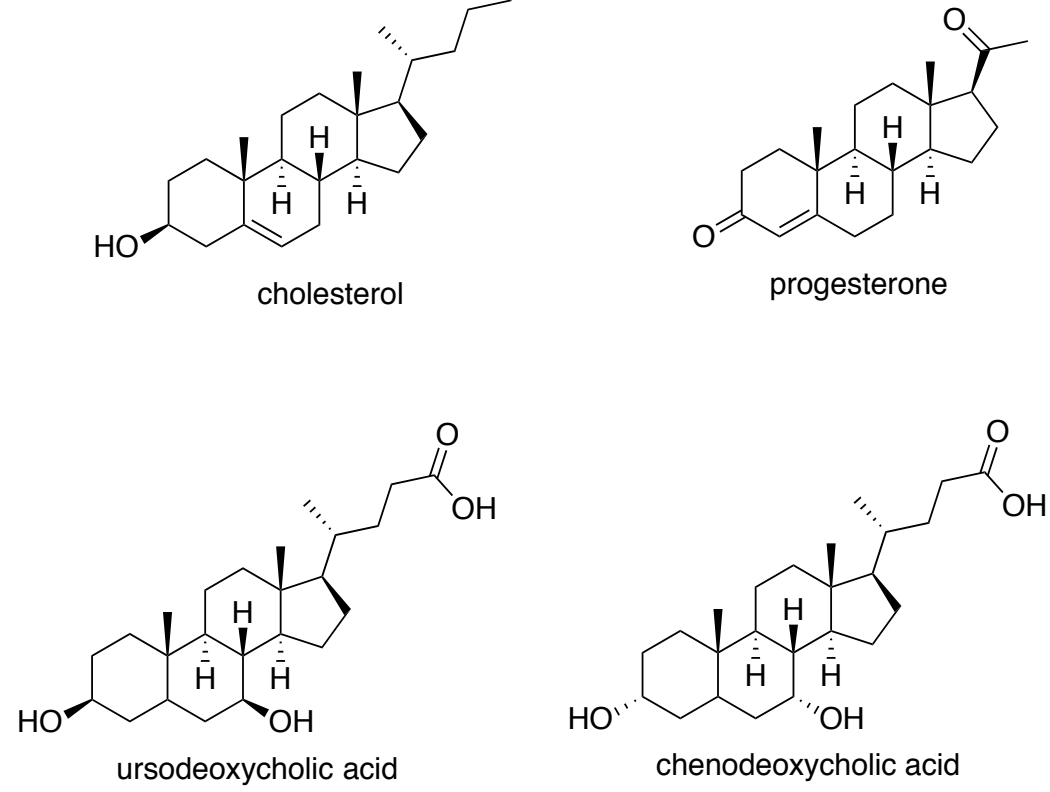

Figure 3.5: Steroid ring system and examples

Bile acids are a group of steroids that assist in the digestion and absorption of fats and fat-soluble compounds in the intestines. ${ }^{77}$ Ursodeoxycholic acid, a bile abundant in bears, differs from chenodeoxycholic acid in the orientation of the hydroxyl group on the C7 position of the steroid backbone (Figure 3.5). Ursodeoxycholic acid has been used for the treatment of primary biliary cirrhosis and to dissolve gallstones. Chenodeoxycholic acid in combination of benzafibrate has been used for the treatment of Hepatitis $\mathrm{C}$ infections. $^{77}$

Triacylglycerols (or triglycerides, Figure 3.6) are fatty acid triesters of glycerol found mostly in the cytoplasm of adipose cells ${ }^{78}$. Triacylglyercol is a highly concentrated and efficient form of energy storage in animals. For example, in a $70 \mathrm{~kg}$ man who has fuel reserves of $100,000 \mathrm{kcal}$ in triacylglycerols, about $11 \mathrm{~kg}$ of his total body weight consists of triacylglycerols. If this energy was instead stored as glycogen, his body weight would 
be about $55 \mathrm{~kg}$ greater. About $7 \mathrm{kcal} / \mathrm{g}$ of energy is released from the complete oxidization of triacylglycerols, much higher than that of carbohydrates and proteins, which are about $4 \mathrm{kcal} / \mathrm{g}{ }^{78}$

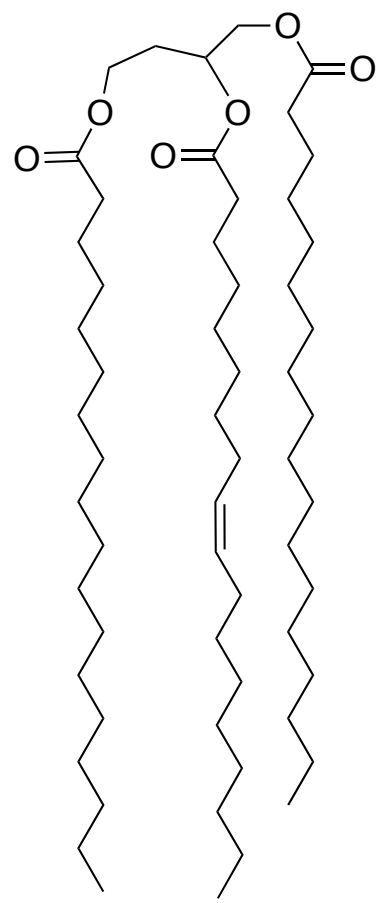

\section{Triglyceride}

Figure 3.6: Example of a triglyceride

\subsection{Micelles and Vesicle Formation}

Micelles and vesicles are able to be formed with phospholipids, glycolipids and fatty acids. Upon addition to water a fatty acid will either come together to form a micelle, form a lipid bilayer, or form a vesicle. In water, the polar headgroups will form a layer on the outside of the vesicle orienting the hydrophobic tails into the interior of the micelle as shown in Figure 3.7. 


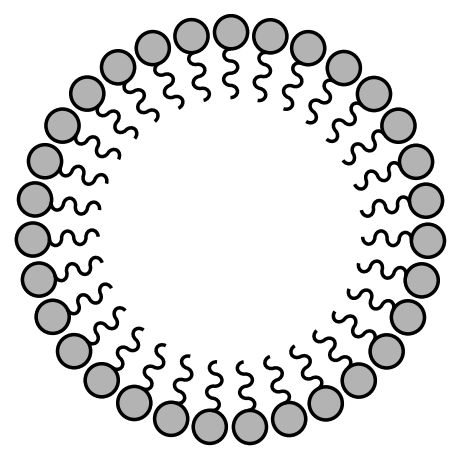

Figure 3.7: Micelle

Fatty acids will form micelles once a specific concentration is present in solution. This is called the critical micelle concentration (CMC). When below the CMC micelles will not form, and above the CMC addition of more fatty acids result in the formation of additional micelles.

\subsection{Lipid Signaling}

Lipids are important in protein function and various signaling processes including cell proliferation, apoptosis, metabolism, and migration. ${ }^{77,79}$ For example, anadamide (Narachidonoylethanolamide, AEA) is a cannabinoid neurotransmitter affecting memory ${ }^{80}$, sleep $^{81}$, appetite ${ }^{82}$, and pain perception ${ }^{83}$. This appetite control is similar to the physiological effect seen with tetrahydrocannabinol (THC) in the body. Structurally similar (Figure 3.8) oleoylethanolamide (OEA) does not bind to cannabinoid receptors, and instead acts as a sleep-inducing fatty acid amide. ${ }^{84}$ Other studied signaling lipids include phosphoinositides, sphingolipids, eicosanoids, and fatty acids, all of which are important for cellular processes. ${ }^{79}$ 


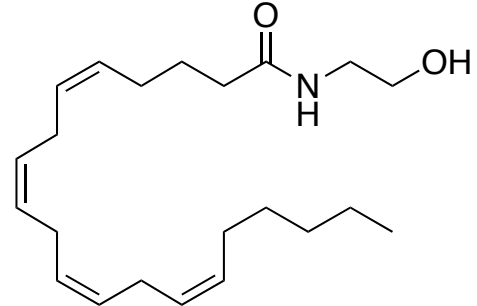

anandamide

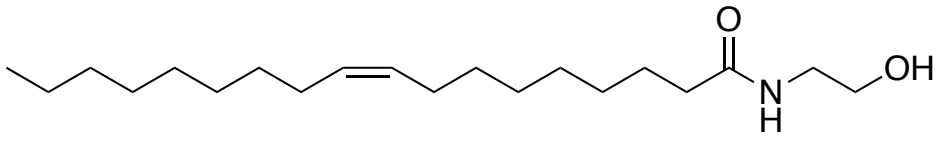

oleoylethanolamide

Figure 3.8: Anandamide and oleoylethanolamide

\subsection{Lipid Recognition}

\subsubsection{Alkane Recognition}

In 2003 Rebek reported one of the first alkane binding receptors ${ }^{85} \mathbf{1 3}$. Initially it was found to bind choline 14 with a $\mathrm{K}_{\mathrm{a}}>10^{4} \mathrm{M}^{-1}$, while carnitine 15 bound with a $\mathrm{K}_{\mathrm{a}}$ of $\sim 10^{2}$ $\mathrm{M}^{-1}$. Furthermore, they found that it did not bind quaternary salts, such as tetrapropylammonium. Upon testing dodecylphosphocholine they expected it would not insert its charged head, however, the research showed that the allyl chain did insert into the cavity. It was found that the receptor recognizes alkanes in a helical (or U-shaped) conformation better than in the extended conformation, despite the 2-3 kcal per mol of strain. In an aqueous solution the molecule adopts a cup-like shape (Figure 3.9) with water bridged between the benzimidiazole groups to form hydrogen bonds, which stabilizes the conformation giving it a hydrophobic cavity to bind these guests. 


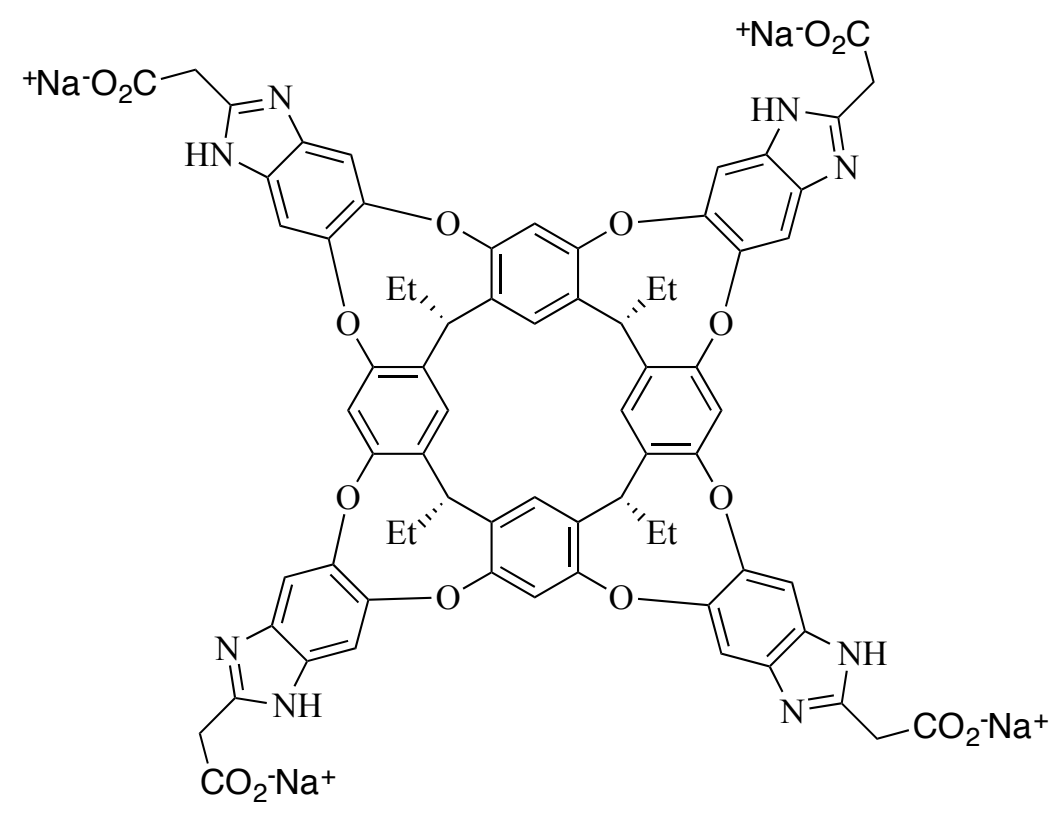

13

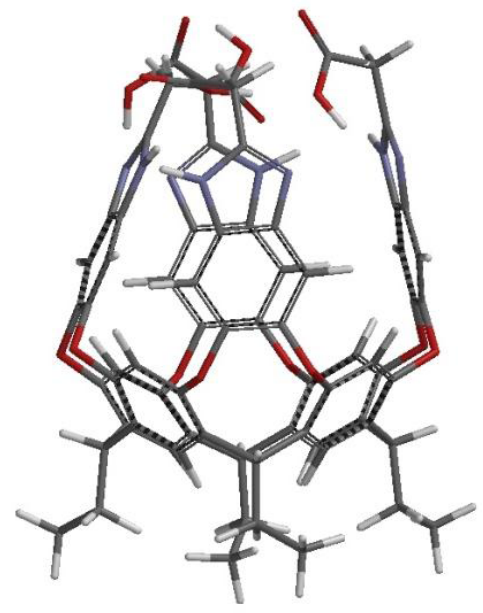

Figure 3.9

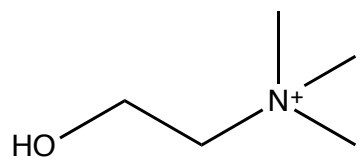

14

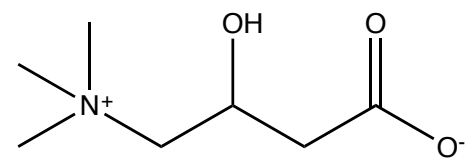

15

Ko et $a l^{86}$ discovered that long chain alkanes adopt a U-shaped conformation when bound in a cucurb[n]uril. As the $\mathrm{CB}[7]$ and $\mathrm{CB}[8]$ are most studied from their 
similarities to the $\beta$ and $\gamma$ cyclodextrins they tested their capabilities of binding alkyl amines. They tested $\mathrm{C}_{12} \mathrm{TA}^{+} 16$ and found that it bound to both $\mathrm{CB}[7]$ and $\mathrm{CB}[8]$ in a 1:1 stoichiometry. ${ }^{1} \mathrm{H}$ NMR indicates that the doedecyl chain penetrates through the CB[7] cavity via the upfield shifts for protons $\mathrm{C}_{1}-\mathrm{C}_{7}$, with little other changes seen for $\mathrm{C}_{8}-\mathrm{C}_{12}$. All the protons for $\mathrm{CB}[8]$ showed a significant upfield shift in addition to intramolecular NOE between the terminal methyl group and trimethylammonium protons, which indicates the alkyl chain adopts a U-shape conformation inside the $\mathrm{CB}[8]$ cavity. Titrations performed by isothermal titration calorimetry (ITC) indicated the binding constant for $\mathrm{CB}[7]$ to be $5.8 \times 10^{5} \mathrm{M}^{-1}$ and for $\mathrm{CB}[8]$ to be $2.8 \times 10^{5} \mathrm{M}^{-1 .}$

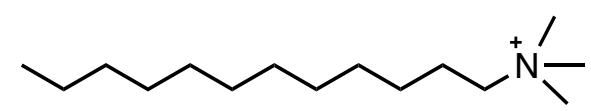

16

\subsection{Glycolipids}

\subsubsection{Overview}

Glycolipids are membrane-anchored lipids composed of a hydrophobic region containing two long hydrocarbon tails, and a polar region containing one or more saccharide residues (Figure 3.10). These carbohydrates extend from the phospholipid bilayer into the aqueous environment outside the cell where they act as recognition sites for specific proteins ${ }^{72}$. Glycolipids generally constitute about $5 \%$ of the lipid molecules in the outer monolayer and are also found in some intracellular membranes. 


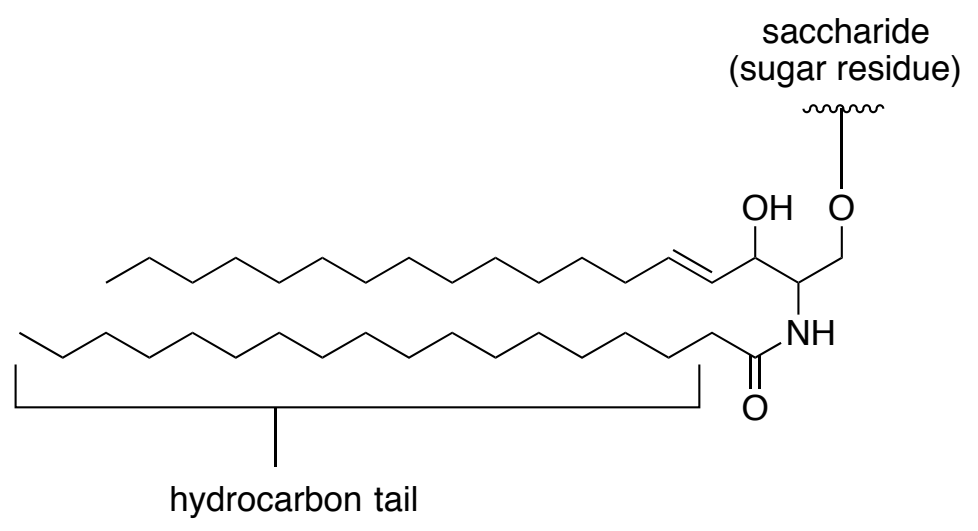

Figure 3.10: A simple glycolipid

Glycolipids, or lipids with a carbohydrate head group (Figure 3.11), are important for cell-to-cell recognition ${ }^{72}$, associated with viral infection, inflammation and tumor metastasis $^{87-89}$. Glycolipids also act as the antigens of the ABO blood types ${ }^{90}$ and are associated with diseases such as atherosclerosis ${ }^{91}$, cancer, and many glycolipid storage diseases $^{92}$. Other forms of glycolipids include glycero-glycolipids and sphingoglycolipids.

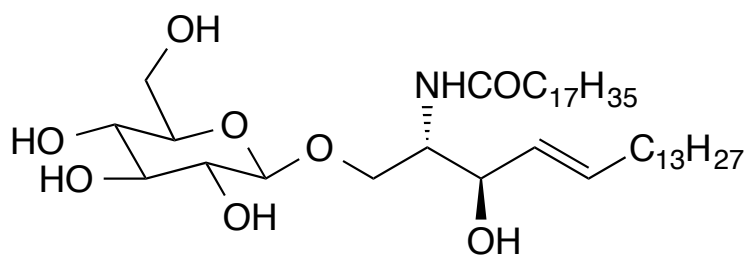

Figure 3.11: Glucocerebroside - a simple glycolipid

\subsubsection{Lipid Storage Diseases}

There exists a class of diseases called lipid storage diseases or lysosomal storage diseases where the body is unable to process lipids. The lysosomal storage disorders (LSD) are a group of about 50 diseases characterized by the accumulation of waste products in the lysosomes due to the loss of digestive function, resulting in the formation of large intracellular vacuoles. Gaucher's Disease was first discovered by Philippe 
Gaucher in $1882 .{ }^{93}$ It was the first identified LSD and is caused by the deficiency of the enzyme $\beta$-glucosidase, also known as glucosylceramidase. The lack of this enzyme causes an accumulation of glucocerebrosides (glycolipids) in tissue macrophages. ${ }^{94}$ This accumulation leads to hepatosplenomegaly, bone marrow suppression, and bone lesions. ${ }^{95-97}$

Gaucher's Disease is known to affect 1 in as many as 450 births in the Jewish population or between 1 in 20,000 to 1 in 200,000 in the general population. ${ }^{98-101}$ Treatment options include enzyme replacement therapy, and substrate reduction therapy. ${ }^{96,} 102$ More recently quinazolines have been proposed as selective Bglucocerebrosidase modulators. ${ }^{103}$ These quinazolines (Figure 3.12 ) are very potent and have been shown to stabilize the misfolded mutant $\beta$-glucocerebrodiase (GCase) over other enzymes, increasing its activity and concentration in cell assays. They have proven to be the most potent noniminosugar GCase modulators that may prove beneficial for treatment of Gaucher's and Parkinson's diseases. Additional LSD's include Fabry disease, Nieman Pick, mucopolysaccharidoses (MPS), and Pompe Disease.
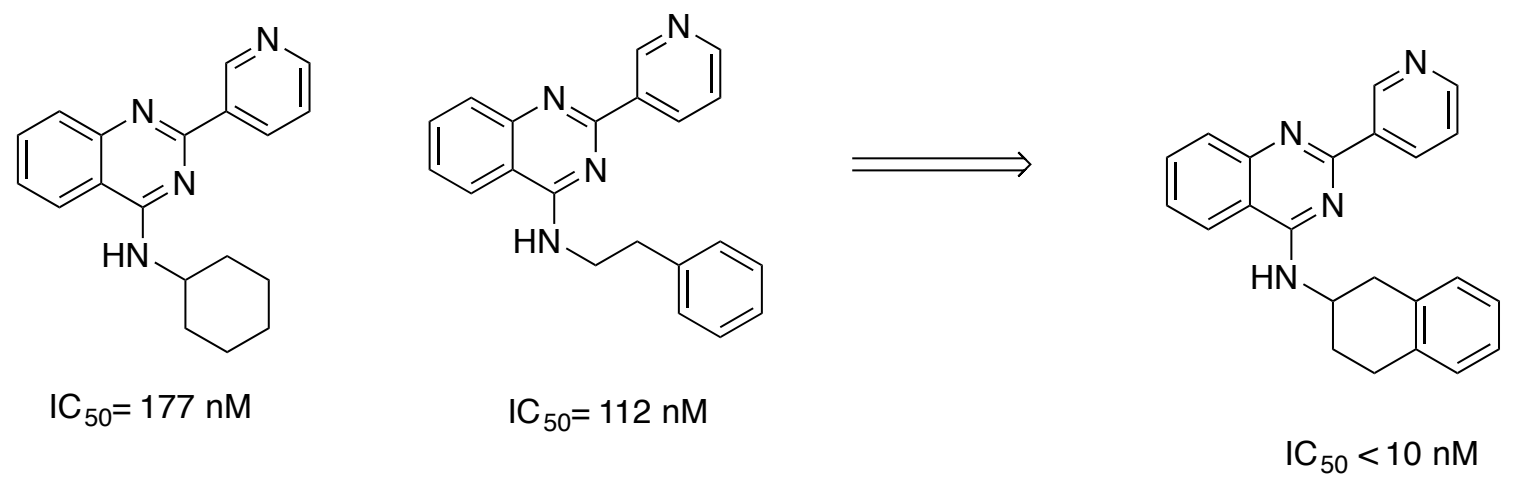

Figure 3.12: Quinazoline modulators 


\subsubsection{Forssmann's Antigen}

Forssmann's antigen is a heterophilic glycolipid antigen possessing structural similarities to the blood group A antigen. ${ }^{104}$ Furthermore, the $G B G T 1$ gene that encodes the Forssmann glycolipid synthase is evolutionarily related to the ABO blood group gene. It is present in non-human mammals including sheep, horses, dogs, and cats. Its structure was described in 1930 by John Forssmann and is shown in Figure 3.13.

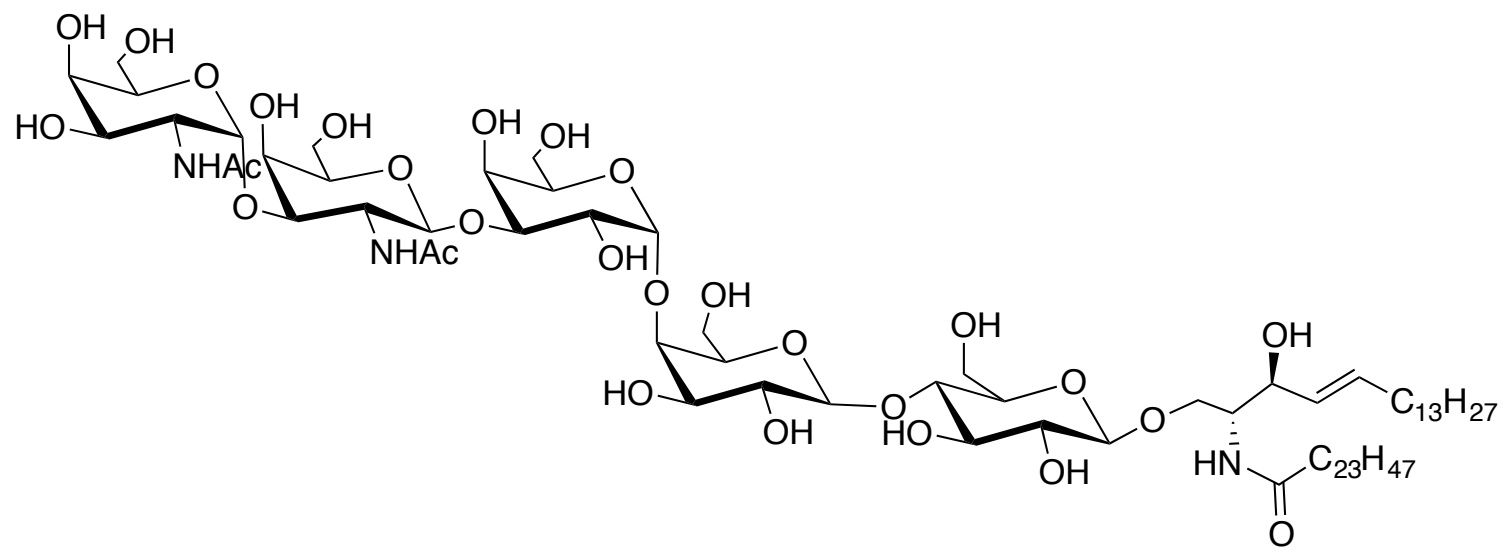

Figure 3.13: Structure of Forssmann's antigen ${ }^{104}$

\subsubsection{ABO Blood Group}

The ABO blood group system was discovered by Austrian scientist Karl Landsteiner in 1900 and is an essential guide today for the success of blood transfusions. ${ }^{105}$ He was later awarded the Nobel Prize in Physiology or Medicine in 1930 for his work. Lansteiner discovered the A, B and O blood antigens, but it wasn't until 1902 that the AB antigen was identified by Alfred von Decastello and Adriano Sturli. 


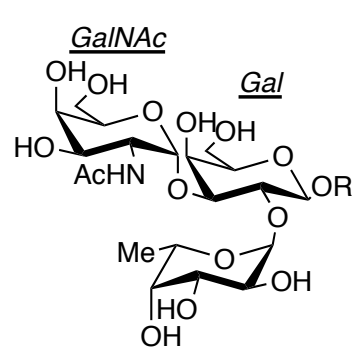

A-antigen

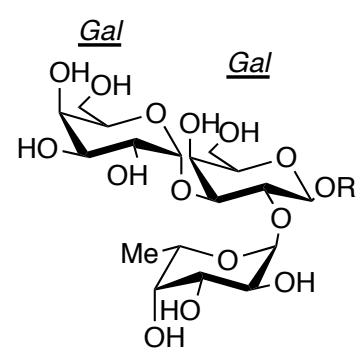

B-antigen

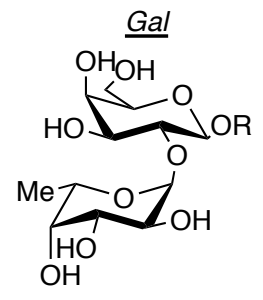

$\mathrm{H}$-antigen (O-type)

Figure 3.14: Blood Group Antigens

The blood group antigens are composed of specific sugars exposed on the exterior of red blood cells (RBC's; erythrocytes), differing according to their blood type (Figure 3.14). The antigens differ by the linkage of the monosaccharides at the end of the carbohydrate chains. The antigenic portion is comprised of one or more carbohydrate chains connected to a ceramide or peptide backbone, which is embedded into the lipid bilayer of the cell membrane. Humans have antibodies to the A or B antigens, which they lack; group-B have anti-A, group-A have anti-B, and group $\mathrm{O}$ has both. If a patient is administered the incorrect blood type during a transfusion, an immune response is triggered which can have fatal hemolytic consequences. ${ }^{106}$ Because group O lacks both the $\mathrm{A}$ and $\mathrm{B}$ antigens, blood type $\mathrm{O}$ is always in high demand with $\mathrm{O}(-)$ blood often in high demand. Table 3.1 shows the percentage of the U.S. population with the respective blood types. 
Table 3.1: Blood Types by population in the U.S. ${ }^{106}$

\begin{tabular}{|c|c|c|c|c|}
\hline & Caucasians & African- & Hispanic & Asian \\
\hline O (+) & $37 \%$ & $47 \%$ & $53 \%$ & $39 \%$ \\
\hline O (-) & $8 \%$ & $4 \%$ & $4 \%$ & $1 \%$ \\
\hline A (+) & $33 \%$ & $24 \%$ & $29 \%$ & $27 \%$ \\
\hline A (-) & $7 \%$ & $2 \%$ & $2 \%$ & $0.5 \%$ \\
\hline B (+) & $9 \%$ & $18 \%$ & $9 \%$ & $25 \%$ \\
\hline B (-) & $2 \%$ & $1 \%$ & $1 \%$ & $0.4 \%$ \\
\hline AB (+) & $3 \%$ & $4 \%$ & $2 \%$ & $7 \%$ \\
\hline AB (-) & $1 \%$ & $0.3 \%$ & $0.2 \%$ & $0.1 \%$ \\
\hline
\end{tabular}

This immune response has lead to the inspiration of creating a "universal blood". While O blood type works for transfusions to individuals with $\mathrm{A}, \mathrm{B}$ and $\mathrm{AB}$ blood, often times it is in short supply and some hospitals may only have type O. Therefore, if there was a method to convert $\mathrm{A}, \mathrm{B}$ or $\mathrm{AB}$ to the corresponding $\mathrm{O}$ blood type, it would theoretically provide an increase to the "universal blood" supply. This idea has lead to the creation of enzymes that can effectively cleave or remove the antigens from the red blood cells. $^{107-108}$

An early study published in 1982 converted B-type erythrocytes into universal Otype blood cells, catalyzed by the use of an exoglycosidase from a coffee bean, $\alpha$ galactosidase. ${ }^{106}$ Selective cleavage of $\alpha$ GalNAc and $\alpha$ Gal residues of the $A$ and B trisaccharide antigens proved successful and the cell was able to survive transfusion. This 
method was not practical, as it required large quantities of the enzyme for conversion. Later, subsequent attempts were pursued to implement the original vision of enzyme cleavage, but the desired levels of activity were unable to be achieved. ${ }^{109-110}$ The use of bacterial glycosidases showed improvements, but the enzyme activity was still insufficent. ${ }^{111}$ Thus, these "improved" methods also required larger quantities of enzyme, up to $60 \mathrm{mg}$ per unit of RBC.

In recent work Stephen Withers et $a l^{107}$ demonstrated a structure-guided directed evolution approach that was applied to Sp3GH98 (Streptococcus pneumonia) for the first time. Sp3GH98 cleaves the entire terminal trisaccharide antigenic determinants of both A and B antigens from selected linkages on RBC surface glycans; however, so slowly that its application was not feasable. Through the structure guided directed evolution, their goal was to enhance enzyme activity towards the cleavage of the Gal $\beta-1,3-G l c N A c$ linkage of type 1A antigens (Figure 3.15, Figure 3.16). Their work showed an increase in the activity of the selective glycoside hydrolase and broadened the substrate specificity of Sp3GH98 towards the cleavage of the Galß-1,3-GlcNAc linkage of type 1 chains. This was achieved without inhibiting the activity towards Galß-1,4-GlcNAc type 2 chains. This sets the stage towards broadening the substrate specificity towards the Gal $\beta-1,3-$ GalNAc linkages of type 3 and 4 chains, which involves the A antigens specifically.Therefore, much more work is required before the production of completely universal blood is possible.. 

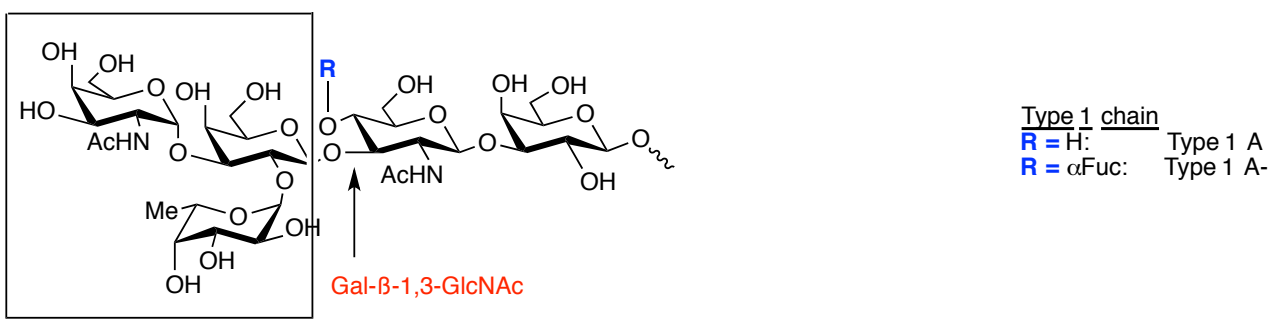

$\mathbf{R}=\alpha$ Fuc: $\quad$ Type $1 \mathrm{~A}$-Le
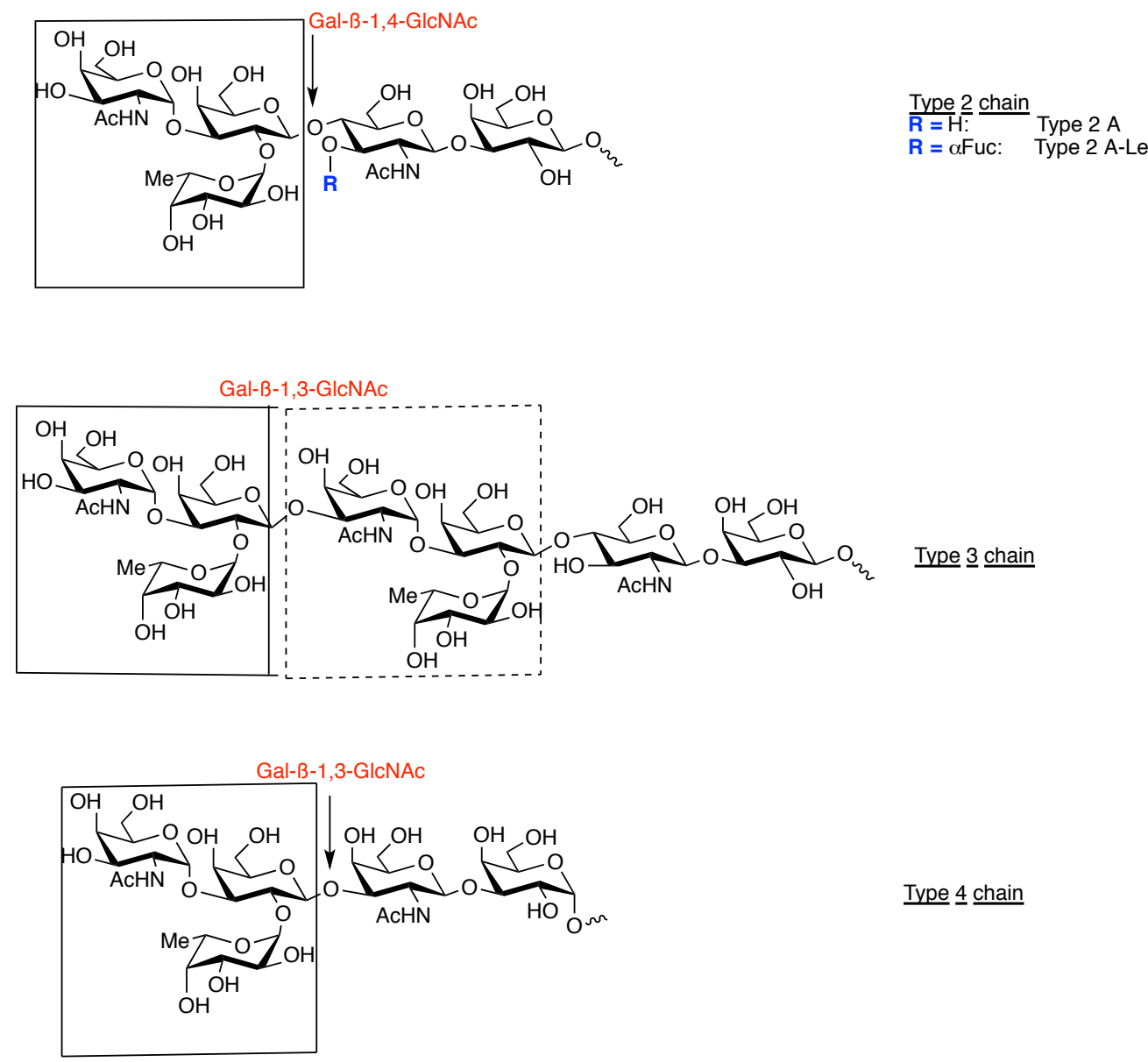

Type 4 chain

Figure 3.15: Various saccharide chain types to which A antigens are present on erythrocytes and other cell types 


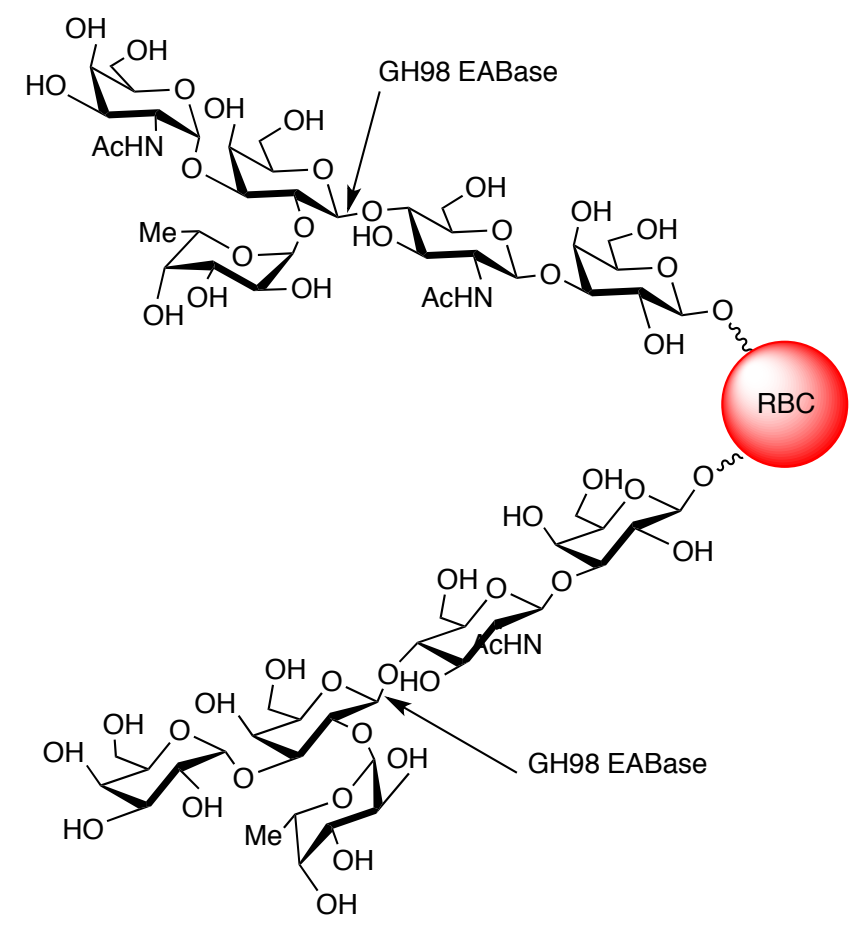

Figure 3.16: Site of cleavage of A or B antigens with GH98 EABase of type 2 chains

The benefit of creating a universal blood would aid in blood transfusions during surgery, or when the O blood type is in short supply, especially from casualties in large disasters. Additionally, it could aid in organ transplants between patients, helping to ensure the incompatible blood has been successfully removed. Therefore, it would be extremely benficial to futher the work towards this concept.

\subsection{Conclusion}

Biological lipids play a fundamental role in living organisms. Their role is valued in processess such as energy storage, signaling pathways, part of the cell membrane, act as steroids, and are involved in transport roles. Glycolipids in particular play an active role in many important diseases today that medicine seeks to cure. 


\section{Chapter 4 Molecular Tubes for the Detection and Extraction of Hydrophobic Amines from Vesicles}

\subsection{History of Molecular Tubes}

\subsubsection{Overview}

Lipid receptors are achieved by varying the size and shape of a hydrophobic cavity to the fit of the desired lipid, while placing hydrophilic groups on the exterior of the molecule to achieve water solubility. Our group has been interested in taking advantage of this knowledge and applying it towards the detection of biologically relevant lipids using molecular tubes. The inspiration for the scaffold of our cavity design comes from the dimerization of 2,7-dihydroxynaphthalene (Scheme 4.1). In the presence of an acid catalyst, 2,7-dihydroxynaphthalene can undergo a condensation with malonaldehyde tetramethyl acetal to produce a naphthalene dimer in efficient yield, providing a great hydrophobic cavitand ${ }^{112}$. This hydrophobic cavitand has nearly a right angle, is fairly rigid, and possesses a large hydrophobic area (Figure 4.1).<smiles>Oc1ccc2ccc(O)cc2c1</smiles><smiles>COC(CC(OC)OC)OC</smiles><smiles>Oc1ccc2ccc3c(c2c1)C1c2c(ccc4ccc(O)cc24)OC1C3</smiles>

Scheme 4.1: Condensation of 2,7-dihydroxynaphthalene 

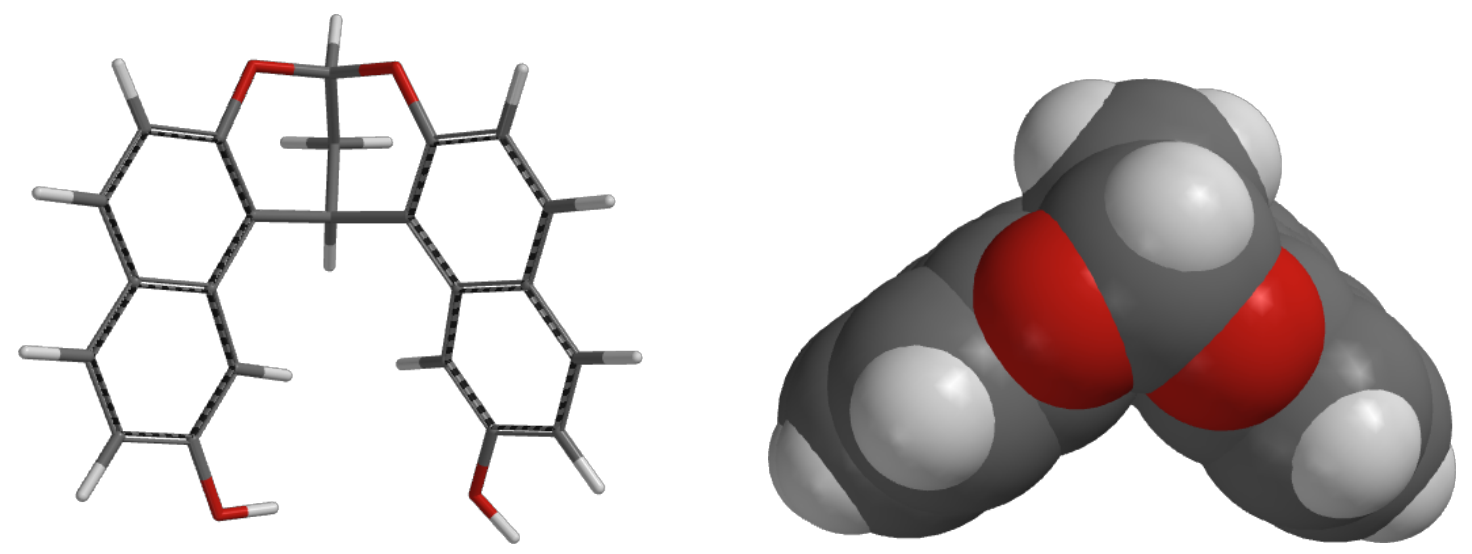

Figure 4.1: Geometries of naphthalene dimer

Previous computer modeling demonstrated linking the naphthalene dimers together by an odd number of atoms would produce an open tube structure, whereas an even number of atoms was more likely to deform the cavity. Furthermore, a tube linked by less than three atoms, would leave the resulting molecule highly strained, resulting in a highly difficult synthesis. Additionally, a CPK model of the tube with a one or two atom linker revealed that their hydrophobic cavities are too small for an alkyl chain. It was found that the size of the tube linked by a three atom linker was most complementary to the volume of extended alkyl chains, enabling the selective detection of alkanes over a cis/trans alkene.

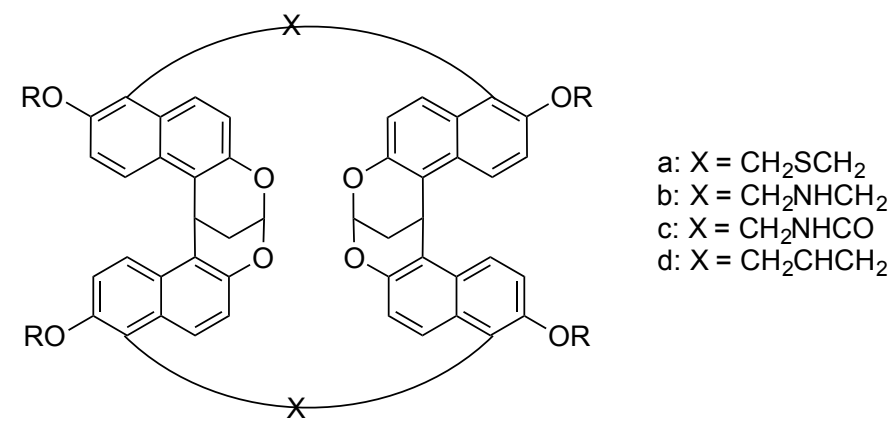




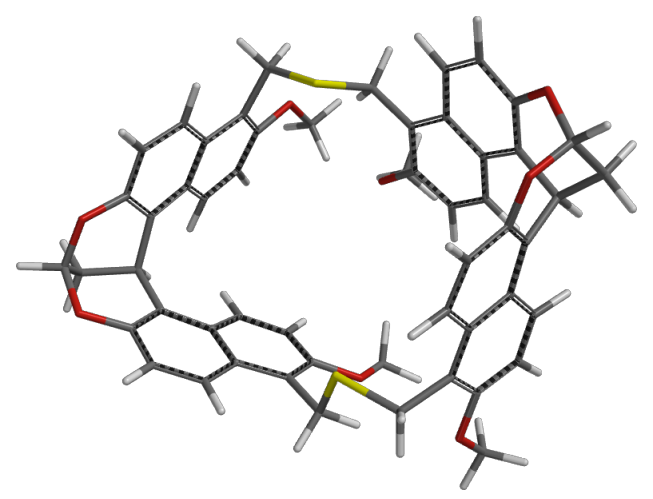

Figure 4.2: Thioether Model

A series of three atoms linkers were examined by our group including a thioether, amine, amide, and alkene 17a-d. Energy minimized calculations showed that flexible linkers, such as the thioether linked $\mathbf{1 7} \mathbf{a}$ and amine linked $\mathbf{1 7} \mathbf{b}$, are not rigid enough to retain an open cavity, and therefore tend to collapse and adopt a deformed structure due to hydrophobic interactions. An example of a collapsed model is showed in Figure 4.2. On the other hand, the amide and allyl groups are remarkable as they keep the tube structure open. Therefore these two were pursued in our group.

\subsubsection{Amide linked molecular tube}

Early work in our group lead to the creation and publication of an amide linked tube in 2004. ${ }^{113}$ The amide linked tube was synthesized starting with 2,6dihydroxynaphthalene $\mathbf{1 8 .}$

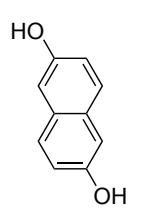

18

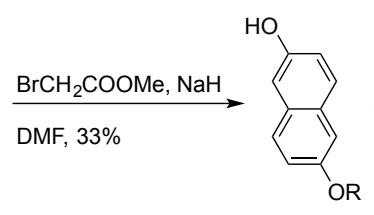

19

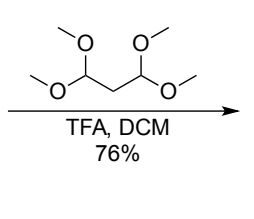

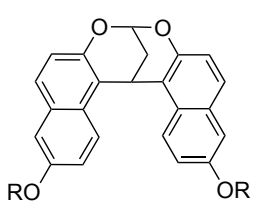

20

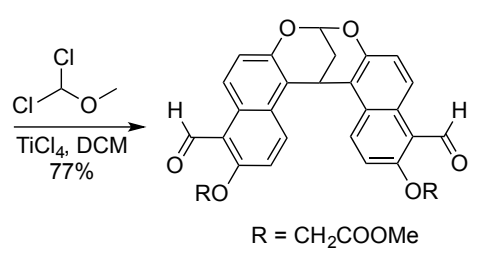

21 


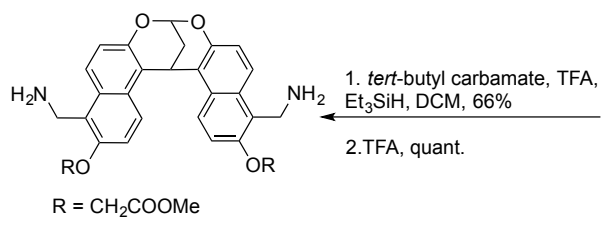

22

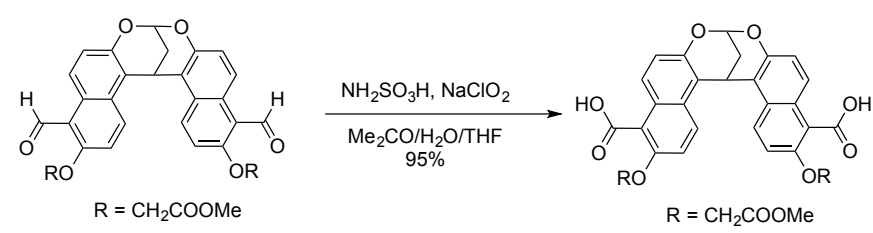

21

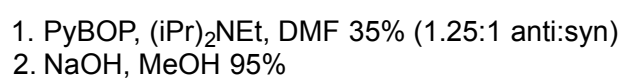

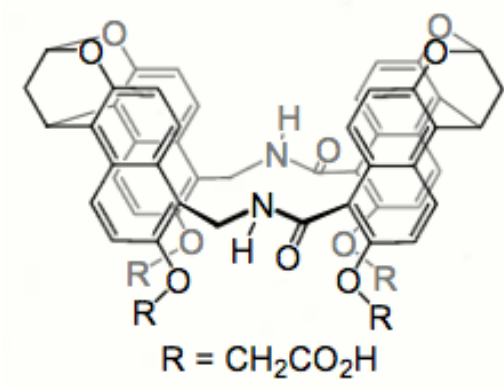

24

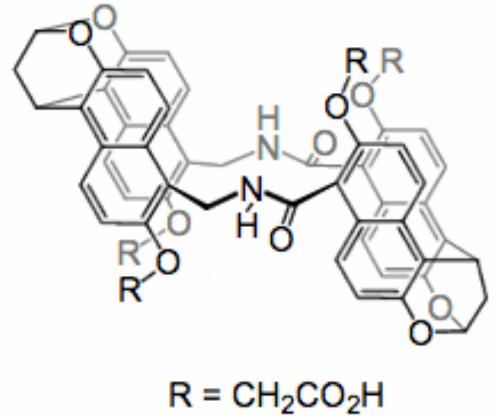

25

The amide sensor showed only small changes in the UV when titrated with fatty acids, however, the fluorescence data showed significant responses (Table 4.1). The titrations were performed at $\mathrm{pH} 8.4$ to maintain solubility of all species. The association constants of both the syn and anti tube inform us that as the alkyl chain length increases the affinity also increases. While the alkene tested has a carboxylic acid, alkenes also occupy a lot of space, and therefore are unable to be comfortably bound inside the cavity. Branching in the middle of the chain, as seen in 4-methyl-octanoic acid, suppresses the binding significantly $\left(\mathrm{K}_{\mathrm{a}}=71\right)$, but branching near the end of the chain is tolerated for 8methyl-nonanoic acid $\left(\mathrm{K}_{\mathrm{a}}=1,600\right)$. Heptanol, a neutral species, was found to bind better than the fatty acids of similar length $\left(\mathrm{K}_{\mathrm{a}}=4,900\right)$, as it avoids the negative-negative charge repulsion that the carboxylates face. Furthermore, heptylamine binds even better than its fatty acid counterpart due to the attraction between its positive charge at $\mathrm{pH} 8.4$, 
and the negatively charged carboxylate. Comparatively, as seen in a trend between the binding constants, the anti tube bound the longer chains slightly better than the syn linked tube. In the case of both sensors, all analytes quenched the fluorescence upon their addition and displayed similar binding patterns.

Table 4.1: Association constants for amide linked tube

\begin{tabular}{|c|c|c|c|c|}
\hline & \multicolumn{2}{|c|}{$\begin{array}{ll}\text { Syn } & \text { Tube } \\
\end{array}$} & \multicolumn{2}{|c|}{ Anti Tube } \\
\hline Guest & $\mathrm{K}_{\mathrm{a}}\left(\mathrm{M}^{-1}\right)$ & $\mathrm{I}_{\mathrm{sat}} / \mathrm{I}_{0}$ & $\mathrm{~K}_{\mathrm{a}}\left(\mathrm{M}^{-1}\right)$ & $\mathrm{I}_{\mathrm{sat}} / \mathrm{I}_{0}$ \\
\hline acetic acid & - & - & - & - \\
\hline butyric acid & 17 & 1.25 & 18 & 0.92 \\
\hline hexanoic acid & 100 & 1.14 & 72 & 0.32 \\
\hline octanoic acid & 250 & 0.39 & 190 & 0.25 \\
\hline decanoic acid & 3,500 & 0.48 & 3,800 & 0.32 \\
\hline dodecanoic acid & 18,000 & 0.47 & 27,000 & 0.31 \\
\hline trans-3-octenoic acid & 92 & 0.61 & 110 & 0.26 \\
\hline 4-methyl-octanoic acid & 71 & 1.05 & 200 & 0.32 \\
\hline 8-methyl-nonanoic acid & 1,600 & 0.57 & 690 & 0.25 \\
\hline cyclohexane carboxylic acid & 470 & 7.1 & 100 & 0.8 \\
\hline triethylene glycol & 63 & 1.83 & 63 & 0.34 \\
\hline 1-heptanol & 4,900 & 0.28 & 6,700 & 0.19 \\
\hline cis-4-hepten-1-ol & 1,200 & 1.32 & 5,200 & 0.58 \\
\hline heptylamine & 16,000 & 0.42 & 16,000 & 0.11 \\
\hline
\end{tabular}

In conclusion, a sensor was established that could detect fatty acids in aqueous solution that provided a fluorescent response selective to the shape and length of the guest. It is well known that water can quench fluorescence ${ }^{70}$, and we would expect that expulsion of water from the cavity would increase the fluorescence upon binding. Given that this did not occur, the quenching effect of the guests left us with some questions and lead to the exploration of allyl linked molecular tubes.

\subsubsection{Allyl linked molecular tube}

We hypothesized that while the amide linker is much more rigid than the thioether and amine linkers, the amide linker may still may not be rigid enough to maintain an 
open conformation and collapses in solution. Therefore, when it binds to the hydrophobic guests there is no water to expel from the cavity, giving rise to a quenched fluorescence. To confirm this hypothesis the allyl linked tube was synthesized as shown below.

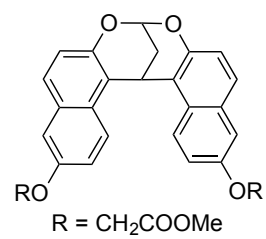

26
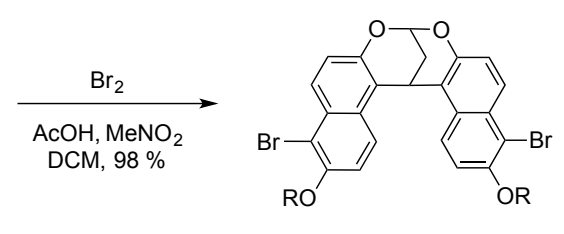

27

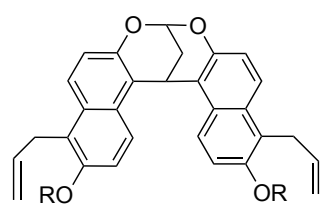

28

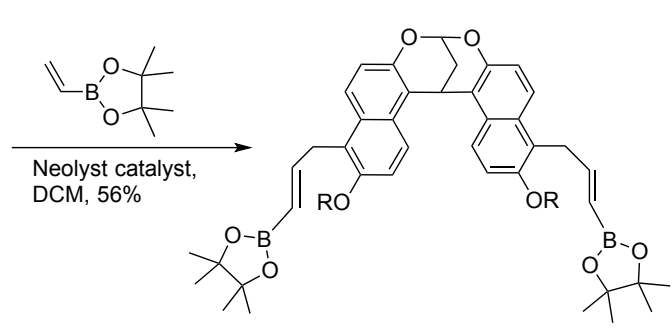

29
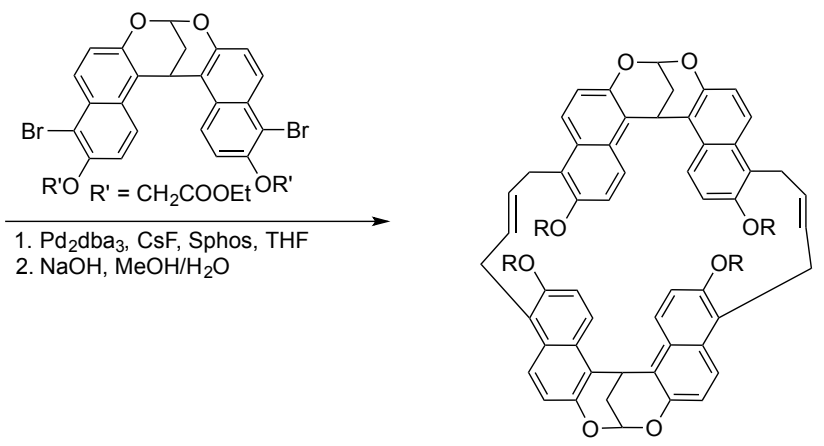

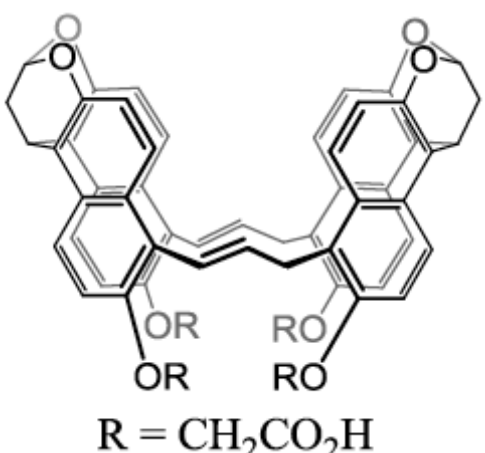

32 Syn

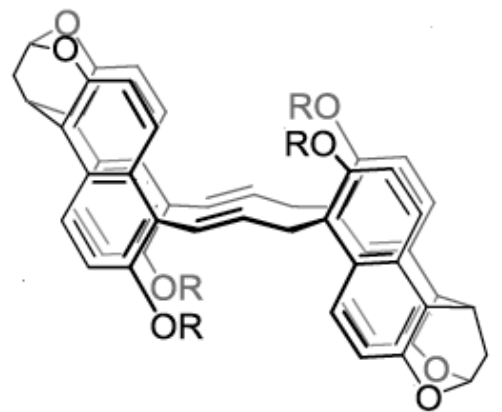

$\mathrm{R}=\mathrm{CH}_{2} \mathrm{CO}_{2} \mathrm{H}$

33 anti 
Table 4.2: Binding constants of allyl linked tube

\begin{tabular}{|c|c|c|c|c|}
\hline \multicolumn{2}{|r|}{ Syn Tube } & \multicolumn{3}{|c|}{ Anti Tube } \\
\hline Guest & $K_{a}\left(M^{-1}\right)$ & $\mathbf{I}_{\mathrm{sat}} / \mathbf{I}_{\mathbf{0}}$ & $K_{a}\left(M^{-1}\right)$ & $\mathbf{I}_{\text {sat }} / \mathbf{I}_{\mathbf{0}}$ \\
\hline butyric acid & - & - & - & - \\
\hline hexanoic acid & 800 & 1.54 & - & - \\
\hline octanoic acid & 17,000 & 1.54 & 5,400 & 1.37 \\
\hline decanoic acid & 140,000 & 1.97 & 120,000 & 1.46 \\
\hline dodecanoic acid & 590,000 & 1.79 & 350,000 & 1.79 \\
\hline 4-methyoctanoic acid & 5,200 & 2.02 & 5,800 & 1.44 \\
\hline 8-methylnonaoic acid & 93,000 & 2.07 & 13,000 & 1.61 \\
\hline 1-heptanol & 420,000 & 1.1 & 240,000 & 1.47 \\
\hline heptylamine & $2,000,000$ & 0.63 & $8,200,000$ & 1.25 \\
\hline cis-4-hepten-1-ol & 39,000 & 0.64 & 28,000 & 1.22 \\
\hline trans-3-octenoic acid & 1,300 & 0.61 & 7,200 & 0.61 \\
\hline
\end{tabular}

The binding constants of the allyl linked tube are significantly higher than the amide linked tube. Specifically, for octanoic acid, the amide linked tube $\mathbf{2 4}$ and $\mathbf{2 5}$ has a $\mathrm{K}_{\mathrm{a}}$ of $\sim 200 \mathrm{M}^{-1}$. For the allyl linked tube $\mathbf{3 2} \mathrm{K}_{\mathrm{a}}=17,000$ and 33 the $\mathrm{K}_{\mathrm{a}}=5,400$. Furthermore, the allyl linked tube also displayed an increase in fluorescence upon binding to these lipids. Therefore, the allyl linked tube provides a "pre-organized" hydrophobic cavity providing a higher affinity and enables a "turn-on" response when binding to lipids. Furthermore, as was noted in previous studies, a preference for uncharged or positively charged species is maintained as in the case of heptylamine with a $\mathrm{K}_{\mathrm{a}}$ of $8,200,000 \mathrm{M}^{-1}$ for 33. The tubes were deemed unsuitable for binding alkenes. In conclusion, this study did prove that our hypothesis was correct.

\subsubsection{Tetraacid open tube}

Our group previously established selectivity for lipid chains with our allyl and amide linked tubes. While they demonstrated selectivity and affinity towards these lipids, they 
presented some limitations: namely their relatively complicated synthesis and low overall yield. Additionally, the more lipid sensitive syn tube was synthetically accompanied by its anti isomer, therefore its maximum yield was only $50 \%$. Thus a similar alternative was pursued.

As we aimed to further these studies towards more biological lipids by modifying the tube with functional groups targeting the head groups of the lipids, we first needed to test the functionality and versatility of a more synthetically accessible scaffold. We planned to test this new scaffold towards the binding of hydrophobic amines, as heptylamine was shown to be the best binding analyte in our previous studies. This lead to the creation and publication of a sensor for the selective detection of hydrophobic amines in aqueous solution by Chun Ren ${ }^{114}$.

This new sensor shown in Figure 4.3 bears many changes. Instead of two naphthalene units being linked together, it retains the naphthalene core but possesses a carbazole unit connected to it by a one atom linker. This one atom linker reduces the rotational freedom, but still provides a snug fit for the alkane chain. The carbazole now acts the fluorophore, which is more red in the UV than the naphthalene and can easily be modified with functional groups to bind the headgroups of the different biological lipid targets. This tube now possesses an open cavity, which would accommodate branching and lipids of irregular shape, allowing the possible binding of biological compounds that possess multiple lipid chains. 

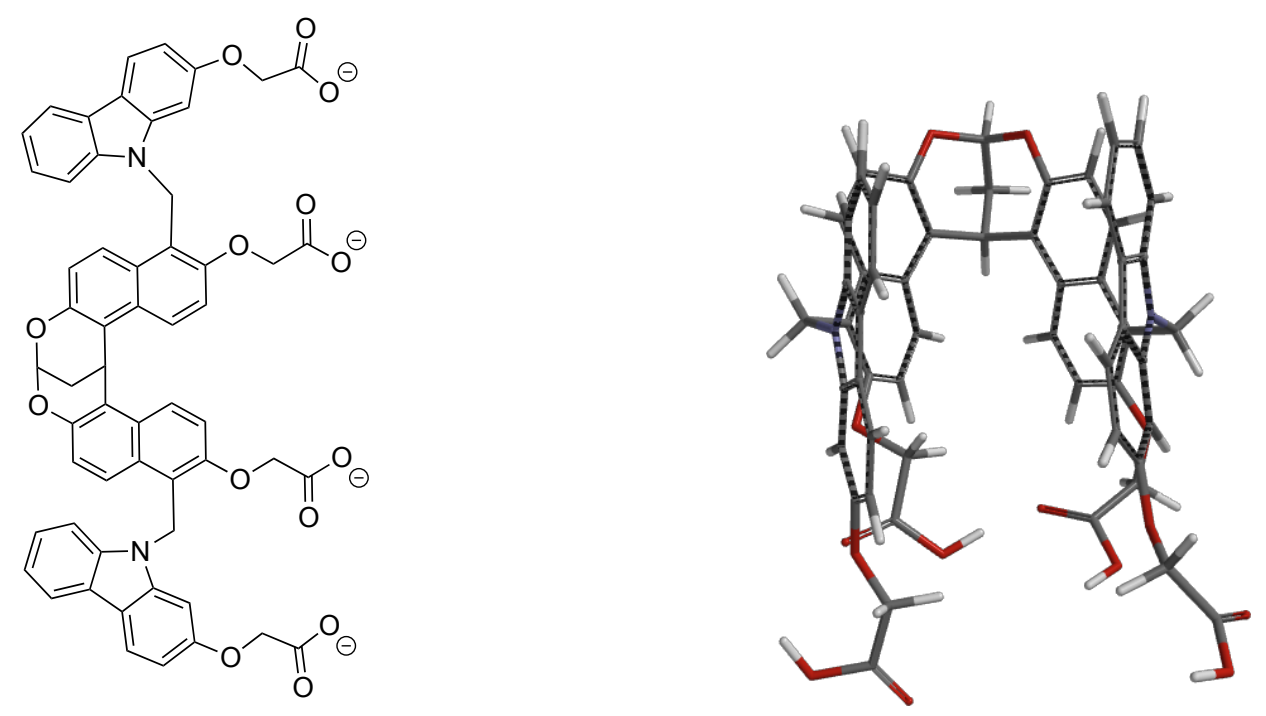

Figure 4.3 First hydrophobic amine sensor by our group

The synthesis of the sensor is shown in Scheme 4.2. The sensor showed selectivity for long chain unbranched lipids; however, it was shown that it also tolerated branching in the case of binding pseudophedrine. Binding constants for some hydrophobic amines tested are shown with the corresponding structures in Figure 4.4. 

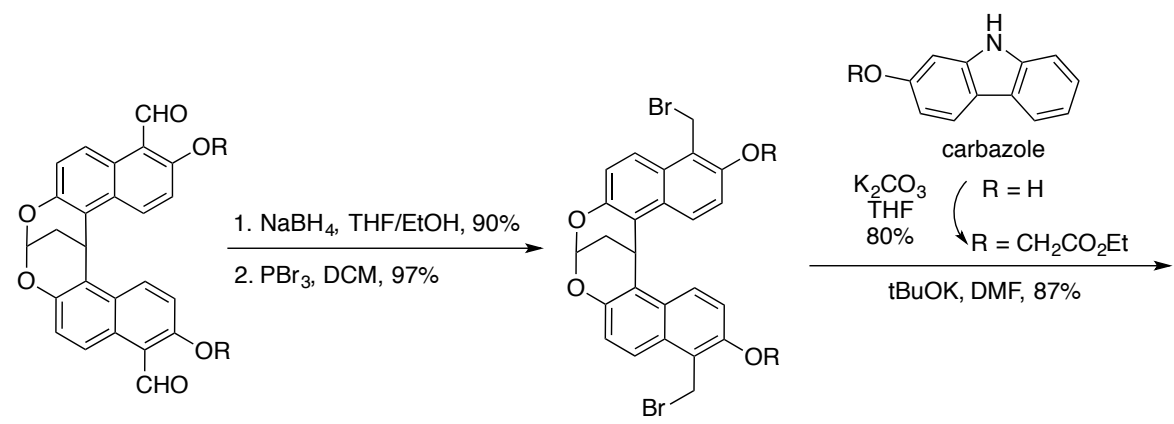

34

35

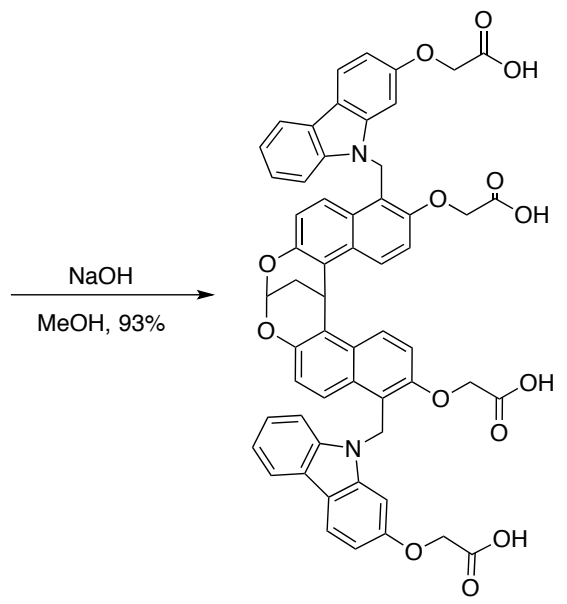

37

Scheme 4.2: Synthesis of hydrophobic amine tube

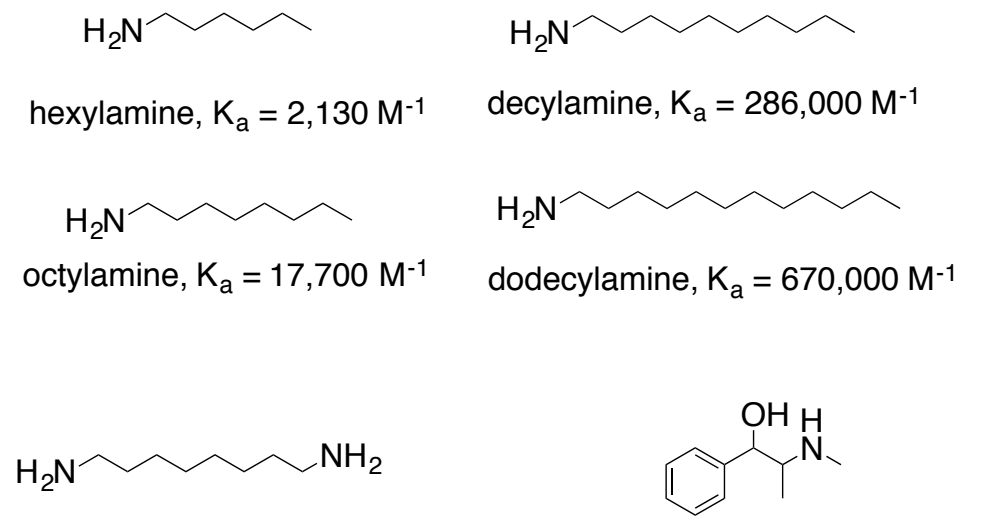

1,8-diaminooctane, $\mathrm{K}_{\mathrm{a}}=1,854 \mathrm{M}^{-1} \quad$ pseudoephedrine, $\mathrm{K}_{\mathrm{a}}=4,894 \mathrm{M}^{-1}$

Figure 4.4 Binding constants for some hydrophobic amines with previous sensor ${ }^{114-115}$ 
This sensor maintained the high binding affinity of the alkyl chains, demonstrating that the open tube concept would be successful providing a hydrophobic cavity sufficient to bind the alkyl chains. Given this success we planned to take this concept further towards lipid extraction.

We wanted to test the ability of the amine sensor to extract dodecylamine from a vesicle. To accomplish this, the sensor needed to be manipulated to ensure the large hydrophobic pocket (Figure 4.5 ) would not embed itself into the lipid bilayer. Therefore a new sensor needed to be designed.

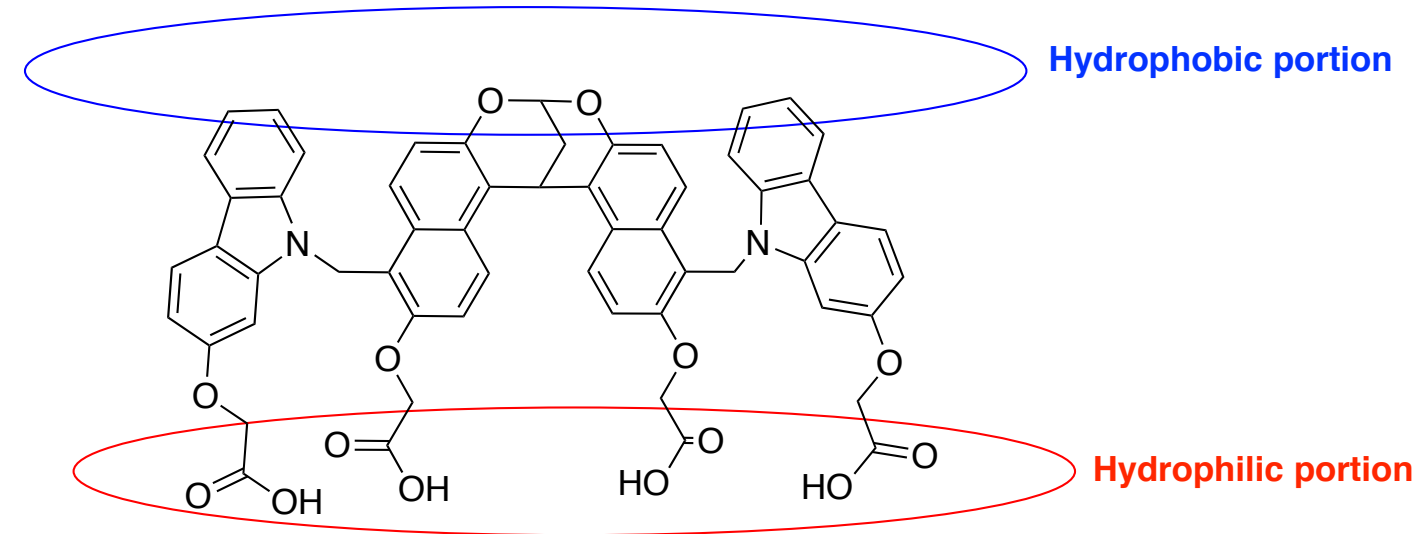

Figure 4.5: Hydrophobic/Hydrophilic portions of amine sensor

To accomplish this we proposed the following structure in Figure 4.6. The installation of the two new carboxylate groups should prohibit the sensor from embedding itself into the lipid bilayer to due to the repulsive charge of the phosphate headgroups against the carboxylates at $\mathrm{pH}$ 7.4. 


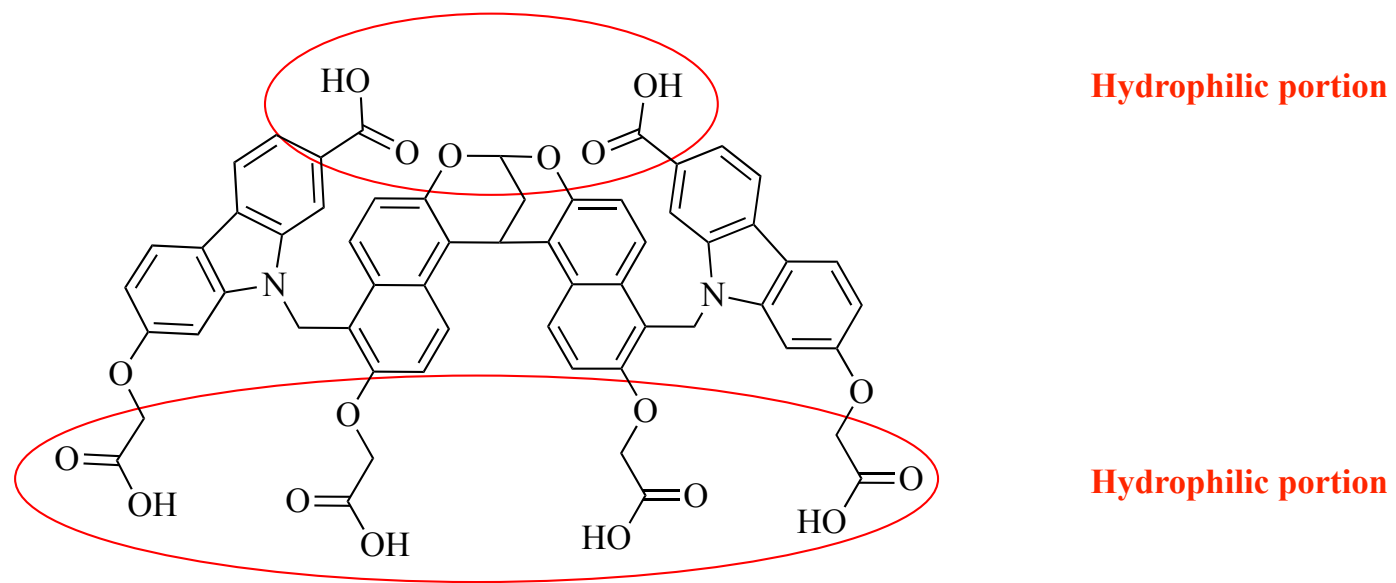

Figure 4.6: Initially designed sensor for lipid extraction

\subsection{Hexaacid open tube}

The previous tetra acid tube possessed ethyl ester groups until the final saponification step. This project encountered synthetic challenges due to solubility requiring a change to a hexyl ester. This required the synthesis of hexyl bromoacetate. The proposed synthesis of the hexa acid sensor Figure 4.6 is shown below.<smiles>O=C(Br)CBr</smiles>

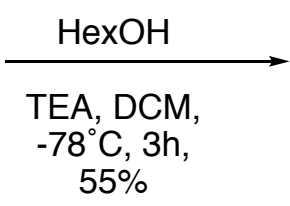

38
39

Scheme 4.3: Hexyl bromoacetate synthesis 


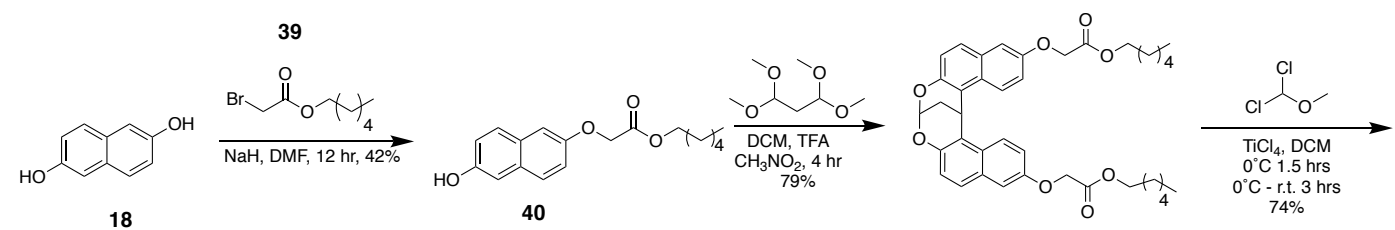

41

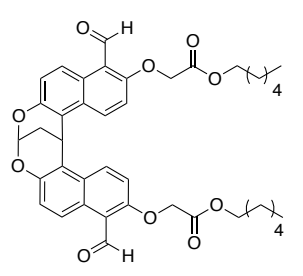

42

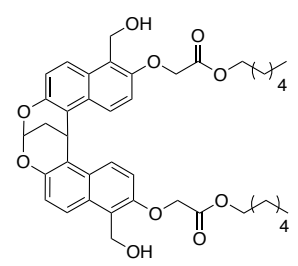

43

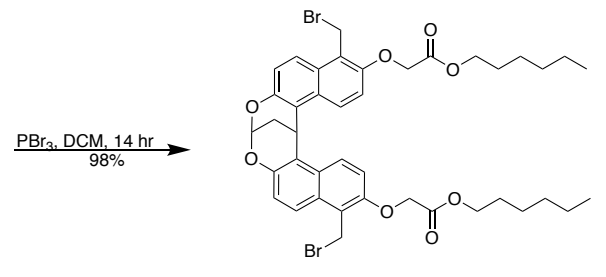

44

Scheme 4.4: Synthesis of hexyl dimer
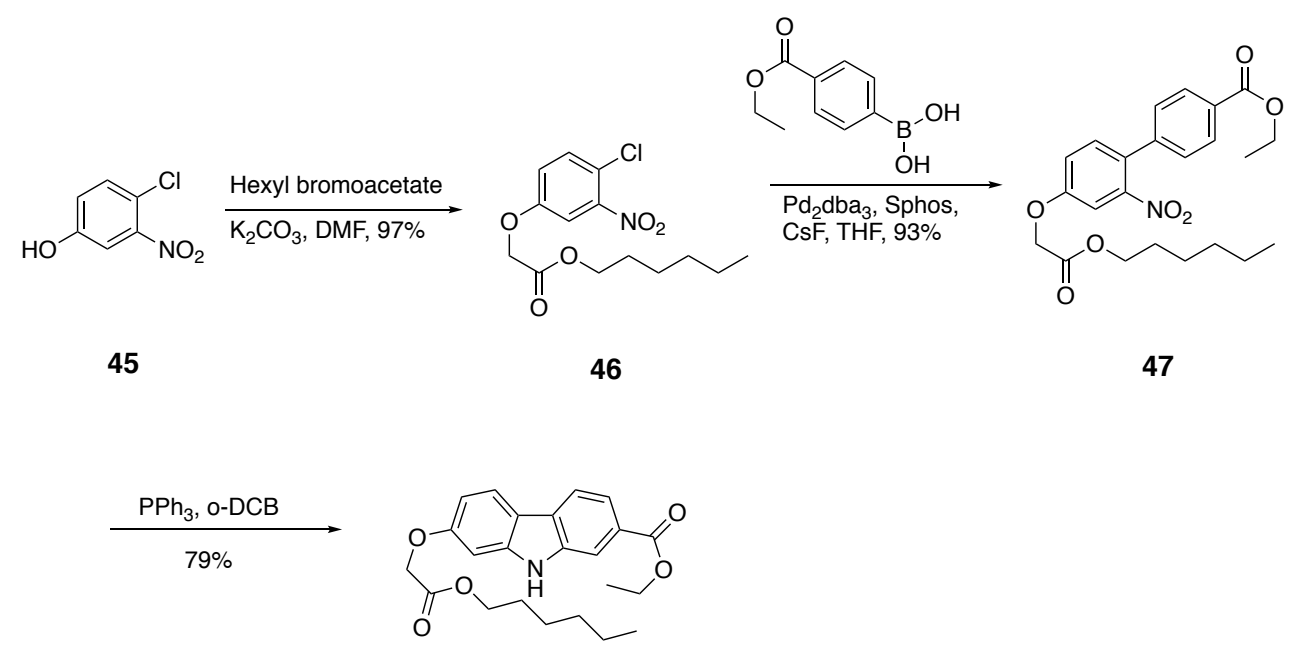

48

Scheme 4.5: Synthesis of hexyl/ethyl ester Carbazole 


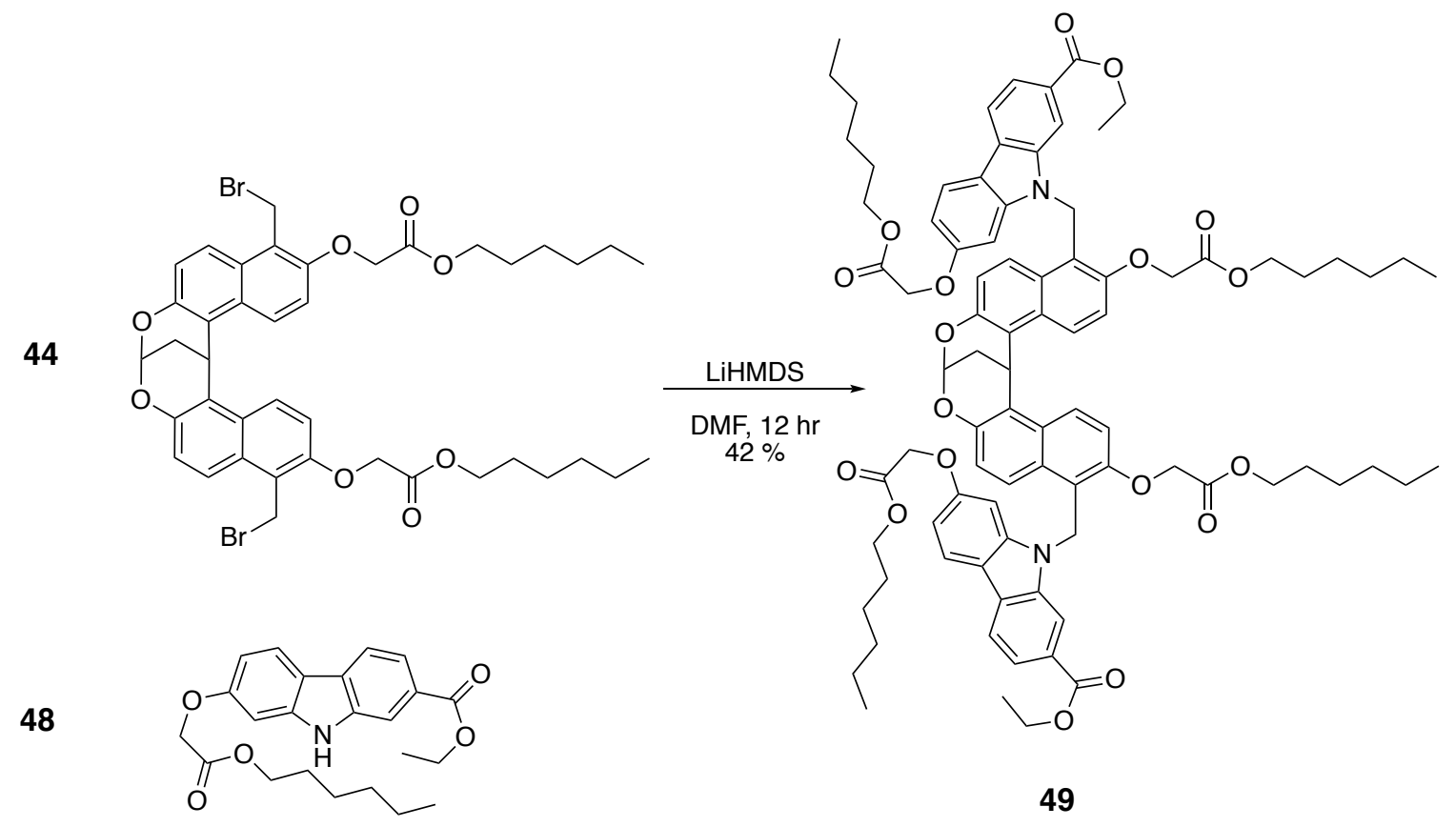

Scheme 4.6: Synthesis of hexyl/ethyl ester open tube

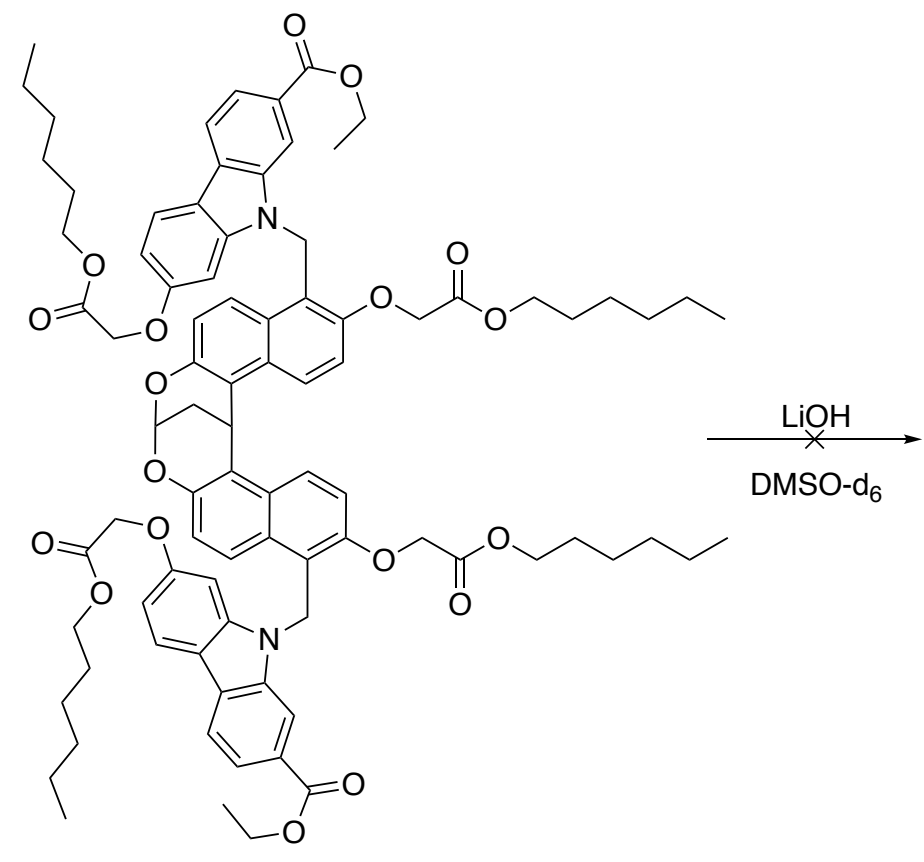

49<smiles></smiles>

50

Scheme 4.7: Saponification of hexyl/ethyl ester tube 
While this sensor was potentially synthesized, the final step yielded a product that was unable to be isolated and characterized. During the course of the final reaction the product either appeared to fall out of solution or solidified into a gel-like solid in DMSO in the NMR tube. There has been a publication with a dicarboxylic acid carbazole substituted in the same positions as a $\mathrm{Zn}^{2+}$ coordination polymer ${ }^{116}$, thus it is possible a metal organic framework (MOF's) could be a contributing factor. Therefore, other alternatives were pursued, such as the installation of a serine or alanine unit. Serine was attempted first as it was expected to make the final product more hydrophilic than alanine.

\subsection{Serine linked hexa-acid Open Tube}

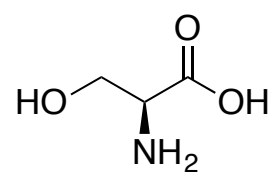

serine

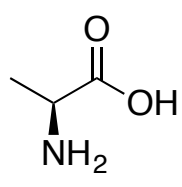

alanine

Figure 4.7: Amino acid groups

Our desire was to install the amino acid groups by an amide bond formation reaction and therefore we needed carboxylic acid groups present on the carbazole. However, the final reductive cyclization step has been shown to fail in the presence of a carboxylic acid functional group and therefore an orthogonal protecting group was pursued that could be deprotected in the presence of the other esters. A trimethylsilylethyl (TMSE) group was chosen, which is cleaved by fluoride. This changed the synthesis only of the carbazole unit, requiring the synthesis of a new phenyl boronic acid, as one was not commercially available. A pinacol boronic acid was chosen, as it would be stable to be purified by column chromatography as opposed to its boronic acid counterpart. Further 
synthesis was performed as before, with the exception of the Suzuki coupling (Scheme 4.8). The previous base for the Suzuki coupling was CsF. This base was changed to $\mathrm{K}_{3} \mathrm{PO}_{4}$ to prevent unwanted deprotection of the TMSE ester during the reaction. This did not have any effect on the yield of the reaction.<smiles>CC1(C)OB(c2ccc(C(=O)O)cc2)OC1(C)C</smiles>

51

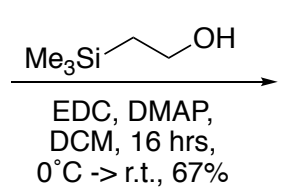

$0^{\circ} \mathrm{C} \rightarrow$ r.t., $67 \%$

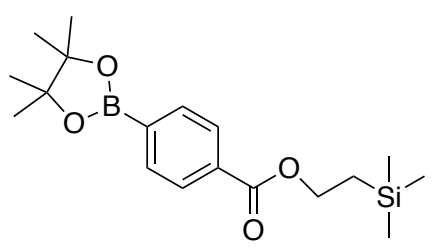

52

Scheme 4.8: Synthesis of TMSE pinacol boronic acid

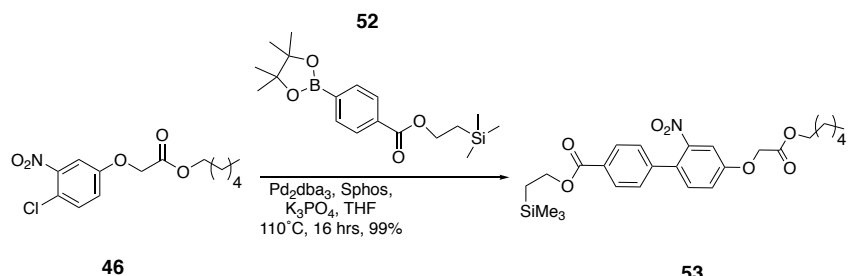

53

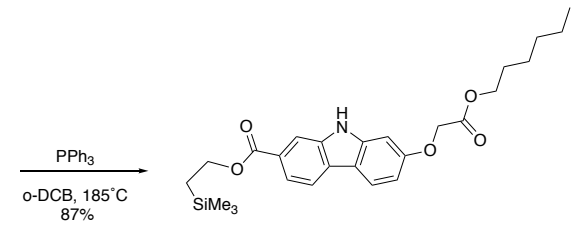

54

Scheme 4.9: TMSE carbazole
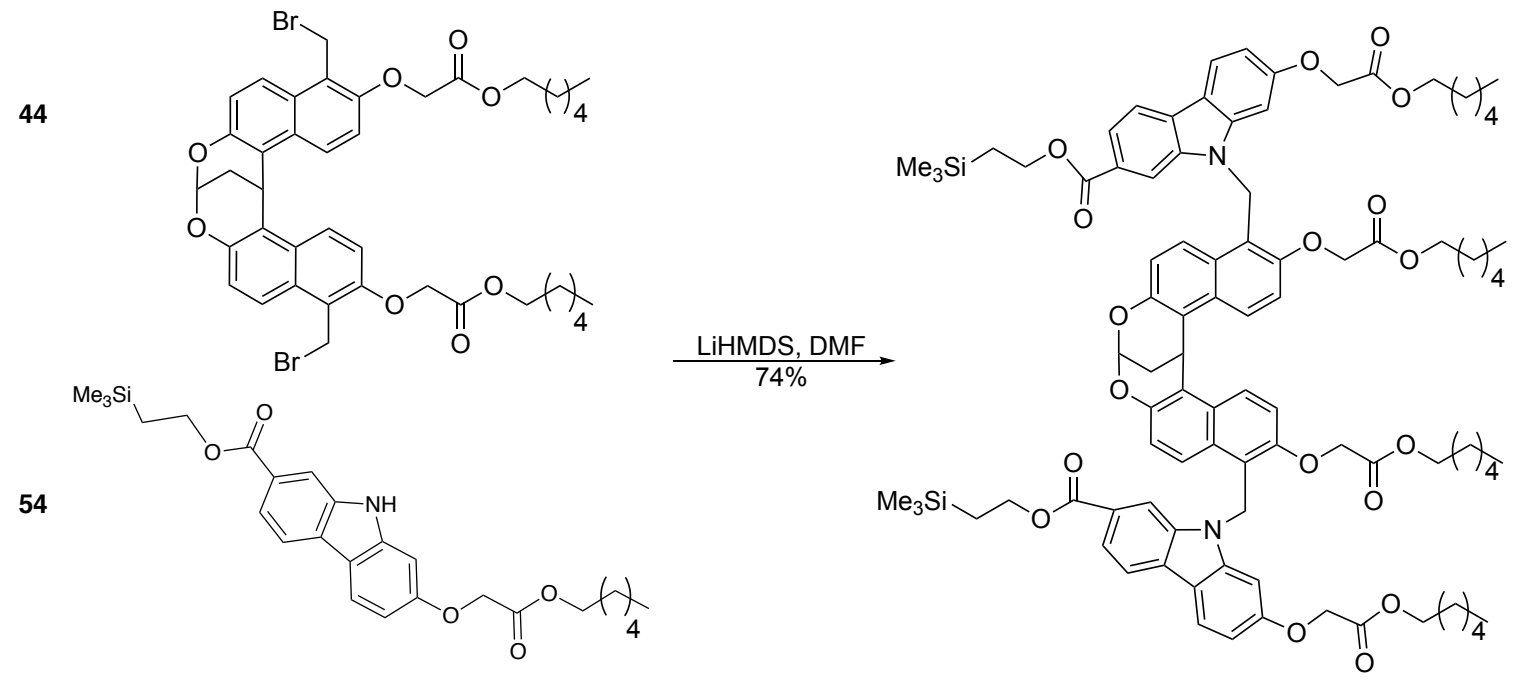

55

Scheme 4.10: TMSE Tube synthesis 


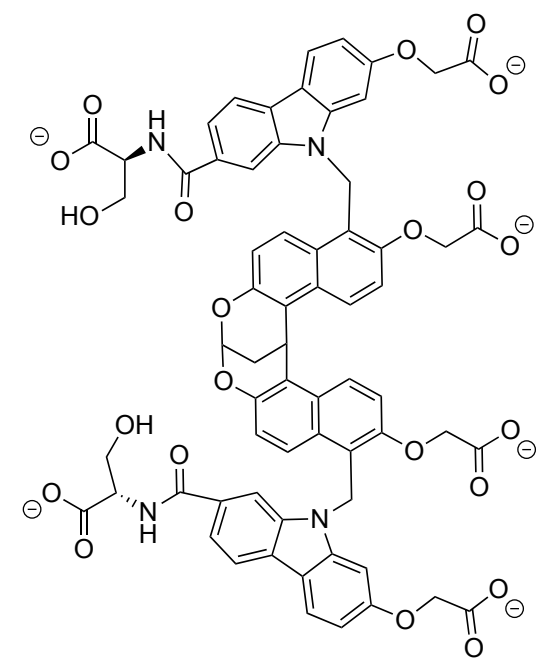

Figure 4.8: Newly designed hydrophobic amine sensor

The newly designed serine hexa acid open tube is shown in Figure 4.8. We hypothesized it would make the sensor even more hydrophilic with the hydroxyl units. To synthesize this sensor, the TMSE tube was deprotected with TBAF and was subjected to an amide coupling reaction with L-serine methyl ester to form the diamide product (Scheme 4.11). While the amide product has been identified by NMR and MS, the saponfied product was unable to be detected by NMR, LC-MS or direct infusion MS. The MS identification failure could be due to the fact that multiple ions are present, it has fragmentation patterns that are unable to be predicted, or it has unstable ionization pathways, or due to alternative reactivity. Also, it is possible under basic conditions the hydroxyl group of serine could attack the other amide and cleave it; a similar phenomenon was seen with a carbazole aldehyde tube reacting with methylamine in Chun Ren's research. 


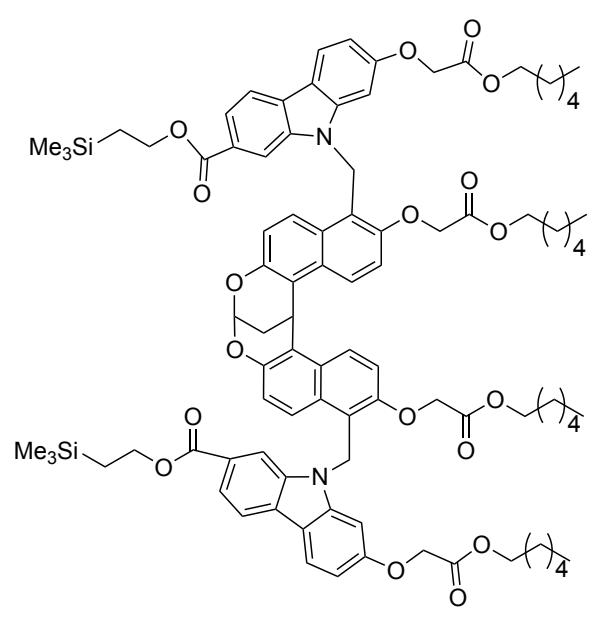

55
1. TBAF, DMF (88\%)

DMF, $59 \%$

$\overbrace{\mathrm{NH}_{3} \mathrm{Cl}} \mathrm{O}^{\prime}$

3. $\mathrm{NaOH}$, DMSO

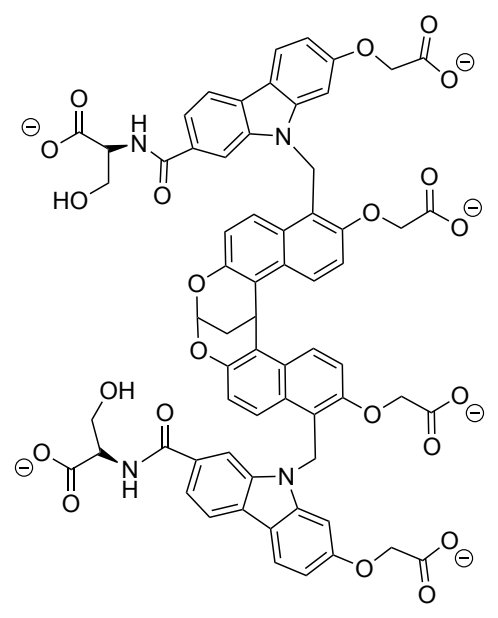

58

Scheme 4.11: TMSE cleavage, amide bond formation, and saponification

This final product displayed solubility in water. The carbazole fluorophore has an absorbance (Figure 4.9a) max of $315 \mathrm{~nm}$ and a fluorescence (Figure 4.9b) emission max at $422 \mathrm{~nm}$.
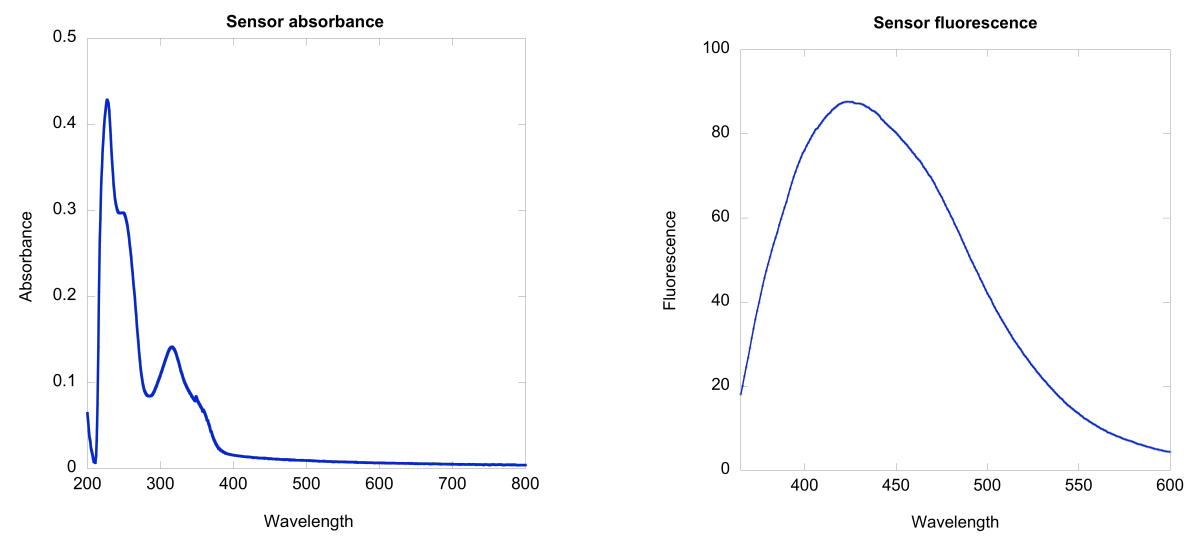

Figure 4.9: Absorbance and fluorescence spectrum of serine amino acid sensor in buffer (25 mM HEPES, $120 \mathrm{mM} \mathrm{NaCl} ; \mathrm{pH}=7.4),[\mathbf{5 8}]=10^{-5} \mathrm{M}$ 


\subsection{Alanine linked hexa-acid open tube}

Since we were unable to fully characterize the final serine tube product by LC-MS or NMR, an alanine version of the tube was synthesized. The hypothesis was that the hydroxyl unit of the serine was the problem. For the alanine tube, a mass spectrometry hit was obtained both by ESI direct injection and $\mathrm{LC}-\mathrm{MS}^{+}$mode with a $\mathrm{C}_{4}$ column. $\mathrm{NMR}$ data was unable to be obtained, and therefore we are using LC-MS as our characterization technique. With this knowledge in mind we decided to use this sensor to test the hydrophobic amines on hand to determine how it responds to them and compare its reactivity to the previously synthesized half tube.

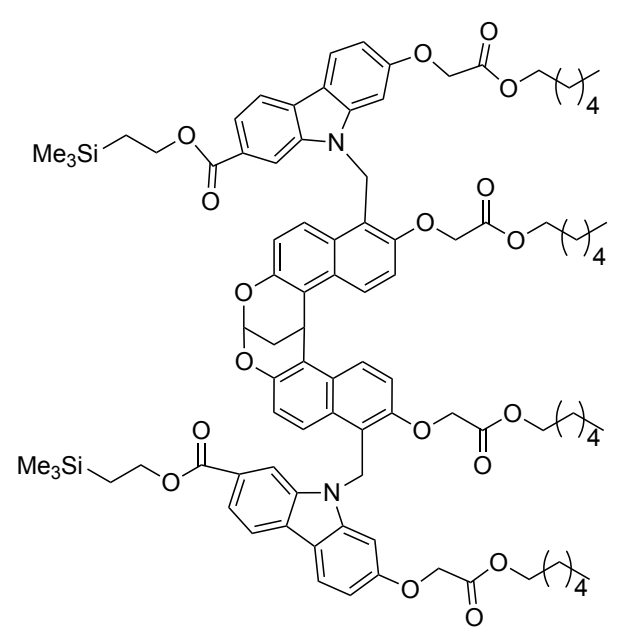

55

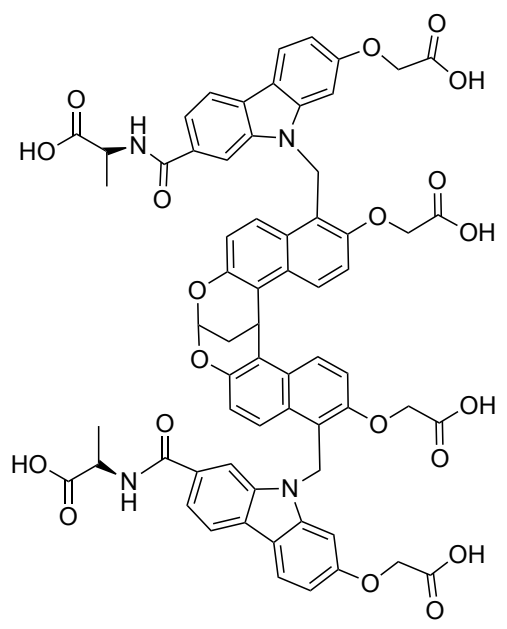

60

Scheme 4.12: Synthesis of alanine tube

The alanine tube had similar characteristics to the serine tube. The absorption max was at $315 \mathrm{~nm}$ for the carbazole fluorophore, with excitation at $315 \mathrm{~nm}$ providing $\lambda_{\max }$ of $429 \mathrm{~nm}$ (Figure 4.10). 

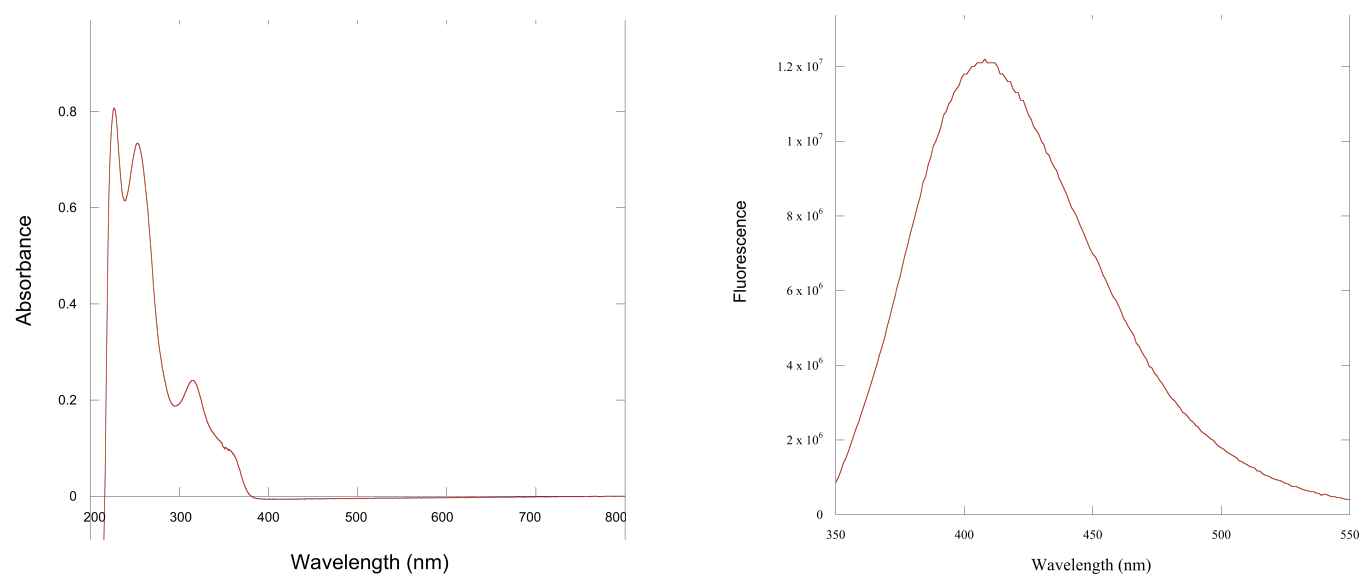

Figure 4.10: Absorbance and fluorescence of sensor 60, $10 \mu \mathrm{M}$ sensor in buffer $(25 \mathrm{mM}$ HEPES, $120 \mathrm{mM} \mathrm{NaCl} ; \mathrm{pH}=7.4),[\mathbf{6 0}]=10^{-5} \mathrm{M}$

The sensor was analyzed for its stability under successive scans and was found to only have a $3 \%$ decrease in fluorescence intensity after 15 successive scans (Figure 4.11). Therefore we expect it to be photo stable for our experiments.

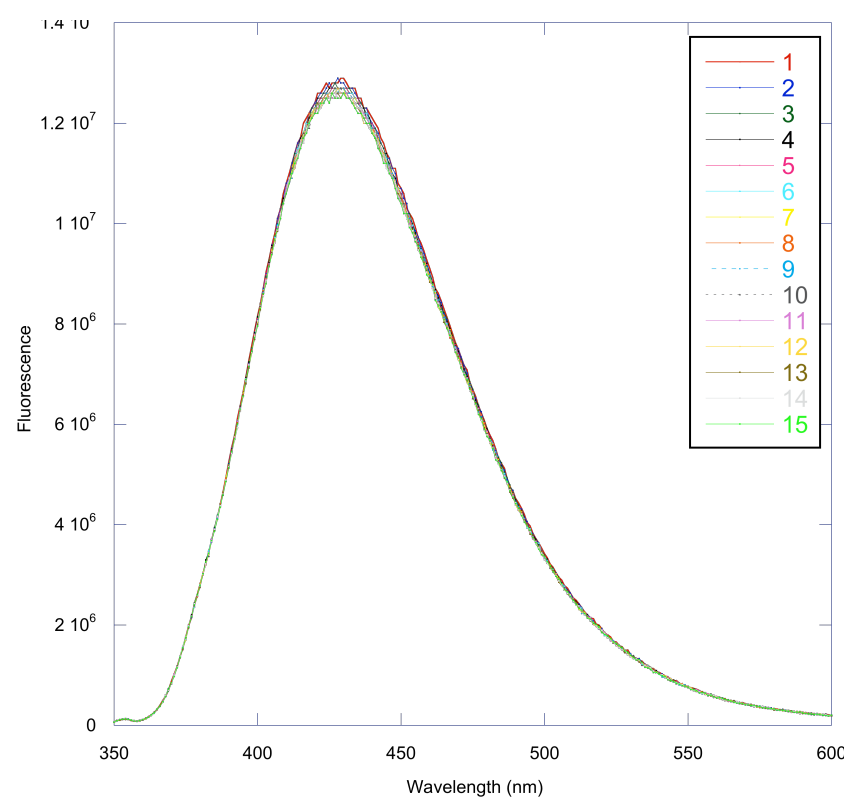

Figure 4.11: Sensor 60 stability scan, excitation $315 \mathrm{~nm}, 10 \mu \mathrm{M}$ sensor in buffer $(25 \mathrm{mM}$ HEPES, $120 \mathrm{mM} \mathrm{NaCl} ; \mathrm{pH}=7.4),[\mathbf{6 0}]=10^{-5} \mathrm{M}$ 


\subsubsection{Free analyte titrations}

Titrations were then carried out to determine the difference between the alanine sensor and the tetra acid sensor previously synthesized by Chun. It was found that the sensor did not sufficiently bind to mono alkylamines, however, it did bind well to diamines and spermine. Upon binding to monoamines, the sensor appeared to oil or fall out of solution. While it was not visually seen in the cuvette, evidence that suggests this is provided by a change in the UV. An initial increase in absorption is seen with decylamine or dodecylamine at $315 \mathrm{~nm}$, followed by a decrease in the absorption below initial levels. This phenomenon lead to the testing of many different amines including trimethylammonium species and two tailed species, as we believed the cavity was binding two amines to fall out of solution.

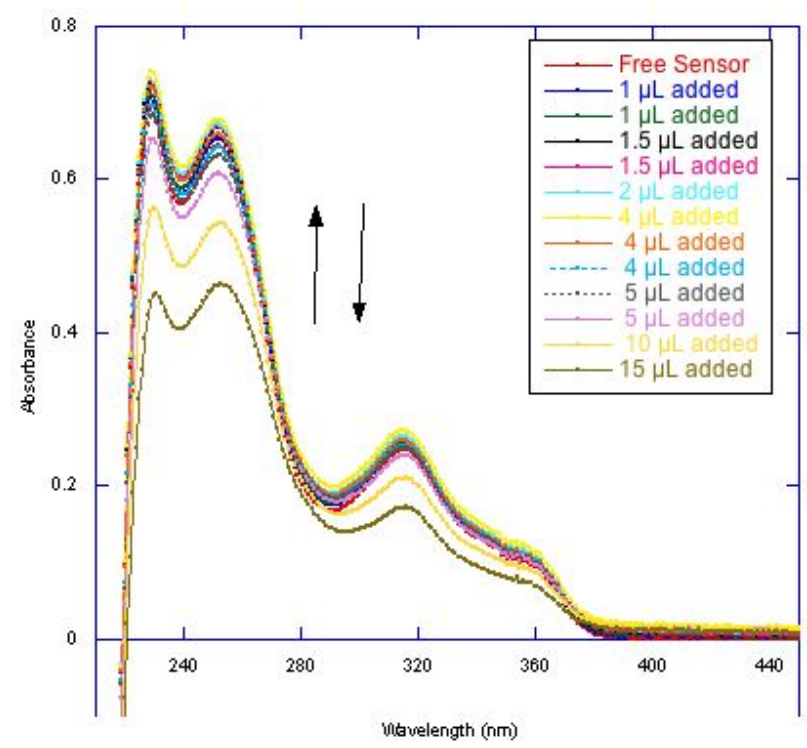

Figure 4.12: UV titration of 60 in buffer (25 mM HEPES, $120 \mathrm{mM} \mathrm{NaCl}$; $\mathrm{pH}=7.4$ ); $[60]=2 \mu \mathrm{M}$. 
Table 4.3: Binding studies of sensor 60 with alkyl amines

\begin{tabular}{|l|l|c|c|c|}
\hline Entry & Guest & $\mathrm{K}_{\mathrm{d}}(\mathrm{M})$ & $\mathrm{K}_{\mathrm{a}}\left(\mathrm{M}^{-1}\right)$ & $\mathrm{I}_{\mathrm{sat}} / \mathrm{I}_{0}$ \\
\hline 1 & 1,7 -diaminoheptane & $2.75 \mathrm{E}-4$ & 3,600 & 0.177 \\
\hline 2 & 1,8 -diaminooctane & $8.25 \mathrm{E}-5$ & 12,100 & 0.379 \\
\hline 3 & 1,10 -diaminodecane & $1.32 \mathrm{E}-5$ & 76,000 & 0.313 \\
\hline 4 & Spermine & $1.52 \mathrm{E}-5$ & 66,000 & 0.182 \\
\hline 5 & Spermidine & $1.66 \mathrm{E}-4$ & 6,000 & 0.207 \\
\hline 6 & Hexylamine & $1.59 \mathrm{E}-3$ & 600 & 0.529 \\
\hline 7 & Octylamine & $4.52 \mathrm{E}-4$ & 2,200 & 0.447 \\
\hline 8 & Decylamine & $4.39 \mathrm{E}-4$ & 2,300 & 0.849 \\
\hline 9 & Benzyl viologen & $3.49 \mathrm{E}-6$ & 290,000 & 0.859 \\
\hline
\end{tabular}

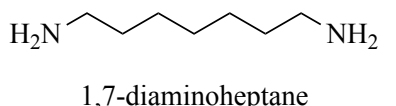

1,7-diaminoheptane

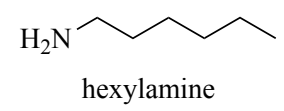

hexylamine

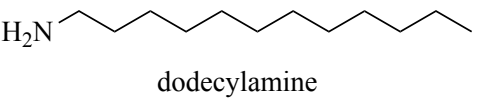

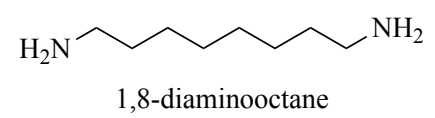

1,8-diaminooctane

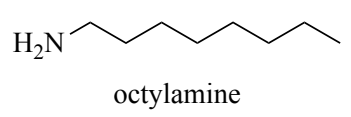

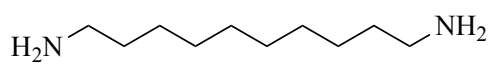

1,10-diaminodecane

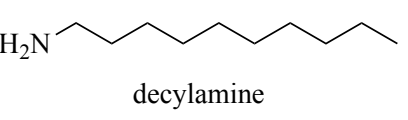<smiles>NCCCNCCCCNCCCN</smiles>

Figure 4.13: Structures of the alkyl amines tested in binding studies 
Of the diamines tested (entries 1-3), 1,10-diaminodecane displayed the best binding, Figure 4.14. 1,12-diaminododecane was not tested, as it did not dissolve completely in the sensor analyte solution. The diamines (entries 1-3) and monoamines (entries 6-8) tested displayed a decrease in the fluorescence. This decrease is due to photoinduced electron transfer (PET) from the amine, quenching the fluorophore fluorescence. Spermine, a polyamine with high positive charge, bound tightly due to electrostatic interactions, but with a fluorescence increase. The alkane portion 1,10diaminodecane binds well within the hydrophobic cavity, while the protonated amines extend out on either side and associate with the negatively charged carboxylate groups of the sensor. This association allows for both hydrophobic binding and charge-charge interactions.
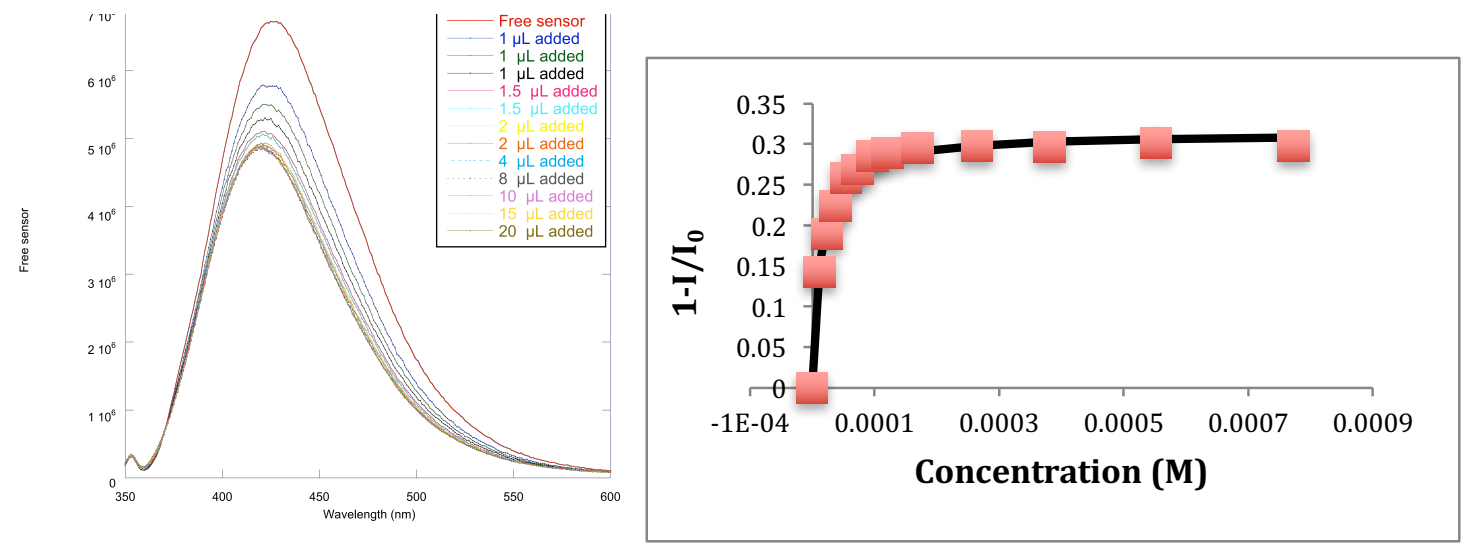

Figure 4.14: Fluorescence titration of sensor 60 with 1,10-diaminodecane in buffer (25 $\mathrm{mM}$ HEPES, $120 \mathrm{mM} \mathrm{NaCl} ; \mathrm{pH}=7.4) ;[60]=2 \mu \mathrm{M}, \lambda_{\mathrm{ex}}=315 \mathrm{~nm}$; a) fluorescence emission spectra as a function of added 1,10-diaminodecane, b) fit of titration data at $\lambda_{\mathrm{em}}$ $=429 \mathrm{~nm}$ to a single-site binding isotherm; $\mathrm{R}^{2}=0.993 ; \mathrm{K}_{\mathrm{d}}=1.32 \mathrm{E}-5 \mathrm{M} ; \mathrm{K}_{\mathrm{a}}=76,000$ $\mathrm{M}^{-1}$ 
Additional amines were tested to determine the extent of the hydrophobic amine binding. The next groups that were tested were $1^{\circ}$ amines with two tails and trimethyl ammonium species of the mono amines. The trimethylammonium species were tested, as we believed the monoamines were binding two within the cavity and falling out of solution. The trimethylammonium group we believed would help to inhibit the binding of the second analyte.

Octyl, decyl, and dodecyltrimethylammonium bromide have no lone pair to allow PET quenching, therefore the binding to the sensor provides a fluorescence increase. The analytes bound, however, they displayed significantly lower binding constants and did not display linear biding. Figure 4.16 shows the binding of octyltrimethylammonium bromide, where there is an initial binding event and plateau, followed by an increase in signal. This is similar to what was observed with dodecylamine. A similar phenomenon is observed with decyltrimethylammonium bromide and dodecyltrimethylammonium bromide. As expected, between 4-heyptylamine and 5-nonylamine, the longer chain amine provided a better binding constant. These two amines showed a linear response as opposed to the response seen with the monoamines, demonstrating that the cavity is potentially binding two lipid tails simultaneously.

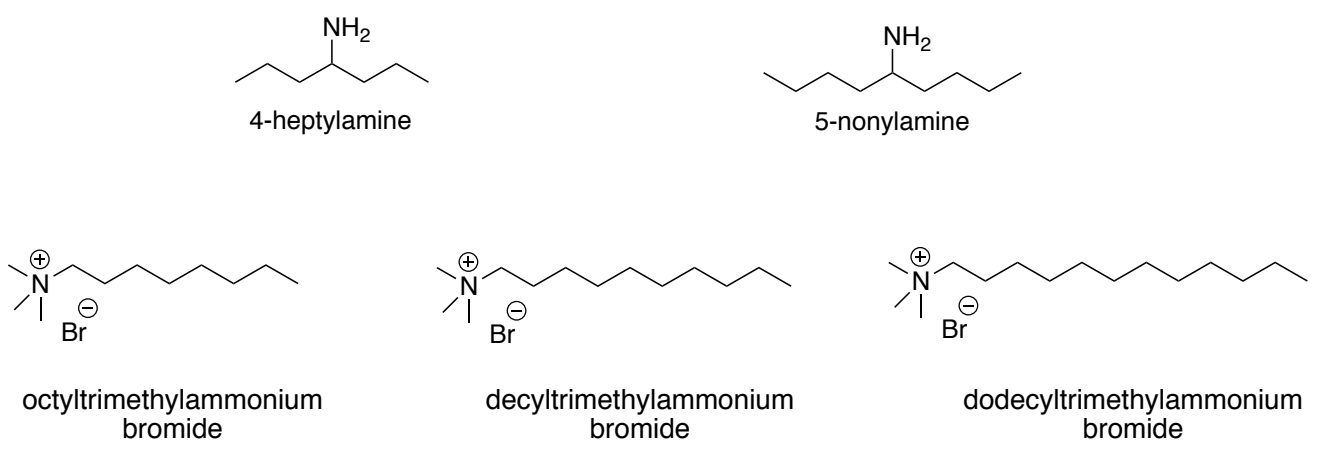

Figure 4.15: Structures of additional analytes tested 

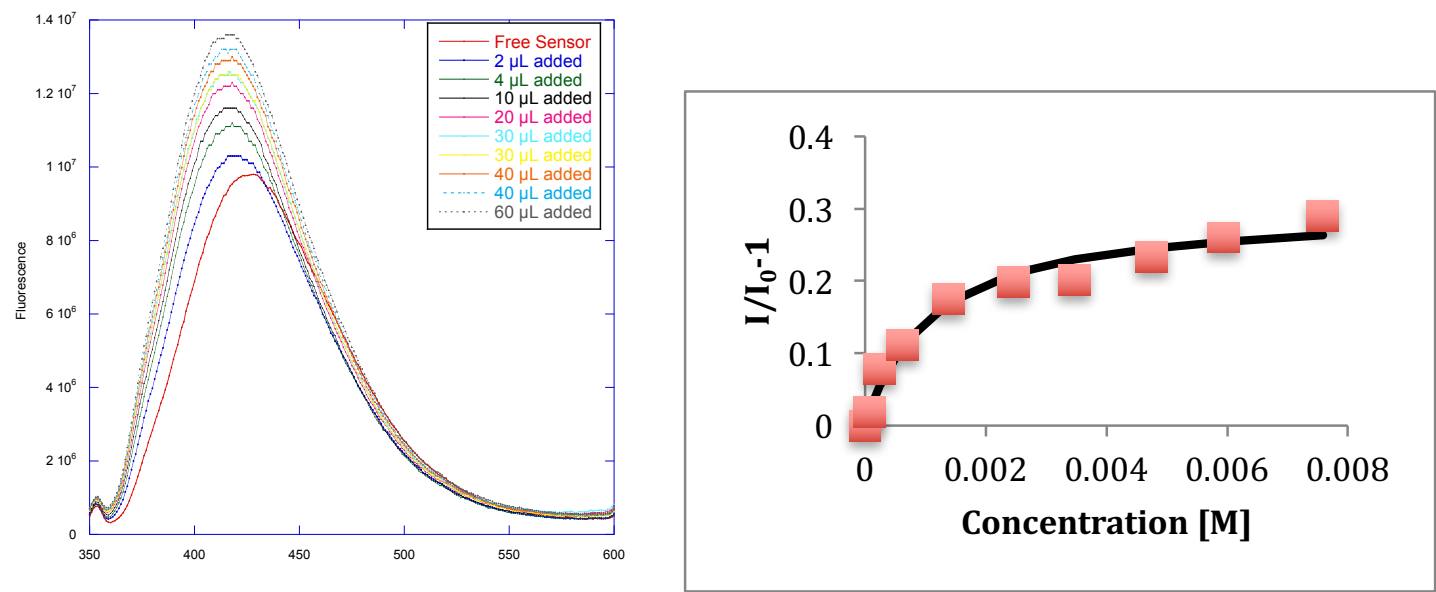

Figure 4.16: Fluorescence titration of sensor 60 with octyltrimethylammonium bromide in buffer (25 mM HEPES, $120 \mathrm{mM} \mathrm{NaCl} ; \mathrm{pH}=7.4) ;[60]=2 \mu \mathrm{M}, \lambda_{\text {ex }}=315 \mathrm{~nm}$; a) fluorescence emission spectra as a function of added octyltrimethylammonium bromide, b) fit of titration data at $\lambda_{\mathrm{em}}=429 \mathrm{~nm}$ to a single-site binding isotherm; $\mathrm{R}^{2}=0.974 ; \mathrm{K}_{\mathrm{d}}=$ $1.05 \mathrm{E}-3 \mathrm{M} ; \mathrm{K}_{\mathrm{a}}=950 \mathrm{M}^{-1}$.
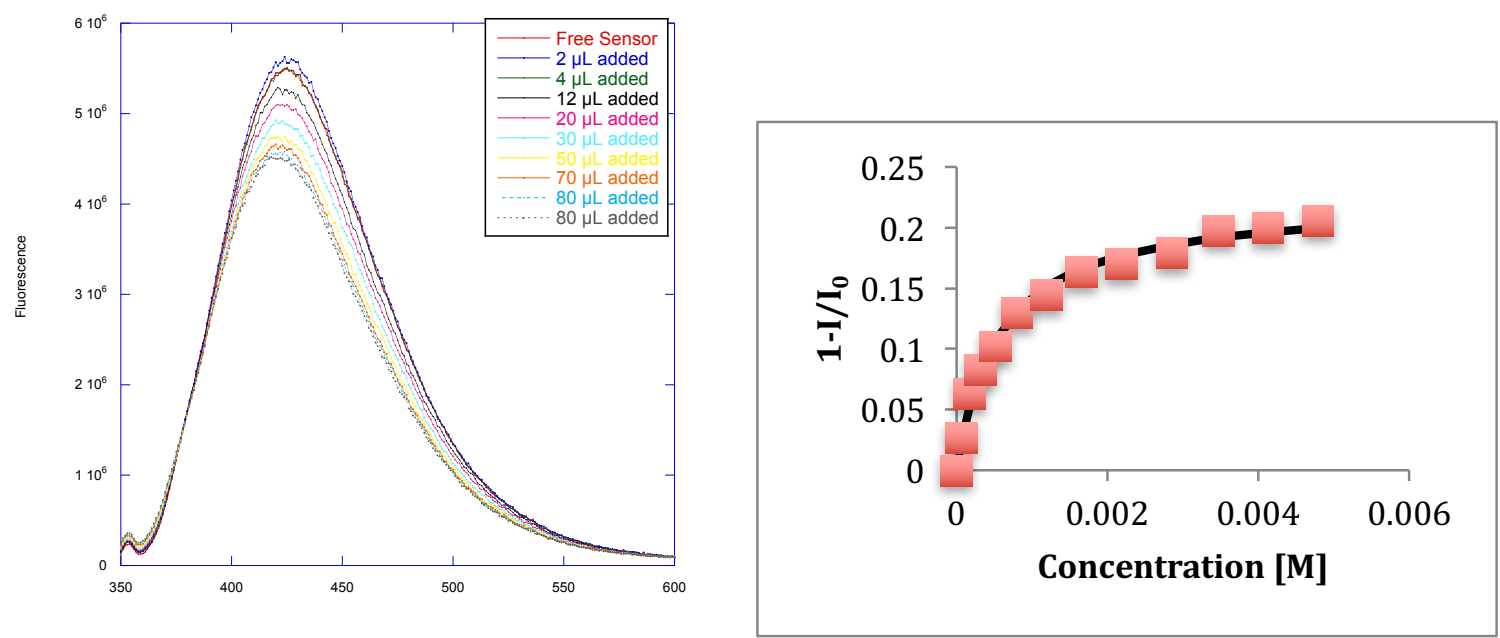

Figure 4.17: Fluorescence titration of sensor 60 with 5-nonylamine in buffer $(25 \mathrm{mM}$ HEPES, $120 \mathrm{mM} \mathrm{NaCl} ; \mathrm{pH}=7.4) ;[60]=2 \mu \mathrm{M}, \lambda_{\mathrm{ex}}=315 \mathrm{~nm}$; a) fluorescence emission spectra as a function of added 5-nonylamine, b) fit of the titration data at $\lambda_{\mathrm{em}}=429 \mathrm{~nm}$ to a single-site binding isotherm; $R^{2}=0.993 ; K_{d}=5.64 \mathrm{E}-4 \mathrm{M} ; \mathrm{K}_{\mathrm{a}}=1,800 \mathrm{M}^{-1}$. 
Given that $1^{\circ}$ amines with two tails appeared to bind to the sensor, we wanted to expand our experiments to additional amines with two tails, leading us to test $2^{\circ}$ amines: diamylamine and dihexylamine (Figure 4.18). These analytes retain a similar number of carbons of the previous analytes and therefore we expect them to display similar binding characteristics. Dihexylamine appeared to bind much better than the two tailed $1^{\circ}$ amines, while diamylamine fit a binding isotherm poorly.

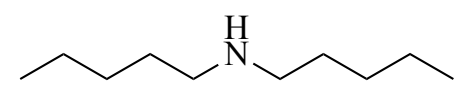

diamylamine

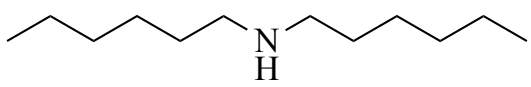

dihexylamine

Figure 4.18: Structures of $2^{\circ}$ amines tested
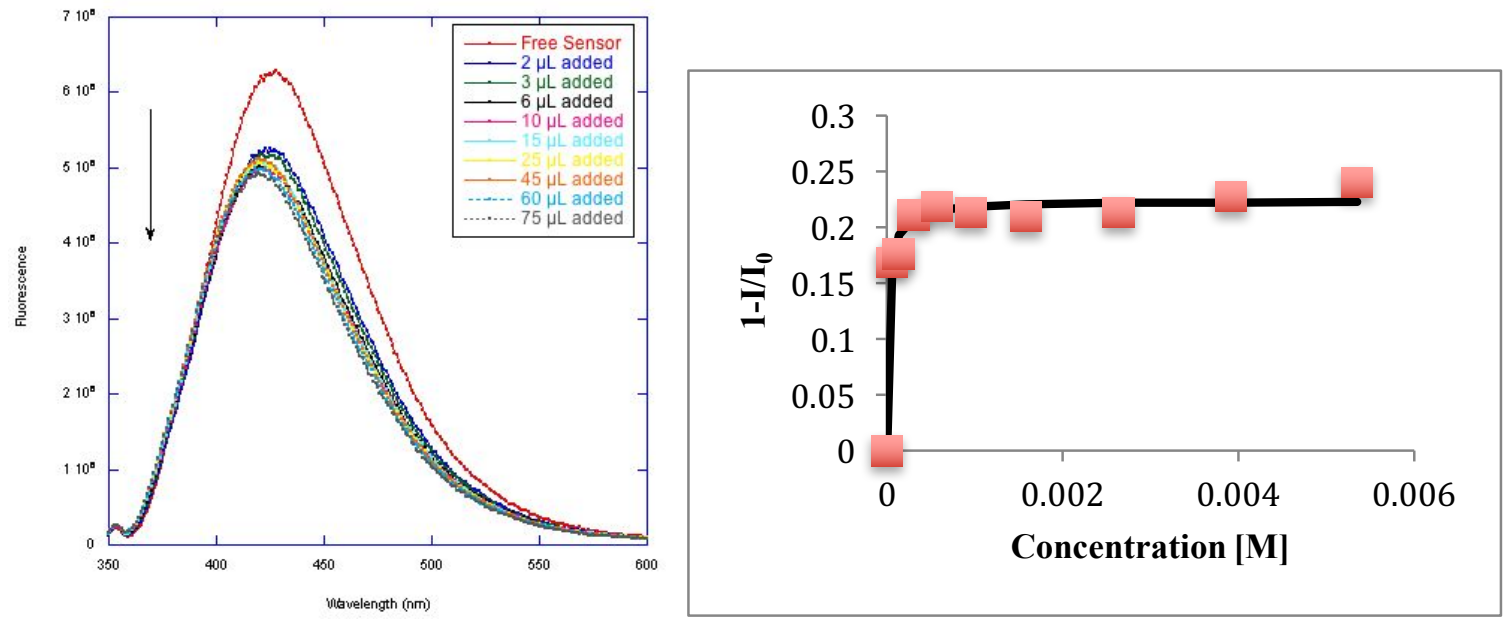

Figure 4.19: Fluorescence titration of sensor 60 with dihexylamine in buffer $(25 \mathrm{mM}$ HEPES, $120 \mathrm{mM} \mathrm{NaCl} ; \mathrm{pH}=7.4) ;[60]=2 \mu \mathrm{M}, \lambda_{\mathrm{ex}}=315 \mathrm{~nm}$; a) fluorescence emission spectra as a function of added dihexylamine, b) fit of the titration data at $\lambda_{\mathrm{em}}=429 \mathrm{~nm}$ to a single-site binding isotherm; $\mathrm{R}^{2}=0.979 ; \mathrm{K}_{\mathrm{d}}=2.17 \mathrm{E}-5 \mathrm{M} ; \mathrm{K}_{\mathrm{a}}=46,000 \mathrm{M}^{-1}$. 
A blue shift can be observed when binding to any of the aforementioned analytes. A few have a more pronounced blue shift than others, specifically the analytes that appeared to bind more tightly. Furthermore, spermine, spermidine, and the trimethylammonium bromide derivatives displayed a fluorescence increase upon binding. While the remaining analytes exhibited a decrease in fluorescence, the intensity of the decrease varied between the sets of analytes. The single chain monoamines appeared to quench the fluorescence more efficiently than the diamines. As our next set of studies would occur in vesicles at a much lower concentration, we explored an additional analyte that would potentially quench the fluorescence more significantly, benzyl viologen.

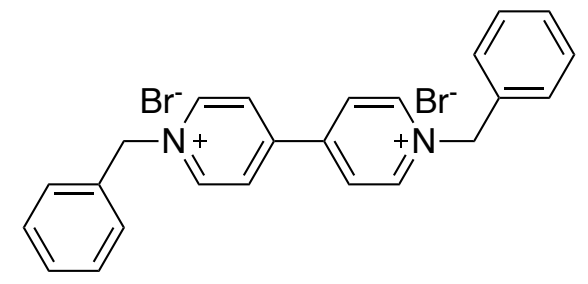

Figure 4.20: Structure of benzyl viologen dibromide

Benzyl viologen is a hydrophobic water soluble molecule, which bound to the alanine hexaacid sensor remarkably well (Figure 4.21). As expected, benzyl viologen quenched the fluorescence significantly, with a decrease of about $86 \%$, while also binding with a $\mathrm{K}_{\mathrm{a}}$ much higher than all previously tested analytes, $\mathrm{K}_{\mathrm{a}}=290,000 \mathrm{M}^{-1}$. 

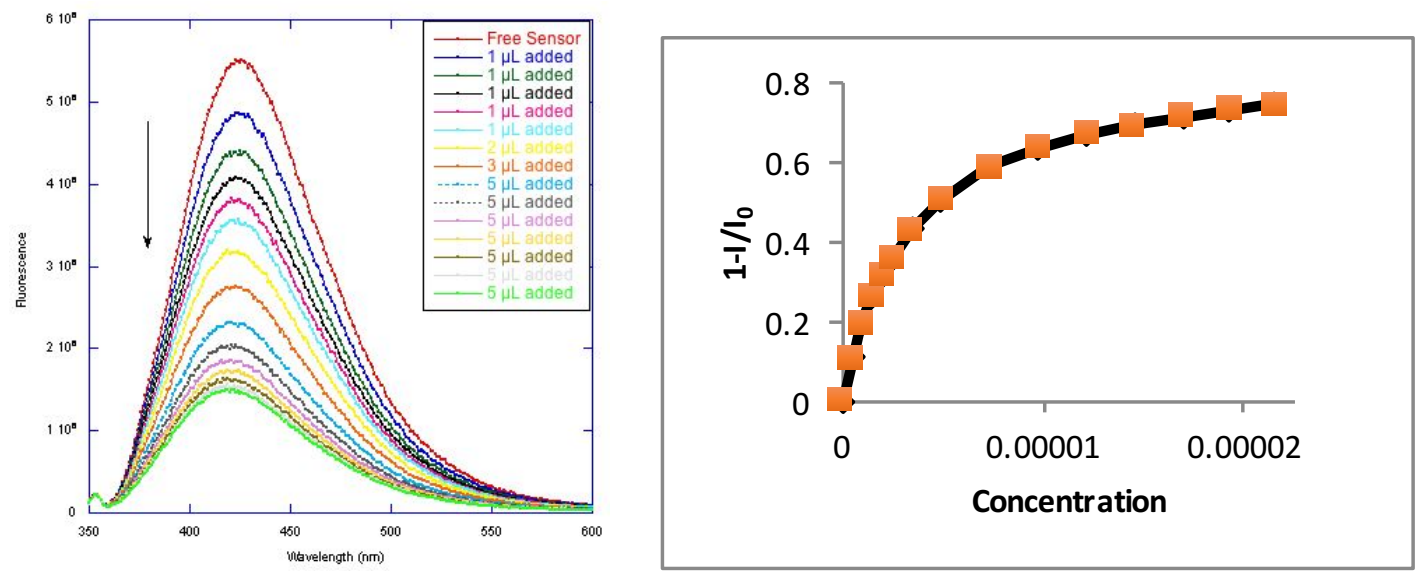

Figure 4.21: Fluorescence titration of sensor 60 with benzyl viologen in buffer $(25 \mathrm{mM}$ HEPES, $120 \mathrm{mM} \mathrm{NaCl} ; \mathrm{pH}=7.4) ;[60]=2 \mu \mathrm{M}, \lambda_{\mathrm{ex}}=315 \mathrm{~nm}$; a) fluorescence emission spectra as a function of added benzyl viologen, b) fit of the titration data at $\lambda_{\mathrm{em}}=429 \mathrm{~nm}$ to a single-site binding isotherm; $\mathrm{R}^{2}=0.999 ; \mathrm{K}_{\mathrm{d}}=3.49 \mathrm{E}-6 \mathrm{M} ; \mathrm{K}_{\mathrm{a}}=290,000 \mathrm{M}^{-1}$.

With these free analyte tests completed we moved forward toward testing the ability of this sensor to extract the tested analytes from synthetically prepared vesicles.

\subsubsection{Vesicle Titrations}

Synthetic vesicles were prepared in our lab from either DMPC (phosphotidyl choline headgroup), DMPS (phosphotidylserine headgroup), or a 80:20 mixture of DMPS/DMPC. The vesicles were extruded to create a uniform distribution of vesicles $<200 \mathrm{~nm}$ in size. To account for the interaction of the sensor with the vesicle, titrations were carried out with analyte free vesicles to determine the affect of scattering on the vesicles. Our fluorescence instrument has a front face mode, which decreased the scattering effect.

DMPC did not fit a binding isotherm, nor did it appear to have a trending effect on the fluorescence (Figure 4.22). DMPS vesicles (100\% DMPS), however, showed a small 
decrease in fluorescence and fit a binding isotherm ((Figure 4.23). As the fluorescence decreased, it is unlikely that the sensor is embedding into the membrane. DMPS is typically present on the inner leaflet of membranes and at around $20 \%$ in membranes, which would explain why the size of these vesicles was significantly smaller than the DMPC vesicles. This would create a vesicle that is significantly more curved, which could permit a closer interaction between the headgroup of the lipid and the sensor, allowing the amine to quench the fluorescence. DMPC/DMPS vesicles (80:20), also did not fit a binding isotherm and had no trending affect on the fluorescence (Figure 4.24). Finally, DMPC vesicles were also tested with $10 \mathrm{~mol} \%$ cholesterol, which exhibited no trending changes in the fluorescence and did not fit a binding isotherm (Figure 4.25). Thus it seemed that the sensor had little interaction with the vesicles, based on the small changes in fluorescence.

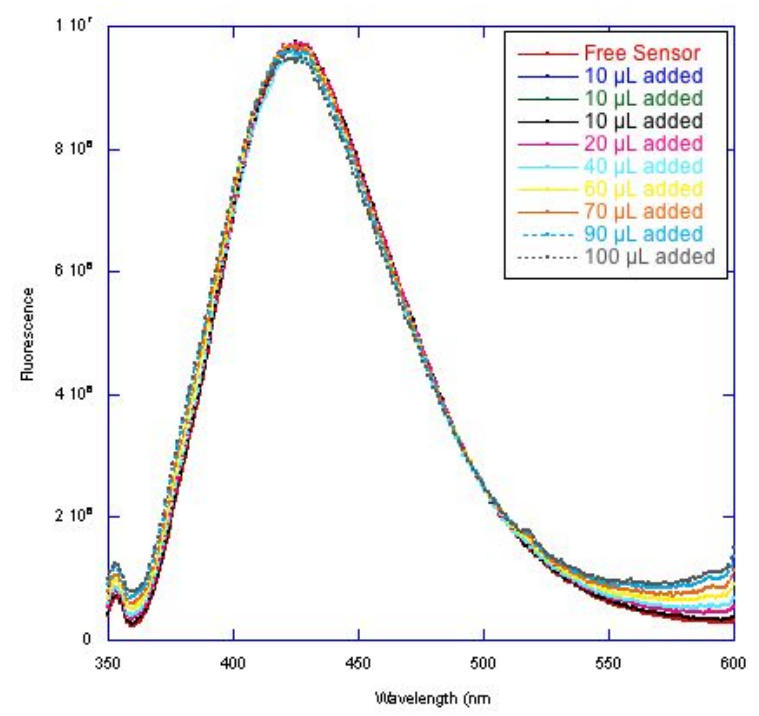

Figure 4.22: Fluorescence titration of sensor 60 with DMPC in buffer ( 25 mM HEPES, $120 \mathrm{mM} \mathrm{NaCl} ; \mathrm{pH}=7.4) ;[\mathbf{6 0}]=2 \mu \mathrm{M}, \lambda_{\mathrm{ex}}=315 \mathrm{~nm} ;$ a) fluorescence emission spectra as a function of added DMPC. 

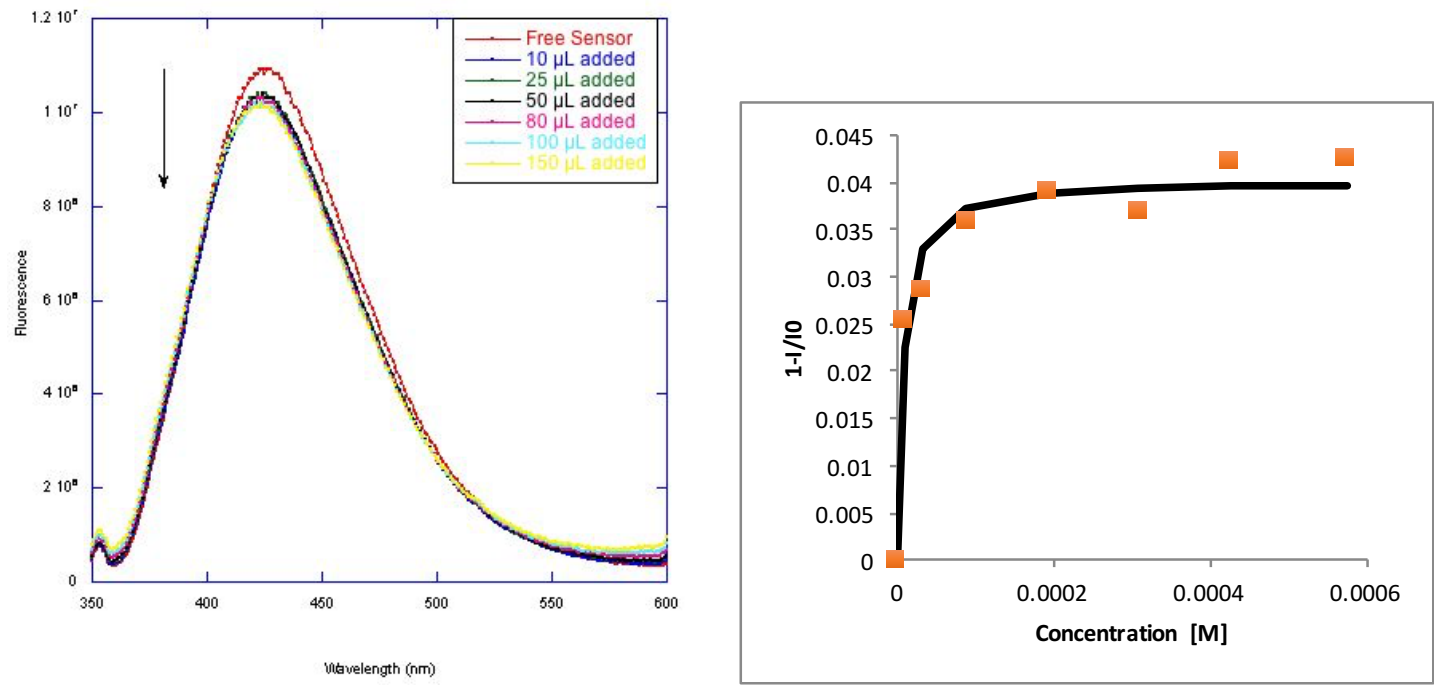

(Figure 4.23: Fluorescence titration of sensor 60 with DMPS in buffer (25 mM HEPES, $120 \mathrm{mM} \mathrm{NaCl} ; \mathrm{pH}=7.4) ;[\mathbf{6 0}]=2 \mu \mathrm{M}, \lambda_{\mathrm{ex}}=315 \mathrm{~nm}$; a) fluorescence emission spectra as a function of added DMPS, b) fit of the titration data at $\lambda_{\mathrm{em}}=429 \mathrm{~nm}$ to a single-site binding isotherm; $\mathrm{R}^{2}=0.966 ; \mathrm{K}_{\mathrm{d}}=7.34 \mathrm{E}-6 \mathrm{M} ; \mathrm{K}_{\mathrm{a}}=136,000 \mathrm{M}^{-1}$.

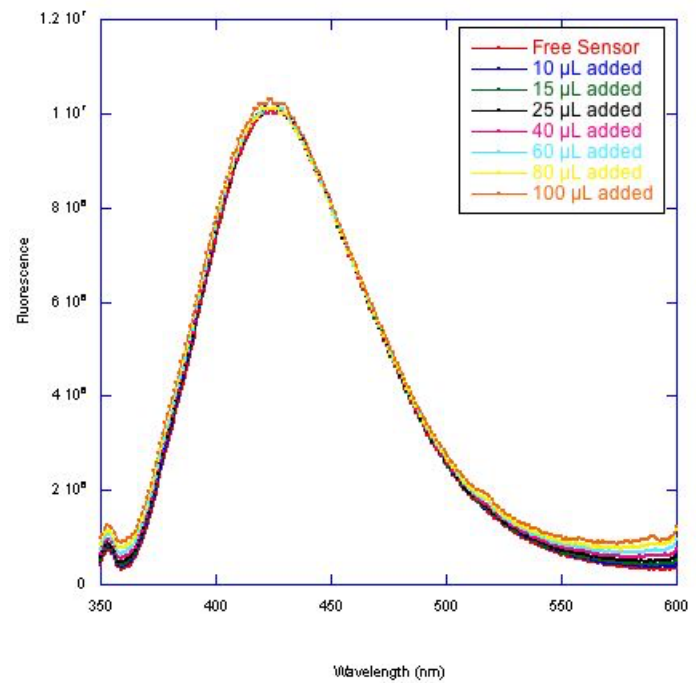

Figure 4.24: Fluorescence titration of sensor 60 with DMPC/DMPS (80:20) in buffer (25 $\mathrm{mM}$ HEPES, $120 \mathrm{mM} \mathrm{NaCl} ; \mathrm{pH}=7.4) ;[60]=2 \mu \mathrm{M}, \lambda_{\mathrm{ex}}=315 \mathrm{~nm}$; a) fluorescence emission spectra as a function of added DMPC/DMPS (80:20). 


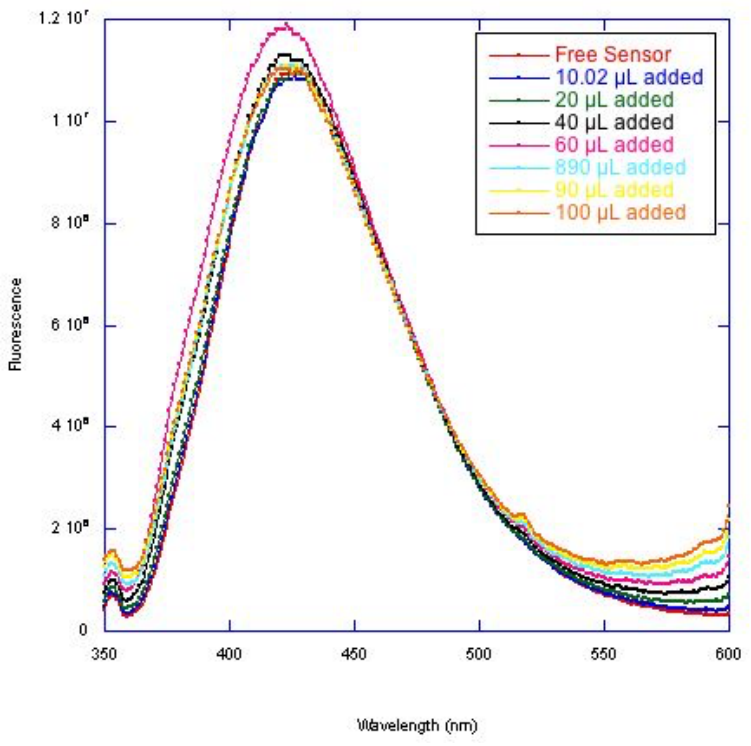

Figure 4.25: Fluorescence titration of sensor 60 with DMPC vesicles with 10 mol\% cholesterol in buffer (25 mM HEPES, $120 \mathrm{mM} \mathrm{NaCl} ; \mathrm{pH}=7.4) ;[\mathbf{6 0}]=2 \mu \mathrm{M}, \lambda_{\mathrm{ex}}=315$ $\mathrm{nm}$; a) fluorescence emission spectra as a function of added DMPC vesicles with 10 mol $\%$ cholesterol.

The best binding free analyte that quenched the fluorescence of the sensor was 1,10diaminodecane and benzyl viologen. Therefore these analytes were explored in our vesicle titration studies. DMPC vesicles were prepared, however, $5 \mathrm{~mol} \%$ of 1,10 diaminodecane (or other tested analytes) was added during the drying or hydration step as indicated in the appendix procedures. The resulting vesicles were similar in size to their parent amine free vesicles. Titration of the 1,10-diaminodecane loaded vesicles displayed a fluorescence decrease and fit a single site binding isotherm (Figure 4.26). Assuming the amine is inside the bilayer of vesicle, the decrease in the fluorescence indicates that the sensor is indeed removing the amine from the vesicle. 

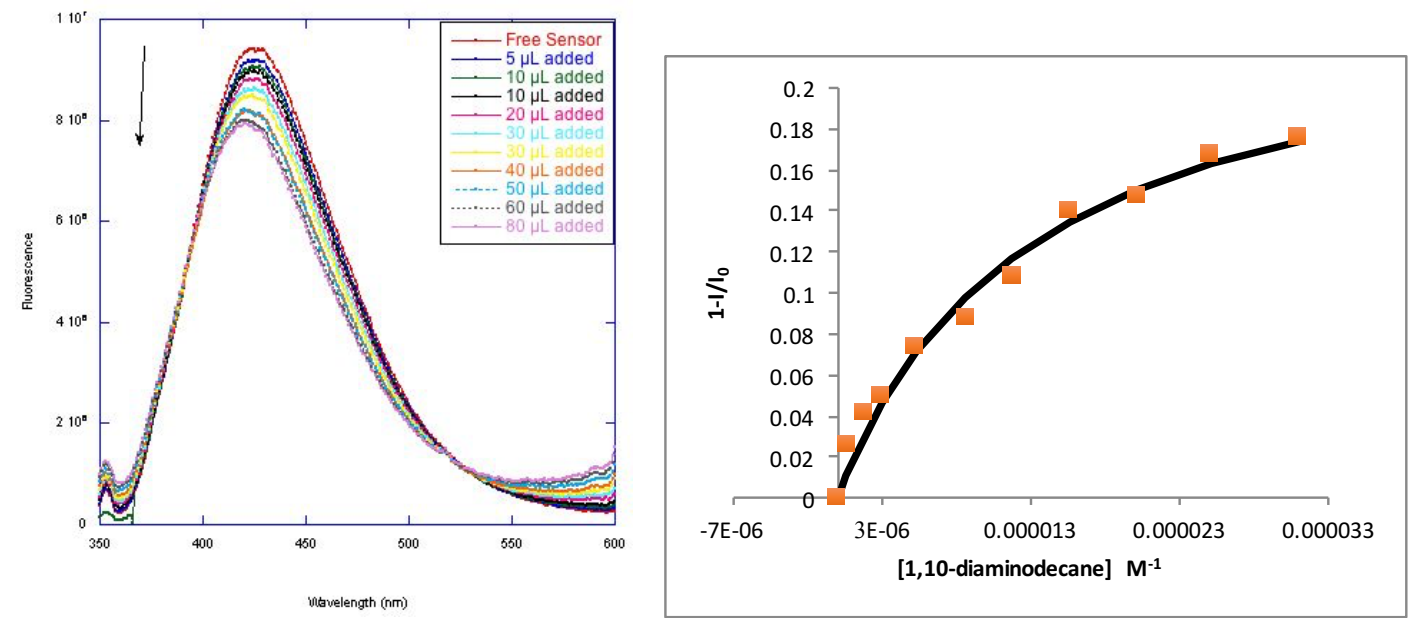

Figure 4.26: Fluorescence titration of sensor 60 with DMPC vesicles with 5 mol\% 1,10diaminodecane in buffer (25 mM HEPES, $120 \mathrm{mM} \mathrm{NaCl}$; $\mathrm{pH}=7.4) ;[60]=2 \mu \mathrm{M}, \lambda_{\mathrm{ex}}=$ $315 \mathrm{~nm}$; a) fluorescence emission spectra as a function of added DMPC vesicles with 5 mol\% 1,10-diaminodecane, b) fit of the titration data at $\lambda_{\mathrm{em}}=429 \mathrm{~nm}$ to a single-site binding isotherm; $\mathrm{R}^{2}=0.986 ; \mathrm{K}_{\mathrm{d}}=1.31 \mathrm{E}-5 \mathrm{M} ; \mathrm{K}_{\mathrm{a}}=77,000$.

The next test was to determine the effect of DMPS on the extraction process, thus the amine was loaded into the 80/20 DMPC/DMPS vesicles. We expected the DMPS to make the extraction of the amine more difficult, however, it did not appear to have a significant impact on the binding (Figure 4.27). The binding constant and fluorescence intensity decrease was similar to the DMPC vesicles, indicating that the DMPS had no effect on the extraction process. 

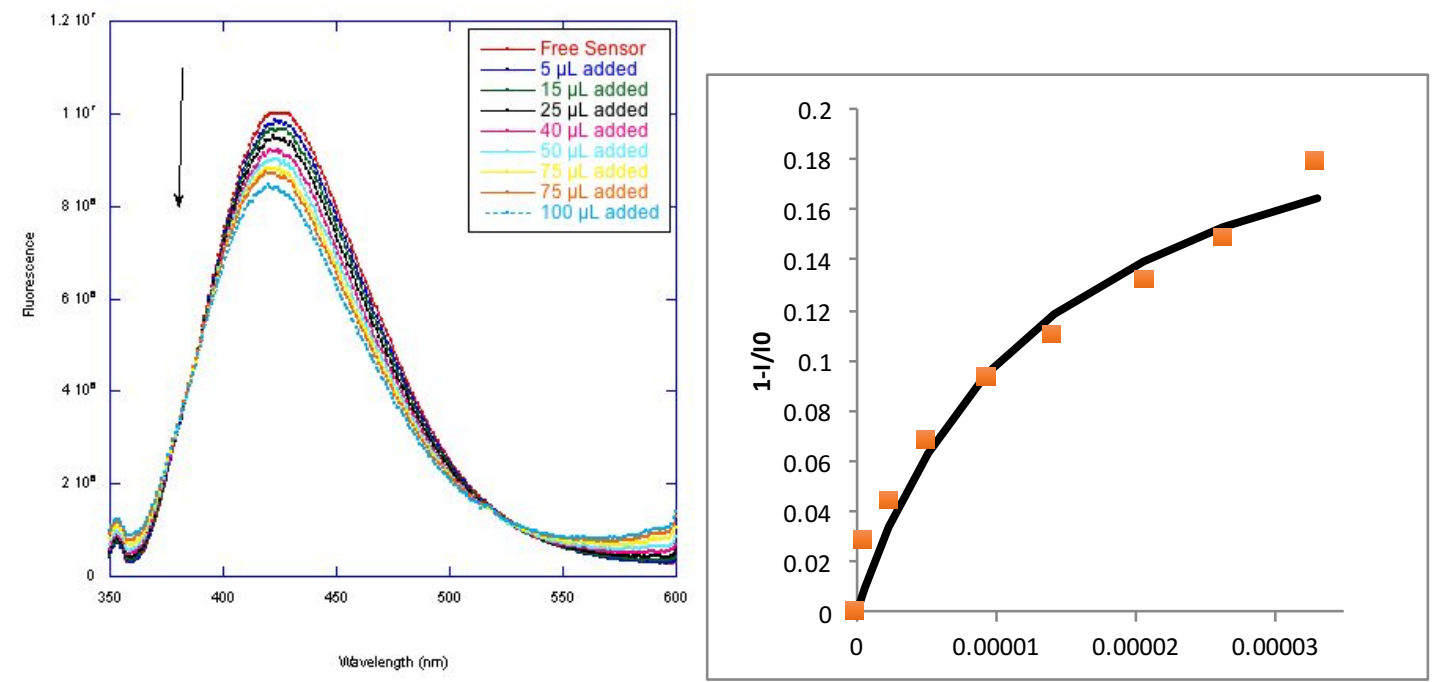

Figure 4.27: Fluorescence titration of sensor 60 with DMPC/DMPS (80:20) vesicles with 5 mol\% 1,10-diaminodecane in buffer (25 mM HEPES, $120 \mathrm{mM} \mathrm{NaCl} ; \mathrm{pH}=7.4) ;[\mathbf{6 0}]=$ $2 \mu \mathrm{M}, \lambda_{\mathrm{ex}}=315 \mathrm{~nm}$; a) fluorescence emission spectra as a function of added DMPC/DMPS (80:20) vesicles with 5 mol\% 1,10-diaminodecane in buffer, b) fit of the titration data at $\lambda_{\mathrm{em}}=429 \mathrm{~nm}$ to a single-site binding isotherm; $\mathrm{R}^{2}=0.977 ; \mathrm{K}_{\mathrm{d}}=1.35 \mathrm{E}-5$ $\mathrm{M} ; \mathrm{K}_{\mathrm{a}}=74,000 \mathrm{M}^{-1}$.

We then wanted to determine how the presence of cholesterol within the vesicle would affect the extraction process. Therefore DMPC vesicles with $10 \mathrm{~mol} \%$ of cholesterol in addition to the $5 \mathrm{~mol} \%$ amine were made and titrated with the sensor. The result showed a decrease in the fluorescence and a fit to a binding isotherm. The presence of cholesterol within the vesicle appears to either facilitate the removal of the amine or helps to stabilize the vesicle, allowing the removal of the amine. 

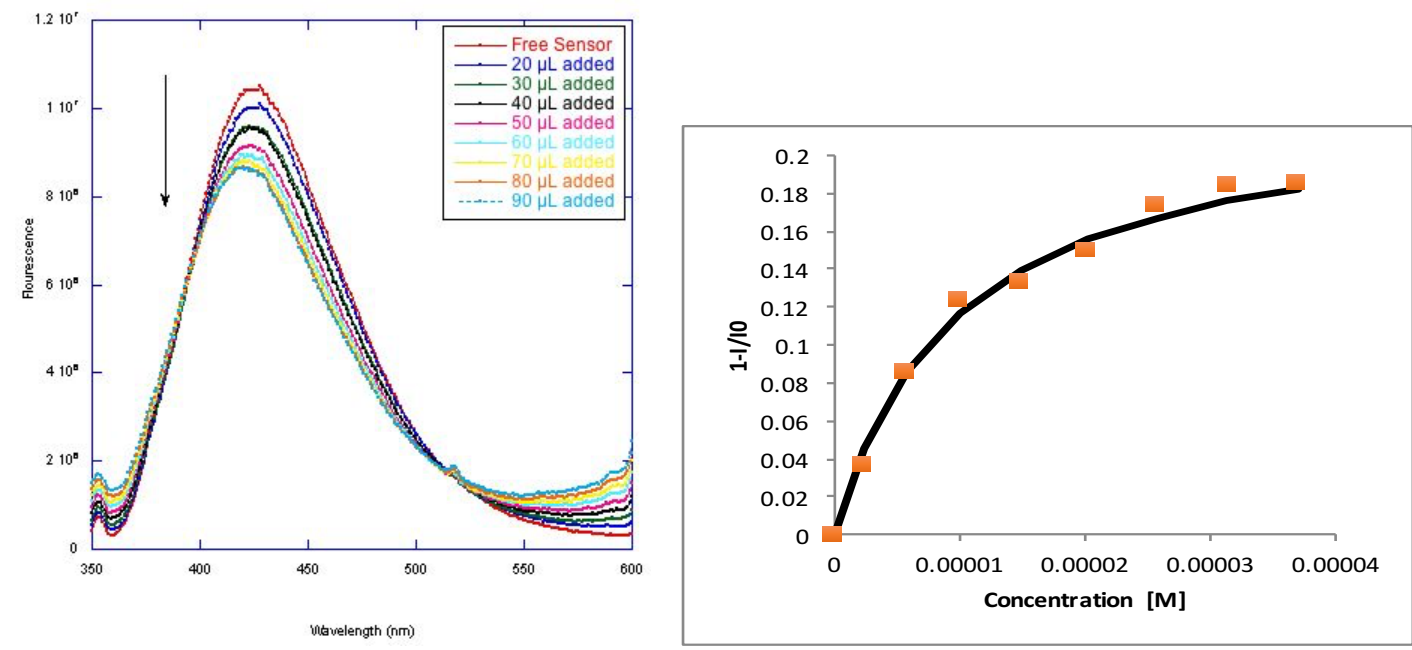

Figure 4.28: Fluorescence titration of sensor 60 with DMPC vesicles containing 10 mol\% cholesterol and $5 \mathrm{~mol} \%$ 1,10-diaminodecane in buffer (25 mM HEPES, $120 \mathrm{mM}$ $\mathrm{NaCl} ; \mathrm{pH}=7.4) ;[\mathbf{6 0}]=2 \mu \mathrm{M}, \lambda_{\mathrm{ex}}=315 \mathrm{~nm}$; a) fluorescence emission spectra as a function of added DMPC vesicles containing $10 \mathrm{~mol} \%$ cholesterol and $5 \mathrm{~mol} \%$ 1,10diaminodecane, $\mathrm{b}$ ) fit of the titration data at $\lambda_{\mathrm{em}}=429 \mathrm{~nm}$ to a single-site binding isotherm; $R^{2}=0.992 ; K_{d}=9.63 \mathrm{E}-6 \mathrm{M} ; \mathrm{K}_{\mathrm{a}}=104,000 \mathrm{M}^{-1}$.

Benzyl viologen, the other free analyte that bound tightly and quenched the fluorescence the most was also tested in vesicles. DMPC vesicles were prepared with the analyte present at $5 \mathrm{~mol} \%$. Titrations (Figure 4.29 ) demonstrated this analyte was able to be extracted from the vesicle, fitting a one-site binding isotherm. The decrease in fluorescence was not as significant as in the free analyte, $73 \%$ vs. $86 \%$. This decrease is far superior to the previous amine analytes, and demonstrates a hydrophobic molecule can be extracted from the bilayer of a membrane. 

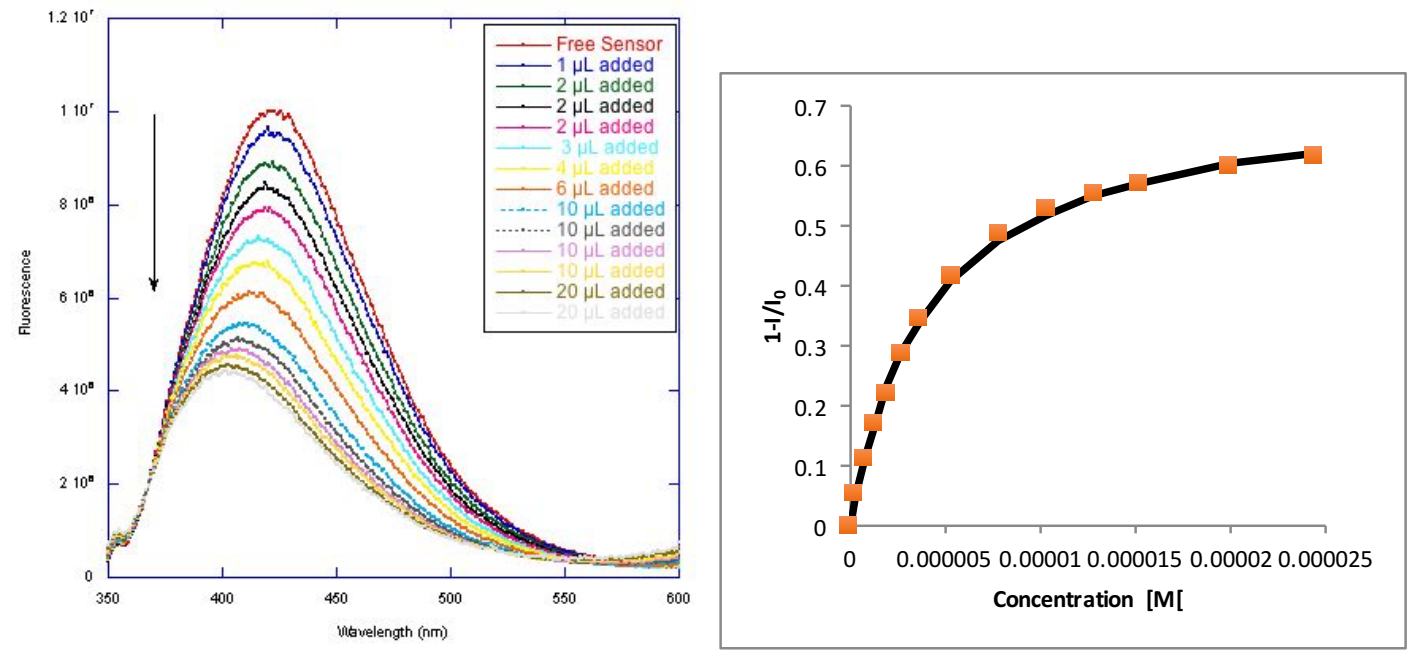

Figure 4.29: Fluorescence titration of alanine hexaacid with DMPC vesicles with 5 mol\% benzyl viologen in buffer (25 mM HEPES, $120 \mathrm{mM} \mathrm{NaCl} ; \mathrm{pH}=7.4) ;[60]=2 \mu \mathrm{M}$, $\lambda_{\text {ex }}=315 \mathrm{~nm}$; a) fluorescence emission spectra as a function of added DMPC vesicles with $5 \mathrm{~mol} \%$ benzyl viologen $\mathrm{b}$ ) fit of the titration data at $\lambda_{\mathrm{em}}=429 \mathrm{~nm}$ to a single-site binding isotherm; $\mathrm{R}^{2}=0.999 ; \mathrm{K}_{\mathrm{d}}=4.16 \mathrm{E}-6 \mathrm{M} ; \mathrm{K}_{\mathrm{a}}=241,000 \mathrm{M}^{-1}$.

Dihexylamine showed an initial binding towards a maxima, and then showed an increase in the fluorescence. The accompanying decrease in fluorescence was only about $5 \%$, with the increase returning the fluorescence to near its initial status. A similar observation was observed with octylamine vesicles. Both spectrums were still accompanied by a blue shift, as observed in all previous titrations. 

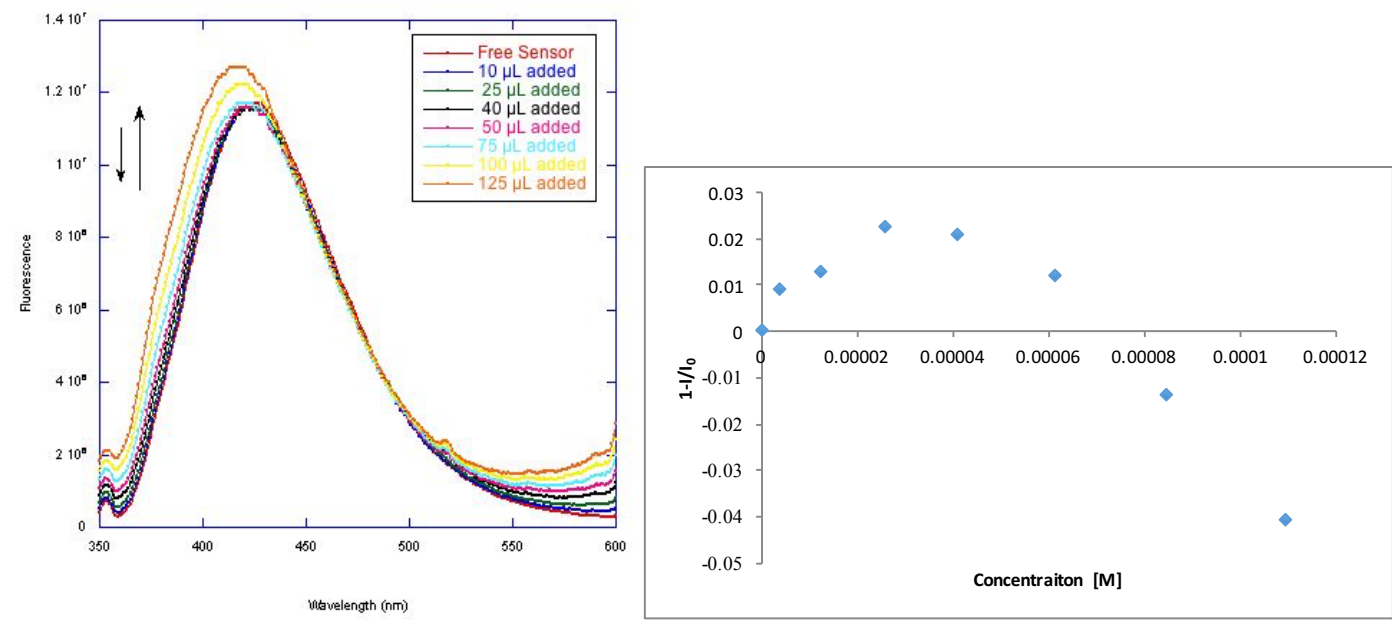

Figure 4.30: Fluorescence titration of sensor 60 with DMPC vesicles with $5 \mathrm{~mol} \%$ octylamine in buffer (25 mM HEPES, $120 \mathrm{mM} \mathrm{NaCl}$; $\mathrm{pH}=7.4) ;[\mathbf{6 0}]=2 \mu \mathrm{M}, \lambda_{\mathrm{ex}}=315$ $\mathrm{nm}$; a) fluorescence emission spectra as a function of added DMPC vesicles with $5 \mathrm{~mol} \%$ Octylamine, b) titration data at $\lambda_{\mathrm{em}}=429 \mathrm{~nm}$.

Dodecyltrimethylammoniumbromide was also tested in vesicles. This analyte was expected to produce an increase in fluorescence on binding, as the amine cannot quench the fluorescence. A binding event and increase in fluorescence was observed along with another phenomena. The binding isotherm appears to show an initial biding event, followed by a linear increase in the fluorescence (Figure 4.31). While UV data was not obtained for this analyte, a similar observation was observed with the free analyte dodecylamine. 

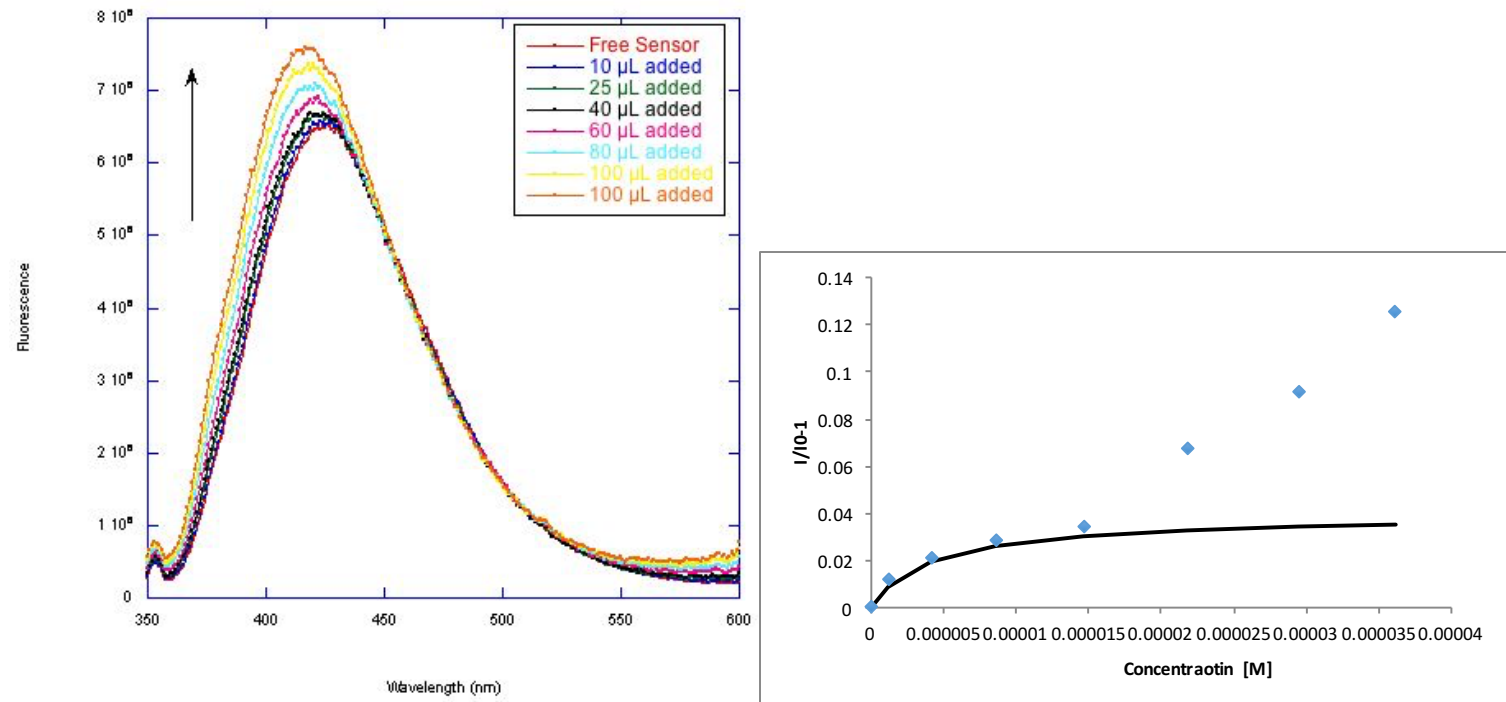

Figure 4.31: Fluorescence titration of sensor 62 with DMPC vesicles with 5 mol\% dodecyltrimethylammonium bromide in buffer $(25 \mathrm{mM}$ HEPES, $120 \mathrm{mM} \mathrm{NaCl}$; $\mathrm{pH}=$ 7.4); $[\mathbf{6 0}]=2 \mu \mathrm{M}, \lambda_{\mathrm{ex}}=315 \mathrm{~nm}$; a) fluorescence emission spectra as a function of added DMPC vesicles with $5 \mathrm{~mol} \%$ dodecyltrimethylammonium bromide, b) titration data at $\lambda_{\mathrm{em}}=429$.

We decided to pursue a biological lipid, sphingosine, to more closely resemble a biological system. However, the analyte in vesicles did not fit a binding isotherm or show a trend in the fluorescence binding. Decylamine, dodecylamine, 1,8-diaminooctane, 5nonylamine and 4-heyptylamine were also tested in vesicles; however, they did not fit a binding isotherm nor did they have a significant effect on the fluorescence as represented with the other examined analytes. 
Table 4.4: Binding constants of sensor 62 with vesicle/analyte systems

\begin{tabular}{|c|c|c|c|c|c|}
\hline Entry & Guest & $\begin{array}{c}\text { phospholipid } \\
\text { system }\end{array}$ & $K_{d}(M)$ & $\underset{1}{\mathrm{~K}_{\mathrm{a}}\left(\mathrm{M}^{-}\right.}$ & $\begin{array}{c}I_{\text {sat }} / I \\
0\end{array}$ \\
\hline 1 & 1,10-diaminodecane & DMPC & $\begin{array}{l}1.31 \mathrm{E}- \\
5\end{array}$ & 77,000 & 0.25 \\
\hline 2 & 1,10-diaminodecane & DMPC/DMPS & $\begin{array}{l}1.35 \mathrm{E}- \\
5\end{array}$ & 74,000 & 0.27 \\
\hline 3 & 1,10-diaminodecane & DMPC/cholesterol & $\begin{array}{l}9.63 \mathrm{E}- \\
6\end{array}$ & $\begin{array}{r}104,00 \\
0\end{array}$ & 0.23 \\
\hline 4 & benzyl viologen & DMPC & $\begin{array}{l}4.16 \mathrm{E}- \\
6\end{array}$ & $\begin{array}{r}241,00 \\
0 \\
\end{array}$ & 0.73 \\
\hline 5 & octylamine & DMPC & - & - & - \\
\hline 6 & $\begin{array}{l}\text { dodecyltrimethylammonium } \\
\text { bromide }\end{array}$ & DMPC & - & - & - \\
\hline 7 & sphingosine & DMPC & - & - & - \\
\hline 8 & decylamine & DMPC & - & - & - \\
\hline 9 & dodecylamine & DMPC & - & - & - \\
\hline
\end{tabular}

\subsubsection{Future Work}

The fluorescent labeled amine lipids in Figure 4.32 will be synthesized and titrations will be carried out with the alanine sensor in vesicles. If this proves successful, an experiment using dialysis membranes will be used to fully ascertain the capability of the sensor to extract these lipids, and ensure it is successfully happening.<smiles>CCCCCCCCCCNc1ccc([N+](=O)[O-])c2nonc12</smiles><smiles>CCCCCCCCCCNS(=O)(=O)c1cccc2c(N(C)C)cccc12</smiles>

Figure 4.32: Fluorescent lipids 


\subsection{Conclusion}

We have synthesized an open tube alanine sensor that shows binding to hydrophobic amines with one or two lipid tails. Furthermore, this sensor has proven to be capable of extracting some of the selected amines from vesicles, without embedding itself into the membrane. This indicates that the alanine amphiphilic sensors design worked as expected. 


\section{Chapter 5 Molecular Tubes for the Detection of Glycolipids}

\subsection{Molecular Tubes for the Sensing of Glycolipids}

Our group has long been interested in developing fluorescent sensors for biologically relevant lipids. One of these aims is to develop a sensor for glycolipids. As discussed earlier, molecular recognition can use the process of both non-covalent and covalent interactions for the recognition of analytes. Glycolipids contain either a sugar or carbohydrates as the polar head group and a non-polar alkyl chain, and our sensor is designed to bind both groups. As mentioned earlier, phenylboronic acids are well known to bind to saccharides and this will be appended to the already designed molecular open tube for its detection, Figure 5.1. The fluorine substituent is used to adjust the $\mathrm{pK}_{\mathrm{a}}$ of the phenylboronic acid $\left(\mathrm{pK}_{\mathrm{a}}=8.8\right)$ towards the physiological range.

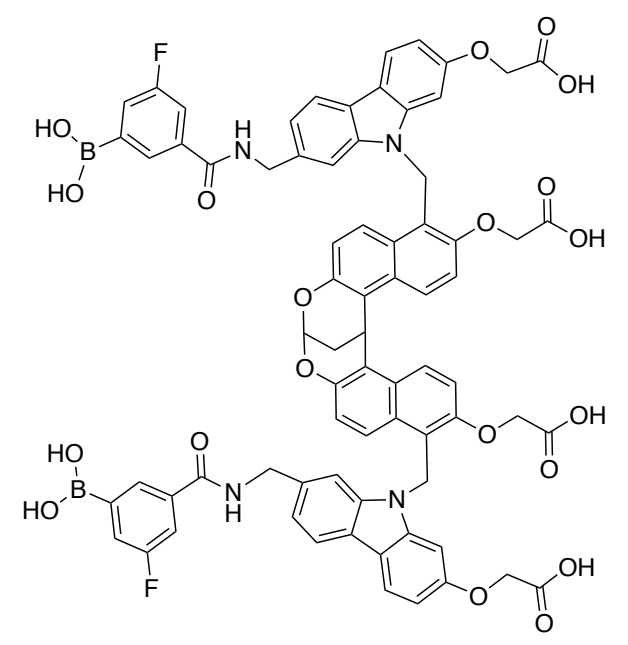

Figure 5.1: Originally designed glycolipid sensor

The original synthesis of the sensor began with an aldehyde-based carbazole with an ethyl ester (Scheme 5.2). The aldehyde was to be reacted with an amine, to later install the phenylboronic acid to via an amide bond formation reaction with a carboxylic acid appended phenyl boronic acid. Earlier in our group we found that the reaction of the open 
tube aldehyde with methyl amine caused an intramolecular reaction upon the first addition, creating a cyclic tube and only installing one amine (Scheme 5.1). Furthermore, use of a boc protected amine lead to complicated mixtures of products upon the deprotection that were unable to be determined or separated.

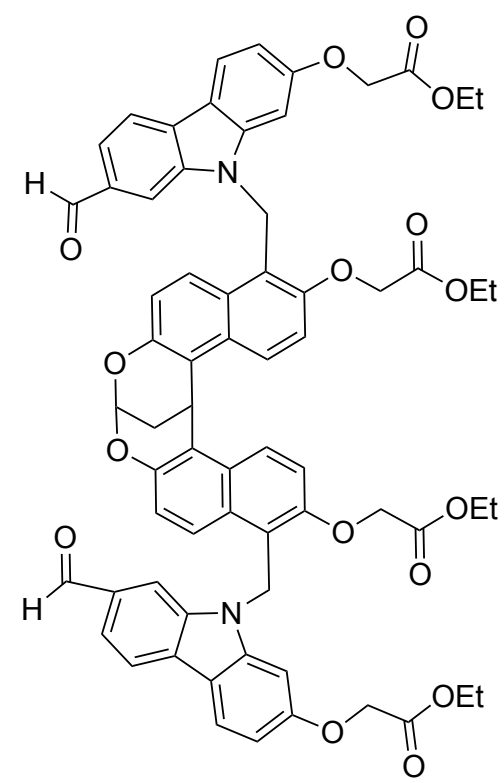

61
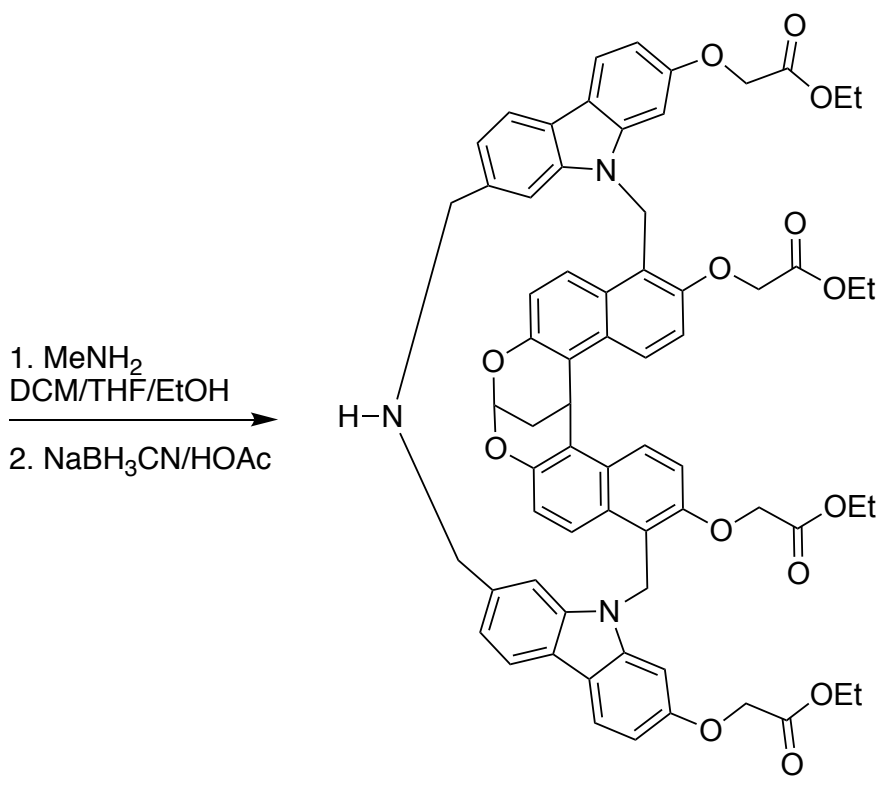

62

Scheme 5.1: Open aldehyde tube intramolecular reaction

With this in mind we attempted an alternative approach to installing a protected amine using an F-moc derivative, using triethysilane (TES) as a hydride source, which also proved unsuccessful. During these attempts solubility was believed to be a problem for the process of the reaction, and thus the ethyl ester was replaced with a hexyl ester in the synthesis and was kept for future syntheses. 


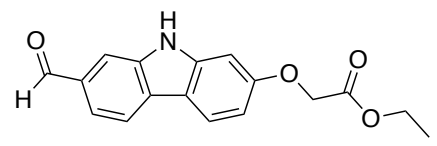

62

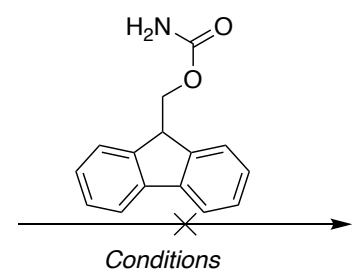

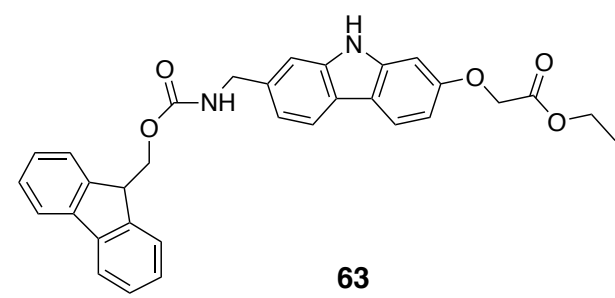

63

Scheme 5.2: Ethyl carbazole aldehyde Fmoc reactivity

Table 5.1: Ethyl carbazole aldehyde Fmoc reaction conditions

\begin{tabular}{|c|c|c|c|c|c|c|}
\hline Entry & Reagents & Equiv. & $\begin{array}{l}\text { Equiv. } \\
\text { FMOC- } \\
\text { amide }\end{array}$ & Solvent & ${ }^{\circ} \mathbf{C}$ & Result \\
\hline 1 & TFA, TES & $\begin{array}{l}6.2 \\
2.98\end{array}$ & 2.8 & $\mathrm{DCM} / \mathrm{MeCN}$ & 80 & $\begin{array}{l}\text { not enough } \\
\text { product to } \\
\text { identify }\end{array}$ \\
\hline 2 & TFA, TES & $\begin{array}{l}7.15 \\
10.7 \\
\end{array}$ & 10 & DCM/MeCN & r.t. & recovered SM \\
\hline 3 & TFA, TES & $\begin{array}{l}13.3 \\
13.2\end{array}$ & 10.2 & $\mathrm{DCM} / \mathrm{MeCN}$ & r.t. & $\begin{array}{l}\text { complex mixture, } \\
\text { unable to separate }\end{array}$ \\
\hline 4 & TFA, TES & 8,8 & 5 & $\mathrm{DCM} / \mathrm{MeCN}$ & r.t. & returned SM \\
\hline 5 & TFA, TES & $\begin{array}{l}13.4 \\
13.3\end{array}$ & 10 & $\mathrm{DCM} / \mathrm{MeCN}$ & r.t. & $\begin{array}{l}\text { incomplete rxn, } \\
\text { unable to separate }\end{array}$ \\
\hline 6 & $\begin{array}{l}\mathrm{Re}_{2} \mathrm{O}_{7}, \\
\text { TES }\end{array}$ & $.02,1.2$ & 1.2 & $\mathrm{DCM} / \mathrm{MeCN}$ & r.t. & no reaction \\
\hline 7 & $\begin{array}{c}\mathrm{Re}_{2} \mathrm{O}_{7}, \\
\mathrm{TES}\end{array}$ & $.02,4.5$ & 1.2 & $\mathrm{DCM} / \mathrm{MeCN}$ & r.t. & no reaction \\
\hline 8 & $\begin{array}{c}\mathrm{Re}_{2} \mathrm{O}_{7} \\
\text { TES }\end{array}$ & $\begin{array}{l}.009 \\
1.2\end{array}$ & 1.2 & DCM & 32 & no reaction \\
\hline
\end{tabular}

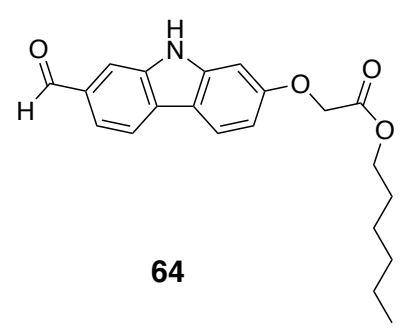

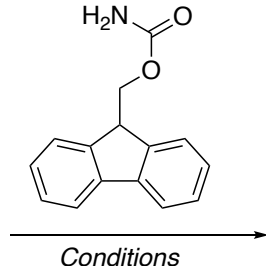

Conditions

Scheme 5.3: Hexyl carbazole aldehyde Fmoc reactivity

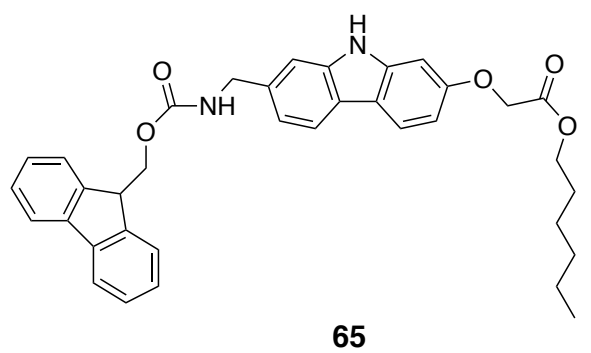


Table 5.2: Hexyl carbazole aldehyde Fmoc reaction conditions

\begin{tabular}{|r|l|l|l|l|r|l|}
\hline Entry & Reagents & Equiv. & $\begin{array}{l}\text { Equiv. } \\
\text { FMOC- } \\
\text { amide }\end{array}$ & Solvent & ${ }^{\circ} \mathbf{C}$ & Result \\
\hline & $\begin{array}{l}\text { thiourea, } \\
\text { Hantzsch } \\
\text { ester }\end{array}$ & $.45,1.16$ & 1 & DCM & 35 & SM returned \\
\hline 2 & $\begin{array}{c}\mathrm{Re}_{2} \mathrm{O}_{7}, \\
\mathrm{TES}\end{array}$ & $.015,1.2$ & 1.2 & $\mathrm{DCM}$ & r.t. & SM returned \\
\hline 3 & $\begin{array}{c}\text { TFA, } \\
\text { TES }\end{array}$ & 5,5 & 5 & DCM/MeCN & r.t. & $\begin{array}{l}\text { NMR (impure) \& MS } \\
\text { indicates product }\end{array}$ \\
\hline
\end{tabular}

As the reaction appeared to work on the hexyl carbazole aldehyde an attempt was made to do the reaction on the aldehyde tube, which proved unsuccessful.

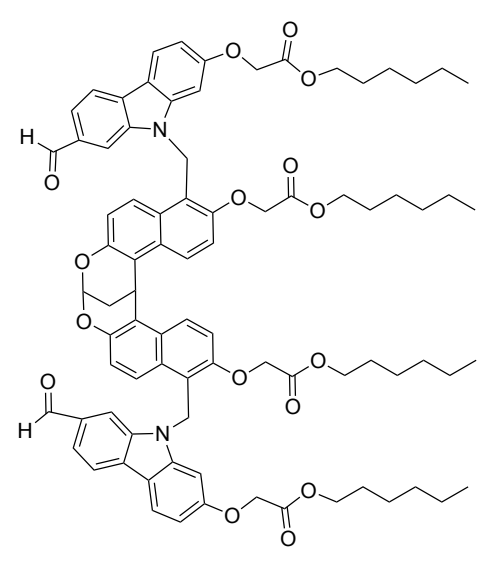

66

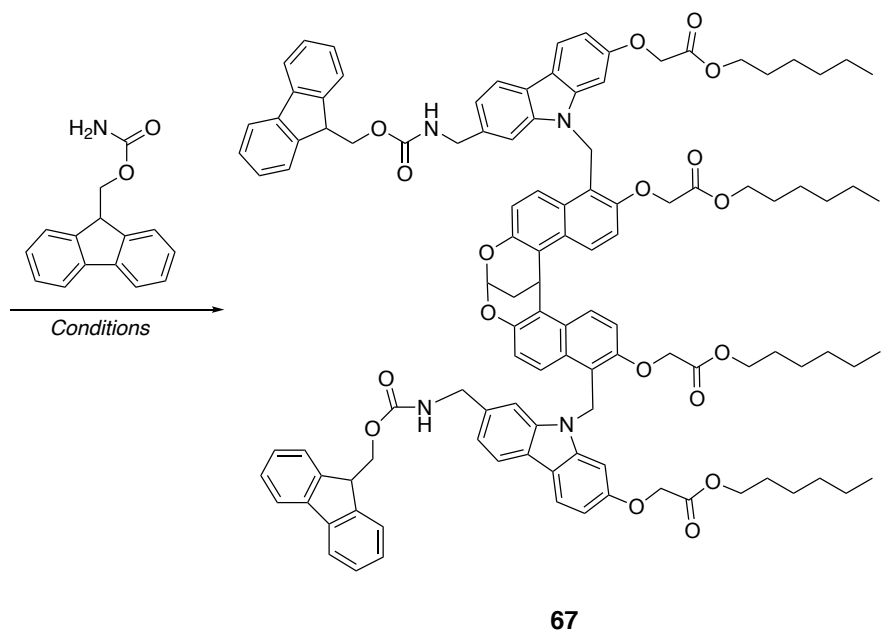

67

Scheme 5.4: Aldehyde tube reaction with Fmoc 
Table 5.3: Aldehyde tube reaction conditions

\begin{tabular}{|c|c|c|c|c|c|c|}
\hline Entry & Reagents & Equiv. & $\begin{array}{l}\text { Equiv. } \\
\text { FMOC- } \\
\text { amide }\end{array}$ & Solvent & ${ }^{\circ} \mathrm{C}$ & Result \\
\hline 1 & $\begin{array}{l}\text { TFA, } \\
\text { TES }\end{array}$ & 16,16 & 16 & $\mathrm{DCM} / \mathrm{MeCN}$ & r.t. & returned SM \\
\hline 2 & $\begin{array}{l}\text { TFA, } \\
\text { TES }\end{array}$ & 35,34 & 20 & $\mathrm{DCM} / \mathrm{MeCN}$ & 40 & complex mixture \\
\hline 3 & $\begin{array}{l}\text { TFA, } \\
\text { TES }\end{array}$ & 35,35 & 10 & $\mathrm{DCM} / \mathrm{MeCN}$ & r.t. & recovered SM \\
\hline 4 & $\begin{array}{l}\text { TFA, } \\
\text { TES }\end{array}$ & 35,34 & 20 & $\mathrm{DCM} / \mathrm{MeCN}$ & r.t. & recovered SM \\
\hline 5 & $\begin{array}{l}\text { TFA, } \\
\text { TES }\end{array}$ & 40,40 & 30 & DCE, MeCN & 65 & SM returned \\
\hline 6 & $\begin{array}{l}\text { TFA, } \\
\text { TES }\end{array}$ & 30,30 & 10 & DCE, MeCN & 79 & $\begin{array}{l}\text { no product upon } \\
\text { deprotection }\end{array}$ \\
\hline 7 & $\begin{array}{l}\text { TFA, } \\
\text { TES }\end{array}$ & 40,40 & 25 & DCE, MeCN & 80 & SM returned \\
\hline 8 & $\begin{array}{l}\text { TFA, } \\
\text { TES }\end{array}$ & 30,30 & 15 & DCE, MeCN & 80 & SM returned \\
\hline
\end{tabular}

Because installing an amine to react with a carboxylic acid functionalized phenylboronic acid was proving unsuccessful, we attempted to react the carbazole aldehyde with an amine functionalized phenylboronic acid. This attempt also proved unsuccessful, either returning starting materials or reducing the aldehyde to the alcohol.<smiles>CCCCCCOC(=O)COc1ccc2c(c1)[nH]c1cc(C=O)ccc12</smiles>

64

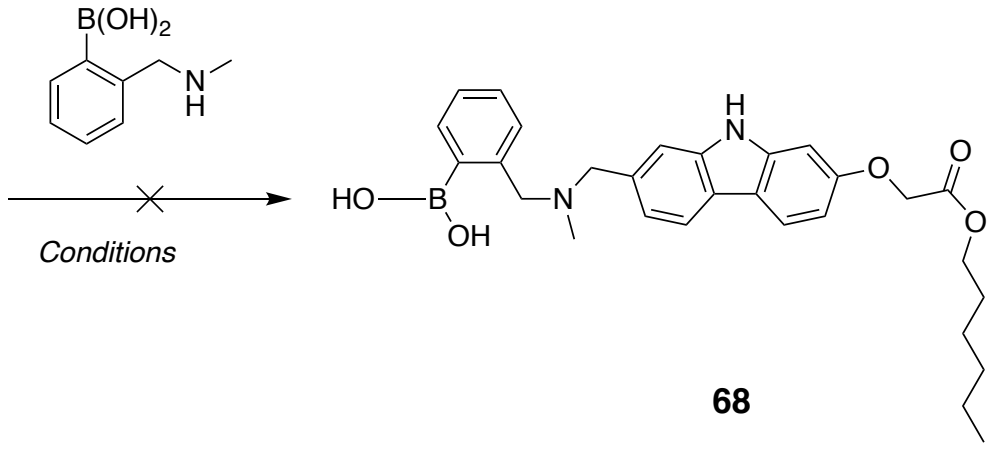

Scheme 5.5: Carbazole reductive amination with amino phenylboronic acid 
Table 5.4: Amino phenylboronic acid reductive amination reaction conditions

\begin{tabular}{|c|c|c|c|c|c|c|}
\hline Entry & Reagents & Equiv. & $\begin{array}{l}\text { Equiv. } \\
\text { Amine }\end{array}$ & Solvent & ${ }^{\circ} \mathrm{C}$ & Result \\
\hline 1 & $\mathrm{NaBH}_{3} \mathrm{CN}$ & 1.1 & 1.1 & DCE & r.t. & SM returned \\
\hline 2 & $\mathrm{NaBH}_{4}$ & 0.62 & 1.5 & $\mathrm{MeOH}$ & r.t. & $\begin{array}{l}\text { obtained alcohol and } \\
\text { ester exchange }\end{array}$ \\
\hline 3 & $\mathrm{NaBH}(\mathrm{OAc})_{3}$ & 1.4 & 1 & DCE & r.t. & SM returned \\
\hline \multirow[t]{2}{*}{4} & $\mathrm{AcOH}$ & Cat. & & $\begin{array}{l}\text { Tolulene, } \\
\text { Ethanol }\end{array}$ & reflux & \\
\hline & $\mathrm{NaBH}_{4}$ & 1.2 & & THF & r.t. & no product formation \\
\hline 5 & $\begin{array}{l}\mathrm{NaBH}_{3} \mathrm{CN}, \\
\mathrm{AcOH}\end{array}$ & $\begin{array}{l}1.2, .5 \\
\mathrm{~mL}\end{array}$ & 1.3 & $\begin{array}{l}\text { DCM, THF, } \\
\text { EtOH }\end{array}$ & 80 & no product formation \\
\hline 6 & $\begin{array}{l}\mathrm{NaBH}_{3} \mathrm{CN} \\
\mathrm{AcOH}\end{array}$ & $\begin{array}{l}1.1, .25 \\
\mathrm{~mL}\end{array}$ & 1 & $\begin{array}{l}\text { THF, EtOH, } \\
\text { DCE }\end{array}$ & 66 & alcohol formed \\
\hline
\end{tabular}

Given that a reductive amination approach was not fruitful, the aldehyde group was replaced with a protected carboxylic acid group that could later be orthogonally deprotected to react with an amine for an amide bond formation reaction as was used previously with the amine sensor. This gave us $\mathbf{6 9}$ as a material for both sensors, which can then be reacted with an amino boronic acid to provide the tetra ester boronic acid, which can then be saponified to provide the final product.

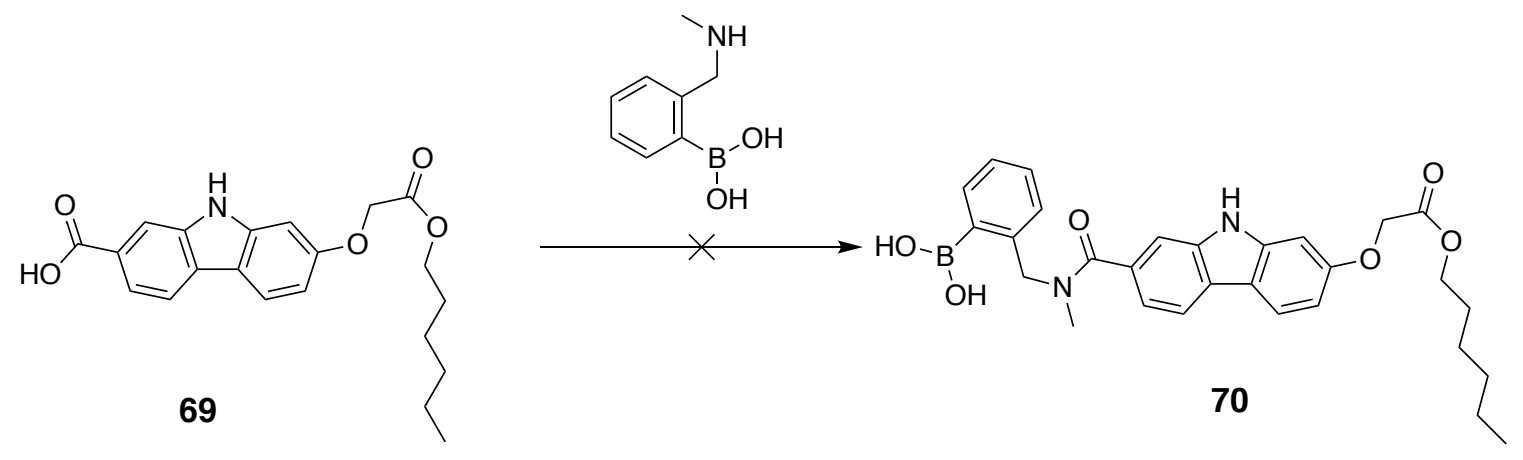

Scheme 5.6: Aminoboronic acid amide bond formation 
Table 5.5: Aminoboronic acid amide bond reaction conditions and results

\begin{tabular}{|c|c|c|c|c|c|c|}
\hline Entry & Reagents & Equiv. & $\begin{array}{l}\text { Equiv. } \\
\text { Amine }\end{array}$ & Solvent & ${ }^{\circ} \mathbf{C}$ & Result \\
\hline 1 & $\begin{array}{l}\text { Pybop, } \\
\text { DIPEA }\end{array}$ & $1.2,2.0$ & 1.1 & DMF & r.t. & Lost boron \\
\hline 2 & $\begin{array}{l}\text { Pybop, } \\
\text { DIPEA }\end{array}$ & $1.2,2.0$ & 1.1 & DMF & r.t. & Lost boron \\
\hline
\end{tabular}<smiles>CCCCCCOC(=O)COc1ccc2c(c1)[nH]c1cc(C(=O)O)ccc12</smiles><smiles>CCCCCCOC(=O)COc1ccc2c(c1)[nH]c1cc(C(=O)NCc3ccc(F)cc3B(O)O)ccc12</smiles>

Scheme 5.7: Fluoroaminoboronic acid amide bond formation

Table 5.6: Fluoroaminoboronic acid amide bond reaction conditions and results

\begin{tabular}{|c|c|c|c|c|c|c|}
\hline Entry & Reagents & Equiv. & $\begin{array}{l}\text { Equiv. } \\
\text { amine }\end{array}$ & Solvent & ${ }^{\circ} \mathbf{C}$ & Result \\
\hline 1 & EDC, HOBt, TEA & $\begin{array}{ll}1.2 & 1.2, \\
2.5 & \end{array}$ & 1 & DMF & r.t. & 67\% HPLC yield \\
\hline 2 & EDC, HOBt, TEA & $\begin{array}{ll}1.2, & 1.2, \\
3.5 & \end{array}$ & 1 & $\mathrm{DMF}$ & r.t. & 71\% HPLC yield \\
\hline
\end{tabular}


Changing the methylaminomethylphenylboronic acid to a fluorine substituted aminomethylphenylboronic acid proved successful. While the above reaction worked, it did not work on the dicarboxylic acid tube. While the crude product from that reaction looked reasonable via ${ }^{1} \mathrm{H}$ NMR, LC-MS did not identify the product. Further saponification of the crude product yielded a product by ${ }^{1} \mathrm{H}$ NMR that was unable to be determined, nor was LC-MS analysis successful. Later attempts to repeat the coupling reaction on the carbazole proved unsuccessful and therefore an alternative coupling reagent was pursued.

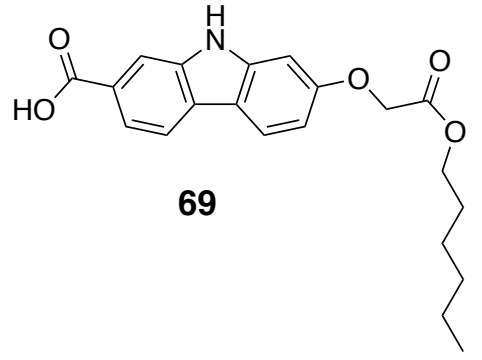

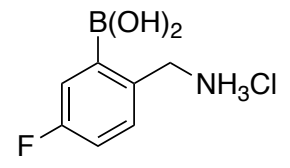

Conditions<smiles>CCCCCCOC(=O)COc1ccc2c(c1)[nH]c1cc(C(=O)NCc3ccc(F)cc3B(O)O)ccc12</smiles>

Scheme 5.8: Fluoroaminoboronic acid amide bond formation with new reagent

Table 5.7: Fluoroaminoboronic acid reaction conditions and results

\begin{tabular}{|l|l|l|l|l|l|l|}
\hline Entry & Reagents & Equiv. & Equiv. & Solvent & ${ }^{\circ} \mathbf{C}$ & Result \\
\hline 1 & HATU & 1.2 & 1.2 & DMF & r.t. & $14 \%$ HPLC yield, 6\% side \\
& DIPEA & 3 & & & & product \\
\hline 2 & HATU & 2 & 4 & DMF & r.t. & $30 \%$ HPLC yield, 16\% side \\
\hline
\end{tabular}


The coupling reagent was changed to HATU and product formation was found, however, in low yield, with a side product. The first attempt gave $14 \%$ yield, with $6 \%$ side product by HPLC and the second attempt gave an increased yield in both product and side product. The side product was determined to have the boron replaced with an alcohol (Figure 5.2), as no boron was present via ${ }^{11} \mathrm{~B} \mathrm{NMR}$, and this product was identified via mass spectroscopy. Further analysis of a previous mass spectrum with the EDC coupling reagent showed this product was also forming in those early reactions as well.

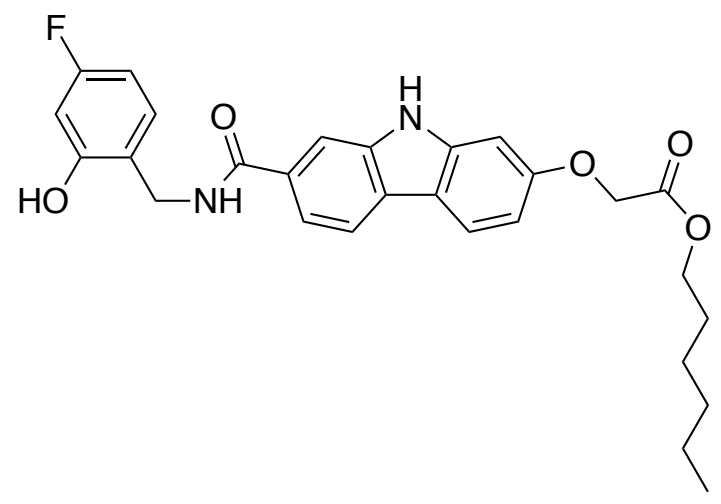

Figure 5.2: Side product obtained from amide bond formation reactions with boronic acid

As an unprotected boronic acid was giving us problems in the amide bond formation, we decided to use a pinacol boronic acid in our synthesis, also allowing us to eliminate the HPLC purification. 


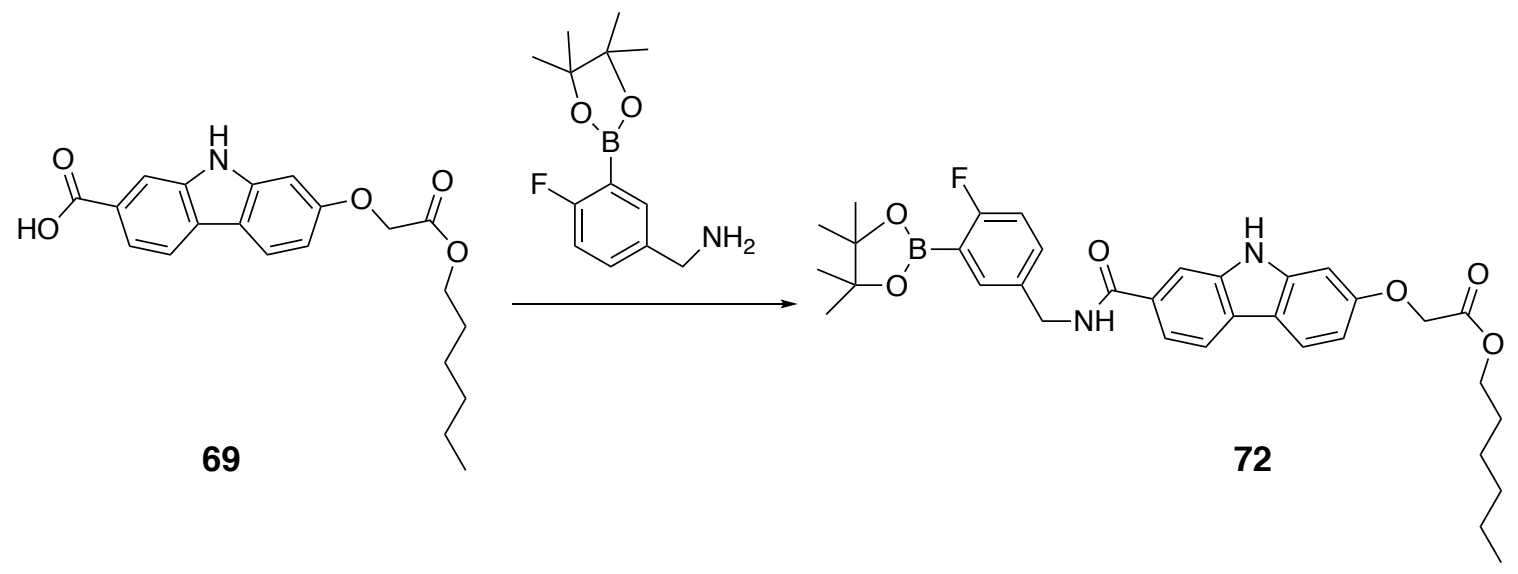

Scheme 5.9: Pinacol boronic acid amide bond formation

Table 5.8: Pinacol boronic acid amide bond reaction conditions and results

\begin{tabular}{|r|c|c|c|c|c|l|}
\hline Entry & Reagents & Equiv. & amine & solvent & ${ }^{\circ} \mathbf{C}$ & Result \\
\hline & & & & & & \\
& HATU & 1.2 & & & & \\
1 & DIPEA & 3.5 & 2.0 & DMF & r.t. & $43 \%$ yield \\
\hline & HATU & 1.2 & & & & \\
2 & DIPEA & 3.5 & 2.0 & DMF & r.t. & $25 \%$ yield \\
\hline & HATU & 1.1 & & & & \\
3 & DIPEA & 3.5 & 2.0 & DMF & r.t. & $38 \%$ yield \\
\hline
\end{tabular}

The reaction also appeared to work, however, in low yield and the crude mass spec also indicated presence of the aforementioned alcohol product. Given the low yield, it would not be ideal to perform the reaction on the carboxylic acid tube, as the resulting product would have a yield below 16\%. Therefore a more convergent approach was attempted, using the carbazole product to react with the dibromide (Figure 5.3). 
72
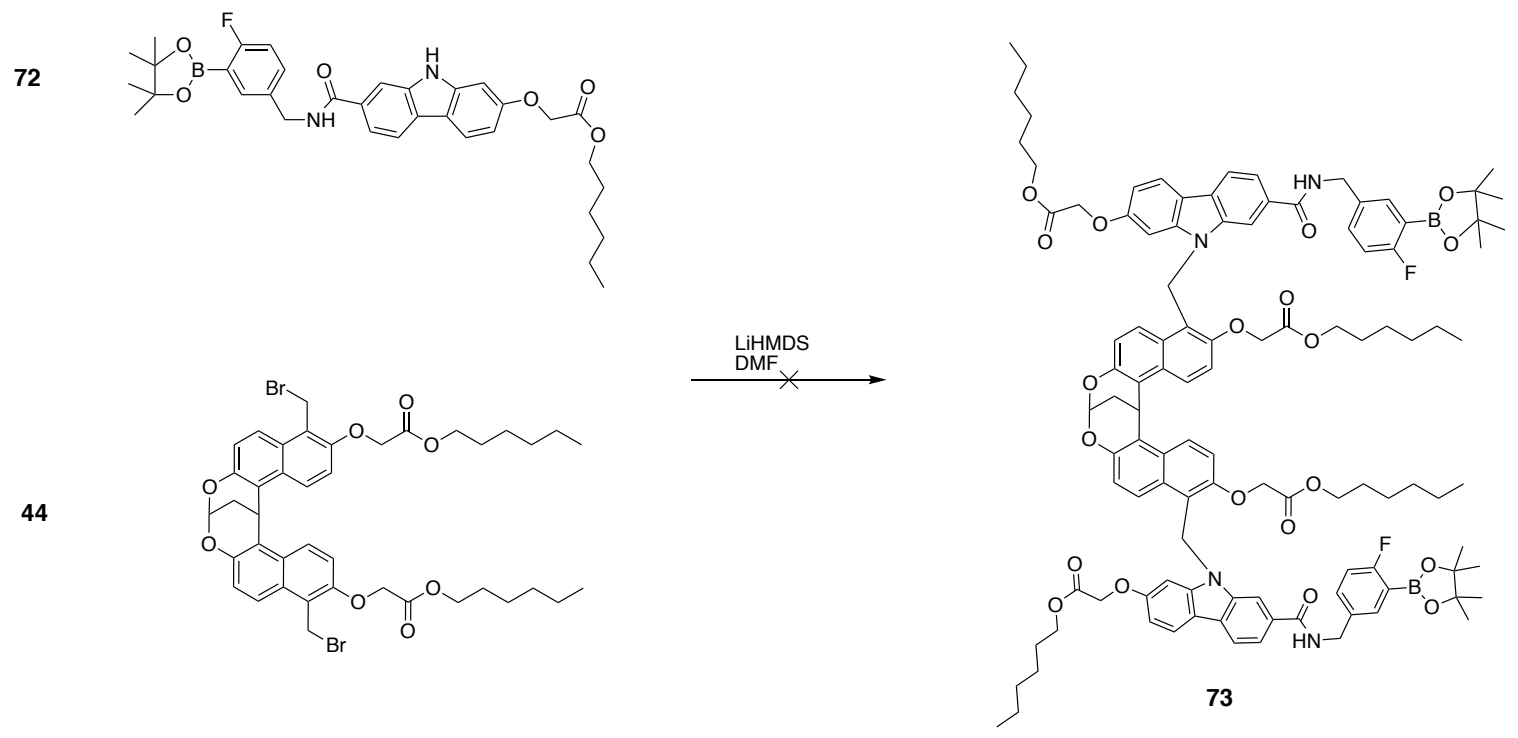

Figure 5.3: Formation of pinacol tetraester tube

Reacting the carbazole phenyl boronic acid with the dibromide proved to be unsuccessful. LC-MS and MS analysis did not indicate any product formation, however it did indicate the presence of the carbazole starting material and the carbazole alcohol product.

\subsection{Future Work}

As a convergent attempt was not successful in synthesizing the pinacol boronic acid tube, we plan to pursue the reaction with (3-bromo-4fluorophenyl)methanamine, followed by a Miyuara Borylation reaction to install the boronic acid or pinacol boronic acid. The reaction series will first be tested on the carbazole acid and if successful will then be carried out on the carboxylic acid tube. 

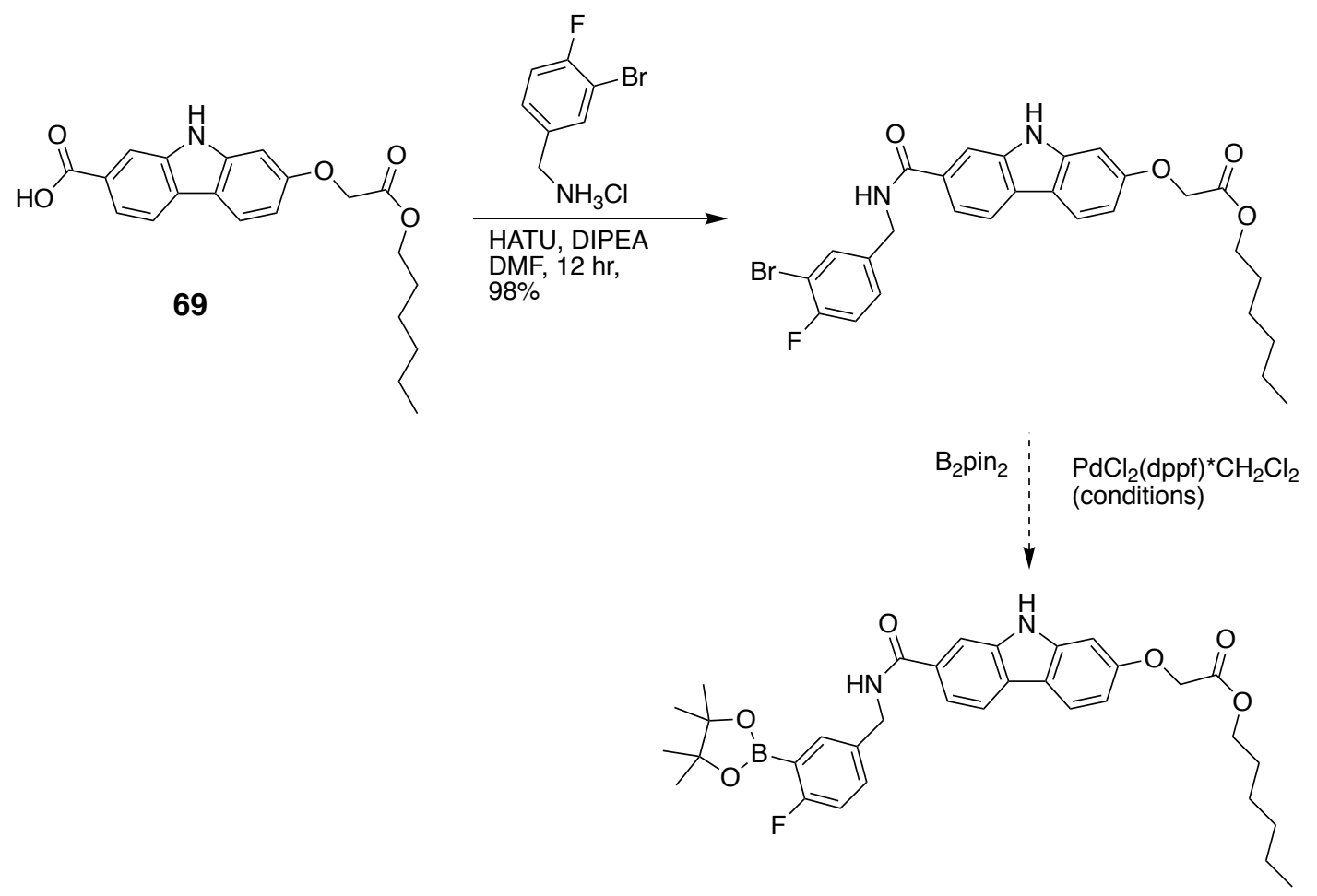

Scheme 5.10: Miyaura borylation approach for carbazole acid
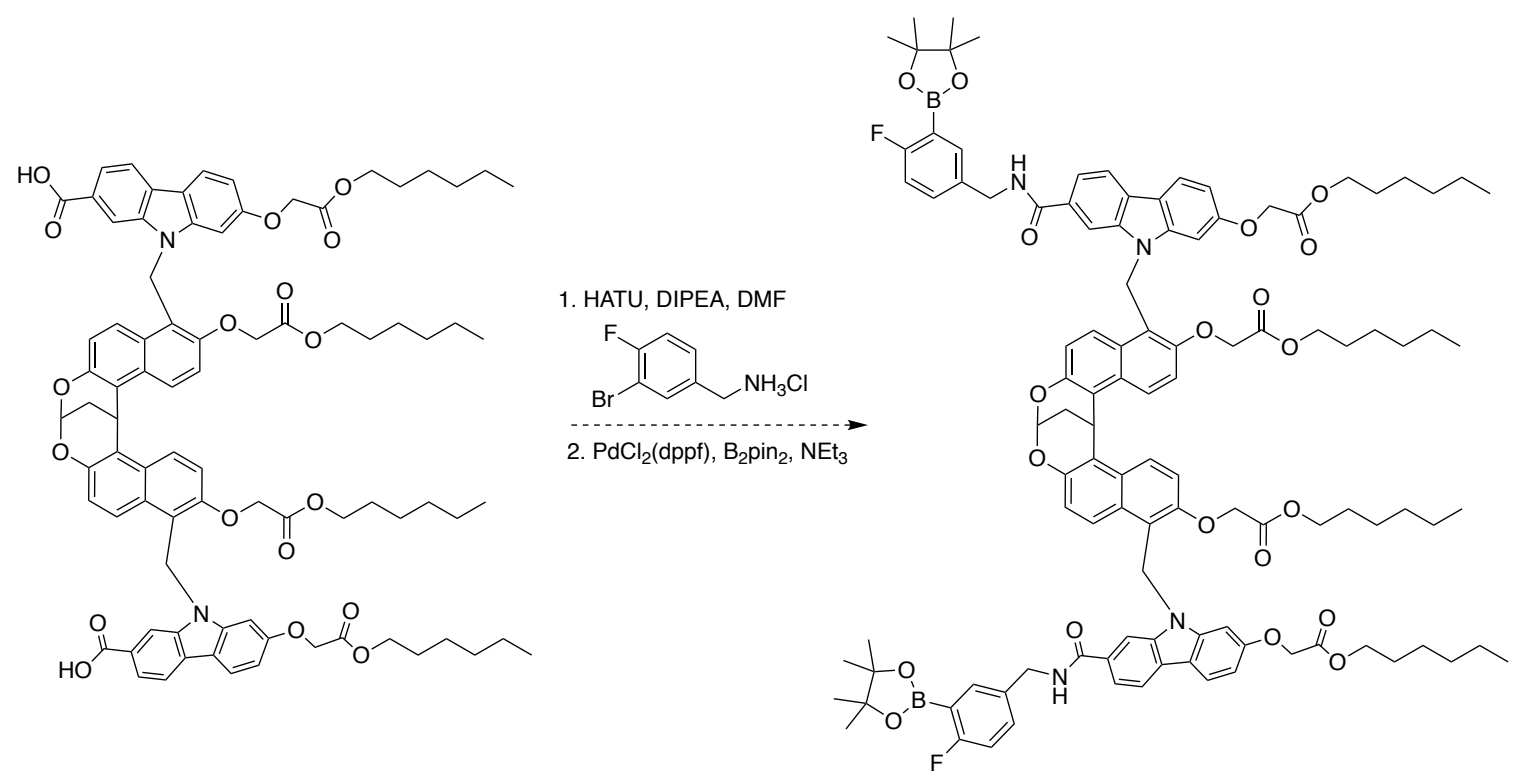

Scheme 5.11: Miyaura borylation approach for tube diacid

If the Miyaura approach proves successful, the resulting pinacol boronic acid tube product will be saponified (Scheme 5.12) to obtain the final tetraacid pinacol 
boronic acid product. This product will then be used for the titrations of the glycolipids (Figure 5.4) both as free analytes and in phospholipid vesicles. If the titrations prove successful, the sensor will then be tested for the ability to extract Forssmann's antigen from sheep blood.

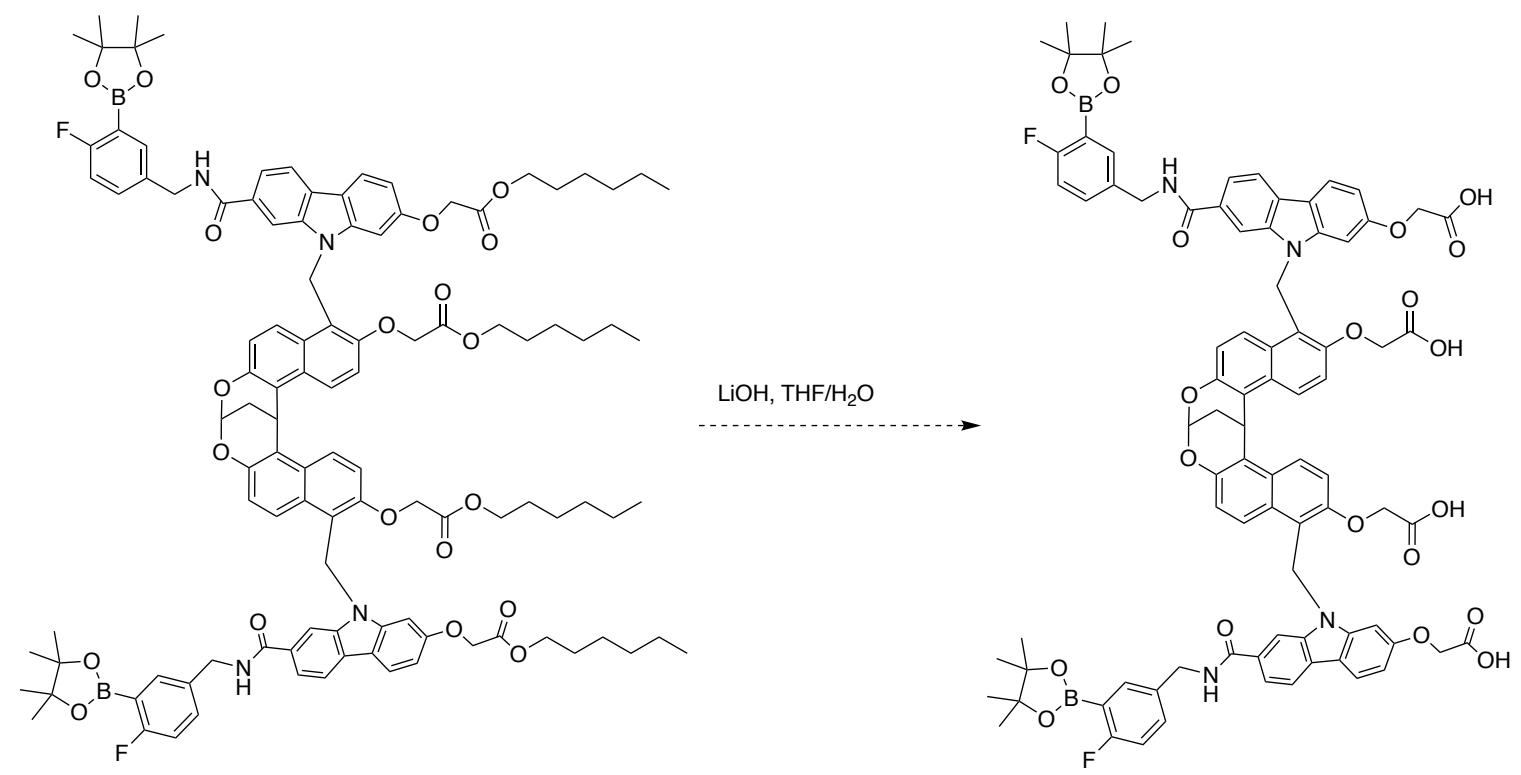

Scheme 5.12: Pinacol boronic acid tube saponification<smiles>CCCCCCCOC1OC(CO)C(O)C(O)C1O</smiles>

octyl-B-D-glucopyranoside<smiles>CCCCCCCCCCCOC1OC(CO)C(O)C(O)C1O</smiles>

n-dodecyl-ß-D-glucopyranoside

Figure 5.4: Glycolipids to be tested 


\section{Chapter 6 Conclusions}

In the course of this project, we have accomplished the ability to bind to hydrophobic lipid chains in aqueous environments. The initial goal of our project was to create a fluorescent sensor that was selective towards hydrophobic tails. Our desire was to apply this sensor for fluorescent sensing of biologically relevant lipids. This would be accomplished by attaching a head-group recognition site the sensor, providing two interaction sites: the hydrophobic cavity and the head-group binding site. To bind to these lipids it would also be necessary to design the sensor have a hydrophobic cavity, yet not embed into membranes. If successful, such a sensor could have many potential applications in biological systems upon further modifications.

Sensor $\mathbf{2 4 / 2 5}$ and $\mathbf{3 2 / 3 3}$ provided a large hydrophobic cavity that encapsulated a hydrophobic guest. They bound better to longer chain guests, however, they were unable to tolerate branching or alkene chains. The amide $\mathbf{2 4 / 2 5}$ sensor was believed to collapse in solution and bound weaker than $\mathbf{3 2 / 3 3}$, which was much more rigid and remained open in solution. The $\mathrm{K}_{\mathrm{a}}$ for the allyl tube $\mathbf{3 2} / \mathbf{3 3}$ reached $10^{6} \mathrm{M}^{-1}$ for some analytes and higher for heptylamine. These binding constants were within what we expected the physiological range to be for some of our biological analytes such as glycolipids. While these sensors displayed good properties, our group wanted a sensor that was easier to synthesize that could bind to two tails. This led us to the design of our next sensor.

The tetraacid sensor was designed similar to the open tube sensor bearing some changes. Instead of linking to naphthalene units together by a bridge, which would create a closed tube, we modified the original sensor to attach a carbazole unit to the naphthalene core by a one-atom linker. This one atom connection allowed for some 
flexibility without allowing the new "open" tube to collapse on itself. The carbazole is easy to synthesize, contributing to the hydrophobic nature of the cavity and still allowing the binding of the intended guests. The synthesis of the new sensor is short, allowing modifications to attach a head-group binding unit for the different intended biological analytes. It remains fluorescent in the UV region but slightly redder than the naphthalene. This new sensor remained water-soluble and the binding studies showed that it bound to long hydrophobic chains of 10 or 12 carbon amines with $\mathrm{K}_{\mathrm{a}}$ on the order of $10^{6} \mathrm{M}^{-1}$ as well, and accommodated alkenes and branching. While the sensor was easier to synthesize and tolerated branching, which could permit binding a second chain, the hydrophobic nature of the sensor would allow it to embed into membranes. This led to the design of a new sensor.

Sensor $\mathbf{6 0}$ was designed to ensure it would not embed into a membrane by appending the hydrophobic end of the tetraacid sensor with charged groups. Sensor 60 was fluorescent with a maximum of $429 \mathrm{~nm}$ and an absorption maximum of $315 \mathrm{~nm}$. The sensor bound to diamines best, with the longer chain 1,10-diamiondecane binding better than shorter chains, all providing a PET quenching effect with Ka's near $10^{6} \mathrm{M}^{-1}$.

Amines tested with the previous tetra acid sensor such as dodecylamine did not fit a binding isotherm, but the PET quenching effect was present providing a fluorescence decrease. The binding isotherm showed an initial plateau, followed by a linear increase afterwards. The UV showed an increase in absorption, which was followed by a decrease below the initial free sensor maximum. This we attributed to the sensor analyte complex falling out of solution, most likely due to the binding of two analytes; this would create a large carbon content in water that could make it oil out of solution. Decylamine provided 
a similar response in the biding isotherm and fluorescence changes. The shorter amines did bind, although, binding constants were lower than with the tetraacid sensor.

Trimethyl ammonium derivatives were tested to determine if they would inhibit the binding of a second analyte. The fluorescence response was an increase instead of a decrease due to the absence of a lone pair for quenching, however, the binding isotherm still showed a linear response. The response was delayed, with the sensor being able to bind more analyte before the linear response was triggered. The UV however, showed little change with the carbazole absorption, but showed an increase with the naphthalene absorption units. While many of the other analytes provided an increase in absorption in the UV, the trimethylammonium derivatives may not have successfully repelled a second chain from entering the cavity.

We tested two chain amines to determine if two chains could bind successfully. This led to test dihexylamine, 4-heptylamine and 5-nonylamine. These all provided binding responses that fit a binding isotherm, showing a fluorescence decrease. Dihexylamine provided the largest binding constant of the three, as would be expected by its longer chain. The shorter chains still bound less poorly, as was observed with previously analytes. This result provides evidence that the hydrophobic cavity is the main driving force for the binding, followed by the association of the negatively charged carboxylates with the protonated amine.

The previously tested analytes only quenched the fluorescence about $30 \%$, so we decided to test benzyl viologen, a known quencher due to its electron poor nature, to achieve a larger quenching effect. It was shown to bind the best, with the $\mathrm{K}_{\mathrm{a}}$ reaching $10^{6}$ $\mathrm{M}$ and quenching near $90 \%$. 
These analytes were then tested for their response in vesicles. Sensor $\mathbf{6 0}$ was then tested with vesicles to ensure it would not embed into membranes. The response in fluorescence when titration with DMPC, DMPC/DMPS or $10 \mathrm{~mol} \%$ cholesterol in DMPC showed little change in fluorescence which did not fit a binding isotherm, indicating to us that we see no interaction between the sensor and the vesicles. This indicates the sensor is not embedding into the membrane and would be applicable for use in titrations.

The vesicles were then loaded with $5 \mathrm{~mol} \%$ analyte to determine if the sensor was able to remove them from the vesicles. 1,10-diaminodecane and benzyl viologen provided positive responses, which could be attributed to the fact that they had high binding constants. The fluorescence response was smaller due to the lower concentration of analyte, but binding constants were still similar to the free analyte titration quantities. Incorporation of DMPS to create an anionic vesicle appeared to have no affect on the ability to remove the amine analyte, while cholesterol enhanced the binding constant indicating it helps to facilitate the removal and binding in some way.

While it was already known that methyl cyclodextrin can remove cholesterol from membranes, there is little on removing biological lipids. This work has shown that it is possible to remove hydrophobic amine analytes from synthetically prepared lipids which have been varied in their content. The process for how this happens is unknown. It is believed that the initial interaction happens between the charged carboxylates and the amine.

As we have shown the ability to extract these amines from vesicles with sensor $\mathbf{6 0}$, the goal is to now modify the sensor to target binding biological lipids. This will be 
accomplished by installing phenylboronic acid units on the carbazole in place of the alanine to bind to glycolipids. The glycolipid sensor will be tested with free analytes and in vesicles to determine its response and ability to remove biological lipids from membranes. If this proves successful, we will test Forssmann's antigen to determine if it is possible to bind to blood group antigens.

If successful, these sensors can be applied to human biological systems. As discussed earlier in Chapter 3, glycolipids are part of the $\mathrm{ABO}$ blood group antigens, located on the surface of the red blood cells (Figure 6.1). Patients with type A have antibodies for type $\mathrm{B}$, and patients with type $\mathrm{B}$ have antibodies for type $\mathrm{A}$, while those with type $\mathrm{O}$ have antibodies for both. Because of these antibodies, transfusion of red cells containing A or B antigens to a patient who has the corresponding antibodies results in a hemolytic event. The ability to remove these antigens from the red blood cells of a donors blood would allow the blood to be transfused without a hemolytic event occurring. This would be incredibly beneficial to patients who have rare blood types, or when disasters occur creating a shortage in the blood supply.

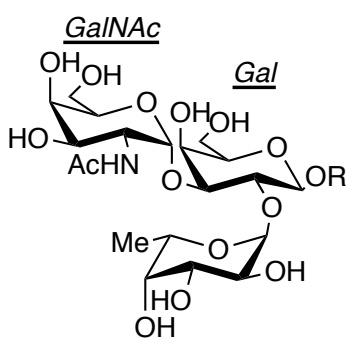

A-antigen

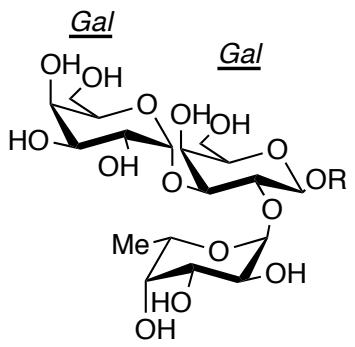

B-antigen

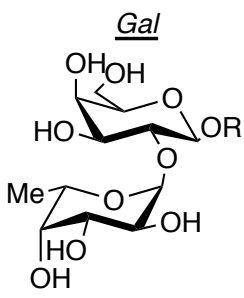

H-antigen (O-type)

Figure 6.1: ABO blood antigen structure

Lipid storage diseases such as Gaucher's disease present another application of this work. As mentioned in Chapter 3, for patients diagnosed with Gaucher's Disease, the body lacks a specific enzyme, $\beta$-glucoside, which is important for the 
digestive function of the glycolipids located in tissue macrophages. This sensor could potentially be applied as a treatment option for patients who suffer from this disease, as it could remove the glycolipids and redistribute them in the body. However, to accomplish this the sensor would require modifications to allow it to be delivered inside the cell, as the disorder is an intracellular process.

The ability to remove these lipids is within reach, as our work with the alanine hexa acid sensor has demonstrated our capability to remove hydrophobic amines from synthetically prepared vesicles. Headgroup modification should permit extraction of the glycolipid. 


\section{Appendix}

\section{Experimental Procedures and Characterization Data}

\section{Instrumentation}

Absorption spectra were recorded on an Agilent Cary 100 UV/Vis spectrophotometer at $25^{\circ} \mathrm{C}$. Fluorescence spectra were recorded on a Horiba Fluorolog-3 spectrofluorometer at $25^{\circ} \mathrm{C}$. NMR spectra were recorded on a Bruker Avance III 500, Bruker Avance III 600, Bruker DRX 300, or Bruker AVII+ 300. Dynamic Light Scattering measurements were performed on a Protein Solutions DynaPro99 MSTC Dynamic Light Scattering Instrument with temperature control. HPLC purifications were performed using Waters 2545 Quaternary Gradient Pump, 2998 photodiode arrary detector, and fraction collector, with helium sparge in solvents from Sigma Aldrich; using a $\mathrm{C}_{18}$ guard column and 19x250 mm XBridge OBD 5 $\mu \mathrm{m} \mathrm{C}_{18}$ column.

\section{Sample Preparation: Hydrophobic Amine Sensors}

Solutions for UV/Vis and fluorescence spectroscopy experiments were prepared from a $.367 \mathrm{mg} \mathrm{mL}^{-1}$ sensor stock solution in water, which was diluted with buffer $(20 \mathrm{mM}$ HEPES, $100 \mathrm{mM} \mathrm{NaCl}, \mathrm{pH}$ 7.4) until a $10 \mu \mathrm{M}$ or $2 \mu \mathrm{M}$ sensor solution was obtained. Analytes were measured and diluted to volume with the buffered sensor solution to keep the sensor concentration constant throughout the course of the titrations. Some analytes required heating of the solution to dissolve into solution.

\section{Sample Preparation: Phospholipid Vesicles}

DMPC (12.5 mg in $\mathrm{CHCl}_{3}$ ) or a 80:20 mixture of DMPC/DMPS purchased from Avanti Polar Lipids was dried in a test tube under $\mathrm{N}_{2}(\mathrm{~g})$ and placed under vacuum in a desiccator to continue drying overnight. The lipids were then hydrated with $0.55 \mathrm{~mL}$ 
phosphate buffer $\left(20 \mathrm{mM} \mathrm{Na}_{2} \mathrm{HPO}_{4}, 5 \mathrm{mM} \mathrm{NaCl}, \mathrm{pH} 7.4\right)$. The test tube was placed in a heated bath at a temperature above the phase transition temperature of the lipid, $40-50^{\circ} \mathrm{C}$ and sonicated for approximately one hour. The mixture was then drawn up in a syringe and extruded with a Lipofast Extruder (purchased from Avanti Polar Lipids) using a $0.200 \mu \mathrm{m}$ polycarbonate membrane. The vesicles were diluted with phosphate buffer to be measured using a DLS and stored in the refrigerator until use.

\section{Sample Preparation: Hydrophobic Amine Containing Vesicles}

For liquid amines:

DMPC (12.5 mg in $\mathrm{CHCl}_{3}$ ) or a 80:20 mixture of DMPC/DMPS purchased from Avanti Polar Lipids was dried in a test tube under $\mathrm{N}_{2}(\mathrm{~g})$ and placed under vacuum in a desiccator to continue drying overnight. The lipids were then hydrated by adding 0.55 $\mathrm{mL}$ phosphate buffer $\left(20 \mathrm{mM} \mathrm{Na}_{2} \mathrm{HPO}_{4}, 5 \mathrm{mM} \mathrm{NaCl}, \mathrm{pH} 7.4\right)$, and then the appropriate $\mu \mathrm{L}$ amount of amine. The test tube was placed in a heated bath at a temperature above the phase transition temperature of the lipid, $40-50^{\circ} \mathrm{C}$, and sonicated for approximately one hour. The mixture was then drawn up in a syringe and extruded with a Lipofast Extruder (purchased from Avanti Polar Lipids) using a $0.200 \mu \mathrm{m}$ polycarbonate membrane.. The vesicles were diluted with phosphate buffer to be measured using a DLS and stored in the refrigerator until use.

For solid amines:

A concentrate stock solution of the amine was prepared in ethanol or chloroform of roughly $40 \mathrm{mg} / \mathrm{mL}$. DMPC or DMPC/DMPS was added to a test tube and $5 \mathrm{~mol} \%$ of the 
amine was added. The resulting solution was dried in a test tube under $\mathrm{N}_{2}(\mathrm{~g})$ and placed under vacuum in a desiccator to continue drying overnight. The lipids were then hydrated with $0.55 \mathrm{~mL}$ phosphate buffer $\left(20 \mathrm{mM} \mathrm{Na}_{2} \mathrm{HPO}_{4}, 5 \mathrm{mM} \mathrm{NaCl}, \mathrm{pH} 7.4\right)$. The test tube was placed in a heated bath at a temperature above the phase transition temperature of the lipid, $40-50^{\circ} \mathrm{C}$ and sonicated for approximately one hour. The mixture was then drawn up in a syringe and extruded with a Lipofast Extruder (purchased from Avanti Polar Lipids) using a $0.200 \mu \mathrm{m}$ polycarbonate membrane. The vesicles were diluted with phosphate buffer to be measured using a DLS and stored in the refrigerator until use.

\section{Binding Constant Calculations}

The concentration of analyte was plotted against the fluorescence intensity and fit to a one-site binding isotherm using PRISM.

\section{Synthetic Procedures}

\section{General Methods}

All reactions were carried out in oven-dried glassware under $\mathrm{N}_{2}$ (g) atmosphere. Tetrahydrofuran and diethyl ether were distilled from sodium benzophenone ketyl. Dichloromethane, toluene, triethylamine, and acetonitrile were distilled from $\mathrm{CaH}_{2}$. NMR spectra were recorded on a Bruker Avance III 500, Bruker Avance III 600, Bruker DRX 300, or Bruker AVII+ 300. IR spectra were recorded on a Nexus 670 FT-IR E.S.P. High resolution mass spectra (HRMS) were carried out by a Bruker Apex-Qe FTMS at the Old Dominion University in Norfolk, Va or Thermo Scientific LTQ Orbitrap XL FTMS at Universtiy of Missouri -Columbia. 


\section{Materials}

All Chemicals were obtained from Sigma Aldrich, Fisher Scientific, Combi-Blocks, TCI America, Acros Organics, Alfa Aesar or Avanti Polar Lipids and were used without any further purification. Flash chromatography was performed with $60 \AA 40-63 \mu \mathrm{m}$ silica gel or $60 \AA 40-75 \mu \mathrm{m}$ premium $\mathrm{R}_{\mathrm{f}}$ silica gel (for molecules $\geq 1000 \mathrm{~g} / \mathrm{mol}$ ) from Sorbent Technologies.

\section{Vesicle Preparation}

DMPC vesicles were prepared by adding 0.5 mL DMPC (Avanti Polar Lipids, 25 $\mathrm{mg} / \mathrm{ML}$, in $\mathrm{CHCl}_{3}$ ), and the chloroform was evaporated over a stream of nitrogen. The test tube was then placed under vacuum in a desiccator overnight. $0.55 \mathrm{~mL}$ phosphate buffer (20 mM phosphate, $5 \mathrm{mM} \mathrm{NaCl}, \mathrm{pH} 7.4)$ was added to the test tube and it was then sonicated in a heated bath $\left(50^{\circ} \mathrm{C}\right)$ for one hour. The resulting milky solution was then drawn into a $1000 \mu \mathrm{L}$ syringe and extruded through a $0.200 \mu \mathrm{M}$ membrane using an extruder (Avanti polar lipids) on a hot plate, passing through 21 times. The final solution was then diluted to a total volume of $6 \mathrm{~mL}$ with HEPES buffer (25 mM HEPES, $120 \mathrm{mM}$ $\mathrm{NaCl}, \mathrm{pH}$ 7.4) to obtain a final vesicle solution used for titrations. The resulting solution was then measured by DLS to obtain the size of vesicles, measuring three times and taking an average: $173 \mathrm{~nm}$. 
<smiles>O=C(Br)CBr</smiles>

38

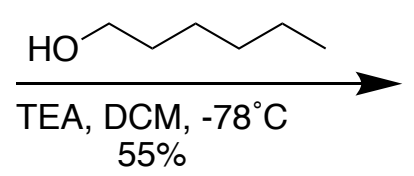

$55 \%$

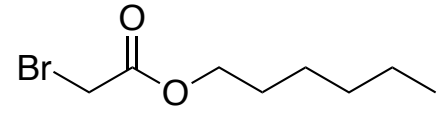

39

hexyl 2-bromoacetate 39: Hexanol (13.75 mL, $115 \mathrm{mmol})$, TEA (16.7 mL, 136 mmol) and DCM (200 mL) were all added to a round bottom flask and chilled to $-78^{\circ} \mathrm{C}$. Bromoacetylbromide $38(10 \mathrm{~mL}, 115 \mathrm{mmol})$ was added via syringe to the chilled solution, stirring for three hours at $-78^{\circ} \mathrm{C}$. The reaction quenched by the addition of water $(100 \mathrm{~mL})$ and extracted with DCM $(3 \times 100 \mathrm{~mL})$. The organic layer was washed with water $(3 \times 100 \mathrm{~mL}), \mathrm{NH}_{4} \mathrm{Cl}(3 \times 100 \mathrm{~mL}), \mathrm{NaHCO}_{3}(3 \times 100 \mathrm{~mL})$ and brine $(3 \times 100$ $\mathrm{mL}$ ). The resulting organic layer was then dried with $\mathrm{MgSO}_{4}$, filtered and concentrated to give the product as a clear yellow liquid $(21.1 \mathrm{~g}, 101 \mathrm{mmol}, 88 \%) .{ }^{1} \mathbf{H}$ NMR $(500 \mathrm{MHz}$, $\left.\mathrm{CDCl}_{3}\right) \delta 4.17(\mathrm{t}, 2 \mathrm{H}, J=6.75 \mathrm{~Hz}), 3.83(\mathrm{~s}, 2 \mathrm{H}), 1.66($ quin, $2 \mathrm{H}, J=7.1 \mathrm{~Hz}), \sim 1.4-1.26$ $(\mathrm{m}, 6 \mathrm{H}), 0.89(\mathrm{t}, 3 \mathrm{H}, J=7.02 \mathrm{~Hz}) ;{ }^{13} \mathrm{C}$ NMR $\left(126 \mathrm{MHz}, \mathrm{CDCl}_{3}\right) \delta 167.47,66.61,31.48$, 28.51, 26.08, 25.55, 22.63, 14.11; IR (neat, $\mathrm{cm}^{-1}$ ) 2956, 2921, 2856, 1736, 1468, 1275, 1164, 1106, 983; HRMS for $\left(\mathrm{C}_{8} \mathrm{H}_{15} \mathrm{BrO}_{2}\right) \mathrm{Na}^{+}$calculatd: 245.014763. Found: 245.014906. 


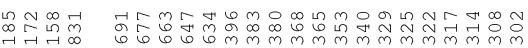

ฟंगं
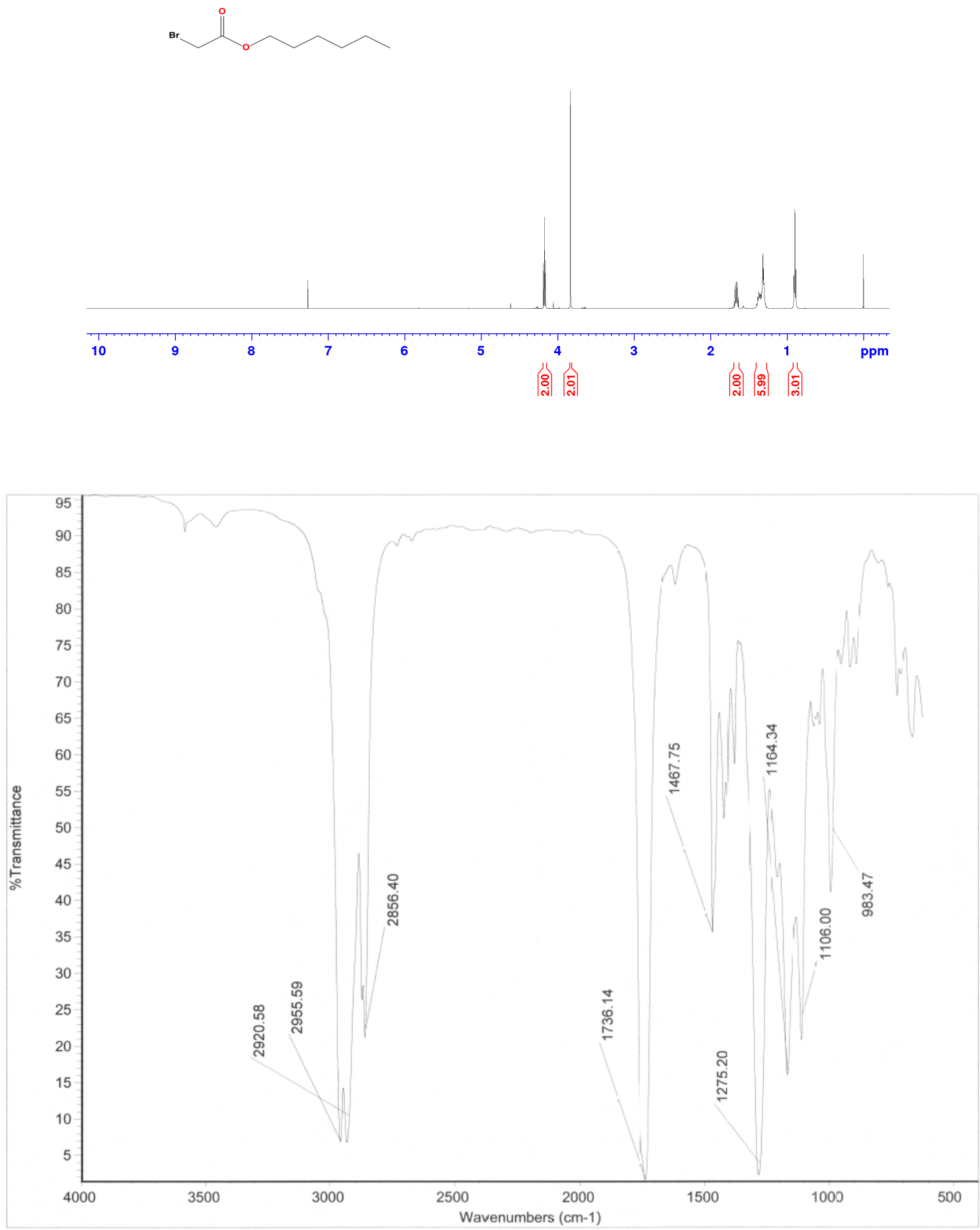
<smiles>Oc1ccc2cc(O)ccc2c1</smiles>

18

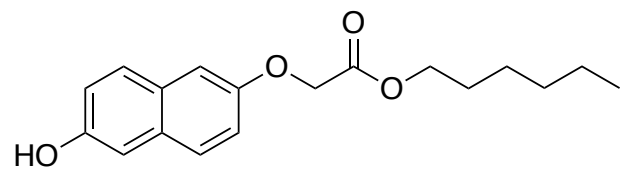

40

Hexyl 2-((6-hydroxynaphthalen-2-yl)oxy)acetate 40: 2,6-dihydroxynaphthalene (14.8 g, $92.41 \mathrm{mmol}$ ) was dissolved in $430 \mathrm{~mL}$ of DMF. To the resulting solution sodium hydride- $60 \%$ in mineral oil $(3.71 \mathrm{~g}, 93.11 \mathrm{mmol})$ was slowly added. The solution was stirred for five minutes, followed by the addition of hexyl 2-bromoacetate $39(12.6 \mathrm{~mL}$, $71.08 \mathrm{mmol})$. The resulting solution was stirred for 22 hours and then concentrated to give a crude solid. To the solid was added $10 \% \mathrm{HCl}$ until no bubbles appeared, and the product was then extracted with DCM (3 x $200 \mathrm{~mL})$, filtered, and concentrated. The crude product was purified by flash $\mathrm{SiO}_{2}$ chromatography with DCM to give the product as a tan solid (9.495 g, $31.4 \mathrm{mmol}, 42 \%)\left(\mathrm{mp} \mathrm{83-86}{ }^{\circ} \mathrm{C}\right) .{ }^{1} \mathbf{H}$ NMR $\left(300 \mathrm{MHz}, \mathrm{CDCl}_{3}\right) \delta$ 7.47-7.55 (m, 2H), $7.14(\mathrm{dd}, 1 \mathrm{H}, J=2.4,9.0 \mathrm{~Hz}), 7.04-7.08(\mathrm{~m}, 2 \mathrm{H}), 7.00(\mathrm{~d}, 1 \mathrm{H}, J=2.4$ $\mathrm{Hz}), 5.93(\mathrm{~s}, 1 \mathrm{H}), 4.72(\mathrm{~s}, 2 \mathrm{H}), 4.23(\mathrm{t}, 2 \mathrm{H}, J=6.8 \mathrm{~Hz}), 1.60-1.69(\mathrm{~m}, 2 \mathrm{H}), 1.24-1.35(\mathrm{~m}$, $6 \mathrm{H}), 0.85(\mathrm{t}, 3 \mathrm{H}, J=6.4 \mathrm{~Hz}) ;{ }^{13} \mathbf{C} \mathbf{N M R}\left(75 \mathrm{MHz}, \mathrm{CDCl}_{3}\right) \delta 169.7,154.1,152.4,130.4$, $129.2,128.4,128.1,119.0,118.4,109.7,107.4,65.7,65.5,31.3,28.5,25.4,22.5,13.9$; IR (neat, $\mathrm{cm}^{-1}$ ) 3407, 2954, 2925, 2852, 1736, 1605, 1511, 1393, 1213, 1111, 1066, 850; HRMS calculated for $\left(\mathrm{C}_{18} \mathrm{H}_{22} \mathrm{O}_{4}\right) \mathrm{Na}^{+}(\mathrm{M}+\mathrm{Na})^{+}: 325.14103$. Found: 325.14111. 

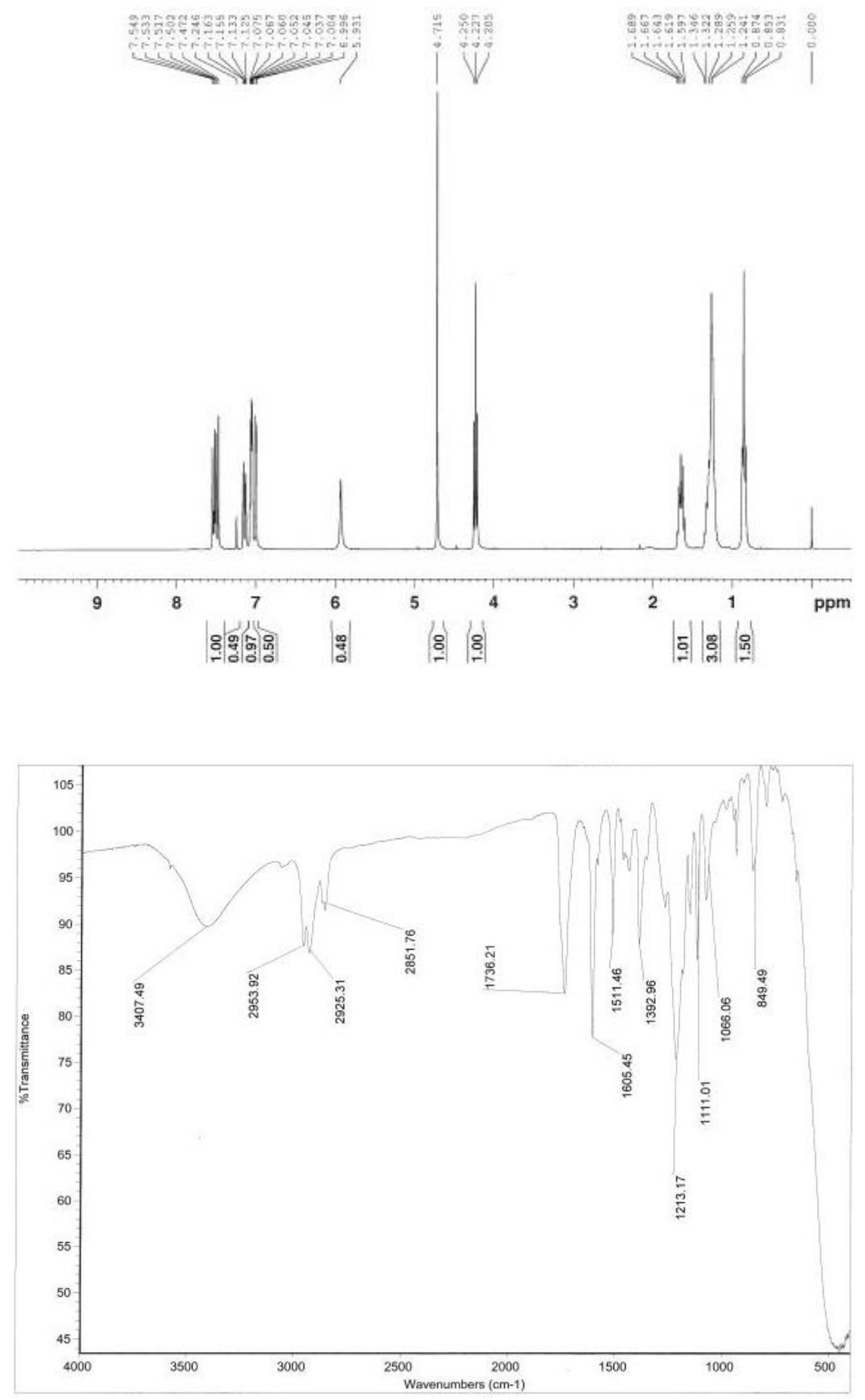


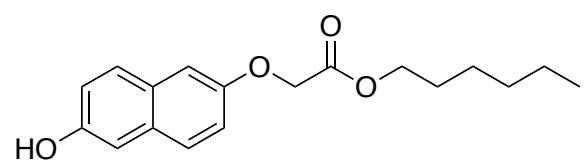

40
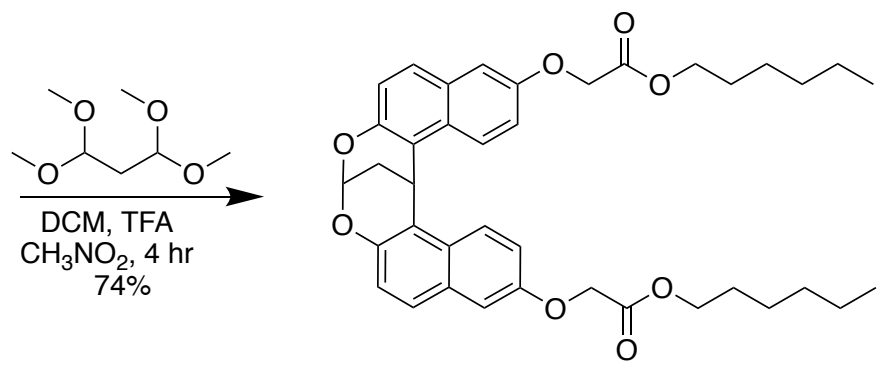

41

dihexyl-2,2'-((16H-8,16-methanodinaphtho[2,1-d:1',2'-g][1,3]dioxocine-3,13-

diyl)bis(oxy))diacetate 41: To a solution of 40 (1.23 g, $3.89 \mathrm{mmol})$ in DCM (4 mL) and $\mathrm{CH}_{3} \mathrm{NO}_{2}(10 \mathrm{~mL})$ was added TFA $(4 \mathrm{~mL}) .1$ 1,1,3,3-tetramethoxypropane $(.383 \mathrm{~mL}, 2.83$ mmol) was dropwise via syringe over two hours. The reaction was continued stirring for 24 hours. The reaction was then concentrated, followed by the addition of $50 \mathrm{~mL}$ sat. $\mathrm{NaHCO}_{3}$, and the product was extracted with DCM $(3 \times 100 \mathrm{~mL})$. The resulting organic layer was dried with $\mathrm{Na}_{2} \mathrm{SO}_{4}$, filtered, and concentrated. The crude product was subjected to flash $\mathrm{SiO}_{2}$ chromatography $(0-2 \% \mathrm{Et} 2 \mathrm{O} / \mathrm{DCM})$ to give the product was a yellow oil/solid (.9891 g, $1.54 \mathrm{mmol}, 79 \%)\left(\mathrm{mp} 85{ }^{\circ} \mathrm{C}\right) .{ }^{1} \mathbf{H}$ NMR $\left(300 \mathrm{MHz}, \mathrm{CDCl}_{3}\right) \delta 8.40(\mathrm{~d}$, $2 \mathrm{H}, J=9.3), 7.39(\mathrm{~d}, 2 \mathrm{H}, J=8.7 \mathrm{~Hz}), 7.28(\mathrm{dd}, 2 \mathrm{H}, J=2.7,9.3 \mathrm{~Hz}), 7.08(\mathrm{~d}, 2 \mathrm{H}, J=9.0$ $\mathrm{Hz}), 6.95(\mathrm{~d}, 2 \mathrm{H}, J=2.7 \mathrm{~Hz}), 6.19(\mathrm{~s}, 1 \mathrm{H}), 5.15(\mathrm{~s}, 1 \mathrm{H}), 4.64(\mathrm{~s}, 4 \mathrm{H}), 4.17(\mathrm{t}, 4 \mathrm{H}, J=6.6$ $\mathrm{Hz}), 2.31(\mathrm{~s}, 2 \mathrm{H}), 1.56-1.77(\mathrm{~m}, 4 \mathrm{H}), 1.20-1.28(\mathrm{~m}, 12 \mathrm{H}), .79-.88(\mathrm{~m}, 6 \mathrm{H}) ;{ }^{13} \mathrm{C}$ NMR (75 $\left.\mathrm{MHz}, \mathrm{CDCl}_{3}\right) \delta 169.0,154.0,148.9,130.4,127.3,126.8,124.4,119.0,118.7,118.4$ $108.6,91.4,65.5,65.4,31.3,28.5,26.7,25.4,22.8,22.4,13.9$; IR (neat, $\mathrm{cm}^{-1}$ ) 2958, 2929, 2868,1753, 1671, 1626, 1454, 1172; HRMS calculated for $\left(\mathrm{C}_{39} \mathrm{H}_{44} \mathrm{O}_{8}\right) \mathrm{Na}^{+}(\mathrm{M}+$ $\mathrm{Na})^{+}: 663.29294$. Found: 663.29210. 

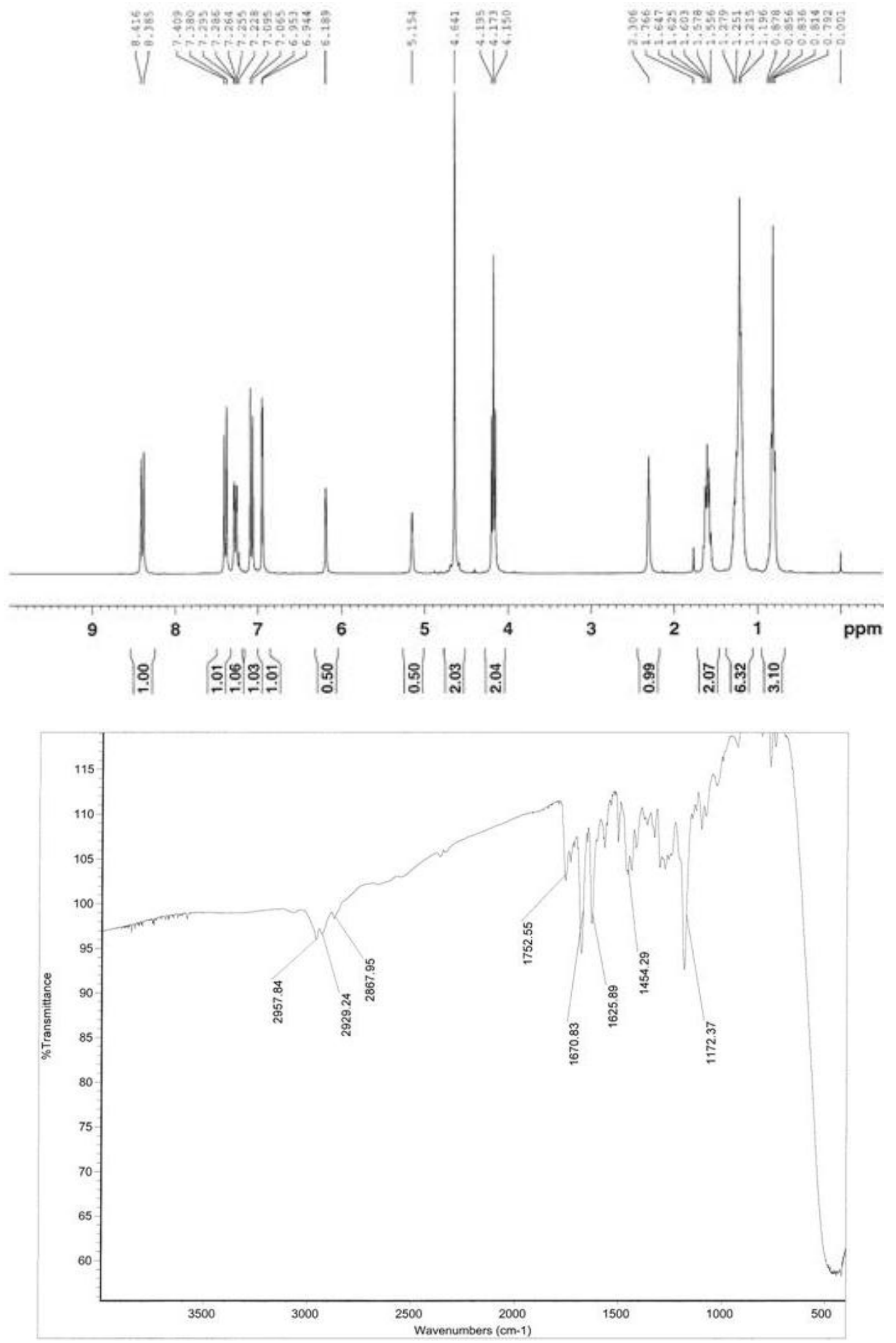


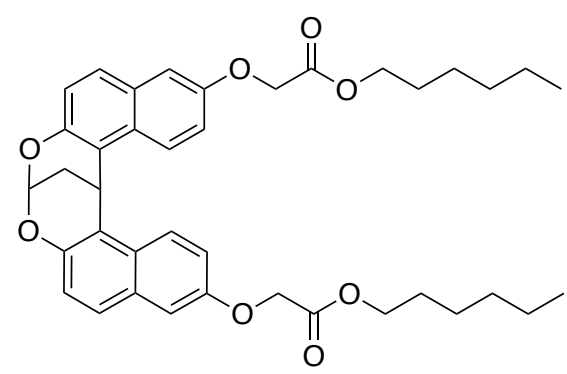

41

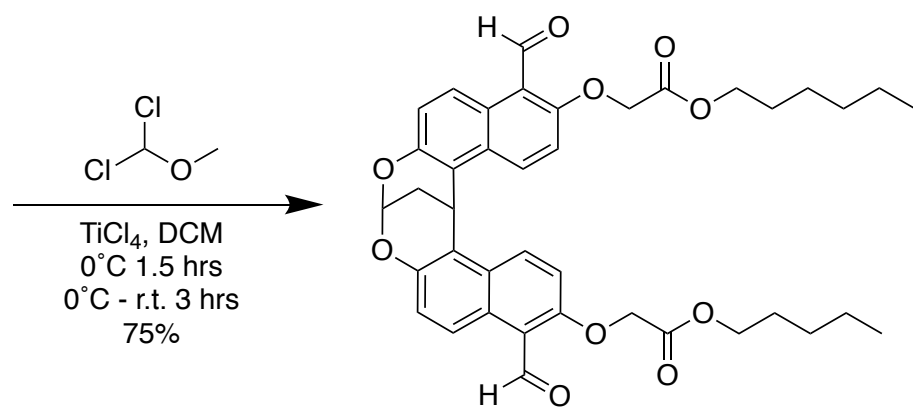

42

\section{hexyl-2-((4,12-diformyl-13-(2-oxo-2-(pentyloxy)ethoxy)-16H-8,16-}

methanodinaphtho[2,1-d:1',2'-g][1,3]dioxocin-3-yl)oxy)acetate 42: To a solution of 41 $(2.7 \mathrm{~g}, 4.22 \mathrm{mmol})$ in $\mathrm{DCM}(42 \mathrm{~mL})$ at $0^{\circ} \mathrm{C}$ was added $\mathrm{TiCl}_{4}-1 \mathrm{M}$ in DCM $(16.9 \mathrm{~mL}$, $16.9 \mathrm{mmol})$. To the resulting solution alpha,alpha-dichloromethyl methyl ether $(1.5 \mathrm{~mL}$, $16.88 \mathrm{mmol}$ ) was added and continued stirring for one hour at $0^{\circ} \mathrm{C}$, after which the solution was slowly raised to room temperature and stirred another three hours. The reaction was then quenched with $\mathrm{NaHCO}_{3}$ and the product was extracted with DCM ( $3 \mathrm{x}$ $100 \mathrm{~mL}$ ) and concentrated. The crude product was then purified by flash $\mathrm{SiO}_{2}$ chromatography $\left(0-10 \% \mathrm{Et}_{2} \mathrm{O} / \mathrm{DCM}\right)$ to give the product as a yellow solid $(2.2 \mathrm{~g}, 3.159$ mmol, 75\%) (decomp $\left.102{ }^{\circ} \mathrm{C}\right) .{ }^{1} \mathbf{H}$ NMR $\left(300 \mathrm{MHz}, \mathrm{CDCl}_{3}\right) \delta 10.84$ (s, 2H), 9.03 (d, 2H, $J=9.6 \mathrm{~Hz}), 8.57(\mathrm{~d}, 2 \mathrm{H}, J=9.6 \mathrm{~Hz}), 7.25(\mathrm{~d}, 2 \mathrm{H}, J=8.4 \mathrm{~Hz}), 7.16(\mathrm{~d}, 2 \mathrm{H}, J=9.6 \mathrm{~Hz})$, $6.22(\mathrm{~s}, 1 \mathrm{H}), 5.14(\mathrm{~s}, 1 \mathrm{H}), 4.79(\mathrm{~s}, 4 \mathrm{H}), 4.17(\mathrm{t}, 4 \mathrm{H}, J=6.9 \mathrm{~Hz}), 2.37(\mathrm{~s}, 2 \mathrm{H}), 1.55-1.64$ $(\mathrm{m}, 4 \mathrm{H}), 1.18-1.27(\mathrm{~m}, 12 \mathrm{H}), .79-.83(\mathrm{~m}, 6 \mathrm{H}) ;{ }^{13} \mathbf{C}$ NMR $\left(75 \mathrm{MHz}, \mathrm{CDCl}_{3}\right) \delta 191.9$ $168.3,160.0,149.5,130.6,127.6,126.7,125.5,122.0,118.4,113.5,91.1,66.4,65.8$, 31.2, 28.4, 26.6, 25.4, 22.7, 22.4, 13.9; IR (neat, $\mathrm{cm}^{-1}$ ) 2958, 2929, 2860, 1748, 1675, 1589, 1524, 1385, 1201, 1054, 907, 817; HRMS calculated for $\left(\mathrm{C}_{41} \mathrm{H}_{44} \mathrm{O}_{10}\right) \mathrm{Na}^{+}(\mathrm{M}+$ $\mathrm{Na})^{+}:$719.28267. Found: 719.28190. 

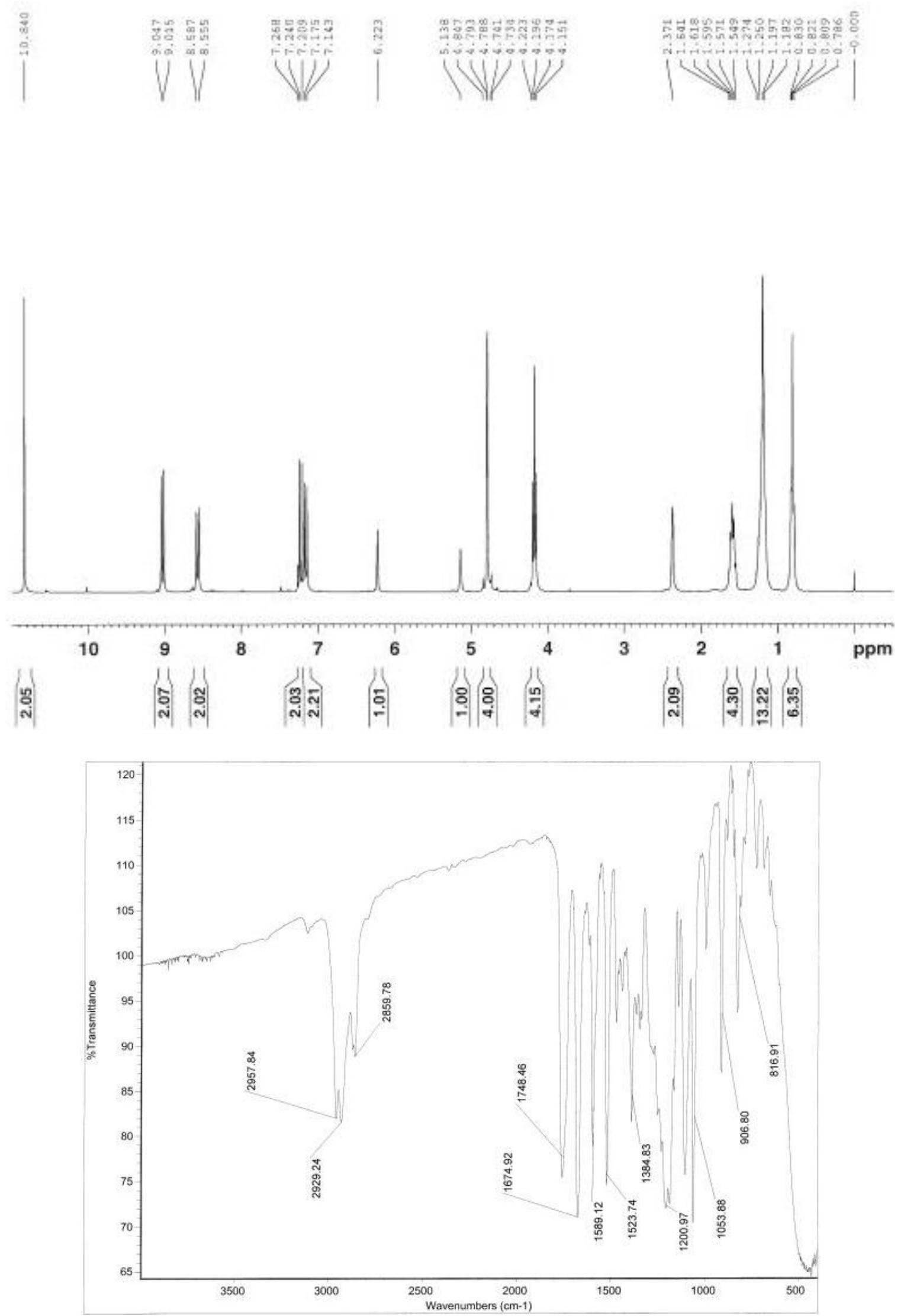

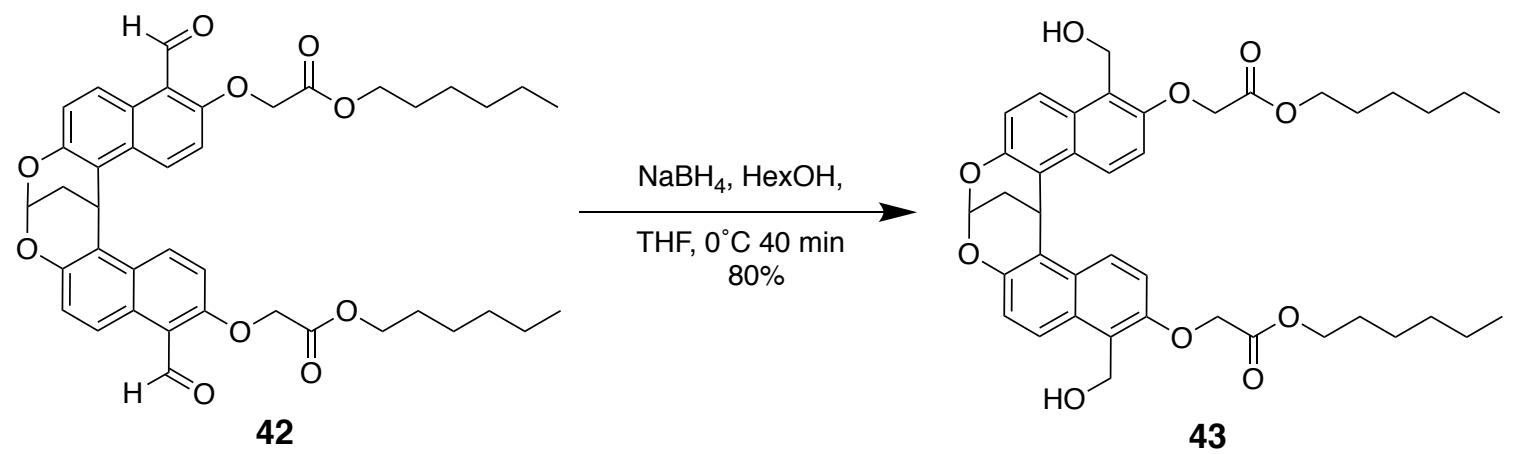

dihexyl-2,2'-((4,12-bis(hydroxymethyl)-16H-8,16-methanodinaphtho[2,1-d:1',2'-

g][1,3]dioxocine-3,13-diyl)bis(oxy))diacetate 43: A solution of $42(570 \mathrm{mg}, 0.819$ mmol) in THF $(13 \mathrm{~mL})$ and hexanol $(10 \mathrm{~mL})$ was chilled to $0^{\circ} \mathrm{C}$. $\mathrm{NaBH}_{4}(89.6 \mathrm{mg}, 2.37$ mmol) was added and stirring was continued for 40 minutes. The reaction was quenched with the addition of cold $\mathrm{NH}_{4} \mathrm{Cl}$ and extracted with $\mathrm{DCM}(3 \times 100 \mathrm{~mL})$. The resulting organic layer was dried with $\mathrm{Na}_{2} \mathrm{SO}_{4}$ and concentrated. The crude product was subjected to flash $\mathrm{SiO}_{2}$ chromatography $\left(0-30 \% \mathrm{Et}_{2} \mathrm{O} / \mathrm{DCM}\right)$ to yield the product as a light yellow oil (461 mg, .658 mmol, 80\%) ${ }^{1} \mathbf{H}$ NMR (300 MHz, CDCl $) \delta 8.49(\mathrm{~d}, 2 \mathrm{H}, J=9.3 \mathrm{~Hz})$, $7.99(\mathrm{~d}, 2 \mathrm{H}, J=9.2 \mathrm{~Hz}), 7.22-7.26(\mathrm{~m}, 4 \mathrm{H}), 6.27(\mathrm{~s}, 1 \mathrm{H}), 5.28(\mathrm{~s}, 1 \mathrm{H}), 5.10-5.15(\mathrm{~m}, 4 \mathrm{H})$, $4.81(\mathrm{~d}, 4 \mathrm{H}, J=4.8 \mathrm{~Hz}), 4.14(\mathrm{t}, 4 \mathrm{H}, J=6.8 \mathrm{~Hz}), 2.43(\mathrm{~s}, 2 \mathrm{H}), 1.56-1.60(\mathrm{~m}, 4 \mathrm{H}), 1.24$ (s, 12H), 0.82-0.85 (m, 6H); IR (neat, $\mathrm{cm}^{-1}$ ) 3440, 2954, 2925, 2848, 1744, 1593, 1520, 1401, 1197' 1103, 1062; HRMS calculated for $\left(\mathrm{C}_{41} \mathrm{H}_{48} \mathrm{O}_{10}\right) \mathrm{Na}^{+}(\mathrm{M}+\mathrm{Na})^{+}: 723.31397$. Found: 723.31323. 

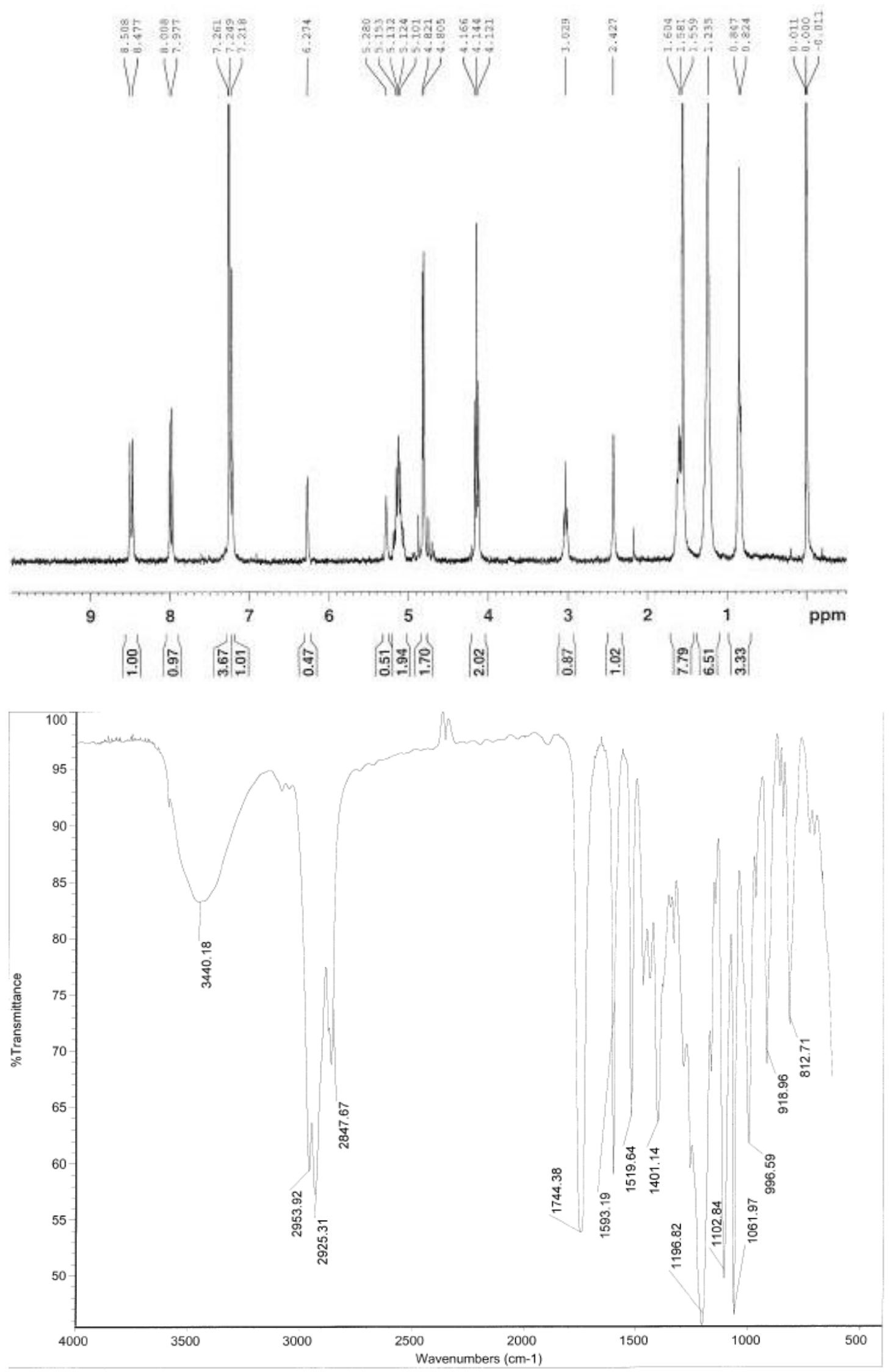


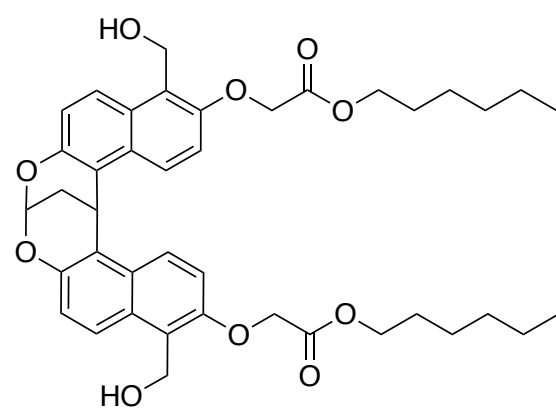

43

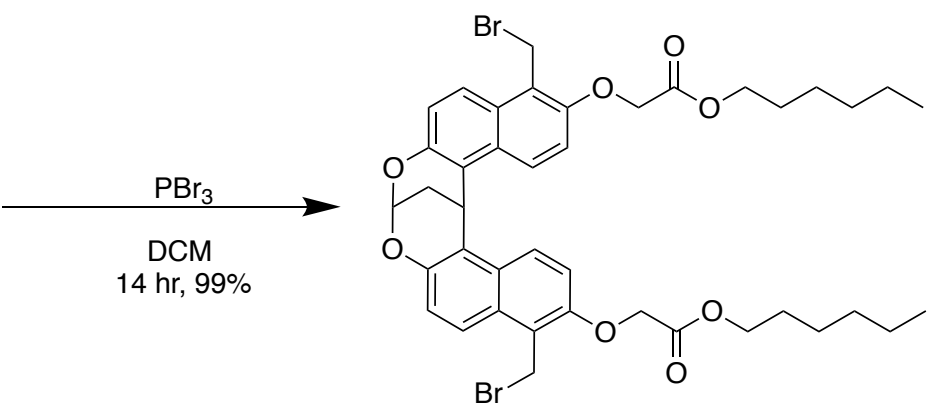

44

dihexyl-2,2'-((4,12-bis(bromomethyl)-16H-8,16-methanodinaphtho[2,1-d:1',2'-

g][1,3]dioxocine-3,13-diyl)bis(oxy))diacetate 44: To a solution of 43 (1.547 g, 2.21 mmol) in $\mathrm{DCM}(20 \mathrm{~mL})$ was added $\mathrm{PBr}_{3}(575 \mu \mathrm{L}, 6.05 \mathrm{mmol})$. The resulting solution was stirred for 14 hours followed by quenching with $\mathrm{NaHCO}_{3}$. The crude was extracted with DCM (3 x $150 \mathrm{~mL})$, dried over $\mathrm{Na}_{2} \mathrm{SO}_{4}$, filtered and concentrated to give the product as a crystalline brown solid (1.8 g, $2.18 \mathrm{mmol}, 99 \%)\left(\mathrm{mp} 62{ }^{\circ} \mathrm{C}\right) .{ }^{1} \mathbf{H}$ NMR $(300$ $\left.\mathrm{MHz}, \mathrm{CDCl}_{3}\right) \delta 8.49(\mathrm{~d}, 2 \mathrm{H}, J=9.6 \mathrm{~Hz}), 7.85(\mathrm{~d}, 2 \mathrm{H}, J=9.3 \mathrm{~Hz}), 7.30(\mathrm{~d}, 2 \mathrm{H}, J=9.6$ Hz), $7.19(\mathrm{~d}, 2 \mathrm{H}, J=9.3 \mathrm{~Hz}), 6.28(\mathrm{~s}, 1 \mathrm{H}), 5.26(\mathrm{~s}, 1 \mathrm{H}), 5.06(\mathrm{dd}, 4 \mathrm{H}, J=10.2,27.2 \mathrm{~Hz})$, $4.82(\mathrm{~s}, 4 \mathrm{H}), 4.19(\mathrm{t}, 4 \mathrm{H}, J=6.6 \mathrm{~Hz}), 2.42(\mathrm{~s}, 2 \mathrm{H}), 1.57-1.64(\mathrm{~m}, 4 \mathrm{H}), 1.20-1.25(\mathrm{~m}$, 12H), 0.80-0.84 (m, 6H); ${ }^{13} \mathbf{C}$ NMR (75 MHz, $\left.\mathrm{CDCl}_{3}\right) \delta 169.0,151.8,149.4,128.5$, $127.4,125.1,123.5,121.0,120.0,118.9,114.4,91.3,66.9,65.6,31.3,28.5,26.8,25.5$, 24.7, 23.0, 22.5, 13.9; IR (neat, $\mathrm{cm}^{-1}$ ) 3428, 2958, 2921, 2852, 1753, 1638, 1593, 1201, 1074; HRMS calculated for $\left(\mathrm{C}_{41} \mathrm{H}_{46} \mathrm{Br}_{2} \mathrm{O}_{8}\right) \mathrm{Na}^{+}(\mathrm{M}+\mathrm{Na})^{+}$: 847.14517. Found: 847.14414. 

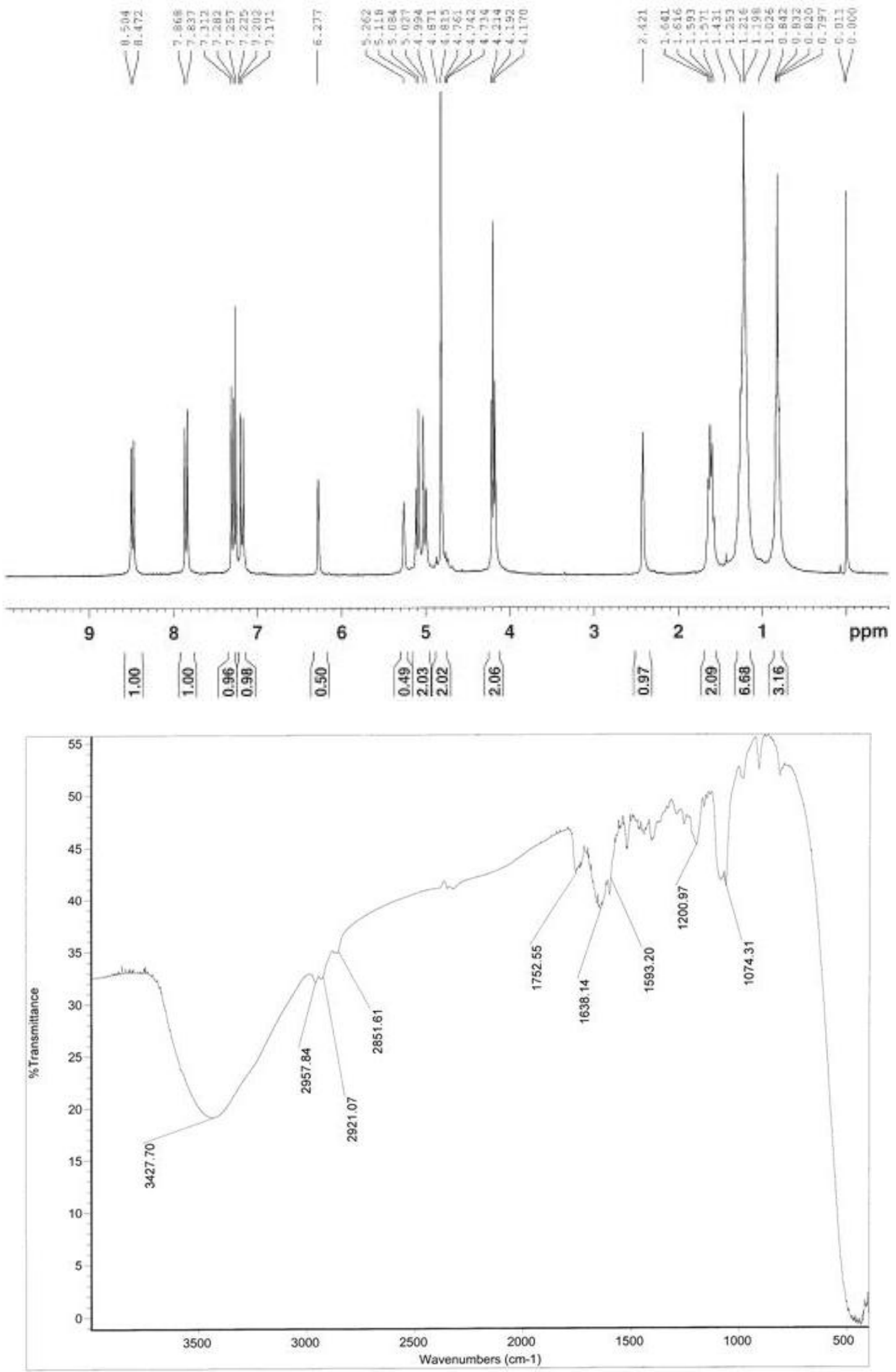
<smiles>CC1(C)OB(c2ccc(C(=O)O)cc2)OC1(C)C</smiles>

51

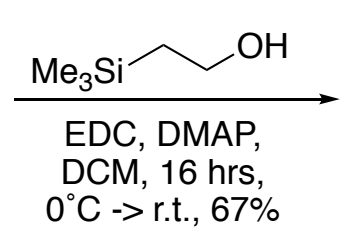

DCM, 16 hrs,
$0^{\circ} \mathrm{C} \rightarrow$ r.t., $67 \%$

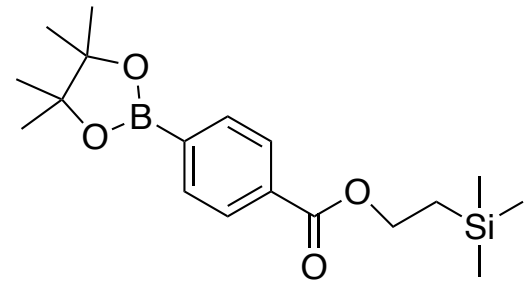

52

2-(trimethylsilyl)ethyl 4-(4,4,5,5-tetramethyl-1,3,2-dioxaborolan-2-yl)benzoate 52: A solution of 4-carboxyphenylboronic acid pinacol ester (3.02 g, $12.17 \mathrm{mmol}$ ), DMAP (320 $\mathrm{mg}, 2.62 \mathrm{mmol})$ and $\mathrm{EDC}(4.7 \mathrm{~g}, 24.52 \mathrm{mmol})$ in DCM (40 mL) was chilled to $0^{\circ} \mathrm{C}$ and stirred for 10 minutes. 2-(trimethylsilyl)ethan-1-ol (2.0 mL, $13.95 \mathrm{mmol})$ was added and the resulting mixture was stirred for 10 minutes, and then raised to room temperature and continued stirring for 16 hours. The reaction was concentrated and quenched by the addition of water, followed by an extraction with DCM (3 x $150 \mathrm{~mL})$ and concentrated. The crude product was purified by flash $\mathrm{SiO}_{2}(\mathrm{DCM})$ to get the product as a white solid $(2.805 \mathrm{~g}, 8.06 \mathrm{mmol}, 67 \%)\left(\mathrm{mp} 81{ }^{\circ} \mathrm{C}\right) .{ }^{1} \mathbf{H}$ NMR $\left(500 \mathrm{MHz}, \mathrm{CDCl}_{3}\right) \delta 8.01(\mathrm{~d}, 2 \mathrm{H}, J=$ $8.3 \mathrm{~Hz}), 7.86(\mathrm{~d}, 2 \mathrm{H}, J=8.25 \mathrm{~Hz}), 4.42(2 \mathrm{H}, \mathrm{m}), 1.35(\mathrm{~s}, 12 \mathrm{H}), 1.14(2 \mathrm{H}, \mathrm{m}), .077(\mathrm{~s}$, $9 \mathrm{H}) ;{ }^{13} \mathbf{C}$ NMR $\left(126 \mathrm{MHz}, \mathrm{CDCl}_{3}\right) \delta 166.76,134.69,132.82,128.49,84.11,63.27,24.85$, 17.37, -1.47; ${ }^{11} \mathbf{B}$ NMR (96 MHz, $\mathrm{CDCl}_{3}$ ) $\delta$ 30.36; IR (neat, $\mathrm{cm}^{-1}$ ) 2977, 2954, 1705, 1498, 1391, 1364, 1272, 1107, 1016; HRMS calculated for $\left(\mathrm{C}_{18} \mathrm{H}_{29} \mathrm{O}_{4} \mathrm{BSi}\right) \mathrm{Na}^{+}(\mathrm{M}+$ $\mathrm{Na})^{+}: 370.18567$. Found: 370.18566 . 

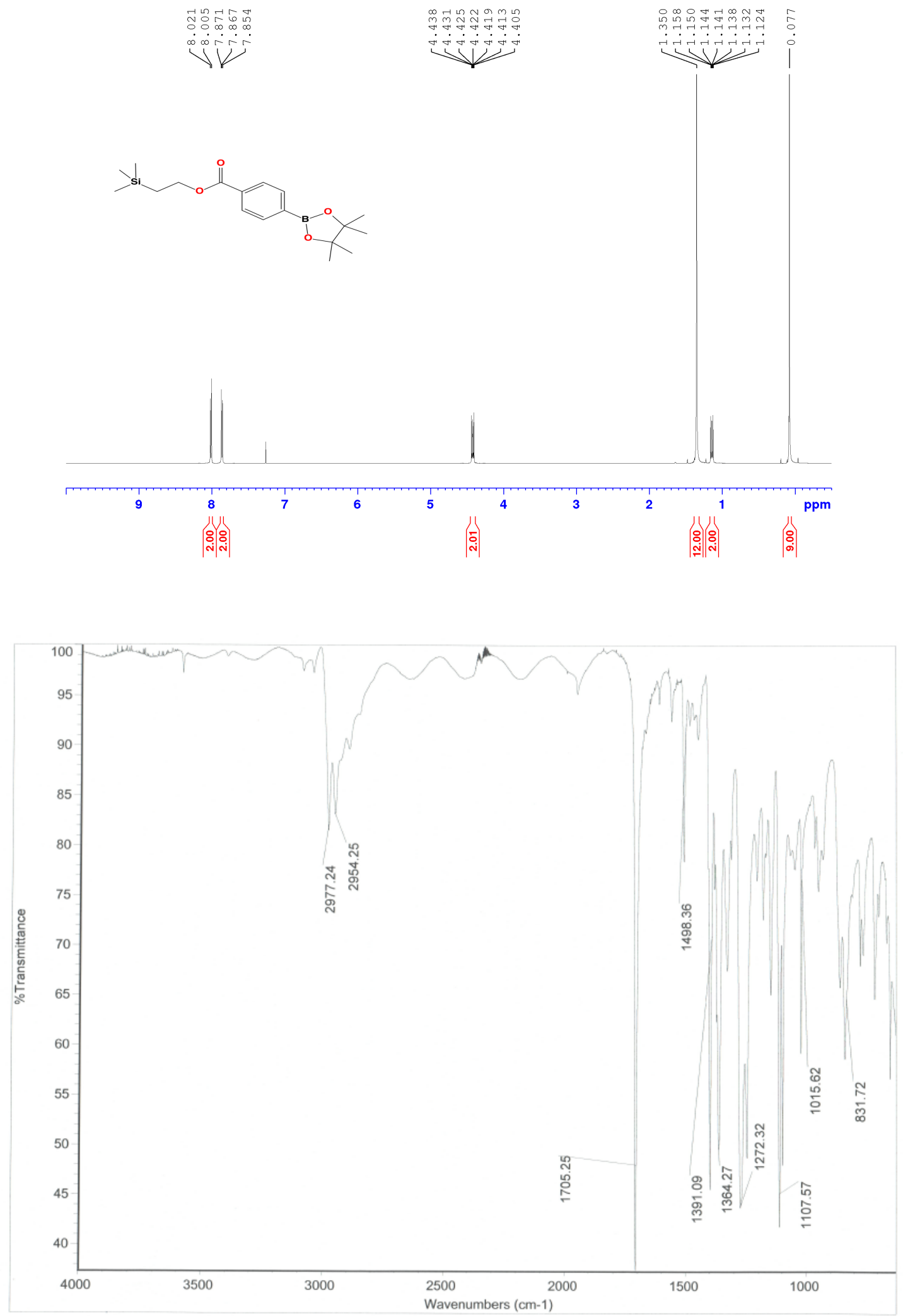
<smiles>O=[N+]([O-])c1cc(O)ccc1Cl</smiles>

45

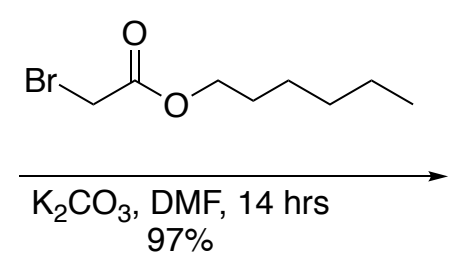

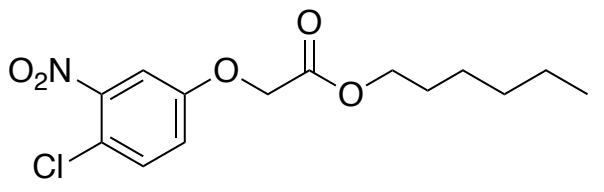

46

hexyl 2-(4-chloro-3-nitrophenoxy)acetate 46: To a solution of 4-chloro-3-nitrophenol (1.00 g, $5.76 \mathrm{mmol})$ in DMF $(50 \mathrm{~mL})$ was added $\mathrm{K}_{2} \mathrm{CO}_{3}(0.993 \mathrm{~g}, 7.2 \mathrm{mmol})$ and stirred for 10 minutes. To the resulting red solution hexyl 2-bromoacetate $40(1.28 \mathrm{~mL}, 7.2$ mmol) was added via syringe and continued stirring for 14 hours. The reaction was concentrated to give crude and quenched by the addition of $10 \mathrm{~mL} 10 \% \mathrm{HCl}$. The product was extracted with DCM (3 x $70 \mathrm{~mL})$ and concentrated to give crude solid. The product was purified via flash $\mathrm{SiO}_{2}(50-75 \% \mathrm{DCM} /$ hexane $)$ to give the product as a clear yellow oil (1.751 g, 5.55 mmol, 97\%) ${ }^{1} \mathbf{H}$ NMR (300 MHz, $\left.\mathrm{CDCl}_{3}\right) \delta 7.45$ (d, 1H, $\left.J=9.0 \mathrm{~Hz}\right)$, $7.40(\mathrm{~d}, 1 \mathrm{H}, J=3.0 \mathrm{~Hz}), 7.10(\mathrm{dd}, 1 \mathrm{H}, J=3.0,9.0 \mathrm{~Hz}), 4.68(\mathrm{~s}, 2 \mathrm{H}), 4.21(\mathrm{t}, 2 \mathrm{H}, J=6.8$ $\mathrm{Hz}), 1.61-1.70(\mathrm{~m}, 2 \mathrm{H}), 1.29-1.33(\mathrm{~m}, 6 \mathrm{H}), 0.90(\mathrm{~m}, 3 \mathrm{H}) ;{ }^{13} \mathbf{C} \mathbf{N M R}\left(75 \mathrm{MHz}, \mathrm{CDCl}_{3}\right) \delta$ $167.7,156.6,148.0,132.5,120.3,119.3,111.5,65.9,65.6,31.2,28.4,25.4,22.4,13.9$; IR (neat, $\mathrm{cm}^{-1}$ ) 3536, 3093, 2958, 2925, 2852, 1748, 1536, 1482, 1352, 1307, 1201, 1078, 805; HRMS calculated for $\left(\mathrm{C}_{14} \mathrm{H}_{18} \mathrm{ClNO}_{5}\right) \mathrm{Na}^{+}(\mathrm{M}+\mathrm{Na})^{+}:$338.07657. Found: 338.07656. 

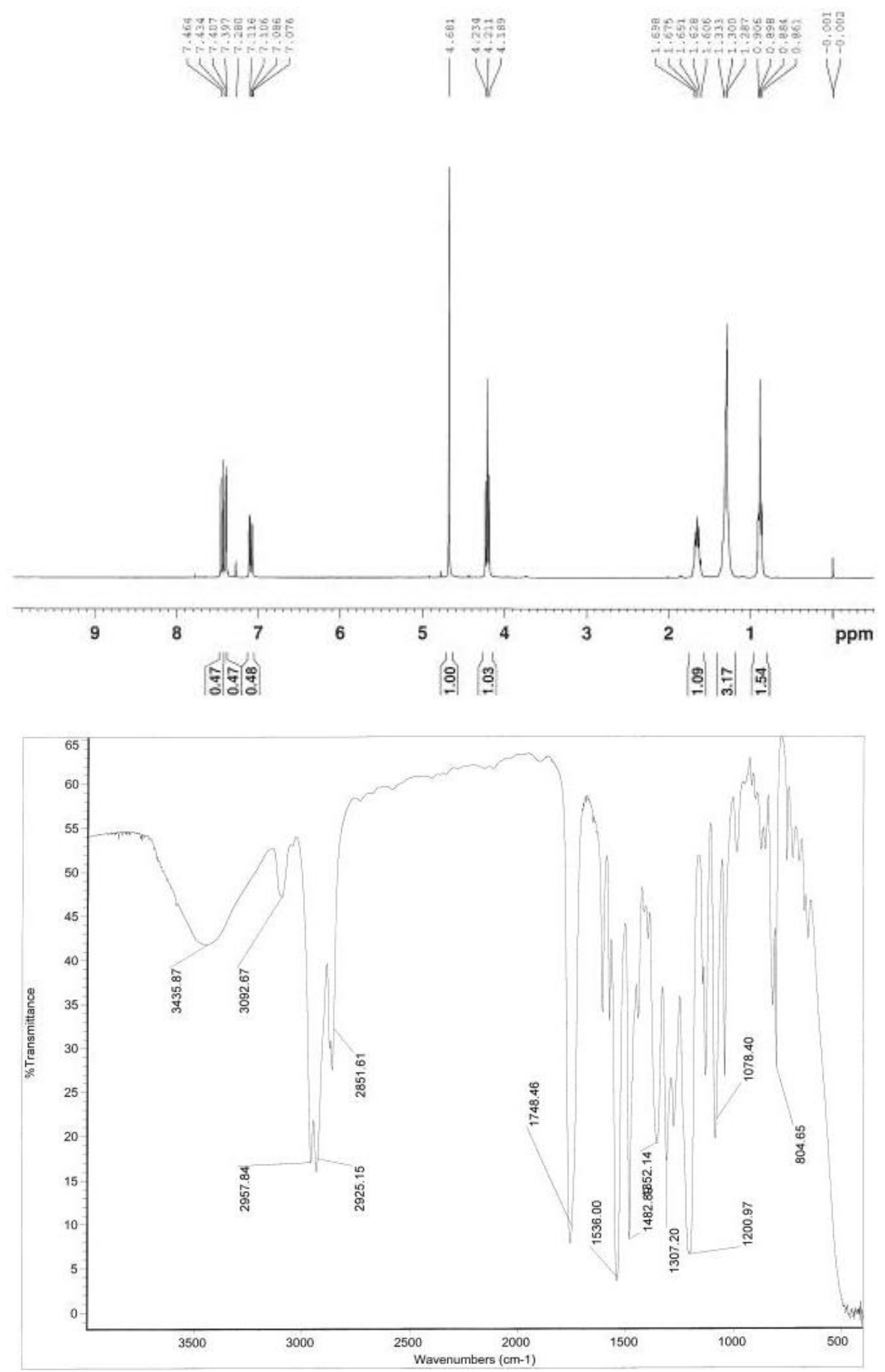


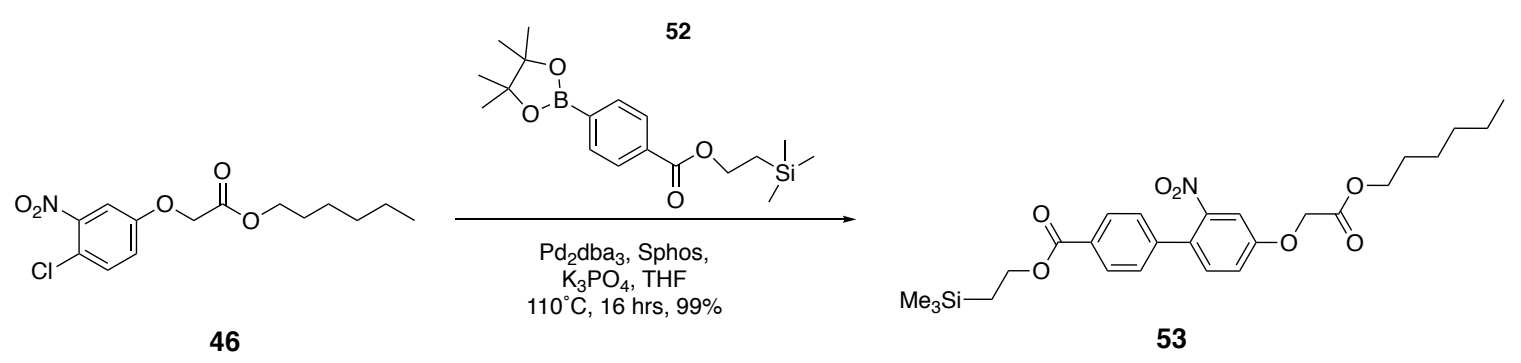

\section{2-(trimethylsilyl)ethyl-4'-(2-(hexyloxy)-2-oxoethoxy)-2'-nitro-[1,1'-biphenyl]-4-}

carboxylate 53: To a sealed tube was added 46 (350 mg, $1.11 \mathrm{mmol})$, 2(trimethylsilyl)ethyl 4-(4,4,5,5-tetramethyl-1,3,2-dioxaborolan-2-yl)benzoate 52 (437 mg, $1.255 \mathrm{mmol}), \mathrm{Pd}_{2} \mathrm{dba}_{3}(51.7 \mathrm{mg}, 0.0565 \mathrm{mmol}), \mathrm{K}_{3} \mathrm{PO}_{4}(957.5 \mathrm{mg}, 4.52 \mathrm{mmol})$ and Sphos (64.9 $\mathrm{mg}, 0.158 \mathrm{mmol})$. The tube was sealed with a septa and the air was evacuated and pumped in $\mathrm{N}_{2}$ (g) for three cycles. Freshly distilled THF $(8 \mathrm{~mL})$ was added to the tube and then sparged with $\mathrm{N}_{2}$ (g) for 5 minutes. The vessel was then capped and heated at $110^{\circ} \mathrm{C}$ while stirring for 16 hours. The reaction was cooled, filtered over a $\mathrm{SiO}_{2}$ plug (150 $\mathrm{mL} 25 \% \mathrm{Et}_{2} \mathrm{O} / \mathrm{DCM}$ ) and concentrated to give crude. The crude was purified via flash $\mathrm{SiO}_{2}(\mathrm{DCM})$ to give the product as a yellow oil (547.9 $\left.\mathrm{mg}, 1.09 \mathrm{mmol}, 99 \%\right) .{ }^{1} \mathbf{H}$ NMR $\left(500 \mathrm{MHz}, \mathrm{CDCl}_{3}\right) \delta 8.07(\mathrm{~d}, 2 \mathrm{H}, J=8.5 \mathrm{~Hz}), 7.43(\mathrm{~d}, 1 \mathrm{H}, J=2.65 \mathrm{~Hz}), \sim 7.36-7.34$ $(\mathrm{m}, 3 \mathrm{H}), 7.20(\mathrm{dd}, 1 \mathrm{H}, J=2.7,8.5 \mathrm{~Hz}), 4.730(\mathrm{~s}, 2 \mathrm{H}), 4.44(\mathrm{~m}, 2 \mathrm{H}), 4.24(\mathrm{t}, 2 \mathrm{H}, J=6.75$ $\mathrm{Hz}$ ), 1.67 (quint, 2H, $J=6.75 \mathrm{~Hz}), \sim 1.35-1.25(\mathrm{~m}, 6 \mathrm{H}), 1.14(\mathrm{~m}, 2 \mathrm{H}), 0.89(\mathrm{t}, 3 \mathrm{H}, 6.9$ $\mathrm{Hz}), 0.094(\mathrm{~s}, 9 \mathrm{H}) ;{ }^{13} \mathbf{C}$ NMR $\left(126 \mathrm{MHz}, \mathrm{CDCl}_{3}\right) \delta 168.09,166.48,157.87,149.43$, $132.97,130.35,129.96,129.09,128.21,119.47,110.46,66.08,63.55,31.47,28.61$, 25.59, 22.64, 17.58, 14.11, -1.28; IR (neat, $\mathrm{cm}^{-1}$ ) 2958, 2923, 2851, 1747, 1709, 1621, 1529, 1352, 1272, 1246, 1196, 1099; HRMS for $\left(\mathrm{C}_{26} \mathrm{H}_{35} \mathrm{NO}_{7} \mathrm{Si}\right) \mathrm{Na}^{+}$calculated: 524.207500. Found: 524.207329. 


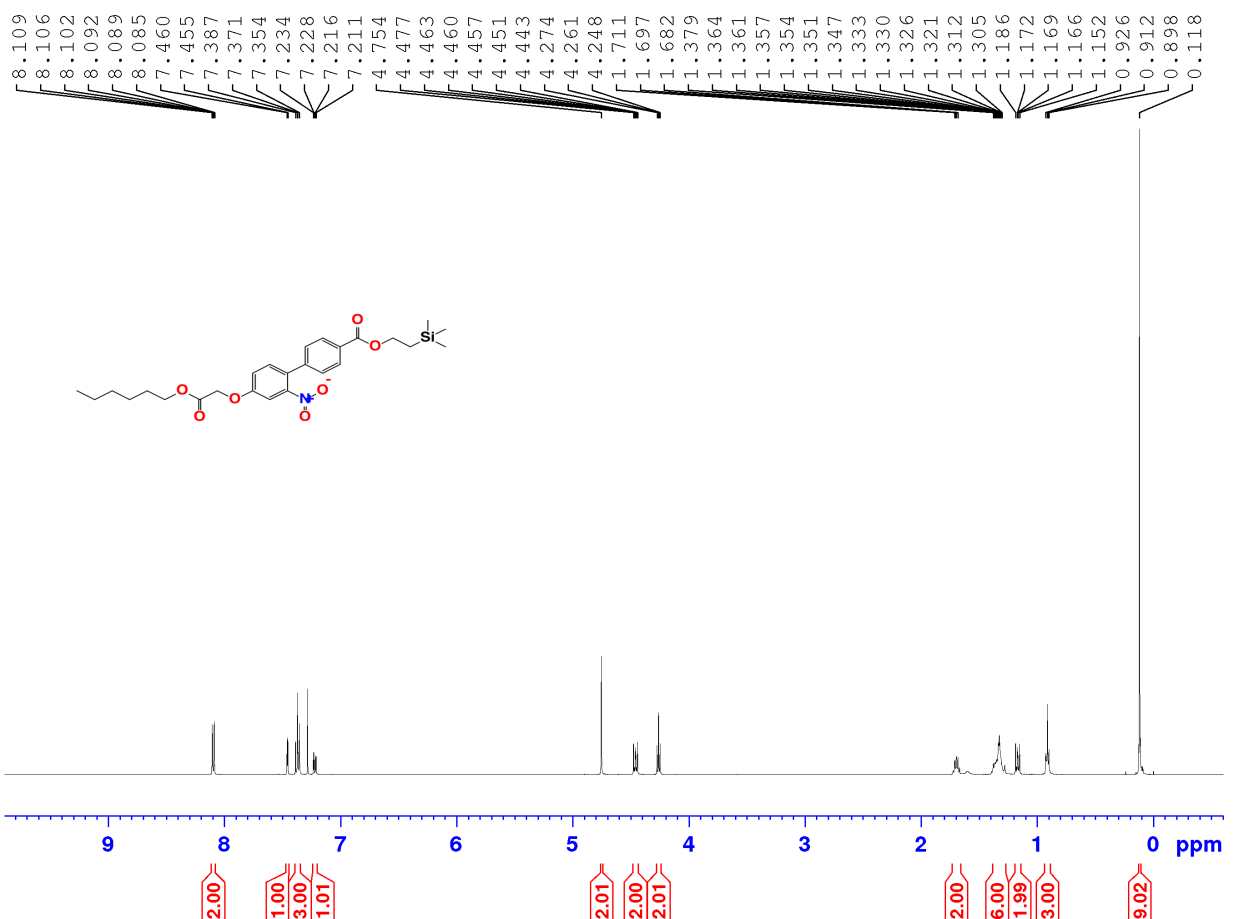

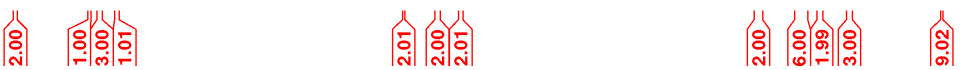

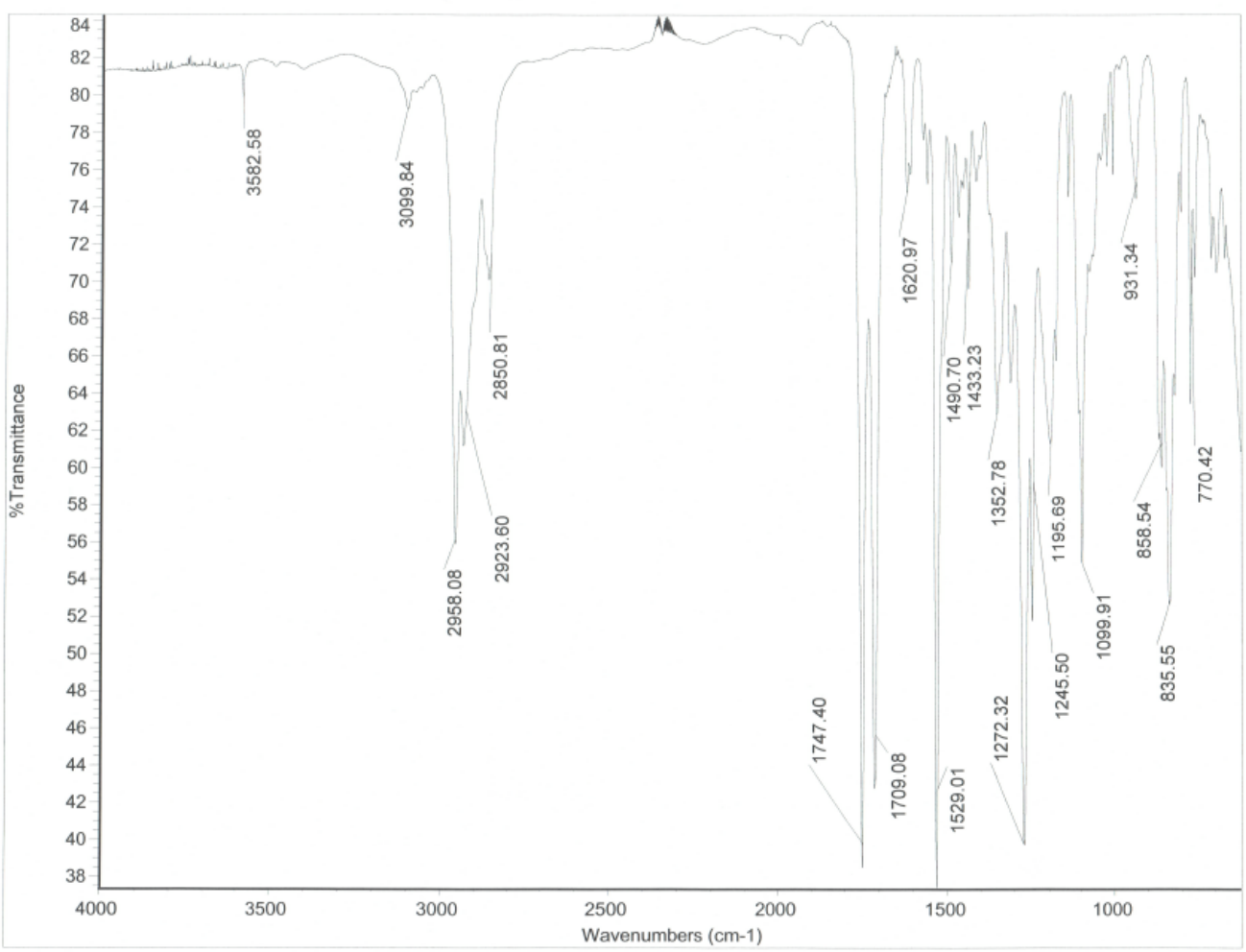



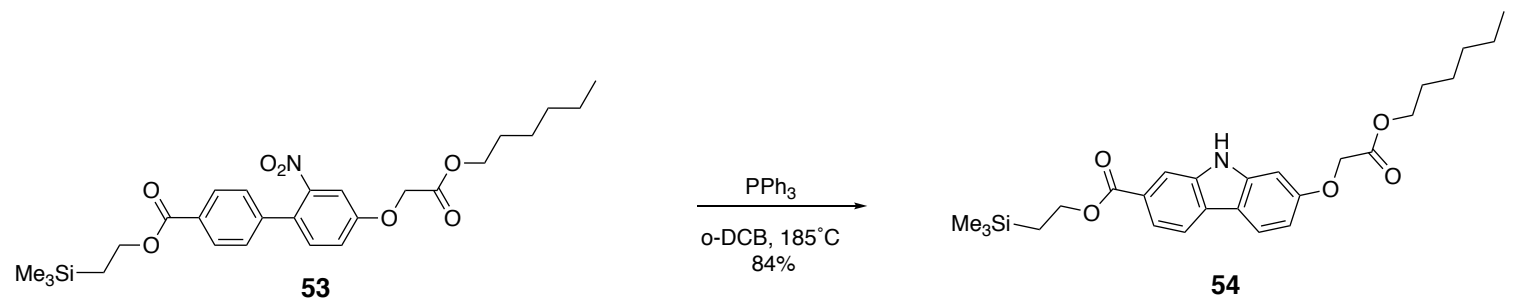

2-(trimethylsilyl)ethyl 7-(2-(hexyloxy)-2-oxoethoxy)-9H-carbazole-2-carboxylate 54:

To a solution of $\mathbf{5 3}(59.9 \mathrm{mg}, 0.1195 \mathrm{mmol})$ in o-dichlorobenzene (1.3 mL) was added $\mathrm{PPh}_{3}(79.9 \mathrm{mg}, 0.305 \mathrm{mmol})$. The resulting mixture was heated to $185^{\circ} \mathrm{C}$ and stirred for 18 hours. The reaction was cooled, concentreated and purified by flash $\mathrm{SiO}_{2}(0-3 \%$ $\mathrm{Et}_{2} \mathrm{O} / \mathrm{DCM}$ ) to give the product (47.4 $\mathrm{mg}, 0.1009 \mathrm{mmol}, 84 \%$ ) as a white solid (m.p. 151 $\left.{ }^{\circ} \mathrm{C}\right) .{ }^{1} \mathbf{H}$ NMR $\left(600 \mathrm{MHz}, \mathrm{CDCl}_{3}\right) \delta 8.195(\mathrm{~s}, 1 \mathrm{H}), 8.10(\mathrm{~d}, 1 \mathrm{H}, J=.78 \mathrm{~Hz}), 7.97(\mathrm{~m}, 2 \mathrm{H})$, $7.91(\mathrm{dd}, 1 \mathrm{H}, J=1.41,8.19 \mathrm{~Hz}), 6.93(\mathrm{~d}, 1 \mathrm{H}, J=2.16 \mathrm{~Hz}), 6.90(\mathrm{dd}, 1 \mathrm{H}, J=2.19,8.58$ $\mathrm{Hz}), 4.73(\mathrm{~s}, 2 \mathrm{H}), 4.46(\mathrm{~m}, 2 \mathrm{H}), 4.22(\mathrm{t}, 2 \mathrm{H}, J=6.72 \mathrm{~Hz}), 1.65$ (quin, $2 \mathrm{H}, J=6.78 \mathrm{~Hz}), \sim$ $1.33-1.23(\mathrm{~m}, 6 \mathrm{H}), 1.18(\mathrm{~m}, 2 \mathrm{H}), 0.84(\mathrm{t}, 3 \mathrm{H}, J=6.96 \mathrm{~Hz}), 0.11(\mathrm{~s}, 9 \mathrm{H}) ;{ }^{13} \mathbf{C}$ NMR (151 $\left.\mathrm{MHz}, \mathrm{CDCl}_{3}\right) \delta 169.23,167.6,158.27,142.08,139.12,127.18,126.99,122.19,121.13$, $119.24,117.56,112.22,109.26,96.16,66.05,65.75,63.30,31.48,28.64,25.59,22.62$, 17.64, 14.08, -1.29; IR (neat, $\mathrm{cm}^{-1}$ ) 3364, 2956, 2915, 2851, 1736, 1701, 1631, 1572, 1421, 1287, 1071; HRMS calculated for $\left(\mathrm{C}_{26} \mathrm{H}_{34} \mathrm{NO}_{5} \mathrm{Si}\right)^{-}(\mathrm{M}-\mathrm{H})^{-}:$468.22117. Found: 468.22111. 

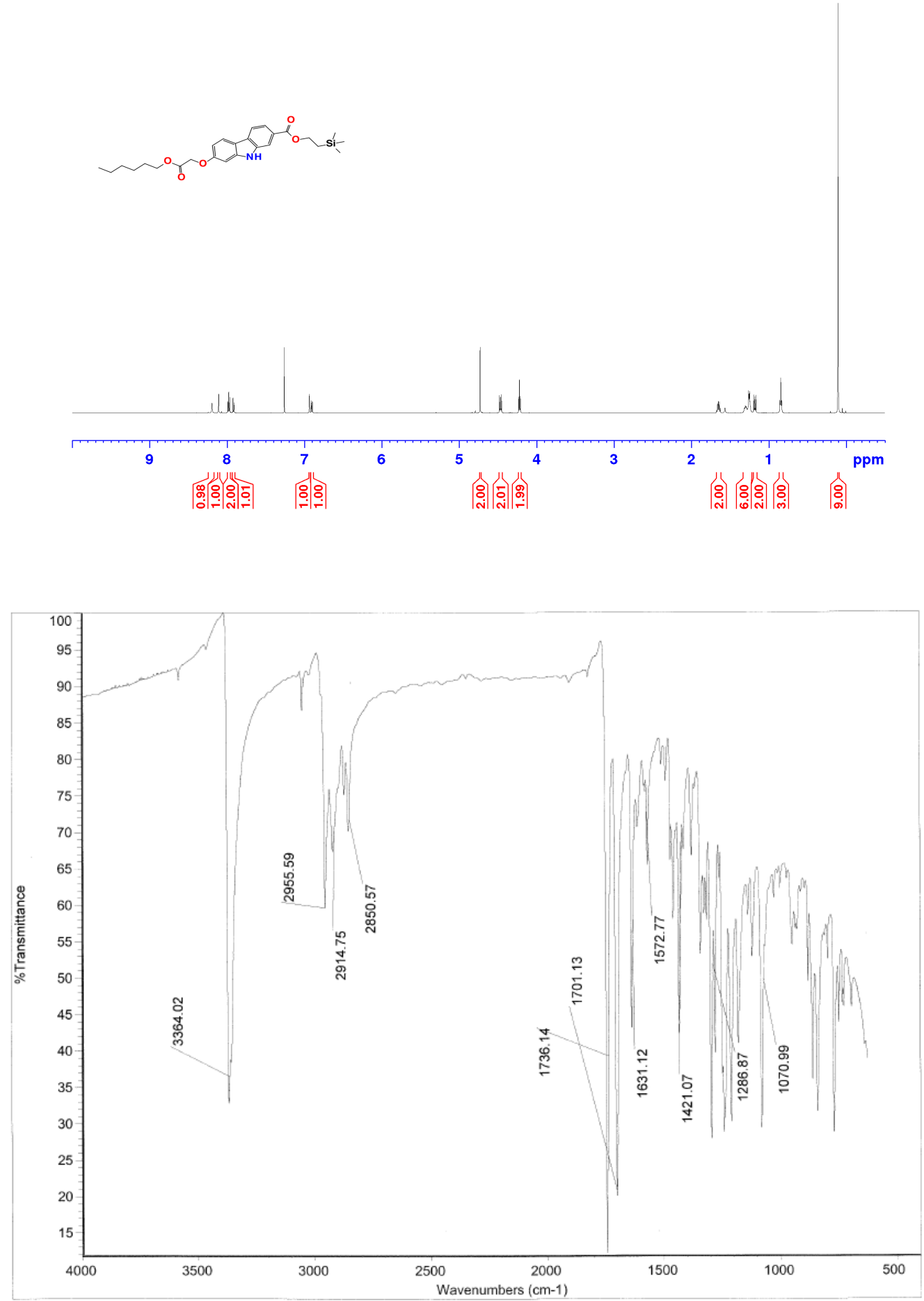


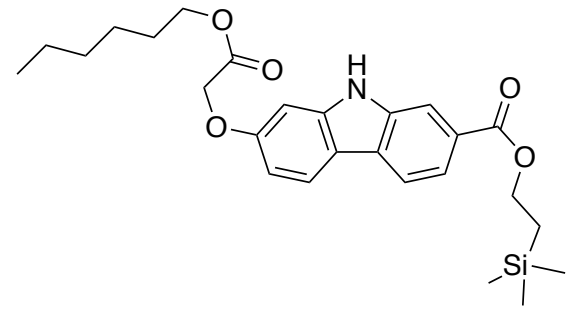

54

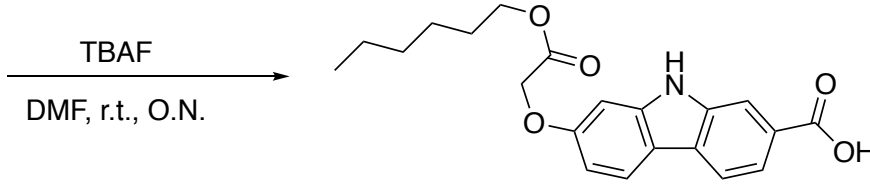

69

7-(2-(hexyloxy)-2-oxoethoxy)-9H-carbazole-2-carboxylic acid 69: To a solution of carbazole 54 (91 mg, $0.194 \mathrm{mmol})$ in DMF ( $2.0 \mathrm{~mL}$ ) was added tetrabutylammonium fluoride $1 \mathrm{M}$ in THF $(776 \mu \mathrm{L}, .776 \mathrm{mmol})$. The mixture was stirred overnight. The reaction was concentrated and purified by flash $\mathrm{SiO}_{2}(1: 1$ EtOAc/Hexane to 97:2:1 EtOAc/HexHOAc) to give the product as a white solid $67.2 \mathrm{mg}(94 \%) .{ }^{1} \mathbf{H}$ NMR (600 MHz, DMSO-d $\left.{ }_{6}\right) \delta 12.375(\mathrm{~s}, 1 \mathrm{H}), 11.29(\mathrm{~s}, 1 \mathrm{H}), 7.97(\mathrm{~m}, 3 \mathrm{H}), 7.65(\mathrm{dd}, 1 \mathrm{H}, \mathrm{J}=8.15$, $1.45 \mathrm{~Hz}), 6.89$ (s, 1H, J = 2.25 Hz), $6.75(\mathrm{dd}, 1 \mathrm{H}, \mathrm{J}=8.65,2.30 \mathrm{~Hz}), 4.81(\mathrm{~s}, 2 \mathrm{H}), 4.04(\mathrm{t}$, $2 \mathrm{H}, \mathrm{J}=6.55 \mathrm{~Hz}$ ), 1.48 (quin, $2 \mathrm{H}, \mathrm{J}=6.99 \mathrm{~Hz}), 1.16-1.08(\mathrm{~m}, 6 \mathrm{H}), 0.69(\mathrm{t}, 3 \mathrm{H}, \mathrm{J}=7.09$ $\mathrm{Hz}) ;{ }^{13} \mathbf{C}$ NMR (126 MHz, DMSO-d 6 ) $\delta 169.41,168.49,158.10,142.69,139.61,126.52$, $122.35,120.21,119.43,116.52,112.54,109.19,95.9,65.49,64.97,31.25,28.51,25.35$, 22.37, 14.24; IR $\left(\mathrm{KBr}, \mathrm{cm}^{-1}\right) 3550,2950,2864,1736,1683,1630,1563,1491,1332$; HRMS calculated for $\left(\mathrm{C}_{21} \mathrm{H}_{22} \mathrm{NO}_{5}\right)^{-}(\mathrm{M}-\mathrm{H})^{-} 368.15035$. Found: 368.15005. 

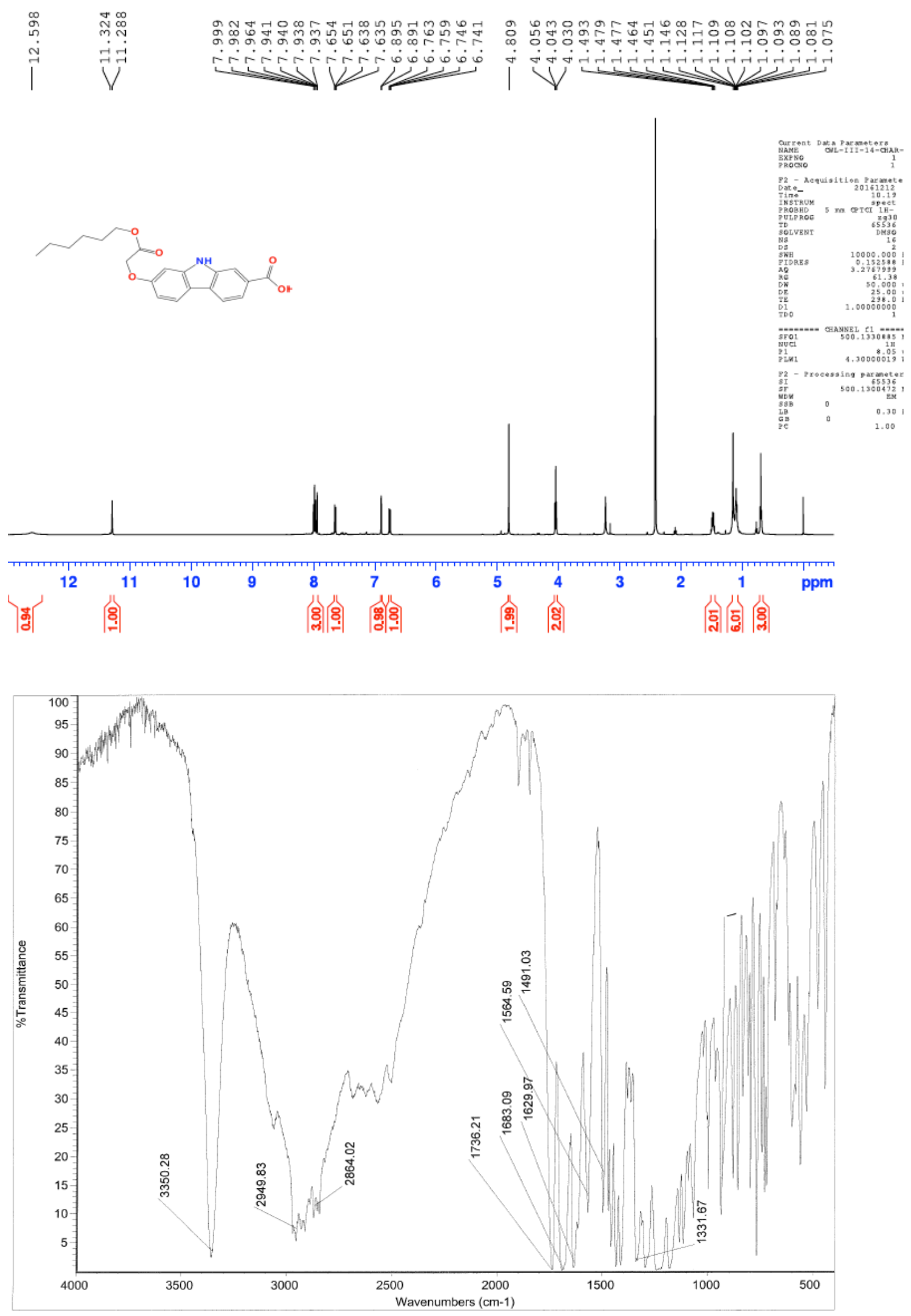


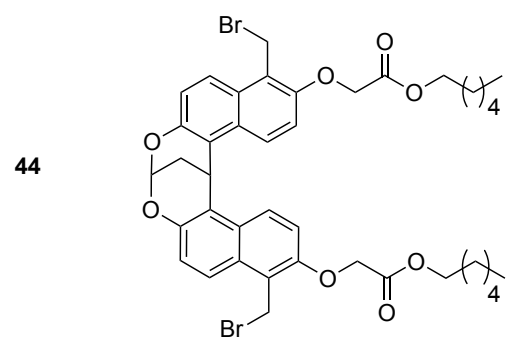

55

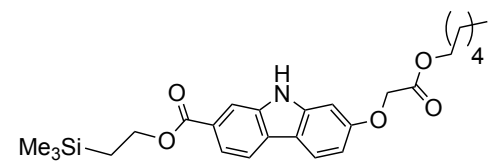

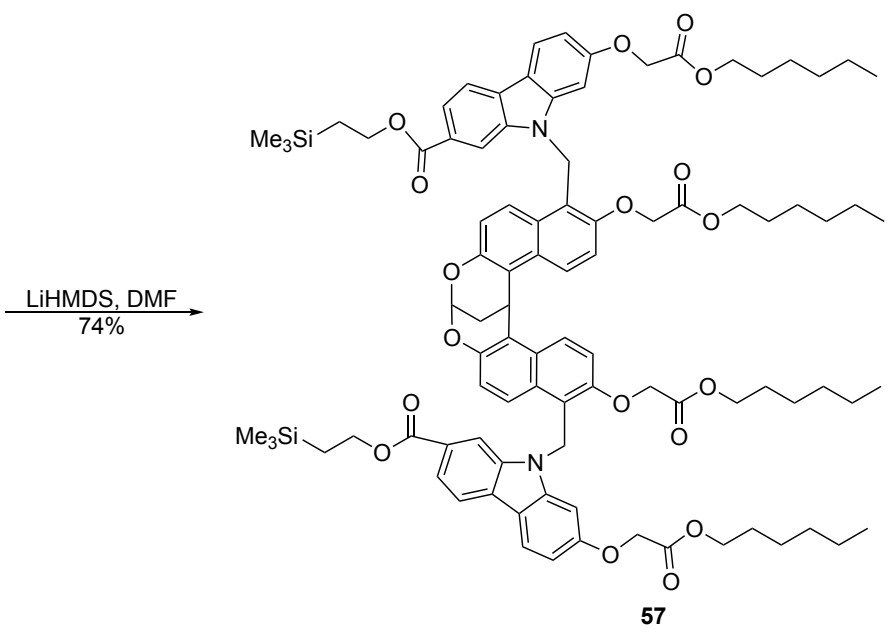

bis(2-(trimethylsilyl)ethyl)-9,9'-((3,13-bis(2-(hexyloxy)-2-oxoethoxy)-16H-8,16methanodinaphtho[2,1-d:1',2'-g][1,3]dioxocine-4,12-diyl)bis(methylene))bis(7-(2(hexyloxy)-2-oxoethoxy)-9H-carbazole-2-carboxylate) 55: To a solution of carbazole $54(56 \mathrm{mg}, 0.119 \mathrm{mmol})$ in DMF $(3.0 \mathrm{~mL})$ at $0{ }^{\circ} \mathrm{C}$ was added LiHMDS (1M in THF) (113 $\mu \mathrm{L}, .113 \mathrm{mmol})$. The mixture was stirred for five minutes. Dibromide 44 (44.2 mg, 0.0536) was dried in a vial, air evacuated $2 \mathrm{x}$ and pump in $\mathrm{N}_{2}$ (g). The solid was then dissolved in DMF (3 mL) and added via syringe to the reaction. The container and syringe were washed with DMF $(2 \times 1.5 \mathrm{~mL})$ and added to the reaction. The reaction was continued stirring 10 minutes at $0^{\circ} \mathrm{C}$ and then raised to room temperature and continued stirring for 16 hours. The reaction was concentrated and quenched with sat. $\mathrm{NH}_{4} \mathrm{Cl}$ and extracted with DCM (3 x $75 \mathrm{~mL})$ to get crude. The crude was purified by flash chromatography (DCM) to give the product as a white solid $(63.6 \mathrm{mg}, .04 \mathrm{mmol}) 35 \%$. ${ }^{1} \mathbf{H}$ NMR $\left(500 \mathrm{MHz}, \mathrm{CDCl}_{3}\right) \delta 8.55(\mathrm{~d}, 2 \mathrm{H}, J=9.5 \mathrm{~Hz}), 7.95(\mathrm{~s}, 2 \mathrm{H}), \sim 7.96-7.85(\mathrm{~m}$, 6H), $7.68(\mathrm{~d}, 2 \mathrm{H}, J=8.2 \mathrm{~Hz}), 7.34(\mathrm{~d}, 2 \mathrm{H}, 9.4 \mathrm{~Hz}), 6.96(2 \mathrm{H}, \mathrm{d}, 9.26 \mathrm{~Hz}), 6.84(\mathrm{~s}, 2 \mathrm{H})$, $6.78(\mathrm{dd}, 2 \mathrm{H}, J=2.1,8.55 \mathrm{~Hz}), 6.13(\mathrm{~s}, 1 \mathrm{H}), 5.86(\mathrm{~m}, 4 \mathrm{H}), 5.22(\mathrm{~s}, 1 \mathrm{H}), 4.82(\mathrm{~m}, 4 \mathrm{H})$, $4.51(\mathrm{~s}, 4 \mathrm{H}), 4.42(\mathrm{~m}, 4 \mathrm{H}), 4.11(\mathrm{~m}, 4 \mathrm{H}), 3.94(\mathrm{t}, 4 \mathrm{H}, J=6.6 \mathrm{~Hz}), 2.30(\mathrm{~s}, 2 \mathrm{H}), \sim 1.6-$ 
$1.49(\mathrm{~m}, 4 \mathrm{H}), \sim 1.37-1.11(\mathrm{~m}, 24 \mathrm{H}), \sim 1.10-0.96(\mathrm{~m}, 8 \mathrm{H}), 0.79(\mathrm{t}, 6 \mathrm{H}, J=7 \mathrm{~Hz}), 0.72$ (t, 6H, $J=7.15 \mathrm{~Hz}), .012(\mathrm{~s}, 18 \mathrm{H}) .{ }^{13} \mathrm{C}$ NMR $\left(151 \mathrm{MHz}, \mathrm{CDCl}_{3}\right) \delta 169.15,169.08$, $167.71,158.06,152.76,149.11,143.32,140.58,129.65,127.58,126.91,126.53,124.92$ $123.52,121.84,120.52,120.3,119.09,119.04,118.99,117.05,114.23,111.08,108.95$, $94.9,91.21,66.8,65.69,65.66,65.45,63.15,31.45,31.34,28.56,28.53,26.98,25.57$, 25.39, 22.57. 22.48, 17.67, 14.07, 13.99, -1.24; IR (neat, $\mathrm{cm}^{-1}$ ) 2954, 2921, 2852, 1761, 1704, 1626, 1597, 1454, 1434, 1246, 1172, 1054; HRMS calculated for $\left(\mathrm{C}_{93} \mathrm{H}_{114} \mathrm{~N}_{2} \mathrm{O}_{18} \mathrm{Si}_{2}\right) \mathrm{Na}^{+}(\mathrm{M}+\mathrm{Na})^{+}: 1625.74974$. Found: 1625.74936. 


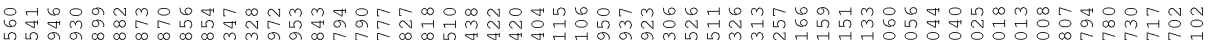

000000

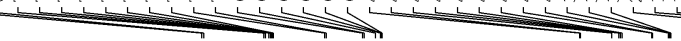
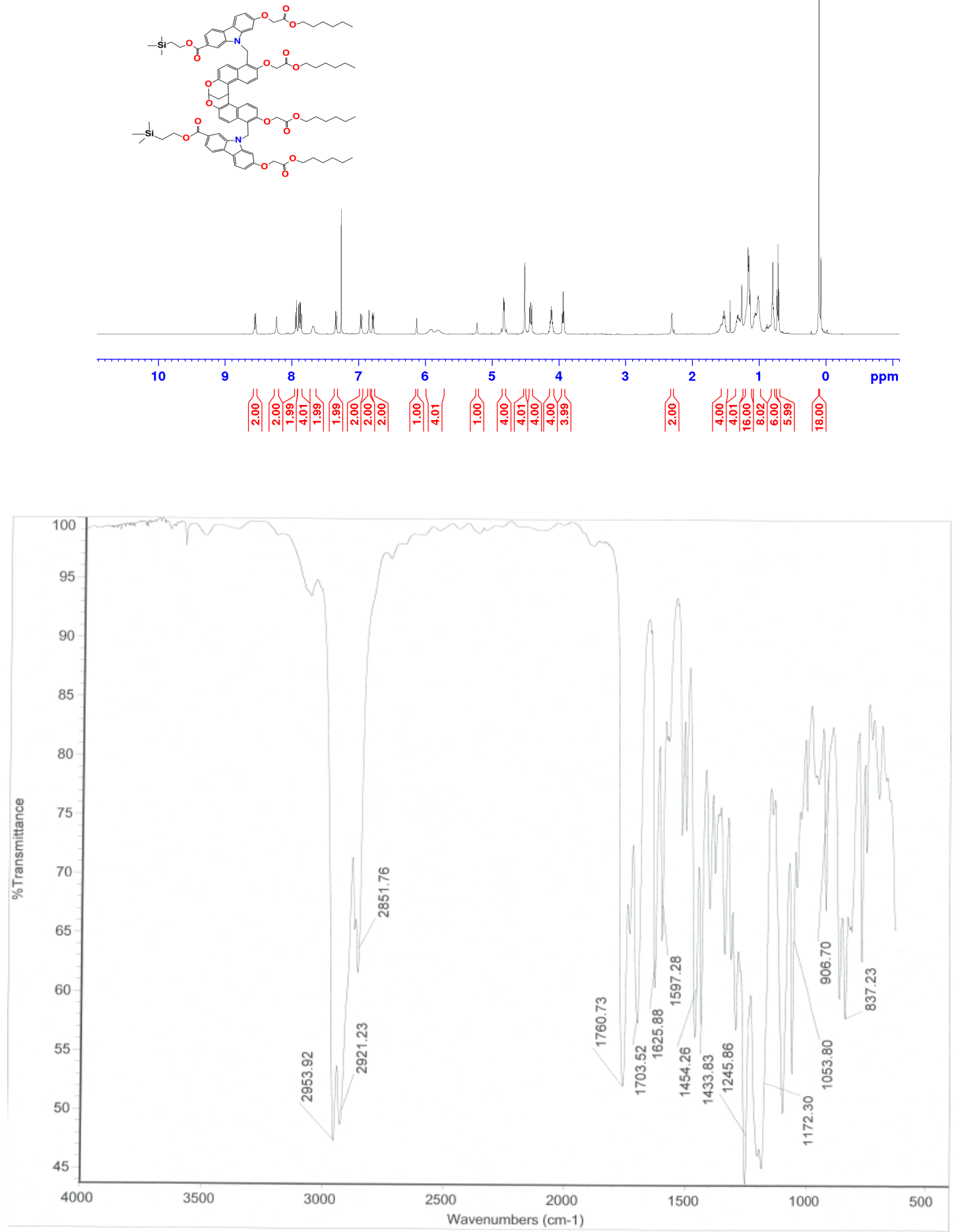


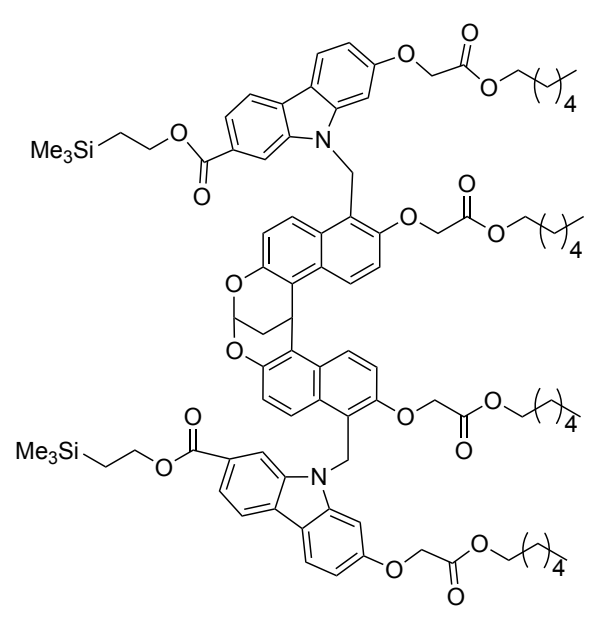

55

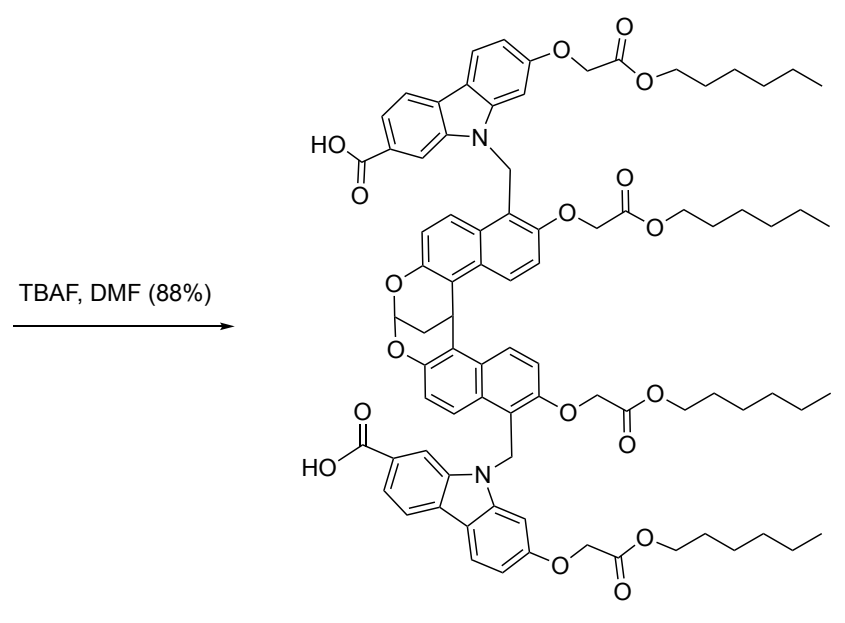

56

9,9'-((3,13-bis(2-(hexyloxy)-2-oxoethoxy)-16H-8,16-methanodinaphtho[2,1-d:1',2'-

g][1,3]dioxocine-4,12-diyl)bis(methylene))bis(7-(2-(hexyloxy)-2-oxoethoxy)-9H-

carbazole-2-carboxylic acid) 56: To a solution of $55(46.1 \mathrm{mg}, 0.0288 \mathrm{mmol})$ in $\operatorname{DMF}(0.8 \mathrm{~mL})$ was added TBAF, $1 \mathrm{M}$ in THF, $(144 \mu \mathrm{L}, .144 \mathrm{mmol})$. The reaction was stirred for 48 hours. The reaction was concentrated and purified by flash $\mathrm{SiO}_{2}$ chromatography (2:1 hexane/EtOAc/1:1 hexane/EtOAc/97:2:1 EtOAc/hexane/HOAc) and concentreated to give the product as a white solid $(35.6 \mathrm{mg}, .0254 \mathrm{mmol}, 88 \%) .{ }^{1} \mathbf{H}$ NMR $\left(500 \mathrm{MHz}, \mathrm{CDCl}_{3}\right) \delta 12.63(\mathrm{~s}, 2 \mathrm{H}), 8.78(\mathrm{~d}, 2 \mathrm{H}, J=9.5 \mathrm{~Hz}), 8.17(\mathrm{~s}, 2 \mathrm{H}), 8.03(\mathrm{~d}$, $2 \mathrm{H}, J=8.05 \mathrm{~Hz}), 8.01(\mathrm{~d}, 2 \mathrm{H}, J=8.5 \mathrm{~Hz}), 7.72(\mathrm{~s}, 2 \mathrm{H}), 7.67(\mathrm{dd}, 2 \mathrm{H}, J=1.25,5.55 \mathrm{~Hz})$ 7.50 (d, 2H, $9.55 \mathrm{~Hz}, 7.17(\mathrm{~s}, 2 \mathrm{H}), 6.90$ (d, 2H, $J=9.2 \mathrm{~Hz}), 6.79$ (dd, 2H, $J=2.1,8.6$ $\mathrm{Hz}), 6.23(\mathrm{~s}, 1 \mathrm{H}), 5.96(\mathrm{br} \mathrm{s}, 4 \mathrm{H}), 5.55(\mathrm{~s}, 1 \mathrm{H}), 5.00(\mathrm{~s}, 4 \mathrm{H}), 4.75(\mathrm{~s}, 4 \mathrm{H}), 4.05(\mathrm{t}, 4 \mathrm{H}, J=$ $6.4 \mathrm{~Hz}$ ), $3.88(\mathrm{t}, 4 \mathrm{H}, 6.35 \mathrm{~Hz}), 2.26(\mathrm{~s}, 2 \mathrm{H}), 1.43$ (quin, 4H, $J=6.98 \mathrm{~Hz}$ ), $1.28-0.89$ $(\mathrm{m}, 24 \mathrm{H}), 0.65(\mathrm{t}, 6 \mathrm{H}, J=7.12 \mathrm{~Hz}), 0.62(\mathrm{t}, 6 \mathrm{H}, J=6.98 \mathrm{~Hz}) ;{ }^{13} \mathbf{C}$ NMR $(151 \mathrm{MHz}$, $\left.\mathrm{CDCl}_{3}\right) \delta 168.69,168.66,167.93,127.07,126.38,125.98,125.57,123.21,121.83$, $120.01,119.52,118.99,118.81,118.06,115.78,114.41,111.21,108.66,94.54,90.65$, $66.23,64.72,64.66,64.41,30.73,30.63,27.92,27.80,24.92,24.70,21.80,21.74,13.67$, 
13.64; IR $\left(\mathrm{KBr}, \mathrm{cm}^{-1}\right) 3416,3068,2954,2929,2852,1748,1675,1622,1597,1519$, $1458,1433,1393,1332,1258,1176,1098,1058$; HRMS calculated for $\left(\mathrm{C}_{84} \mathrm{H}_{92} \mathrm{~N}_{2} \mathrm{O}_{17}\right) \mathrm{Na}^{+}(\mathrm{M}+\mathrm{Na})^{+}:$1425.60808. Found: 1425.60853. 

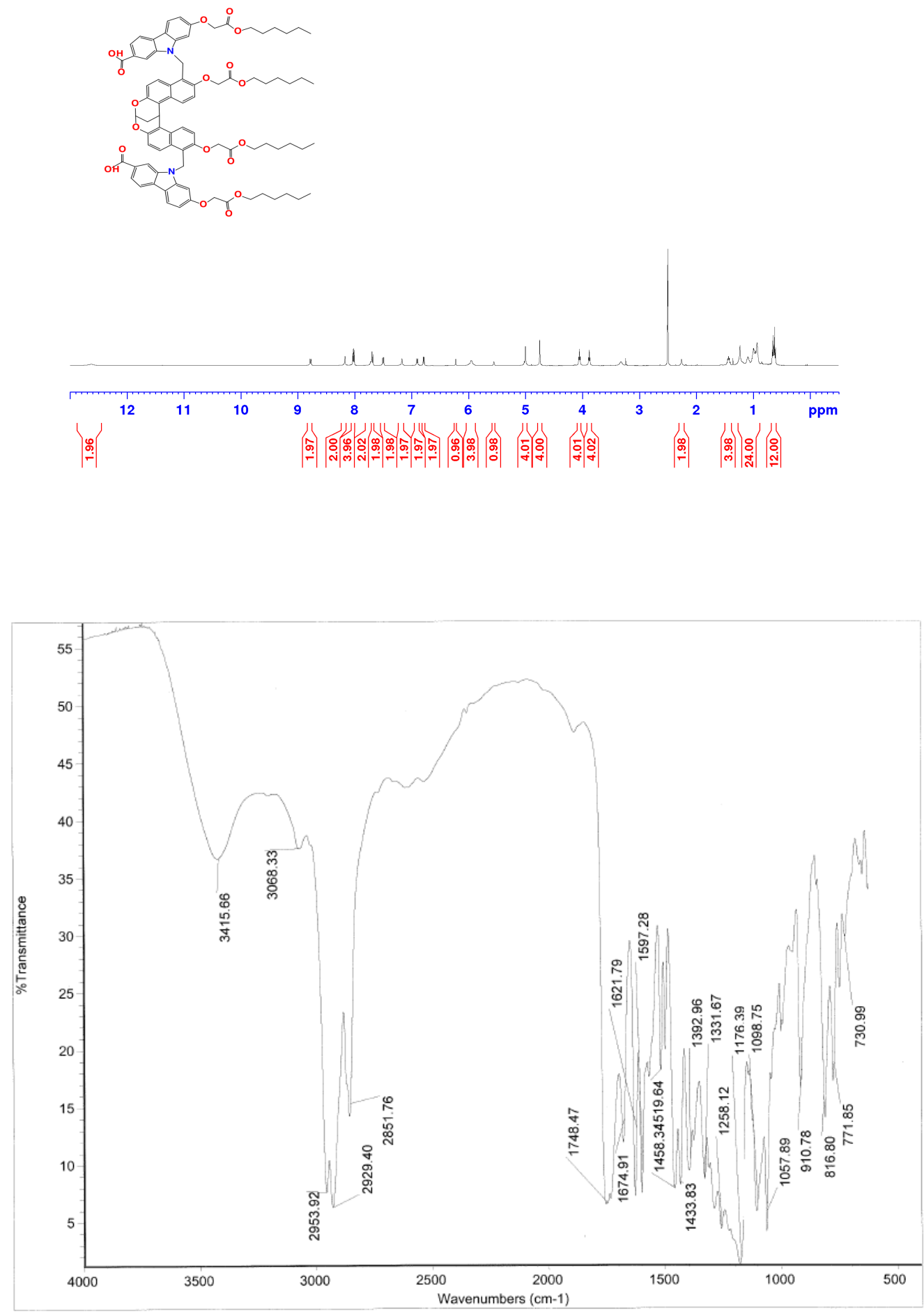

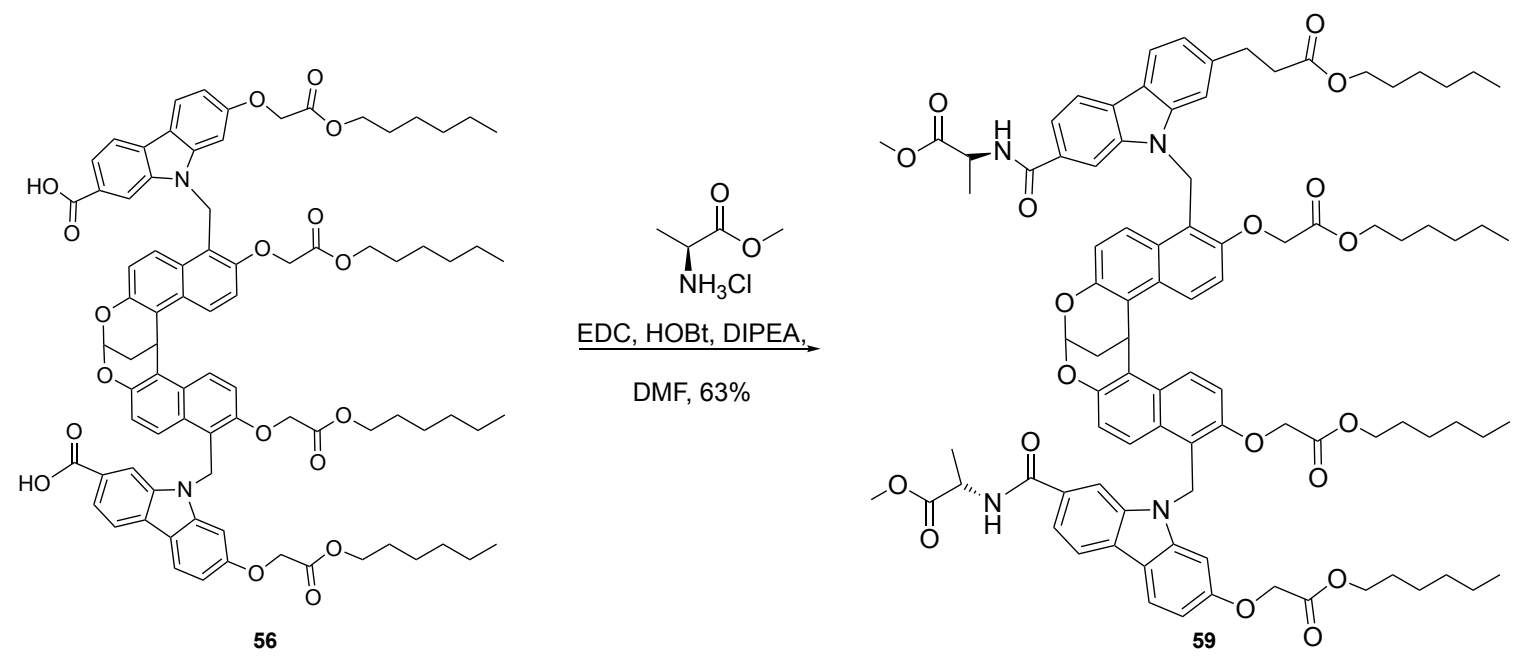

dihexyl-2,2'-((4-((2-(2-(hexyloxy)-2-oxoethoxy)-7-(((S)-1-methoxy-1-oxopropan-2yl)carbamoyl)-9H-carbazol-9-yl)methyl)-12-((2-(3-(hexyloxy)-3-oxopropyl)-7-(((R)1-methoxy-1-oxopropan-2-yl)carbamoyl)-9H-carbazol-9-yl)methyl)-16H-8,16methanodinaphtho[2,1-d:1',2'-g][1,3]dioxocine-3,13-diyl)bis(oxy))diacetate $59: 56$ (50.2 mg, $0.0358 \mathrm{mmol})$ was dissolved in DMF (5 mL) with HOBT (11.6 mg, 0.0859 mmol), DIPEA (59 $\mu \mathrm{L}, .358 \mathrm{mmol})$, and EDC (16.5 mg, 0.0859mmol) and stirred for 10 minutes. L-alanine methyl ester hydrochloride $(11 \mathrm{mg}, 0.0788 \mathrm{mmol})$ was added and the reaction was stirred for 16 hours. The reaction was then concentrated to give crude, which was washed with water and extracted with DCM $(3 \times 50 \mathrm{~mL})$ and concentrated. The resulting crude was then purified by flash $\mathrm{SiO}_{2}$ (DCM $-10 \%$ THF/DCM to give the product as a white solid (36 mg, .0229 mmol, 64\%). ${ }^{1}$ H NMR (500 MHz, DMSO) $\delta 8.78$ $(\mathrm{t}, 2 \mathrm{H}, J=9 \mathrm{~Hz}), 8.04(\mathrm{dd}, 2 \mathrm{H}, J=2.93,8.77 \mathrm{~Hz}), 7.99(\mathrm{dd}, 2 \mathrm{H}, J=2.05,8.55 \mathrm{~Hz}), 7.68$ $(\mathrm{d}, 2 \mathrm{H}, J=8.25 \mathrm{~Hz}), 7.5(\mathrm{dd}, 2 \mathrm{H}, J=3.75,9.55 \mathrm{~Hz}), 7.07(\mathrm{~s}, 1 \mathrm{H}), 7.02(\mathrm{~s}, 1 \mathrm{H}), 6.8(\mathrm{~d}$, $2 \mathrm{H}, J=9.25 \mathrm{~Hz}), 6.76(\mathrm{~m}, 2 \mathrm{H}), 6.22(\mathrm{~s}, 1 \mathrm{H}), 5.95(\mathrm{~m}, 4 \mathrm{H}), 5.56(\mathrm{~s}, 1 \mathrm{H}), 5.02(\mathrm{~s}, 4 \mathrm{H})$, $4.70(\mathrm{~s}, 2 \mathrm{H}), 4.68(\mathrm{~s}, 2 \mathrm{H}), 4.51$ (quind, $2 \mathrm{H}, J=1.93,7.2 \mathrm{~Hz}), 4.06(\mathrm{t}, 4 \mathrm{H}, J=6.33 \mathrm{~Hz})$, 
$3.88(\mathrm{~m}, 4 \mathrm{H}), 3.65(\mathrm{~d}, 6 \mathrm{H}, J=1.65 \mathrm{~Hz}), 2.26(\mathrm{~s}, 2 \mathrm{H}, 1.46(\mathrm{~m}, 4 \mathrm{H}), 1.42(\mathrm{~d}, 6 \mathrm{H}, J=7.25$ $\mathrm{Hz}), \sim 1.30-0.90(\mathrm{~m}, 24 \mathrm{H}), 0.70(\mathrm{~m}, 6 \mathrm{H}), 0.64(\mathrm{t}, 3 \mathrm{H}, J=7.2 \mathrm{~Hz}), 0.63(\mathrm{t}, 3 \mathrm{H}, J=7.35)$;

${ }^{13} \mathrm{C}(126 \mathrm{MHz}, \mathrm{DMSO}) \delta 168.79,168.67,166.69,166.62,157.44,157.40,152.41$, $142.55,140.04,129.56,129.49,128.73,127.05,125.57,124.89,123.19,121.63,119.53$, $118.99,118.71,11.18,117.96,115.95,114.49,108.39,94.60,90.64,66.17,64.64,64.40$, $51.82,48.28,30.75,30.62,30.61,27.93,27.81,27.79,24.92,24.70,24.68,21.84,21.75$, 21.74, 16.87, 16.86, 13.72, 13.65; IR (neat, $\mathrm{cm}^{-1}$ ) 3376, 3300, 2950, 2926, 2851, 1742, $1625,1520,1456,1258,1199,1094,1048$; HRMS calculated for $\left(\mathrm{C}_{92} \mathrm{H}_{106} \mathrm{~N}_{4} \mathrm{O}_{19}\right) \mathrm{H}^{+}(\mathrm{M}$ $+\mathrm{H})^{+}:$1573.73167. Found: 1573.73169 . 

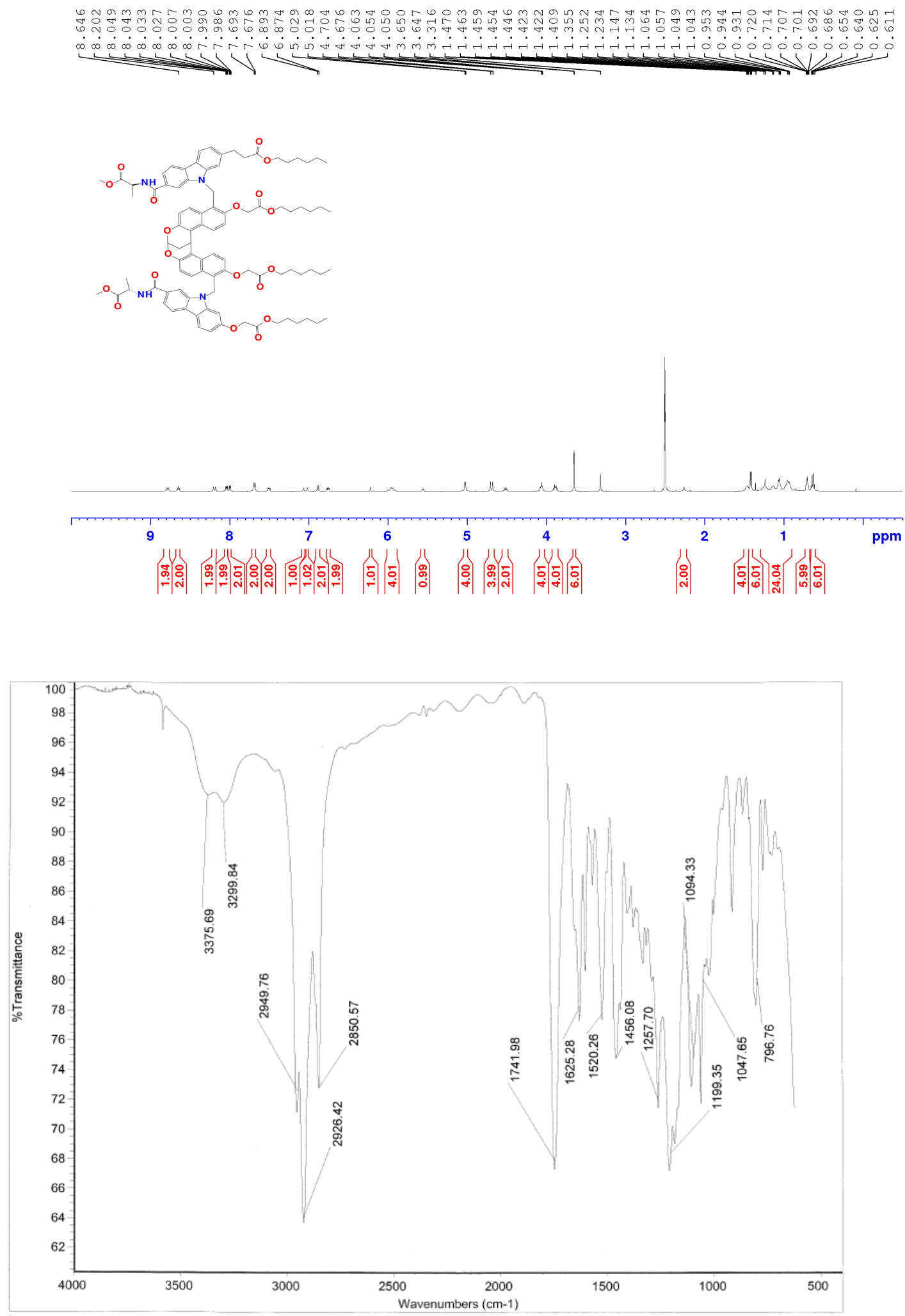

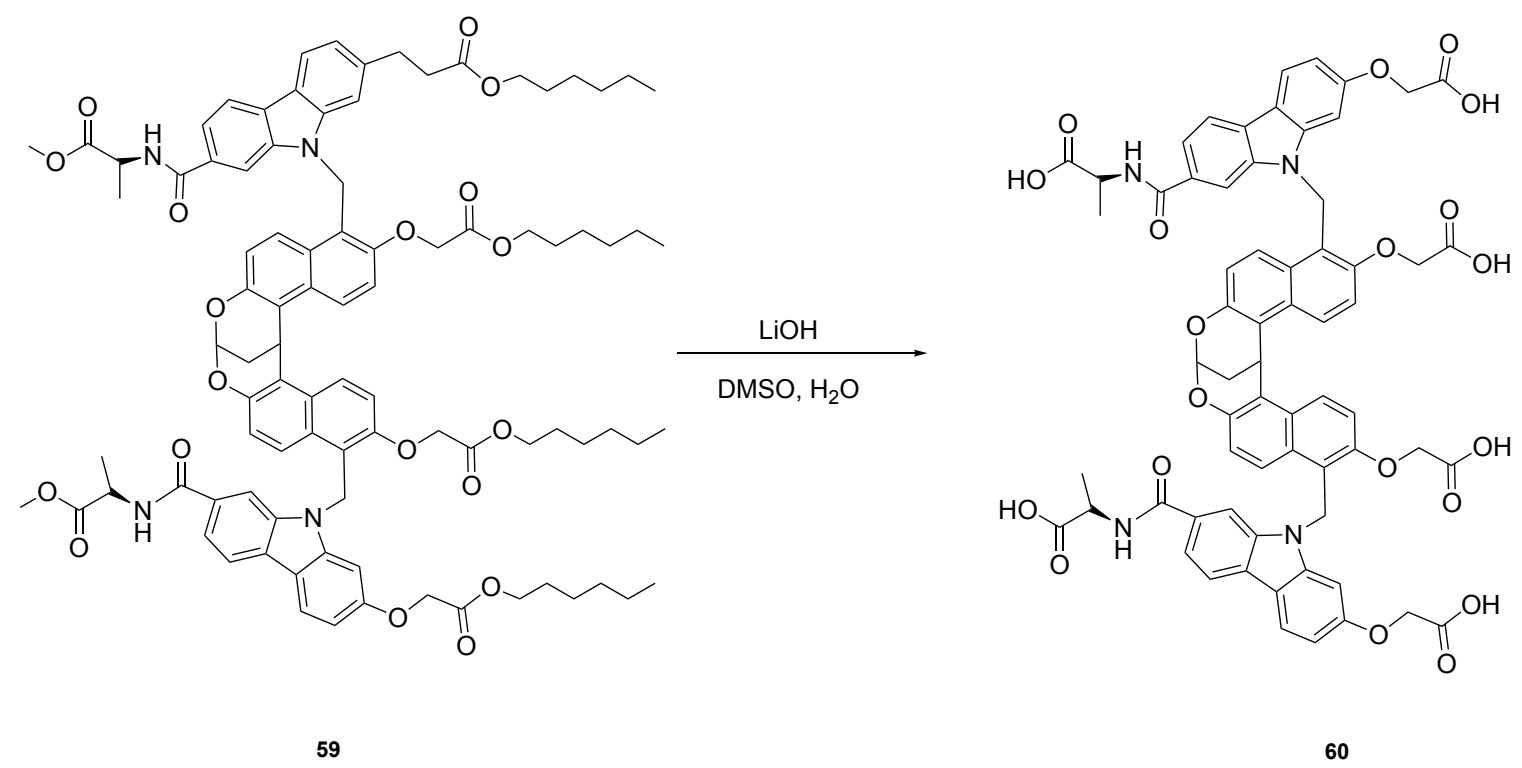

2,2'-((4-((2-(((R)-1-carboxyethyl)carbamoyl)-7-(carboxymethoxy)-9H-carbazol-9yl)methyl)-12-((2-(((S)-1-carboxyethyl)carbamoyl)-7-(carboxymethoxy)-9Hcarbazol-9-yl)methyl)-16H-8,16-methanodinaphtho[2,1-d:1',2'-g][1,3]dioxocine-3,13diyl)bis(oxy))diacetic acid 60:

To a solution of $\mathbf{5 9}(18.7 \mathrm{mg}, .01163 \mathrm{mmol})$ in DMSO $(1.2 \mathrm{~mL})$ was added $\mathrm{LiOH}$ in $\mathrm{H}_{2} \mathrm{O}$ $(80.6 \mu \mathrm{L}, .08155 \mathrm{mmol}, 42.48 \mathrm{mg} / \mathrm{mL})$ and water $(100 \mu \mathrm{L})$ and the reaction was stirred for three days. The flask was then placed on the vacuum for two days until dry, dissolved in $2 \mathrm{~mL} \mathrm{H}_{2} \mathrm{O}$ and subjected to HPLC purification on a $\mathrm{C}_{18}$ column using a $\mathrm{H}_{2} \mathrm{O} / \mathrm{MeCN}$ gradient to obtain the product as a blue solid $6.7 \mathrm{mg}, 48 \%$. Product was analyzed by LCMS for purity and mass analysis. LC-MS calculated mass $\left(\mathrm{C}_{65} \mathrm{H}_{53} \mathrm{~N}_{4} \mathrm{O}_{20}\right) \mathrm{H}^{+}(\mathrm{M}+\mathrm{H})^{+}$: 1209.3248, found: $1209.04 ;\left(\mathrm{C}_{65} \mathrm{H}_{53} \mathrm{~N}_{4} \mathrm{O}_{20}\right) \mathrm{Na}^{+}(\mathrm{M}+\mathrm{Na})^{+}: 1231.3073$, found: 1231.31 . 


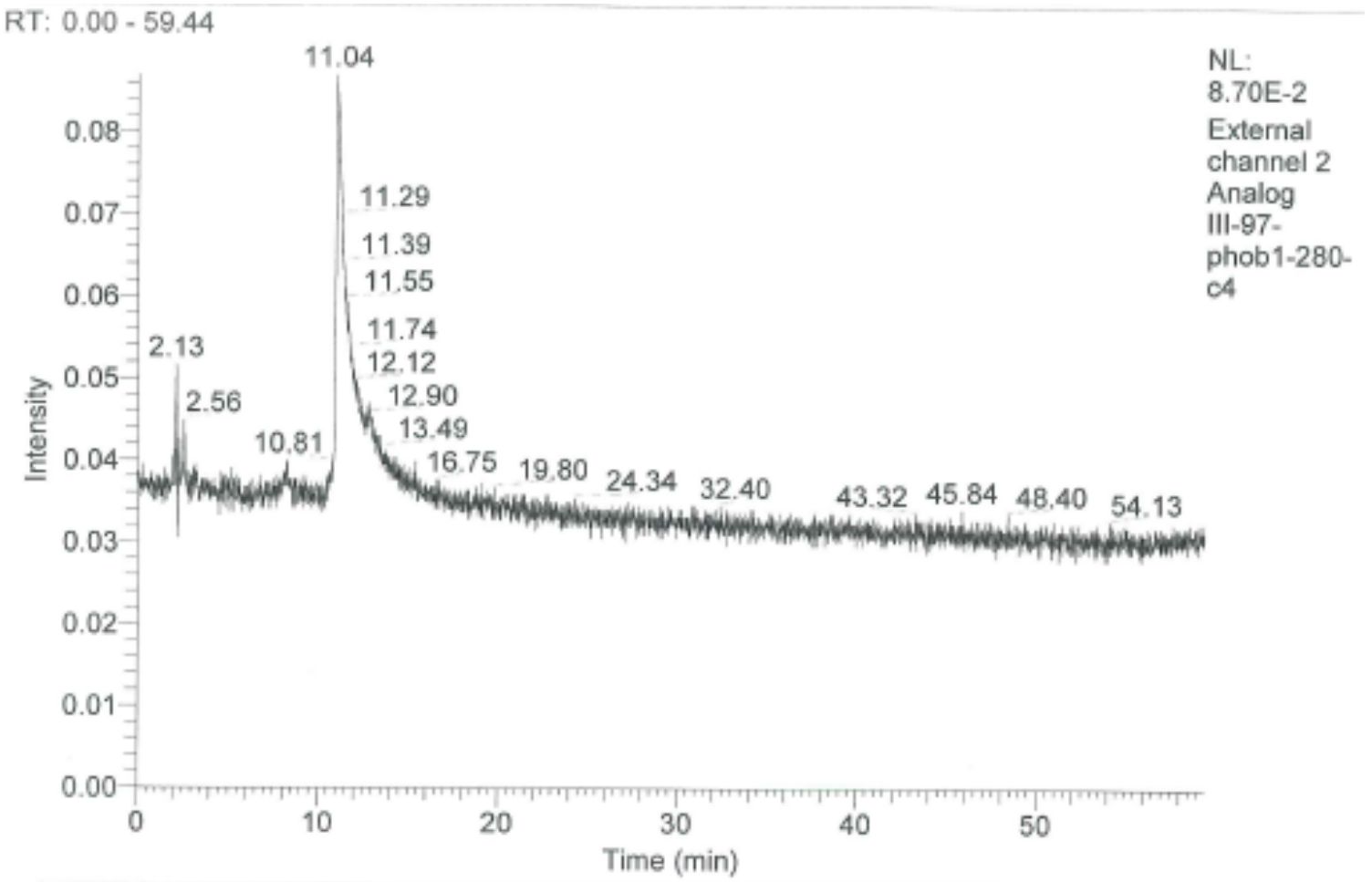

III-97-phob1-280-c4 \#791-880 RT: 11.11-12.36 AV: 90 NL: 4.96E2

T: ITMS + c ESI Full ms [150.00-2000.00]

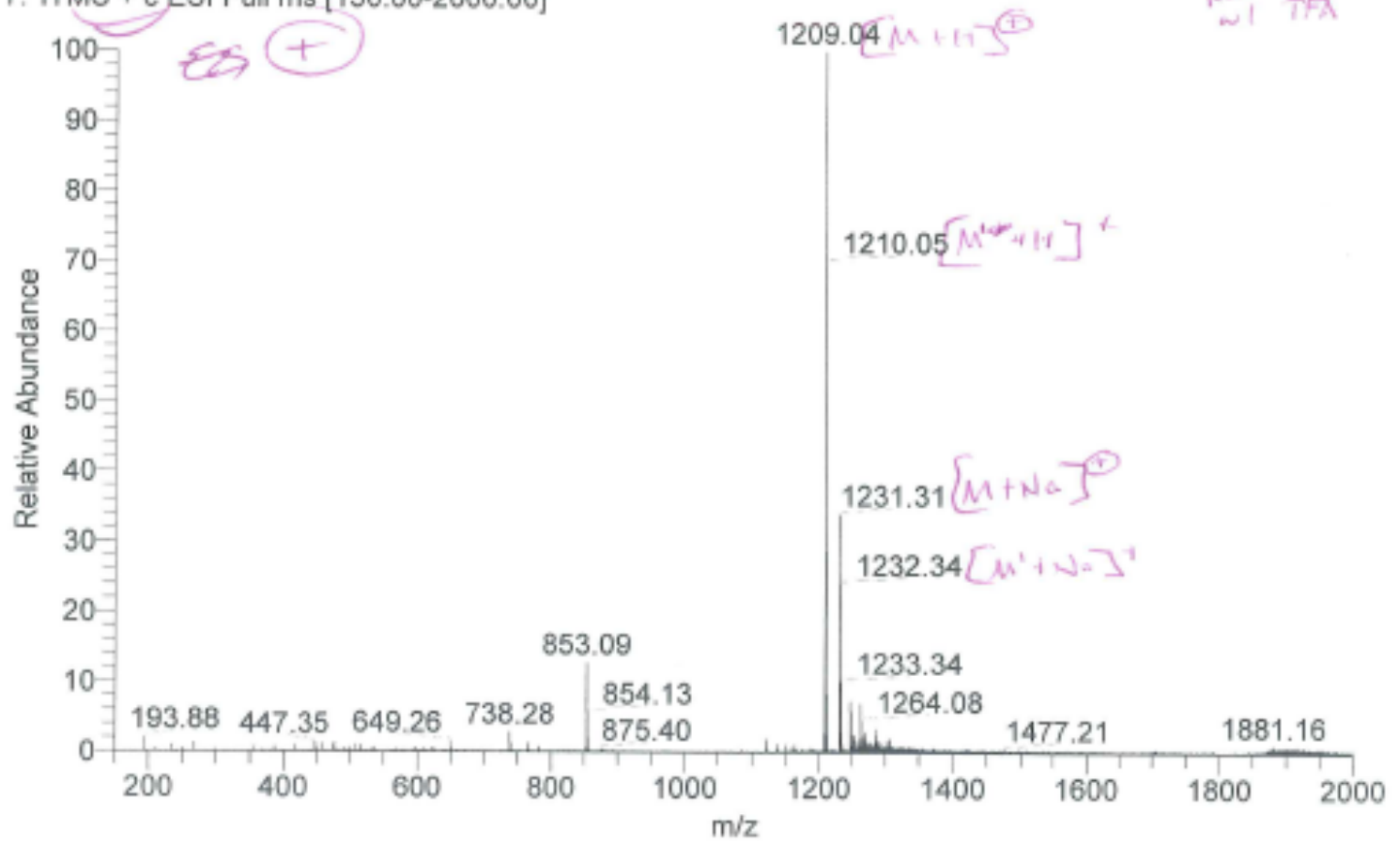




\section{Fluorescence Titrations}
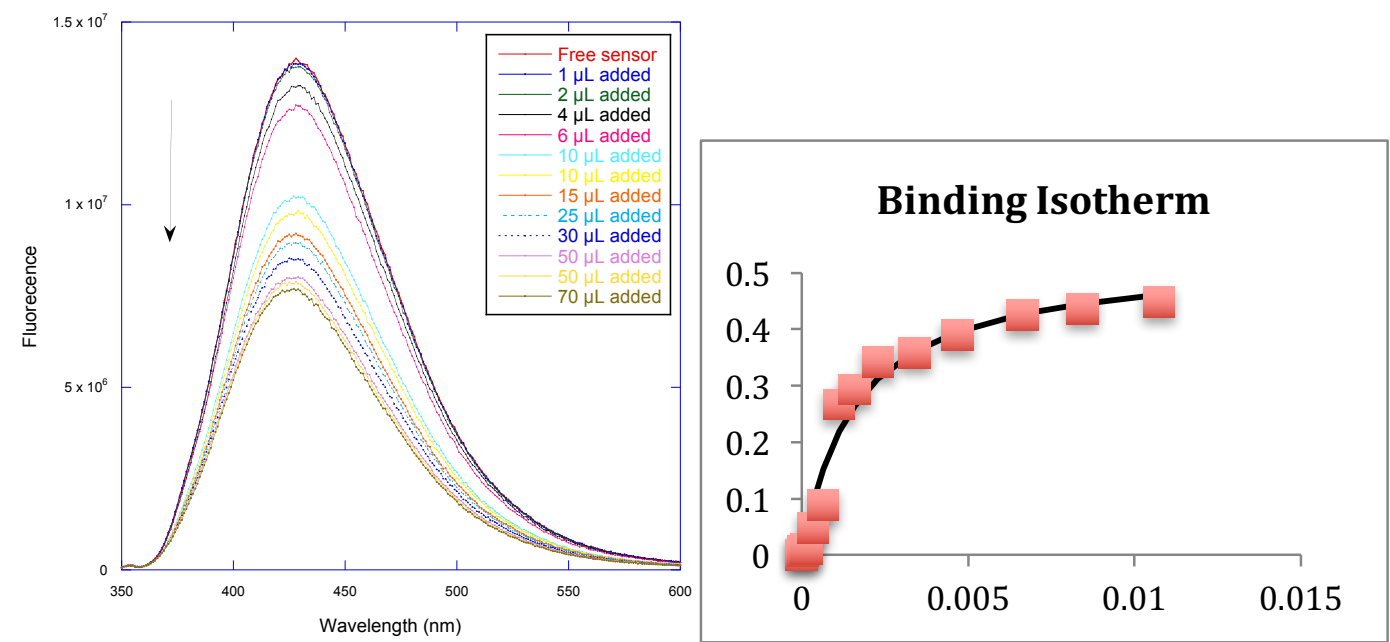

Figure S-1 Fluroescence titration of $\mathbf{6 0}$ with hexylamine in buffer (25 mM hepes, 120 $\mathrm{mM} \mathrm{NaCl}, \mathrm{pH} 7.4 ;[60]=10^{-5} \mathrm{M} ;[$ Hexylamine $\left.]=.05 \mathrm{M}, \lambda_{\mathrm{ex}}=315 \mathrm{~nm}\right):$ a) Fluorescence emission spectra as a funciton of added hexylamine, b) fit of titration data at $\lambda_{\mathrm{em}}=429 \mathrm{~nm}$ to a single site binding isotherm, $\mathrm{R}^{2}=0.9735$.
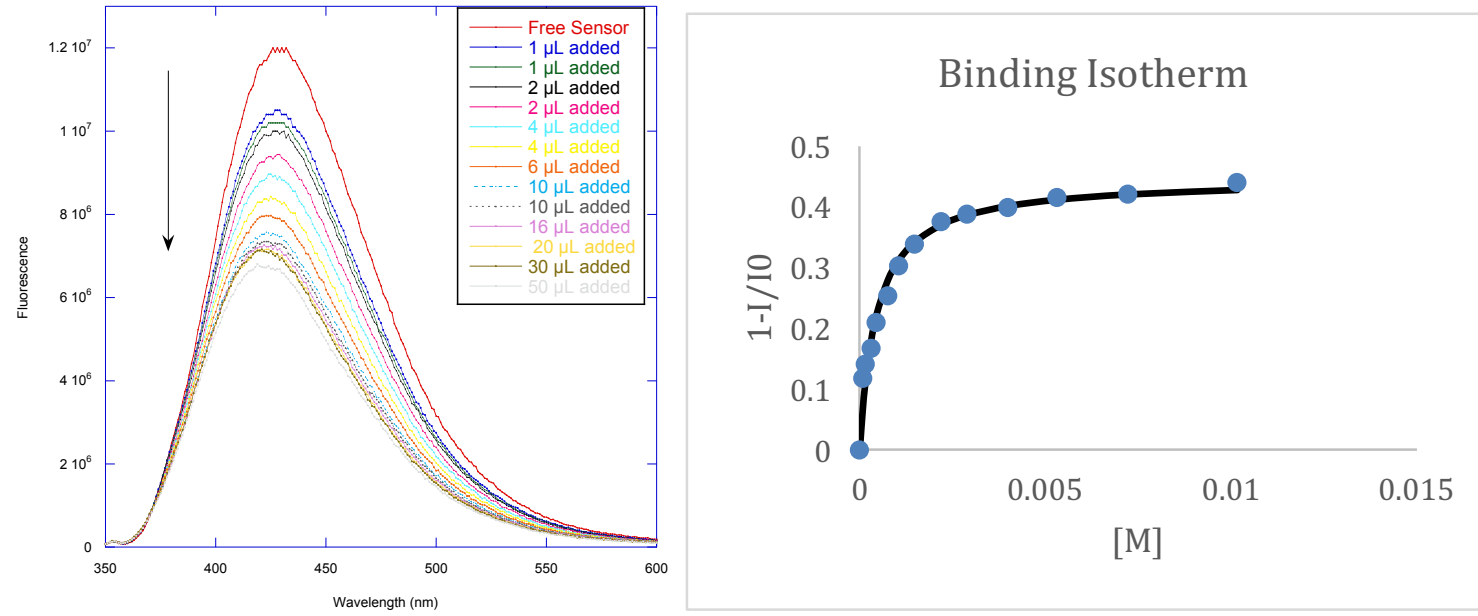

Figure S-2 Fluroescence titration of $\mathbf{6 0}$ with octylamine in buffer ( $25 \mathrm{mM}$ hepes, 120 $\mathrm{mM} \mathrm{NaCl}, \mathrm{pH} 7.4 ;[\mathbf{6 0}]=10^{-5} \mathrm{M} ;$ [octylamine] $\left.=.0753 \mathrm{M}, \quad \lambda_{\mathrm{ex}}=315 \mathrm{~nm}\right):$ a) Fluorescence emission spectra as a funciton of added octylamine, b) fit of titration data at $\lambda_{\mathrm{em}}=429 \mathrm{~nm}$ to a single site binding isotherm, $\mathrm{R}^{2}=0.9824$. 

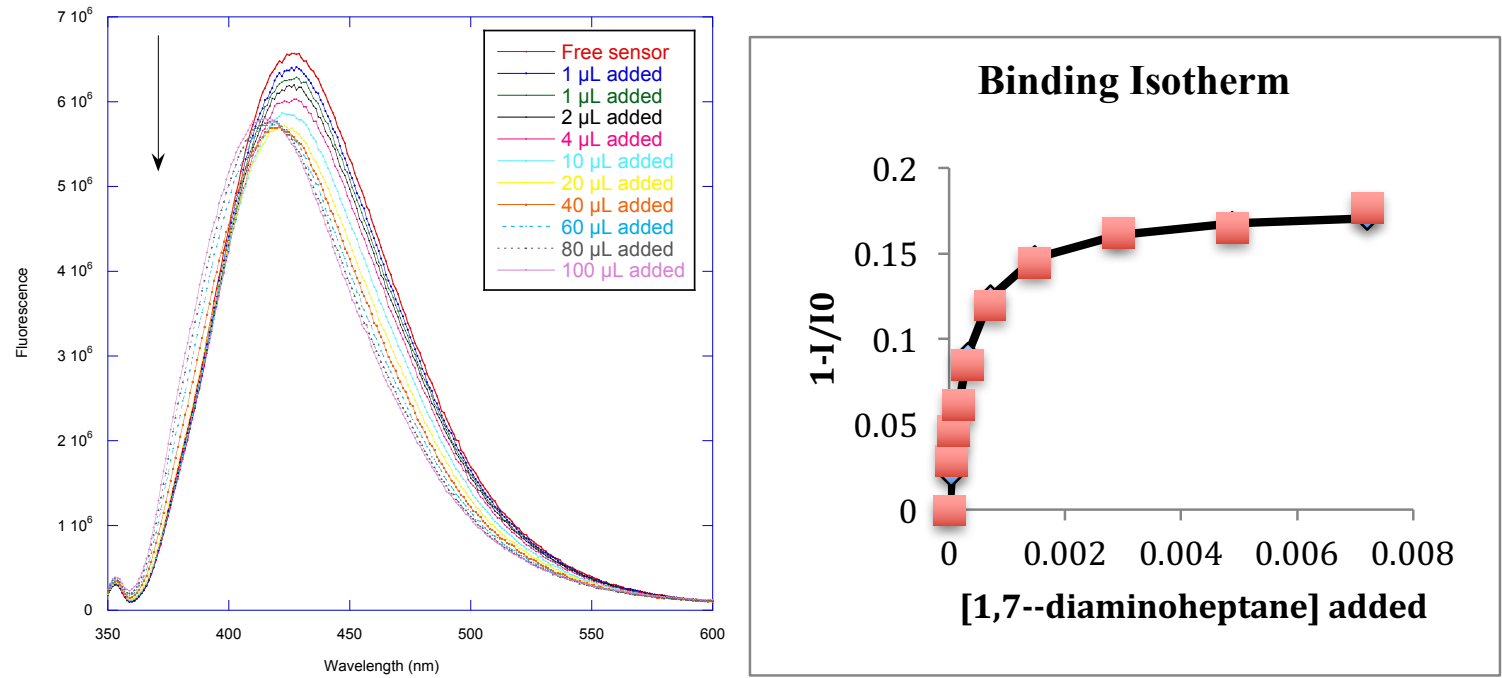

Figure S-5 Fluroescence titration of $\mathbf{6 0}$ with 1,7-diaminoheptane in buffer ( $25 \mathrm{mM}$ hepes, $120 \mathrm{mM} \mathrm{NaCl}, \mathrm{pH} 7.4 ;[60]=10^{-5} \mathrm{M} ;[1,7-$ diaminoheptane $\left.]=.04031 \mathrm{M}, \lambda_{\mathrm{ex}}=315 \mathrm{~nm}\right)$ : a) Fluorescence emission spectra as a funciton of added1,7-diaminooheptane, b) fit of titration data at $\lambda_{\mathrm{em}}=429 \mathrm{~nm}$ to a single site binding isotherm, $\mathrm{R}^{2}=0.9941$.
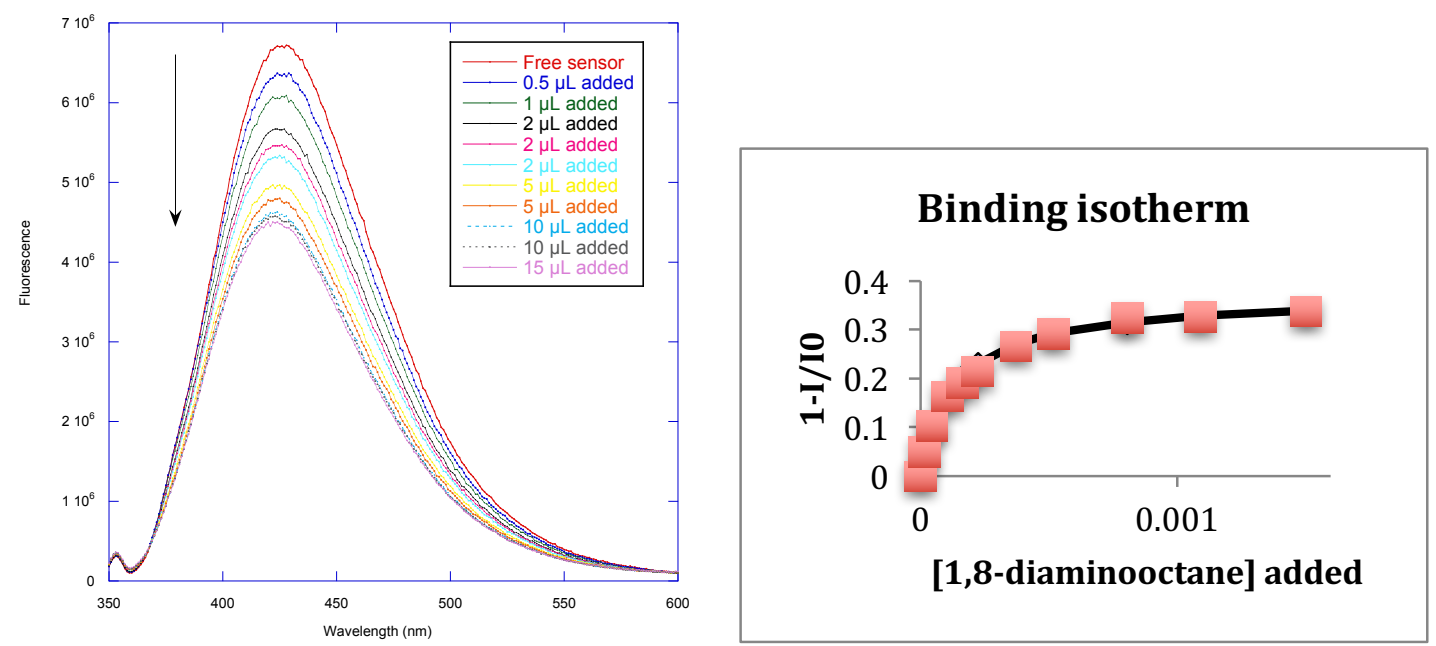

Figure S-6 Fluroescence titration of $\mathbf{6 0}$ with 1,8-diaminooctane in buffer ( $25 \mathrm{mM}$ hepes, $120 \mathrm{mM} \mathrm{NaCl}, \mathrm{pH} 7.4 ;[\mathbf{6 0}]=2.0 \times 10^{-5} \mathrm{M} ;[1,8$-diaminooctane $]=.0302 \mathrm{M}, \lambda_{\mathrm{ex}}=315$ $\mathrm{nm})$ : a) Fluorescence emission spectra as a funciton of added 1,8-diaminooctane, b) fit of titration data at $\lambda_{\mathrm{em}}=429 \mathrm{~nm}$ to a single site binding isotherm, $\mathrm{R}^{2}=0.9952$. 

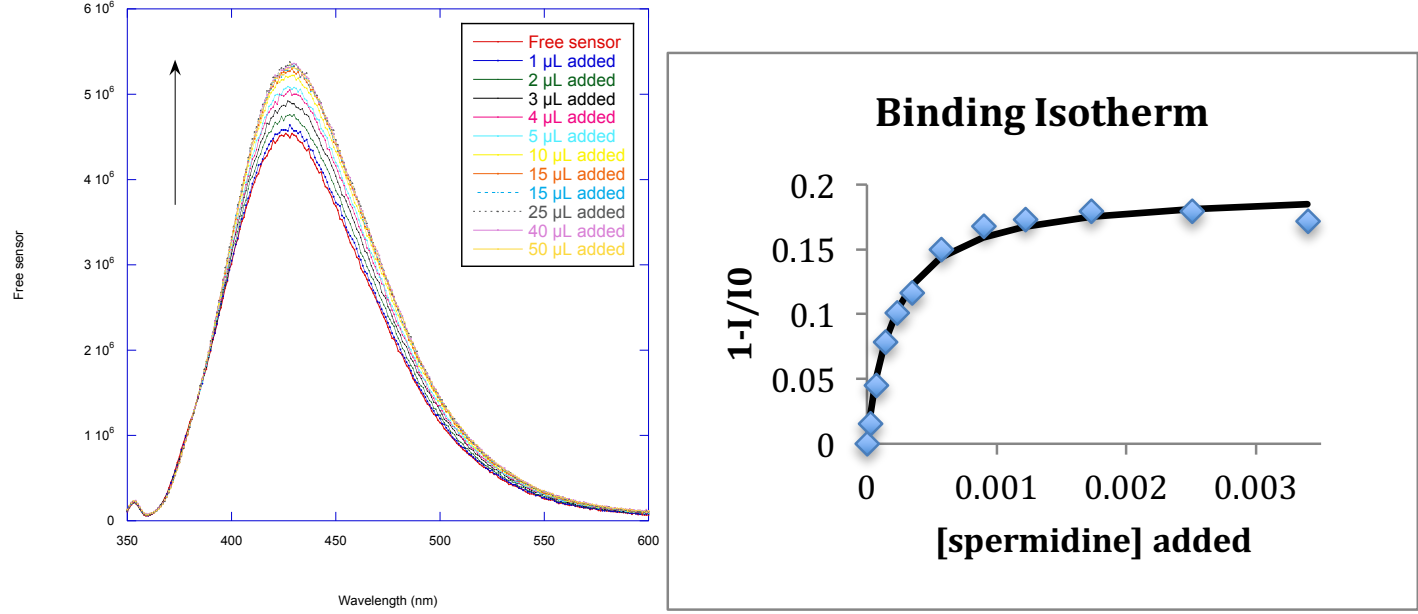

Figure S-7 Fluroescence titration of $\mathbf{6 0}$ with spermidine in buffer $(25 \mathrm{mM}$ hepes, 120 $\mathrm{mM} \mathrm{NaCl}, \mathrm{pH} 7.4$; [alanine tube $]=2.0 \times 10^{-5} \mathrm{M}$; $[$ spermidine $]=.02334 \mathrm{M}, \lambda_{\text {ex }}=315 \mathrm{~nm}$ ): a) Fluorescence emission spectra as a funciton of added spermidine, b) fit of titration data at $\lambda_{\mathrm{em}}=429 \mathrm{~nm}$ to a single site binding isotherm, $\mathrm{R}^{2}=0.9865$.
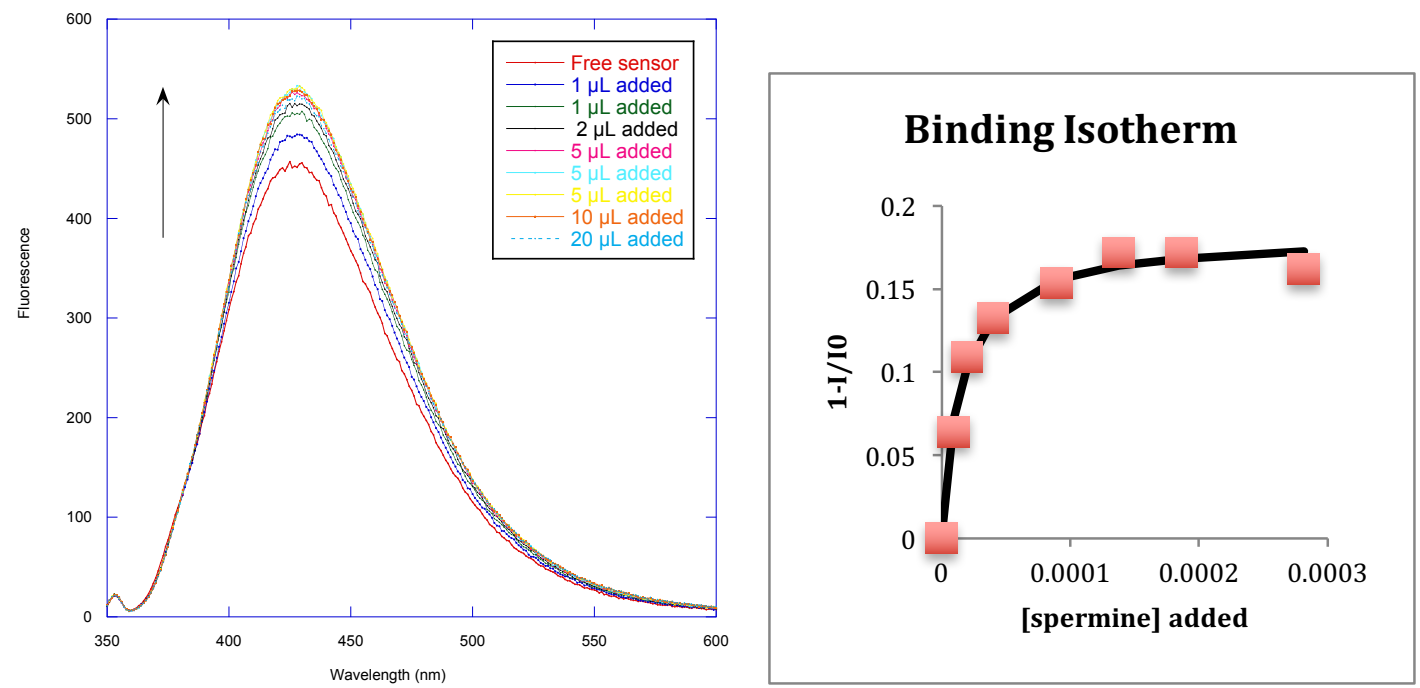

Figure S-8 Fluroescence titration of $\mathbf{6 0}$ with spermine in buffer $(25 \mathrm{mM}$ hepes, $120 \mathrm{mM}$ $\mathrm{NaCl}, \mathrm{pH} 7.4 ;[60]=2.0 \times 10^{-5} \mathrm{M}$; $[$ spermine $]=.01 \mathrm{M}, \lambda_{\mathrm{ex}}=315 \mathrm{~nm}$ ): a) Fluorescence emission spectra as a funciton of added spermine, b) fit of titration data at $\lambda_{\mathrm{em}}=429 \mathrm{~nm}$ to a single site binding isotherm, $\mathrm{R}^{2}=0.9888$. 


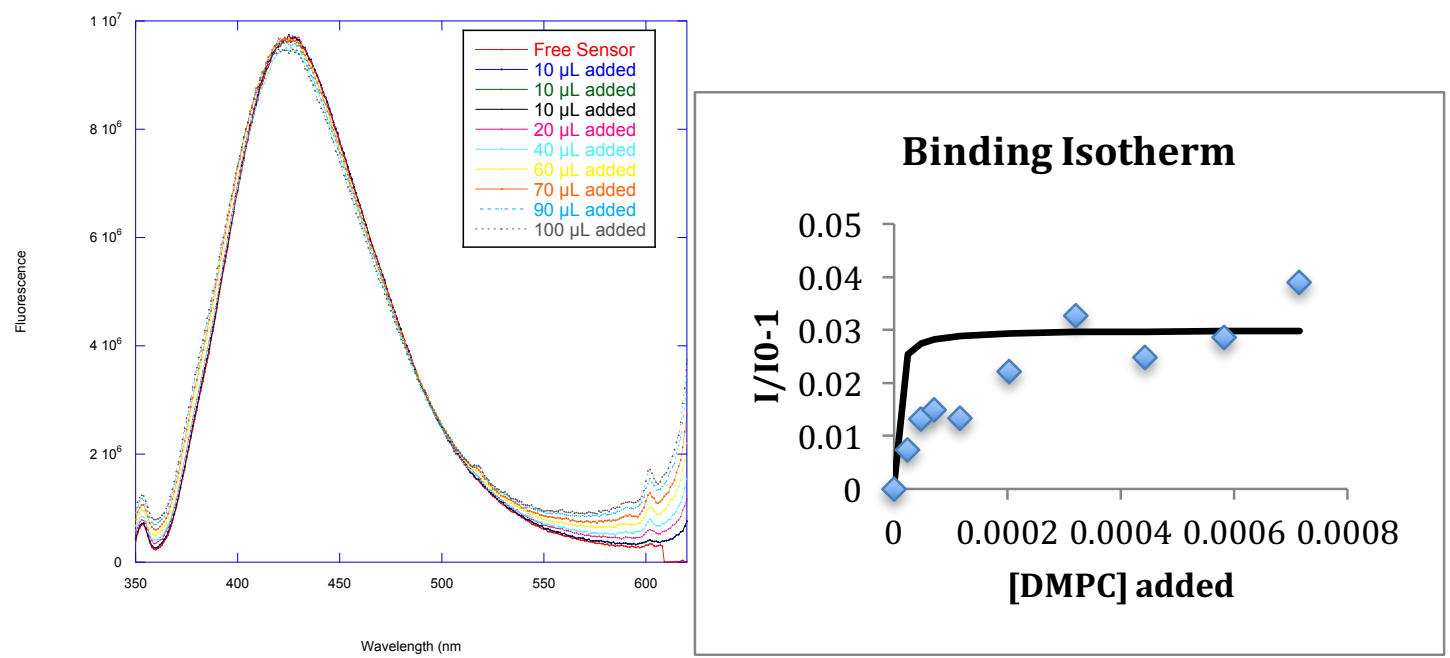

Figure S-9 Fluroescence titration of $\mathbf{6 0}$ with DMPC vesicles in buffer (25 mM hepes, $\left.\left.120 \mathrm{mM} \mathrm{NaCl}, \mathrm{pH} 7.4 ;[60]=2.0 \times 10^{-5} \mathrm{M} ;[\mathrm{DMPC}]=.002458 \mathrm{M}, \lambda_{\text {ex }}=315 \mathrm{~nm}\right): \mathrm{a}\right)$ Fluorescence emission spectra as a funciton of added DMPC, b) fit of titration data at $\lambda_{\mathrm{em}}$ $=429 \mathrm{~nm}$ to a single site binding isotherm, $\mathrm{R}^{2}=0.4445$.

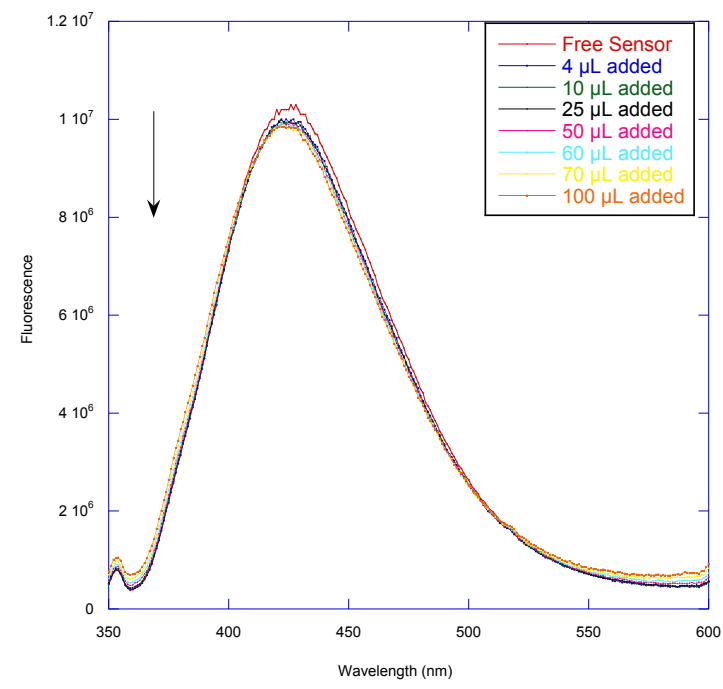

\section{Binding Isotherm}

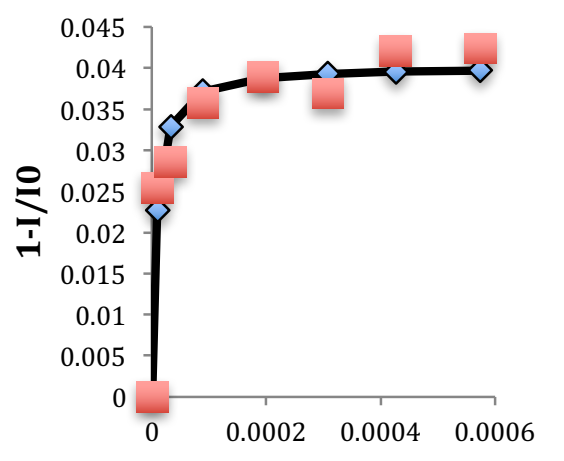

Figure S-10 Fluroescence titration of 60 with DMPS vesicles in buffer ( $25 \mathrm{mM}$ hepes, $\left.\left.120 \mathrm{mM} \mathrm{NaCl}, \mathrm{pH} 7.4 ;[60]=2.0 \times 10^{-5} \mathrm{M} ;[\mathrm{DMPS}]=.002347 \mathrm{M}, \lambda_{\mathrm{ex}}=315 \mathrm{~nm}\right): \mathrm{a}\right)$ Fluorescence emission spectra as a funciton of added DMPS, b) fit of titration data at $\lambda_{\mathrm{em}}$ $=429 \mathrm{~nm}$ to a single site binding isotherm, $\mathrm{R}^{2}=0.9657$. 


\section{References}

1. Pedersen, C. J., Journal of the American Chemical Society 1967, 89, 7017.

2. Atwood, J. W. S. J. L., Supramolecular Chemistry. 2nd ed.; Wiley: UK, 2009.

3. Zhai, D. T., Y. Q. E.; Xu, W.; Chang, Y.T., Development of a fluorescent sensor for illicit date rape drug GHB†. Chem. Commun. 2014, 50, 2904.

4. $\quad$ Fan, T. X., w.; Yao, J.; Jiao, Z.; Fu, Y.; Zhu, D.; He, Q.; Cao, H.; Cheng, J., NakedEye Visible Solid Illicit Drug Detection at Picogram Level via a Multiple-Anchored Fluorescent Probe. ACS Sens. 2016, 1, 312-317.

5. Mohr, G. J., New chromogenic and fluorogenic reagents and sensors for neutral and ionic analytes based on covalent bond formation. Anal Bioanal Chem 2006, 386, 1201-1214.

6. $\quad$ de Greñu, B. D. M., D.; Torroba, T.; Berg, A.; Gunnars, J.; Nilsson, T.; Nyman, R.; Persson, M.; Pettersson, J.; Eklind, I.; Wästerby, P., Fluorescent Discrimination between Traces of Chemical Warfare Agents and Their Mimics. J. Am. Chem. Soc. 2014, 136, 4125-4128.

7. Curiel, D. S. a., G.; Mas-Montoya, M.; Tarraga, A.; Molina, P., Rational design of a fluorescent receptor for the recognition of anthrax biomarker dipicolinate. Analyst 2012, 137, 5499.

8. Balamurugan, A. L., H., A Visible Light Responsive On-Off Polymeric Photoswitch for the Colorimetric Detection of Nerve Agent Mimics in Solution and in the Vapor Phase. Macromolecules 2016, 49, 2568-2574. 
9. Sambrook, M. R. H., J. R.; Cook, A.; Green, A. C.; Holden, I.; Vincent, J. C.; Gale, P.

A., Hydrogen bond-mediated recognition of the chemical warfare agent soman (GD). Chem. Commun. 2012, 48, 5605-5607.

10. Sun, X. J., T. D., Glucose Sensing in Supramolecular chemistry. Chem. Rev.

\section{5.}

11. Raker, J. G., T.E., J. Org. Chem. 2001, 66, 6505.

12. Hargrove, A. E. N., S.; Zhang, T.; Sessler, J. L.; Anslyn, E. V., Chem. Rev. 2011, $111,6603$.

13. Xu, Z. S., N. J.; Lin, J.; Pan, J.; Kim, H. N.; Park, S.; Kim, K. S.; Yoon, J., Angew. Chem. Int. Ed. 2009, 131, 15528.

14. March, J. S., M.B., March's Advanced Organic Chemistry: Reactions, Mechanisms, and Structure. Sixth ed.; Wiley \& Sons, Inc.: Hoboken, New Jersey, 2007.

15. Fan, E. V. A., S. A.; Kincaid, S.; Hamilton, A. D., Moelcular Recognition: Hydrogen-bonding receptors that function in highly competitive solvents. J. Am. Chem. Soc. 1993, 115, 369-370.

16. Saenger, W., Angew. Chem. Int. Ed. 1980, 19, 344-362.

17. Gimpl, G. G.-B., K. , Steroids 2011, 76, 216-231.

18. Christian, A. E. H., M. P.; Phillips, M. C.; Rothblat, G. H., J. of Lipid Res. 1997, 38, 2264-2272.

19. Karuppiah, N. K., P. B.; Kapustka, S. A.; Sharma, A., Michrochem. Jour. 1993, 47, 325-329.

20. Challa, R. A., A.; Ali, J.; Khar, R.K., Cyclodextrins in Drug Delivery: An Updated Review. AAPS PharmSciTech 2005, 6 (2), E329-E357. 
21. Muthukrishnan, R. G., C. D., J. Org. Chem. 1979, 44, 3962.

22. Gutsche, C. D. D., B.; No, K. H.; Muthukrishnan, R., J. Am. Chem. Soc. 1981, 103, 3782.

23. Matthews, S. B., P. D., Supramolecar Chemistry 2005, 17, 411-435.

24. Ikeda, A. S., S., Chem. Rev. 1997, 97, 1713-1734.

25. Atwood, J. L. O., G.W.; Juneja, R.K.; Bott, S.G.; Hamada, F., Pure \& Appl. Chem. 1993, 65, 1471-1476.

26. Arora, V. C., M.; Singh, S. P., Calixarenes as sensor materials for recognition and separation of metal ions. Spec. Iss. Rev. and Accts. 2007, 2, 172-200.

27. Kalchenko, O. C., S.; Yushchenko, 0.; Kalchenko, V., J. Incl. Phenom. Macrocycl. Chem 2013, 76, 29-36.

28. Behrend, R. M., E.; Rusche, F., Justus Liebig's Annalen der Chemis 1905, 339, 137.

29. Freeman, W. A. M., W. L.; Shih, N. -Y., J. Am. Chem. Soc. 1981, 103, 7367-7368.

30. Cao, L. S., M.; Zavalij, P. Y.; Mlinaric-Majerski, K.; Glaser, R.; Isaacs, L., Angew. Chem. Int. Ed. 2014, 53, 988-993.

31. Association, A. D. Statstics About Diabetes. http://www.diabetes.org/diabetes-basics/statistics/ (accessed 11/1/2016).

32. Feuster, E. K. G., T. E., J. Am. Chem. Soc. 2003, 125 (52), 16174.

33. Kuivila, H. G. K., A. H.; Soboczenski, E. J., J. Org. Chem. 1954, 19.

34. James, t. D. P., M.D.; Shinkai, S., Boronic Acids in saccharide Recognition. Cambridge: 2006. 
35. James, T. D. S., K.R.A.S.; Iguchi, R.; Shinkai, S., J. Am. Chem. Soc. 1995, 117, 8982-8987.

36. Eggert, H. F., J.; Morin, C.; Norrild. J.C., J. Org. Chem. 1999, 64, 3846-3852.

37. James, T. D. S., K.R.A.S.; Iguchi, R.; Shinkai, S., Angew. Chem. Int. Ed. Engl. 1996, 35, 1910-1922.

38. Wang, W. G., S.; Wang, B., Org. Lett. 1999, 1, 1209-1212.

39. Yoon, J. C., A.W., J. Am. Chem. Soc. 1992, 114, 5874-5875.

40. Adhikiri, D. P. H., M.D., Tetrahedron Lett. 1999, 40, 7893-7896.

41. Yang, W. H., H.; Drueckhammer, D.G., Angew. Chem. Int. Ed. 2001, 40, 17141718.

42. Draffin, S. P. D., P.J.; Duggans, S.A.M., Org. Lett. 2001, 3, 917-920.

43. Gardiner, s. S., B.; Duggan, P.; Karpa, M.; Griffin, G., Tetrahedron 1999, 55, $2857-2864$.

44. Karpa, M. D., P.; Griffin, G.;Freudigmann, s., Tetrahedron 1997, 53, 36693678.

45. Mohler, L. K. C., A.W., J. Am. Chem. Soc. 1993, 115, 2998-2999.

46. Paugam, M. F. B., J.T.; Smith, B.D.; Chrisstoffels, L.A.J.; de Jong, F.; Reinhoudt, D.N., J. Am. Chem. Soc. 1996, 118, 9820-9825.

47. $\quad$ Riggs, J. A. H., K.A.; Smith, B.D.; Karpa, M.J.; Griffin, G.; Duggan, P.J., Tetrahedron Lett. 1996, 37, 6303-6306.

48. Smith, B. D. G., S.J., Munro, T.A.; Paugam, M.F.; Riggs, J.A.; , J. Incl. Phenom. Mol. Recogn. Chem. 1998, 32, 121-131.

49. Westmark, P. R. G., S.J.; Smith, B.J., J. Am. Chem. Soc. 1996, 118, 11093-11100. 
50. Hageman, J. H.; Kuehn, G. D., Boronic Acid Matrices for the Affinity

Purification of Glycoproteins and Enzymes. In Practical Protein Chromatography,

Kenney, A.; Fowell, S., Eds. Humana Press: Totowa, NJ, 1992; pp 45-71.

51. Adamek, V. L., X.C.; Zhang, Y.A.; Adamkova, K; Scouten, W.H., J. Chromatogr. 1992, 625, 91-99.

52. Psotova, J. J., O. Chem. Listy 1995, 89, 641-648.

53. Seliger, H. G., V., Experientia 1974, 30, 1480-1481.

54. Westmark, P. R. V., L.S.; Smith, B.D., J. Chromatogr. A. 1994, 664, 123-128.

55. Liu, x. H., J.; Scouten, W., J. Organomet. Chem. 1995, 493, 91-94.

56. Springsteen, G. W., B., Chem. Commun. 2001, 1608-1609.

57. Springsteen, G. W., B., Tetrahedron 2002, 58, 5291-5300.

58. Secor, K. G., T.E., Org. Lett. 2004, 6, 3727-3730.

59. Tran, T. M. A., Y.; Glass, T. E., A highly selective fluorescent sensor for glucosamine. Chem. Commun. 2015, 51, 7915-7919.

60. Springsteen, G. W., B., Tetrahedron 2004, 60, 11205-11209.

61. Yoon, J. C., A.W., Fluorescent Chemosensing of Carbohydrates-A Means of Chemically Communicating the Binding of Polyols in Water by Chelation-Enhanced Quenching. J. Am. Chem. Soc. 1992, 114, 5874-5875.

62. Jin, S. C., Y.; Reid, S.; Li, M.; Wang, B., Carobohydrate Recognition by boronolectins, small molecules and lectins. Med. Res. Rev. 2010, 30, 171-257. 63. Mader, H. S. W., O.B., Boronic acid based probes for microdetermination of saccharides and glycosylated biomolecules. Microchim. Acta 2008, 162, 1-34. 
64. Badugu, R. L., J.R.; Geddes, C.D., A glucose-sensing contact lens: from bench top to patient. Curr. Opin. Biotechnol. 2005, 16, 100-107.

65. Zhang, W. B., D. I.; Crumpton, J.B.; Wynn, J.; Santos, W.L., Chem. Commun. 2013, 49, 2436-2438.

66. Zhang, W. B., D. I.; Crumpton, J.B.; Wynn, J.; Santos, W.L., Targeting folded RNA: a branched peptide boronic acid that binds to a large surface area of HIV-1 RRE RNA. Org. Biomol. Chem. 2013, 11, 6263-6273.

67. Tsukagoshi, K. S., S., J. Org. Chem. 1991, 56, 4089-4091.

68. Pappin, B.; Kiefel, M. J.; Houston, T. A., Boron-Carbohydrate Interactions. 2012.

69. Lakowicz, J. R., Principles of Fluorescence Spectroscopy. Second ed.; Kluwer Academic/Plenum Publishers: New York, New York, 1999.

70. Valeur, B., Molecular Fluorescence: Principles and Applications. Wiley-VCH: Weinheim: New York, 2002.

71. Demchenko, A. P., Introduction to Fluorescence Sensing. Springer: New York, 2009.

72. Alberts, B. J., A.; Lewis, J.; Raff, M.; Roberts, K.; Walter, P., Molecular Biology of the Cell. Fourth ed.; Wiley: New York, 2002.

73. Gunstone, F. D. H., J. L.; Dijkstra, A.J., Lipid Handbook. CRC Press: 2007.

74. Ball, M. M., J., Lipids and Heart Disease, A Guide for the Primary Care Team. 2nd ed.; Oxford University Press: New York, 1994.

75. Hanahan, D. J., Guide to Phospholipid Chemistry. Oxford University Press: New York, 1997. 
76. Micromedex Dexamethasone. http://www.mayoclinic.org/drugssupplements/dexamethasone-oral-route/description/drg-20075207 (accessed November 3).

77. Vance, D. E. V., J. E., Biochemistry of lipids, lipoproteins and membranes. 5th ed.; Elsevier: Boston, 2008.

78. Berg, J. M. T., J.L.; Stryer, L., Biochemistry. W.H. Freeman: New York, 2002.

79. Wymann, M. P. S. R., Lipid Signalling in Disease. Nature Reviews 2008, 9, 162176.

80. Costanzi, M. B., M.; Populin, R.; Cestari, V.; Castellano, C., Neurobiology of Learning and Memory 2003, 79, 204.

81. Mechoulam, R. F., E.; Hanu, L.; Sheskin, T.; Bisogno, T.; Di Marzo, V.; Bayewitch, M.; Vogel, Z., Nature 1997, 389, 25.

82. Jamshidi, N. T., D.A., British Journal of Pharmacology 2001, 134, 1151.

83. Walker, J. M. H., S.M.; Strangman, N.M.; Tsou, K.; Sañudo-Peña, M.C., Proceedings of the National Academy of Sciences 1996, 96, 12198.

84. Fu, J. G., S.; Oveisi, F.; Lo Verme, J.; Serrano, A.; Rodriguez de Fonseca, F.; Rosengarth, A.; Luecke, H.; Di Giacomo, B.; Tarzia, G.; Piomelli, D., Nature 2003, 425, 90.

85. Trembleau, L.; Rebek, J., Jr., Helical conformation of alkanes in a hydrophobic cavitand. Science 2003, 301 (5637), 1219-20.

86. Ko, Y. H. H., K.; Kim, Y.; Kim, K., U-Shaped Conformation of Alkyl Chains Bound to a Synthetic Host. Angew. Chem. Int. Ed. 2008, 47, 4106-4109.

87. Hakomori, S., Adv. Ca. Res. 1989, 52 (257-331). 
88. Hounsell, E. F. Y., M.; Davies, M. J., Clinical Science 1997, 93 (287-293).

89. Hakomori, S., Tumor Malignancy Defined by Aberrant Glycosylation and Spingo(glyco)lipid Metabolism. Cancer Res. 1996, 56, 5309-5318.

90. Glycolipid Metabolism. http://www.nutriology.com/GLmetab.html (accessed April 1).

91. Ariga, T. M., M.P.; Yu, R. K., Role of ganglioside metabolism in the pathogenesis of Alzheimer's disease--a review. J. of Lipid Res. 2008, 49, 1157-1175.

92. Gieselmann, V. M., U.; Klein, D.; Mansson, J.E.; D'Hooge, R.; DeDeyn, P.D.;

Rauch, R.L.; Hartmann, D.; Harzer, K., Gene Therapy: Prospects for glycolipid storage diseases. Phil. Trans. R. Soc. Lond. 2003, 358, 921-925.

93. Mehta, A., Epidemiology and natural history of Gaucher's disease. Eur. J Intern Med. 2006, 17, S2-S5.

94. Hollak, C., An evidence- based review of the potential benefits of the taligucerase alfa in the treatment of patients with Gaucher Disease. Core Evid. 2012, $7,15-20$.

95. Grabowski, G. A., Phenotype, diagnosis, and treatment of Gaucher's disease. Lancet 2008, 372, 1263-1271.

96. Bennett, L. L. M., D., Gaucher disease and its treatment options. Ann. Pharmacother. 2013, 47, 1182-1193.

97. Grabowsky, G. A. Z., A.; Ida, H., Gaucher disease types 1 and 3: phenotypic characterization of large populations from the ICGG Gaucher Registry. Am. J. Hematol. 2015, 90 (Suppl S1), S12-S18. 
98. Zimran, A. G., T.; Westwood, B.; Grabowski, G.A.; Beutler, E., High frequency of the Gaucher disease mutation at the nucleotide 1226 among Ashkenazi Jews. Am J Hum Genet 1991, 49, 855-889.

99. Altarescu, G. S., r.; Parker, C.C., Comparative efficacy of dose regimens in enyme replacement therapy of type I gauchers disease. Blood Cells Mol Dis. 2000, 26, 285-290.

100. Martins, A. M. V., E.R.; Porta, G., Recommendations on diagnosis, treatment, and monitoring for Gaucher disease. J Pediatr. 2009, 155, S10-S18.

101. Disease, N. T. A. P. o. G., Gaucher disease: current issues in diagnosis and treatment. JAMA 1996, 275, 548-553.

102. Tekoah, Y. T., S.; Kizhner, T., Hainrichson, M.; Gantman, A.; Golembo. M.; Aviezer, D.; Shaaltiel, Y., Glycosylation and functionality of recombinant betaglucocerbrosidase from various production systems. Biosci. Rep. 2013, 33, e00071. 103. Zheng, J. C., L.; Schwake, M.; Silverman, R.; Krainc, D., Design and Synthesis of Potent Quinozolines as Selective ß-Glucocerebrosidase Modulators. J. of Med. Chem. 2015, 59, 8508-8520.

104. Yamamoto, M. C., E.; Yamamoto, F., Molecular genetics basis of the human Forssman glycolipid antigen negativity. Scientific Reports 2012, 2 (975).

105. Reid, M. E. L.-F., C.; Olsson, M.I., The Blood Group Antigen Facts Book. Elsevier: New York, 2012.

106. Carson, J. L. G., B.J.; Kleinman, S.;; Tinmouth, T.; Marques, M.B.; Fung, M.K.; Holcomb, J.B.; Illoh, O.; Kaplan, L.J.; Katz, L.M.; Rao, S.V.; Roback, J.D.; Shander, A.; 
Tobian, A.A.R.; Weinstein, R.; McLaughlin, G.S.; Djulbegovic, B., Ann. Intern. Med. 2012, 157, 49-58.

107. Kwan, D. H. C., I.; Chapanian, R.; Higgins, M.A.; Kotzler, M.P.; Samain, E.;

Boraston, A.B.; Kizhakkedathu, J.N.; Withers, S.P., Toward Efficient Enzymes for the Generation of Universal Blood through Structure-Guided Directed Evolution. J. Am. Chem. Soc. 2015, 137, 5695-5705.

108. Sun, Z. I., A.; Reetz, M., Towards the Production of Universal Blood by Structure-Guided Direction Evolution of Glycoside Hydrolases. Angew. Chem. Int. Ed. 2015, 54, 9158-9160.

109. Anderson, K. M. A., H.; Maskos, K.; Dell, A.; Li, S.C.; Li, Y.T., J. Biol. Chem. 2005, $280,7720-7728$.

110. Liu, Q. P. Y., H.; Bennett, E.P.; Levery, S.B.; Nudelman, E.; Spence, J.; Pietz, G.;

Saunders, K.; White, T.; Olsson, M.L.; Henrissat, B.; Sulzenbacher, G.; Clausen, H., J. Biol. Chem. 2008, 283, 8545-8554.

111. Liu, Q. P. S., G.; Yuan, H.; Bennett, E.P.; Pietz, G.; Saunders, K.; Spence, J.; Nudelman, E.; Levery, S.B>; White, T.; Neveu, J.M.; Lane, W.S.; Bourne, Y.; Olsson, M.L.; Henrissat, B.; Clausen, H., Nat. Biotechnol. 2007, 25, 454-464.

112. Banihashemi, A. R., A., Tetrahedron 1999, 55, 7271.

113. Shorthill, B. J. A., C. T.; Glass, T. E., Shape Selective Sensing of Lipids in Aqueous Solution by a Designed. J. Am. Chem. Soc. 2004, 126, 12732-12733.

114. Ren, C. L., J. S.; Glass, T. E., Supramolecar Chemistry 2014.

115. Ren, C. G., T. E., unpublished work from dissertation. 
116. Yi, X. C. X., F. G.; Wang, K.; Su, Z.; Gao, E. Q., J. of Solid State Chem. 2013, 206, 293-299. 


\section{Vita}

C.W. Littlfield was born on August $29^{\text {th }}, 1987$, in Orange Park, Florida. At the age of three his family relocated to Bullhead City, Arizona. He attended and graduated from Mohave High School after which he continued on to community college locally, before transferring to Nevada State College where he began as a Biology major. With the intentions of going to graduate school for chemistry he changed schools and went to Northern Arizona University in Flagstaff, Arizona, where he earned a Bachelor of Science in Chemistry. There he began undergraduate research in synthetic organic chemistry, specifically total synthesis, which led him to pursue a graduate career. In 2011 he began his graduate work at the University of Missouri and joined Dr. Timothy Glass' group in the Spring of 2012. 